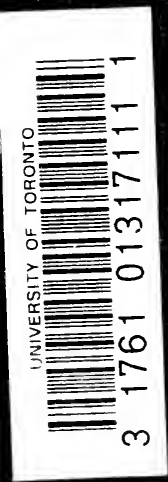




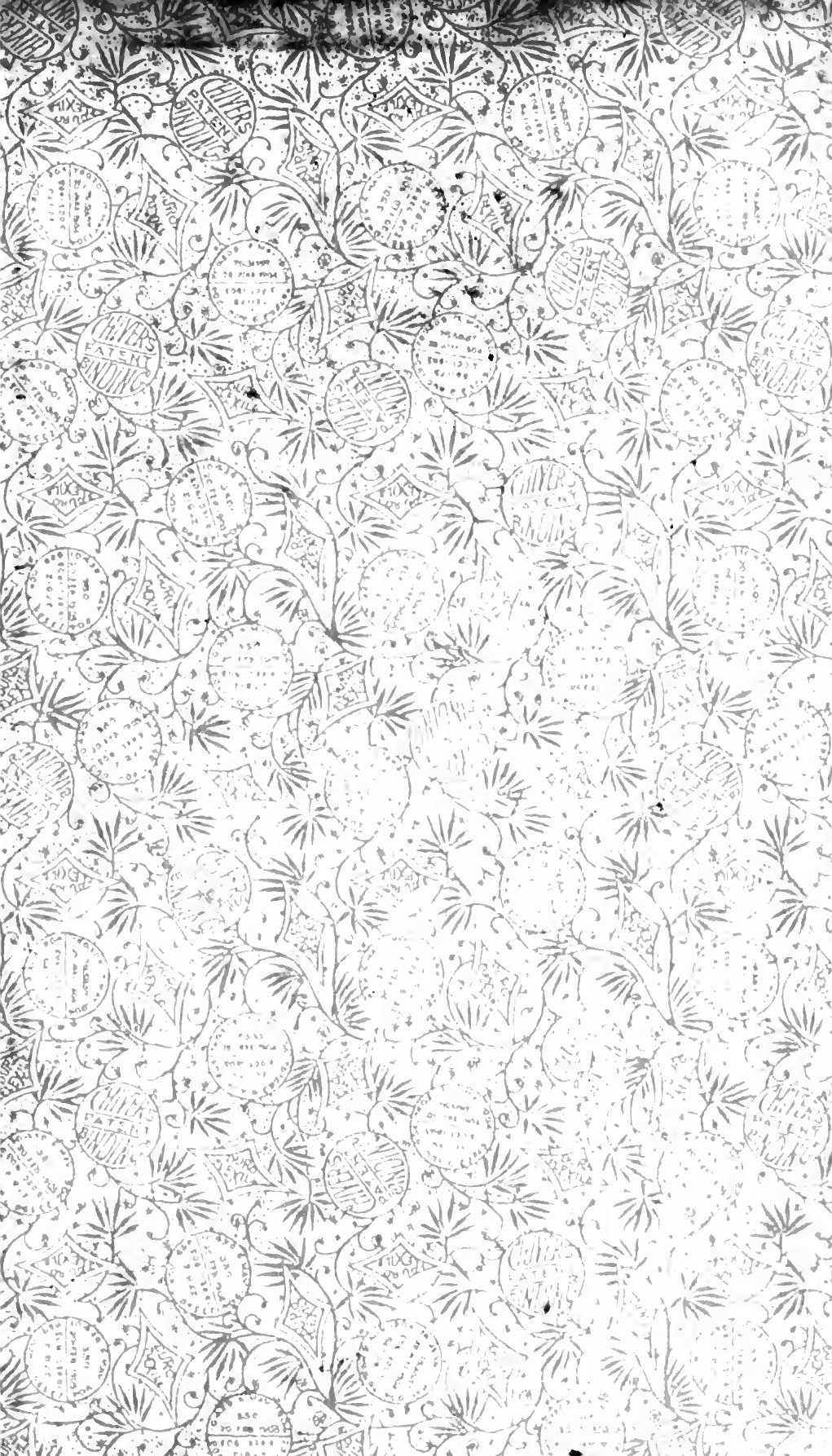
(6)

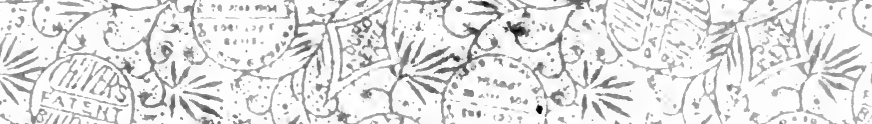

$$
\text { 1 }
$$$$
\text { Min. }
$$$$
\text { o }
$$$$
\text { (1) y }
$$

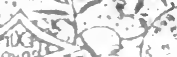$$
\Rightarrow v 0
$$ 



THE DEVELOPMENT OF

\section{GREEK PHILOSOPH Y}





\title{
THE DEVELOPMENT OF
}

\section{GREEK PHILOSOPHY}

$\mathrm{BY}$

\author{
ROBER'T ADAMSON \\ SOMETIME PROFESSOR OF LOGIC AND RHETORIC IN THE \\ UNIVERSITY OF GLASGOW
}

EDITED BY

W. R. SORLEY

FELLOW OF THE BRITISH ACADEMY

PROFESSOR OF MORAL PHILOSOPHY AT CAMBRIDGE

AND

R. P. HARDIE

LECTURER QN

LOCIC AND METAPHYSICS IN THE UNIVERSITY OF EDINBURGH

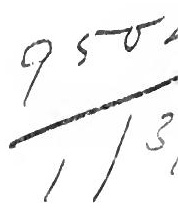

WILLIAM BLACKWOOD AND SONS

EDINBURGH AND LONDON

1908 
Digitized by the Internet Archive in 2007 with funding from Microsoft Corporation 


\section{P R E F A C E}

THE following pages do not claim to be founded upon elaborate research. The author's primary interest was philosophical; but philosophy, he held, must be studied in connexion with its history; and he devoted much of his time to the study of the Greek philosophers. In their writings he found an unprejudiced and continuous endeavour to give clear answers to the fundamental questions of knowledge and reality. And it is as an estimate, from the philosophical point of view, of the history and results of Greek thought that his work is now published. It is hoped also that it may prove of value to students as an introduction to Greek philosophy. The labours of the editors have been specially directed towards fitting it for the latter purpose.

The author did not live to write out any part of the book. But for many years he had been accustomed, as part of his university work, to lecture upon some period of Greek philosophy. He used few notes in lecturing, but he made constant reference to the text of the writers with whom he dealt; and he spoke so slowly that a rapid writer could take down almost every word. The material placed at the disposal of the editors has been preserved in this way; and 
they have endeavoured to present it to the reader in a form which does not obtrude its origin in the class-room. They are encouraged to believe that this is not an impossible task by the reception already given to the author's Development of Modern Philosophy.

The first three parts of the present volume, which deal with the early Greek thinkers, with Plato, and with Aristotle, are taken from lectures given in the University of Glasgow in 1897-98 and the succeeding academical year. A later course has, however, been drawn upon for the concluding chapter both of Part II. and of Part III. The account of the Stoic philosophy which follows has been compiled from two different sets of lectures. One of these, given in 1899-1900, contains a brief sketch of the thinking of the Stoics as a whole. The other, two years later, enters in much greater detail into their discussions of the theory of knowledge: but this course was brought to a sudden close by the author's fatal illness.

In preparing the work for publication the editors have added a number of references to authorities in the footnotes. These have not been distinguished in printing from the references which the author himself gave to his students. Square brackets have been used only when the note is intended to modify a statement in the text, or where the editors are not sure that the author would have adopted their words. In his lectures on the early philosophers before Plato the author seems to have used Ritter and Preller's Historia Philosophice Groeca as a text-book. When this is quoted the reference to the original authority is given in parentheses. In other cases, where the original authority seems to have been used but the passage is also to be found in Ritter and Preller's book, the section of the latter is added in parentheses. The eighth edition of 
Ritter and Preller has been used, and it is cited throughout as R.P.

The editors desire to place on record their great obligations to Dr Henry Jackson, O.M., Regius Professor of Greek at Cambridge; Mr H. H. Joachim, Fellow of Merton College, Oxford; and Mr W. D. Ross, Fellow of Oriel College, Oxford, who have assisted them in revising the proof-sheets. They are not responsible for the final form in which any statement appears, but many valuable suggestions are due to them, and they have detected errors which otherwise might have escaped editorial notice. The thanks of the editors are due also to $\mathrm{Mr}$ J. A. Smith, Fellow of Balliol College, Oxford, who read the work in MS.; to Mr John Handyside, Edinburgh University, who has assisted in various ways; and to Dr John Burnet, Professor of Greek at St Andrews, for enabling them to give references to the forthcoming second edition of his Early Greek Philosophy. The Indexes have been compiled by the author's daughter, Mrs C. J. Hamilton.

W. R. S.

R. P. H.

October 1908. 



\section{ONTENTS}

CHAP,

PREFACE

INTRODUCTION

PAGE

\section{PART I}

\section{GREEK PHIJOSOPHY BEFORE PLATO}

I. THE EARLY IONIAN PHILOSOPHERS . . . . 5

II. PYTHAGORAS AND THE PYTHagOREANS . . . 17

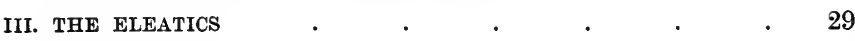

IV. HERACLITUS . . . . . . . . 42

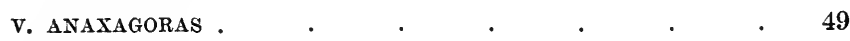

VI. EMPEDOCLES .

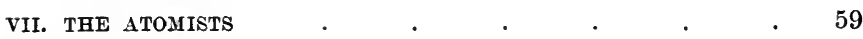

VIII.THE SOPHISTS AND SOCRATES . . . . . $\quad$. 67

IX. THE MINOR SOCRATIC SCHOOLS . $\quad$. $\quad$. 78

\section{PART II}

\section{PLATO}

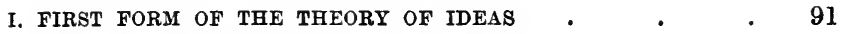

II. LATER METAPHYSIC: THE PARMENIDES, SOPHIST, AND PHILEBUS, •

III. DOCTRINE OF SOUL : THE PHEDO AND PHEEDRUS . . 114 
IV. FINAL METAPHYSIC : THE TIMAUS . . . $\quad 119$

V. PLATO'S SOLUTION OF THE PROBLEM . . . . 129

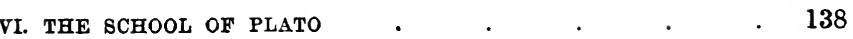

PART III

ARISTOTLE

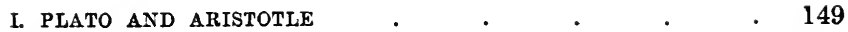

II. FUNDAMENTAL CONCEPTIONS . $\quad$. $\quad . \quad$. 152

i. General Division of the Realm of Existence . 152

ii. The Conceptions of Change and Purpose . 153

iii. The Conceptions of Form and Matter . 158

iv. The First Cause $\Varangle \quad$. $\quad . \quad$. $\quad . \quad 159$

v. The Soul $\quad . \quad$. $\quad . \quad$. $\quad$. 163

III. THEORY OF KNOWLEDGE $\quad$. $\quad . \quad$. $\quad . \quad$. 170

i. Demonstration and Opinion . . . . 170

ii. The Principle of Contradiction a $\quad$. 172

iii. Metaphysical Principles of the Theory of Knowledge 177

iv. The Concrete Individual a $\quad . \quad$. 182

v. Place of the Syllogistic Forms . . . 186

vi. Syllogism and Induction . . . . . 188

vii. The Ultimate Data of Knowledge . . . 190

viii. The Immediate Object of Apprehension . $\quad 193$

ix. Induction and the Universal ... . . . . . 194

x. Intuition and Discursive Thought $\quad$ • $\quad$ • 195

IV. PSYCHOLOGY

i. The General Nature of Soul . $\quad$. $\quad$ • $\quad 199$

ii. The Sensitive Soul $\quad$. $\quad$. $\quad$. $\quad 204$

iii. Intermediates between Sense-perception and Reason . 213

iv. The Rational Soul . . . . . 217

v. Reason in Man and the Absolute Reason . $\quad 227$

v. REASON AS THE FACULTY OF FIRST PRINCIPLES • $\quad 232$

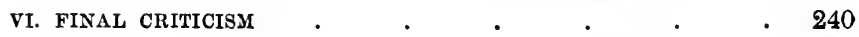




\section{PART IV}

\section{THE STOIC PHILOSOPHY}

\begin{tabular}{|c|c|c|c|c|c|c|c|}
\hline I. & THE STOICS & . & • & - & . & . & \\
\hline II. & PHYSICS & . & . & - & - & . & . \\
\hline III. & THEORY OF & F KNOWLEDGE & • & . & - & . & . \\
\hline IV. & ETHICS & . $\quad$. & • & . & - & . & . \\
\hline & INDEX OF & ADTHORITIES & . & - & . & . & \\
\hline & INDEX OF & GREEK WORDS & - & . & . & . & \\
\hline & GENERAL I & INDEX & . & . & . & . & \\
\hline
\end{tabular}



THE

\section{DEVELOPMENT OF GREEK PHILOSOPHY}

\section{INTRODUCTION}

Greer philosophy forms a continuous development. The Aristotelian system is based on and complementary to the Platonic both in general character and in its treatment of special problems. The Platonic system, in its turn, can be understood only as carrying out tendencies which had found expression in earlier thought. The interest of these earlier thinkers is not merely historical. They exhibit philosophy in the making. And if we seek to solve the problem of the place of philosophical reflexion in human culture as a whole, we can approach an answer only by the slow method of tracing the origin and history of thought. Greek philosophy has impressed itself on modern thinking, raising the problems for it and suggesting the methods of their solution. It implied a conception of the general aim and possibilities of philosophy to which modern thought must adjust itself, adopting, rejecting, or modifying it. It is besides the one instance in history of a reflective movement which, starting from the mythical stage, has afterwards 
built for itself an independent foundation and established an independent position.

At the same time, the influence of the earlier mythical stage may be traced in the speculative distinctions of apparently disinterested thinking as they come before us in the Greek philosophers. One very general point may be taken as illustrating this. The view that it is the business of philosophy to find a conception which will unify the results of the special sciences has an unmistakable resemblance to a characteristic of the earliest myths. For they seek to give a complete story of how things have come about, such as will satisfy the rudimentary needs of the inquiring mind. And this resemblance suggests the interesting question whether the developed conception of the philosophical mind has more justification or other foundation in the reality of things than the primitive mythological impulse which. expressed itself in early stories of gods and men.

In the earliest efforts of Greek philosophy we can detect more than this general resemblance between philosophical and mythological conceptions. The characteristic of the mythological work is twofold. There is, in the first place, the primitive process called personification, which lies at the root of animism, the tendency to regard objects and processes of nature as like in kind to personal beings and human activities. Equally prominent, in the second place, is the tendency to depict the personal being, his motives, thoughts, and acts, after the gross image of external things. Thus, in the stage of mythical reflexion, the Soul is represented in most material fashion. At first it is no more than the shadowy aerial image of the corporeal living being. Such a soul is anything but the bearer of those psychical activities which are familiar enough in the details of ordinary life. At a still earlier stage, the thoughts, feelings, and actions of the human being were not regarded as the expression of a 
shadowy double of the concrete person; they were represented, without distinction of corporeal and spiritual, as merely dependent on the living body.

The main lines of development which proceed from this mythical basis are the cosmological and the psychological. I/ It has been well said that the problem of cosmological speculation differs from the aim of mythology in this: that while the latter represented the connexions between its assumed ground and existing realities after the crude fashion of temporal sequence, the more philosophical view raised the question, what is the permanent element in ratexistence and of what are actual things composed? 1 . Whe change of question implied a restriction upon the free fay of imagination, which constitutes the difference between philosophy and mythology. The cosmological inquiry generally aimed, in the first instance, at what Aristotle called a material principle or cause of things. ${ }^{2}$ The simplicity of the answers given corresponds to the imperfect development of the experience which called for explanation. And the gradual deepening of these answers was determined not merely by insight into the imperfection of preceding solutions, but by increased range and accuracy of concrete experience. Indeed, the most serious obstacle to understanding the course of Greek speculation is that the character and history of the ordinary knowledge of nature among the Greeks are known to us only in outline.

From the early Ionian school to the time of Plato there can be traced a tolerably definite line of speculations as to the permanent substratum $\left(v^{\prime} \lambda \eta\right)$ of natural fact and as to the way in which that substratum is connected with the particulars of concrete experience. The psychological line of development is not conspicuous till a later stage.

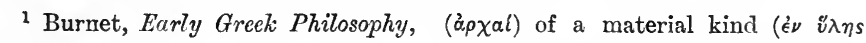
8. (10, 2nd ed.)

2 "The majority of the earliest philosophers thought that principles $\left.\epsilon^{\iota} \zeta \delta \epsilon \iota\right)$ alone are the principles of all things."-Arist. Met. A 983 b 6. (R.P. 10.) 



\section{GREEK PHILOSOPHY BEFORE PLATO}

\section{CHAPTER I}

\section{THE EARLY IONIAN PHILOSOPHERS}

1. Thales of Miletus. ${ }^{1}$ - We begin with the thinker to whom Aristotle assigned the position of leader in philosophical speculation. When Aristotle called Thales the leader, the first of those who speculated philosophically on nature, ${ }^{2}$ he undoubtedly implied a contrast between the tenor of the new conception and something which had preceded it. What that something is, Aristotle nowhere explicitly declares. It is probable, however, that he has in view the antecedent mythologies, whether in their cruder form, as expressed, for example, in Hesiod, or in a more developed fashion, as in the speculations of Pherecydes. The characteristic of the new line of investigation of which Thales is regarded as the originator was certainly that it took for its object the structure of the universe as it existed and was apprehended, and sought to find an explanation of

1 Born about 625 B.c.; died about

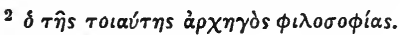
547 B.C. -Arist. Met. A 983 b 20. (R.P. 10.) 
it in some component, constituent, or relation of that universe itself. The term $\phi v ́ \sigma \iota s$ (nature), as we can see more definitely from the immediate successor of Thales, was - beginning to lose its personified significance and to retain as the fundamental elements of its meaning (1) the total mass of actual fact, and (2) the generating principle thereof.

Thales, then, beginning his speculation on nature, seems to have offered as the fundamental principle of explanationWater. ${ }^{1}$ All things are formed from water; water is the primitive substance of all that is. On what he based this assertion, by what arguments he defended it, we do not know. Already in Aristotle's time there was only tradition respecting the utterances of Thales. ${ }^{2}$ It is to be added, however, that Thales evidently did not contemplate any such separation as afterwards was seen to be inevitable between the material substratum (as we call it) and the motive power or principle of change. To him evidently these two, being and change, were identical. Water, we may suppose, trans- : formed itself into the variety of the changing universe by some inherent principle, or power of movement, which was not distinct from the material substratum itself. It cannot even be said that Thales attempted even in the most general terms to define in what way, or by what procedure, the material substratum transformed itself into the variety of the changing universe. That he identified the inherent principle of change with what is divine in nature and with the soul ${ }^{3}$ must be interpreted as meaning only that for Thales the fundamental principle of the universe was naturally the greatest, the divine, and that, like all the early thinkers, he - drew no distinction between what we call mechanical or

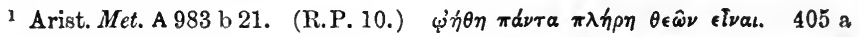

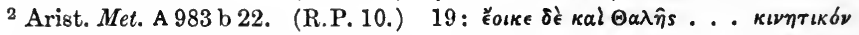

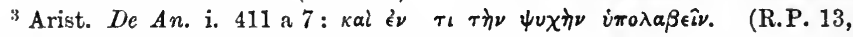

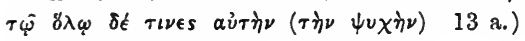

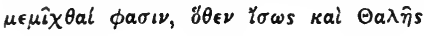


externally determined movement, and spontaneous, selfdetermined change such as appears to be due to the soul. Throughout the thought of this early period, the term $\psi v \chi \eta^{\prime}$ (soul) has a far wider denotation than with us. It signifies quite generally the principle of movement at large.

2. Anaximander of Miletus. ${ }^{1}$ - Far more important, because representing a much more advanced stage of abstraction, is the work of Anaximander, who is regarded as the immediate successor of Thales. Anaximander, according to tradition, was among the first to do work in astronomical science. $\mathrm{He}$ is said to have been the first to construct a map; and the first to have constructed the sun-dial ${ }^{2}$ (though this is probably erroneous). His speculations about the visible universe he is said to have embodied in a work on nature ( $\pi \epsilon \rho i$ $\phi \dot{v} \sigma \epsilon \omega s)$, of which nothing but a few words now remain. ${ }^{3}$ Anaximander, so far as the specially philosophical side of his work is concerned, brings forward, as the principle or founda-

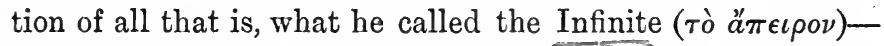
an ambiguous term, of which Anaximander does not seem to have offered any unambiguous explanation. It is perhaps from a misunderstanding of a passage in Theophrastus that a later writer has said, "Anaximander was the first to use the

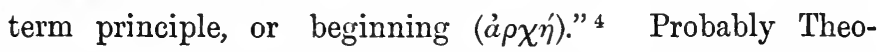
phrastus only meant to say that Anaximander was the first to declare as the principle and element of things, 'the Infinite.' In all probability Anaximander did speak of his 'Infinite' as the 'beginning' of things, for, however confusedly he may have conceived the matter, his speculations about the universe involved the distinction between the primitive condition and what follows therefrom.

1 Born about 610 B.c. ; died after 540 B.c.

2 R.P. 15. (Diog. Laert. ii. 1.)

3 R.P. 16. (Theophrast. fr. 2 ap.
Simpl. Phys. 24, 13.)

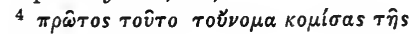

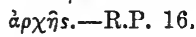


In the second place, Aristotle repeatedly and explicitly assigns to Anaximander a definite conception of the way in which the multiplicity, the variety, of things is generated. from the Infinite. He uses always for the process the term -

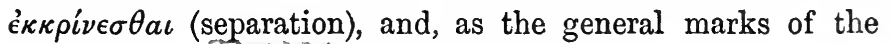

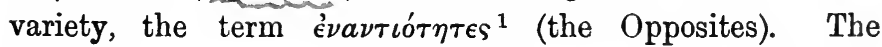
Opposites are sundered out from the Infinite. These opposites we no doubt name now by the terms of qualitiesdry and moist, cold and hot; but it is quite certain that the abstract notion of quality formed no part of the philosophical equipment at that time. There was no distinction then between thing and quality, such as is logically possible now. Anaximander meant by 'the Hot,' 'the Cold,' the concrete quanta or masses, forming part of the visible, tangible world, ${ }^{2}$ brought together, so to speak, rather in a collective fashion than logically by abstraction.

It would follow from this that Anaximander, so far as the general process of change in the universe is concerned, conceived of it as a constant emergence of opposites from the substratum, their coexistence in varying amounts, and in all probability their return according to some general law into the substratum itself-a cyclical process', in which the relation of the opposites to one another is metaphorically represented by the help of the term a $\delta \iota \kappa i a$ (injustice, intrusion): the one opposite being conceived to encroach or intrude on the other. ${ }^{3}$ Evidently Aristotle is proceeding on the ground

${ }^{1}$ Arist. Phys. i. 187 a $20 . \quad$ (R.P. $16 \mathrm{c.})$

${ }^{2}$ Hot, cold, dry, moist, are roughly equivalent to fire, air, earth, waterthe four elements. In Aristotle fire is the hot-dry, air the hot-moist, earth the cold-dry, and water the cold-moist.

3 Theophrastus's account of Anaximander is as follows :-
"Anaximander of Miletus, son of Praxiades, a fellow-citizen and associate of 'Thales, said that the principle [= material cause] and first element of things was the Infinite, he being the first to introduce this name for the principle. He says it is neither water, nor any other of what are now called the elements, but a substance ( $\phi \dot{v} \sigma \iota s$ ) different from them, which is 
of this notion of encroachment or intrusion when he says that according to Anaximander's view the ultimate component of things could not be any one of the elements, for if it were any one of these, by surpassing, as it were, all the others, it would destroy the variety of things. ${ }^{1}$

Anaximander is also credited with a quantity of speculation of an astronomical kind ${ }^{2}$ the outlines of which at least must be taken into account before we endeavour to answer the fundamental question, what is the significance

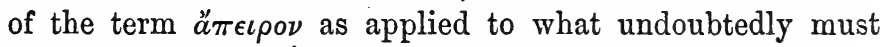
be regarded as the material substratum of the visible and tangible universe?

Anaximander offers a very peculiar account of what we may call the cosmological system. Without defining the mode in which the successive changes come about, he seems to have taught that somehow from the Infinite there was separated off that which contained in itself the source of the Warm and the Cold; that these were sundered from one another in the generation of things; that on the one hand the cold element is a kind of covering of air surrounding the earth-with-its-quantum-of-water, and that on the other hand the fiery element is wrapped round the air like bark round a tree, as he puts it pictorially.

This second envelope of fire or perhaps of fiery vapour is in some way broken up. It is not impossible that the breaking up may have been vaguely explained by Anaxi-

infinite, from which arise all the heavens (oupavol) and the worlds ( $\kappa \delta \sigma \mu o \iota)$ within them.

And into that from which things take their rise they pass away once more, 'as is ordained; for they make reparation and satisfaction ( $\delta\llcorner\delta o ́ \nu \alpha \iota$ $\delta i \kappa \eta \nu \kappa a i \tau\{\sigma(\nu)$ to one another for their injustice according to the ap-

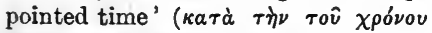
$\tau a ́ k(\nu)$, as he says in these somewhat poetical terms.

He did not ascribe the origin of

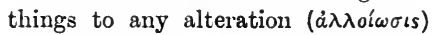
in matter, but said that the oppositions in the substratum, which was a boundless body, were separated out." -R.P. 16. (Simpl. Phys. 24, 13.)

1 Arist. Phys. iii. 204 b 22. (R.P. $16 \mathrm{b.}$ )

2 See Burnet, Early Greek Phil. 62-73 (61-72, 2nd ed.); and R.P. 19-21. 
mander from the analogy of the familiar experience of the sling. The circular motion, it might have been thought, would give rise to this breaking up of the continuous envelope into certain rings or hoops which Anaximander represented as encircling the earth-with-its-covering-of-air, and themselves surrounded by coverings of air. These sheaths of air had orifices through which the fiery vapour escaped and became visible; and by these orifices Anaximander explained the appearance of the sun and stars and their changes. The hoops or wheels of fiery vapour which thus constituted the heavenly bodies were at various distances from the earth; and Anaximander's conception, if represented pictorially, would take form as a series of three or, including the earth, of four concentric circles, the outer boundary of the wheel of the sun being the most distant from us, and the total diameter of the orbit of the sun being twenty-eight times the diameter of the earth. As the sun itself was regarded as no larger than the earth, its inner boundary was the circumference of a circle whose diameter was twenty-seven times that of the earth; the inner diameter of the orbit of the moon was eighteen times that of the earth; the stars, especially the Milky Way, had an orbit whose inner diameter was nine times that of the earth. ${ }^{1}$ The only interest here is (1) the conception of the stars as being nearer than moon or sun, and (2) the evidently designed arrangement of the numbers expressing the distances: they are multiples of three.

In the centre of the cosmical system was the earth, which Anaximander regarded as somehow maintained in its position in the centre by its equal distance from what

1 This is an inference of $P$. Tannery (Science hellene, 91). There is obviously a discrepancy in the accounts of the diameter of the sun, due to a confusion between the outer and inner diameter of the ring. 
surrounded it. In figure the earth resembled the section of a solid pillar, and the diameter of the flat surface was three times the depth of the solid section.

This definitely formed system is what the later authorities

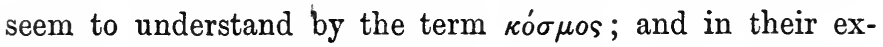
pressions about Anaximander's view there is implied an

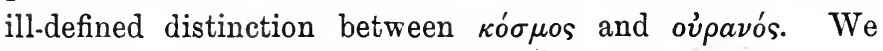
shall find later these two terms reappearing with a considerably altered meaning. At first the oúpavós seems to have been conceived as the more comprehensive of the two. ${ }^{1}$ In connexion with these terms we are also informed that according to Anaximander there were infinite worlds, and with this assertion seems to go an opinion recorded on some authority by Cicero. "Anaximander's opinion was," says Velleius in Cicero, ${ }^{2}$ "that there were gods who came into being, rising and passing away at long intervals, and that these were the innumerable worlds." The generated gods here are evidently the infinite, that is, the indefinitely numerous, worlds; but it is not easy to determine what is meant by their "rising and setting at long intervals." Zeller is of opinion that the intervals are of time, Burnet that they are of space. According to the one, therefore, 'the innumerable worlds' means no more than the constant generation of an ordered world out of the Boundless, and the equally constant return thereto. According to the other, the worlds that are formed must to some extent coexist-an opinion which in its own way anticipates the later doctrine of Democritus and Epicurus, according to which by necessity, owing to the infinite concourse of atoms, there must be formed side by side in

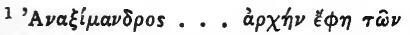

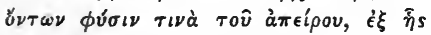

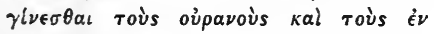

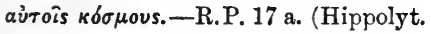

Ref. Har. i. 6.)

2 Cic. Deor. Nat. i. 25. Cf. Burnet, Early Greck Phil. 67 (64, 2nd ed.);

R.P. 21, 21 a b.
} 
the void innumerable worlds, separate but coexisting. On the whole, I think the balance of probability is with Zeller, and that Cicero or his authority mixed up two distinct doctrines of Anaximander; for we learn that Anaximander in his own way anticipated a quite different doctrine of the atomists, by which they sought to explain the gods and dæmons of popular theology.

Anaximander's cosmical view presents, as we see, a curious if distant analogy to the very much later conception called technically the Nebular Theory; and we might even hypothetically assume that his Infinite or Boundless was vaguely represented as a vaporous mass which by internal movement split up into the definite forms of the cosmos. There is an equally interesting and equally vague resemblance between later theories and certain speculations of Anaximander regarding the genesis of organic life. Living creatures, Anaximander says, arose from the moist as it was evaporated by the heat of the sun. Man at the outset was like the fish. His reason for insisting that man had not originally the form he now has shows some acuteness. "While other animals quickly find food for themselves, man alone requires a long period of suckling. Hence he could never have survived had he been originally as he now is." 1

We may now put the final inquiry as to the definite character of that important factor, the principle of things, characterised by him as boundless, infinite, indeterminate. We start, of course, with the admission that at all events - the Boundless was corporeal, although in respect to this admission it must be borne in mind that for us the corporeal has definiteness through the opposition to spirit or mind, which must have been wholly absent from the thought of Anaximander. In its own nature the principle of things, - las Anaximander treats it, is distinct from any of the quali-

1 R.P. 22. (Ps.-Plut. Strom. fr. 2. Dox. 579, 17.) 
tatively definite opposites which are separated out from it. Is it then to be conceived of as a mixture of these qualitatively distinct opposites, either of the nature of (1) mechanical juxtaposition, or of (2) chemical combination? Or is it to be conceived of as (3) wholly devoid of quality? or if it has quality of its own, is (4) that quality intermediate between the elementary opposites or some pairs of them ? 1

(1) Although Aristotle frequently uses the term $\mu \hat{\imath} \gamma \mu a$ (mixture) with reference to Anaximander, his expressions enable us at once to reject the view that the Infinite is just the boundless coexistence of the elementary opposites. Aristotle repeatedly contrasts the view of Anaximander with later conceptions, such as that of Empedocles, of which this description would be an accurate account. ${ }^{2}$

(2) It is more difficult to deal with the second interpretation, according to which the Boundless would be conceived of as in a state of, so to speak, chemical indifference. Still it can hardly be thought justifiable to impose this tolerably definite conception on the records of the notion as put forward by Anaximander.

(3) And it is certainly impossible to ascribe to Anaximander the conception of a substratum which is wholly devoid of specific quality. Undoubtedly the distinction he draws between the principle and elementary opposites separated out from it, leads logically, and by a very simple step, to the antithesis of unqualified matter and its qualities; but the utmost we may say is that Anaximander does not assign a specific quality to the principle; we cannot say that he defines the principle as devoid of quality.

(4) As regards the last view, that Anaximander represented the Infinite as being something intermediate between

${ }^{1}$ Cf. Burnet, Early Greek Phil. 53. $\quad{ }^{2}$ Cf. Burnet, Early Greck Phil. 54. $(52,2 \mathrm{nd}$ ed. $)$ $(59,2$ nd ed.) 
the elements, it finds its only support from the negative argument that we do not know who else is referred to by Aristotle when he criticises some such view. On the other hand, Aristotle explicitly says of those who adopted such a view that they regard the generation of things as coming about by the process of thickening and thinning, and contrasts with that view the theory of Anaximander. ${ }^{1}$

It remains then to ask whether any more definite inter-

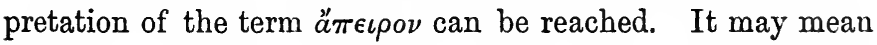
obviously 'without qualitative distinctness,' 'without limit in space,' 'without limit in time,' 'without want or deficiency.' Now, in regard to these, only the last can be said to be unambiguously indicated by Anaximander himself. $\mathrm{He}$ does give apparently as a reason for the characteristic of boundlessness, that the principle must be capable of yielding the whole cycle of generation: it must be ä $\pi \epsilon \iota \rho o \nu$, that generation may not cease. ${ }^{2}$ But there must be added to this that, also in accordance with Anaximander's view, such boundlessness would be incompatible with the possession of any one specific qualitative distinctness on the part of the principle. On his view apparently generation would cease were the principle to be of one kind only. Accordingly

- we must add to the mark of infinite potentiality something of the nature of qualitative indifference.

${ }^{1}$ Cf. Burnet, Early Greek Phil. 57 , note 66 . (59, note 2 , 2nd ed.) His view turns on the following passage in Aristotle, Phys. i. 187 a 12: "As to the assertions of the natural philosophers ( $\left.\phi v \sigma \iota o^{\prime}\right)$, two varieties are to be distinguished. The first regard the fundamental substratum, corporeal in character, as one, either one of the three (fire, air, water) or something different, which is thicker than fire and finer than air, and then they explain the variety of things by supposing that they are generated by thickening and thinning. ... The others, regarding the elementary opposites as inhering in the One, say that they are separated out from it, as Anaximander declares, and as those say who assert the conjoint existence of a Oue and Many, as, c.g., Empedocles and Anaxagoras." (R.P. 16 c.)

2 R.P. 16 a. (Ps.-Plut. Plac. i. 3, 3.) 
Moreover, as, according to Anaximander - though it is put by him in rather vaguer terms than by his successorsthere is a constant cycle of generation, there must also be allowed to his notion a certain reference to infinity of 1 time. Not that this was either peculiar to him or very definite. The conception of an absolute limit of time, if possible at all for the human intellect, does not present itself among the early Greek thinkers.

Finally, Anaximander's notion does not explicitly exclude, but it can hardly be said in any way to include, the definite conception of boundlessness in space. He may have thought vaguely of an unexhausted and inexhaustible quantum of reality which extended beyond the limits of the formed world or cosmos; but his representation of that is extraordinarily vague.

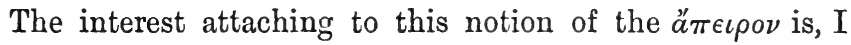
think, that it marks the first step in the progress, which . $\checkmark$ the Greek mind took with remarkable rapidity, of abstraction

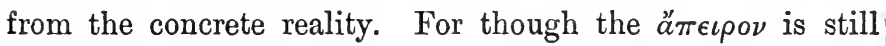
held as something existing in rerum natura, yet, in the conception of it, all the features which characterise concrete objects are removed: the first opposition is made between the real which is not directly apprehended but is held on grounds of logical necessity, and the apparent world of multiform concrete existences which is apprehended through the senses.

3. Anaximenes.-Anaximander is said to have had as immediate follower the third representative of the Early Ionian School-Anaximenes, ${ }^{1}$ a native of Miletus. According to Anaximenes the principle of things was one and boundless, but not, as with Anaximander, indeterminate in respect of quality: it had the specific nature of Air (án $\rho)$.

If Died probably before 500 B.C. 
It is obvious from our authorities that Anaximenes in this opinion was mainly influenced by consideration of the function which Air plays in supporting animal life. ${ }^{1}$ The vital air, the breath, is that which supports and sustains the human body, and from that analogy Anaximenes proceeded to the general position that the whole Cosmos depended on Breath or Air. In its own nature this principle - possesses the capacity for movement or change. Just as

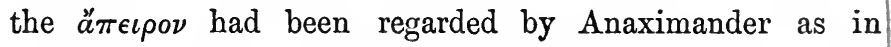
constant movement, so Air or Breath was constantly active.2 From it arise and into it pass all the definite concrete objects of the Cosmos, and they do so by the process of thickening and thinning (Condensation and Rarefaction).

With this general doctrine Anaximenes united certain special positions with regard to the astronomical system. ${ }^{3}$

${ }^{1}$ R.P. 24. (Ps.-Plut. Plac. i. 3, 4.) ${ }^{3}$ For which see Burnet, Early Greck

2 R.P. 26. (Simpl. Phys. 26, 28.) Phil. 79 ff. (\$ 29, 2nd ed.)

R.P. 28. (Hippolyt. Ref. Her. i. 7.) 


\section{CHAPTER II}

\section{PYTHAGORAS AND THE PYTHAGOREANS}

THE Ionian school is no doubt rightly characterised as prevailingly physical in its ideas and methods. But it prepared the way for much more abstract conceptions and for distinctions which imply-if they do not rest on-the opposition between the abstract and the concrete. The Pythagorean school represents a more developed stage in this kind of reflexion-so much more developed than anything which precedes, that it stands out in the history of Greek thought as constituting an independent source which determined one line of thought in all the later Greek work. Unfortunately, however, it is almost impossible to recover the earliest forms of Pythagorean speculation. Our authorities are almost all of relatively late date. The school of Pythagoreanism had a continuous though somewhat disturbed existence, incorporated readily elements from quite different philosophical views, and therefore, while retaining some of its original positions, applied them in quite novel ways. Our authorities almost without exception relate to these later developments of Pythagoreanism. In a broad historical way there are perhaps only two main points about which we can feel assured that we possess traces of the work of the early Pythagoreans: their views on Transmigration, and their interest in and promotion of mathematical studies. 
(It is an interesting question how they came to combine these two.)

The founder of the Pythagorean school was by universal consent Pythagoras, ${ }^{1}$ a native of Samos, who must, even outside Magna Græcia, the region specially affected by Pythagoreanism, have very early attained a high reputation. Heraclitus writes of him, "Pythagoras, son of Mnesarchus, practised inquiry beyond all other men, and made himself a wisdom of his own, which was but a knowledge of many things and an art of mischief." 2 Of his career very little is known: there are biographies of him with abundance of detail, but all belonging to the period of Neo-Pythagoreanism, after the Christian Era, resting on no authority, and demonstrably false. The travels ascribed to Pythagoras may have some foundation in fact, or they may only rest on the obvious similarity of some of his views to Egyptian and Oriental doctrines. About the age of forty he settled at Croton in Magna Græcia, and there beyond a doubt he was successful, largely owing to the historical circumstances of the moment, in founding what was later called a tiaros (Order or Society), which practised a certain rule of life and also a common ritual or ceremonial, which finds expression in a large body of rules, but which we cannot now very clearly understand. ${ }^{3}$

The Pythagorean society, the fate of which was determined by political movements, was probably not at first political in character, but ethical, social, or religious. Certainly a community of this kind could hardly fail to exercise political influence, all the more by reason of the peculiar conditions of political life in the small Greek City-States. Whether the secrecy of doctrine which we find ascribed to the

1 Said to have been born about 582 в.c. and to have died about 506 B.c.
2 R.P. 31 a. (Diog. Laert. viii. 6.)

${ }^{3}$ See Burnet, Early Greek Phil. $93 \mathrm{ff}$. 
Pythagoreans concerned the doctrines or ceremonials of the community on its practical side or related to their more abstract speculations in mathematics can hardly be made out with certainty. It seems perhaps to us a little unnatural to assume that secrecy was inculcated with regard to geometrical theories; but we have evidence distinctly in favour of this view, and we know of no secret religious doctrines which might have constituted a special sacred possession of the members of the society. It is not impossible that at a later date the two things grew into a kind of combination, and that the latent possibility of symbolic interpretation which attaches to mathematical theorems and principles became explicit. Even pretty early one of the peculiar diagrams of the Pythagoreans, the regular pentagram, was certainly adopted as a kind of symbol of welcome, or of fellowship, in the society; and it may have been that the tendency abundantly manifested in later Pythagoreanism made itself apparent at a comparatively early stage.

The transmigration of souls, an undoubted doctrine of the earliest Pythagoreans (for we find it referred to by Xenophanes, almost a contemporary of Pythagoras), ${ }^{1}$ was in some way connected with the very obscure body of practices and accompanying beliefs referred to under the title of the Orphic doctrine. These Orphic mysteries constitute a very obscure chapter in the development of Greek religion. Historically there is no doubt that their first appearance coincides with the period of Pythagoras; and influence may have been exercised by one on the other from the first. It may be, too, that there is historical justification for the view that the appearance at this time of the Orphic doctrines and practices indicates a kind of 'revival' of religious beliefs, a revival that may in turn have been called forth

${ }^{1}$ R.P. 88. (Diog. Laert. viii. 36.) 
by the misfortunes which had overtaken the greater portion of the Greek world. ${ }^{1}$

The transmigration of souls carried with it also a consequence which on its own merits deserves recognition. Eudemus said, "If one is to believe the Pythagoreans, once on a time I too with this staff in my hand was prattling away to you, you too, just as you are now, sitting before me; and so with everything else." ${ }^{2}$ According to this the Pythagoreans contemplated a continuous cycle of existence. All human events were repeated time after time, endlessly. This is a notion which plays a part throughout all the later Greek speculation. It was, in fact, their equivalent for the modern conception of progress. Aristotle and Plato vaguely, and the Stoics quite definitely, express the same view. Undoubtedly in the Greek mind it connected itself with the fundamental proposition which was implied even in the early Ionian cosmologies, and which presently we shall see formulated in all exactness by the Eleatics - that out of nothing comes nothing, that there is in reality neither coming into being nor passing out of being. As they interpreted this axiom, it implied a continual process which, if definitely conceived, would involve the repetition endlessly of the same conjunctures, the same events.

On the philosophical side far more interest attaches to the work of the Pythagoreans in pure science; for it is in accordance with the statement of Aristotle, our best authority, that we suppose the development of philosophy to be determined by the progress of scientific research. Aristotle begins thus his account of the Pythagoreans: ${ }^{3}$ "In the age of these thinkers, and even before their time, appeared the so-called Pythagoreans" (he ascribes nothing to Pythagoras, never speaks of him) "who, applying them-

1 See Plato, Phadr. 244 D.

2 Simpl. Phys. 732, 30.

3 Arist. Met. A 985 b 23. 
selves to mathematics, were the first to bring these studies into prominence, and by being trained exclusively therein, came to think that the principles of mathematics were the principles of all things whatsoever; and as in mathematics numbers are naturally first in order, and as they fancied that they could discern many more resemblances in numbers to the facts and processes of concrete existence than they could in fire or earth or water, for instance that such-andsuch a quality of numbers was Justice, another, Soul or Intelligence, a third, Favourable Opportunity, and so on, and as they noted, moreover, that the properties and laws of harmonies all depended on number - since thus all things in their nature seemed modelled upon numbers, and numbers were prior to everything else in nature, they formed the general conception of the first elements of numbers as the first elements of all things whatsoever, and of the whole cosmical system as harmony, number."

Aristotle's statement, then, explains the general position of the Pythagorean philosophy - that the essence of things a is number, harmony, or ratio-by connecting it as a consequence with their mathematical studies. What, then, was the peculiarity of their study of mathematics which enabled the Pythagoreans with such rapidity to effect this philosophical generalisation?

Proclus in his Commentary on Euclid says distinctly: "Next Pythagoras turned the study of geometry into the form of a liberal education, for he examined its principles to their foundation, and investigated its theorems without restriction to matter, and in a way purely intellectual. It was he who discovered the doctrine of irrational quantities (incommensurables) and the composition of the cosmical figures (the five regular solids)." 1 A contrast is thus made between the generality and abstractness of geometry as cultivated

\footnotetext{
${ }^{1}$ Proclus, Comm. in prim. Eucl. elem. librum, 65 ed. Friedlein.
} 
by the Pythagoreans and what had preceded. So far as our knowledge of the development of geometry extends, there is abundant justification for the general statement that it is characteristic of the Greek geometry, and of it only, that it effected the complete separation of geometrical form from matter, and thus rendered possible a pure science of geometrical relations. The contribution of Pythagoras to this all-important work seems to have been of decisive importance. If we compare what is on good authority ascribed to him in the way of geometrical speculations with what other early Greek thinkers are credited with, the superiority in method, and above all in range of generalisation, is wholly on the side of Pythagoras. For example, to him is ascribed the general proof of the all-important theorem about the sum of the interior angles of a plane triangle; and we gather that his general proof was arrived at after the theorem had been made out separately for the several cases that are possible.

The propositions in elementary geometry which are assigned to Pythagoras extend over a considerable portion of the field. They concern plane figures and likewise solids. In dealing with these geometrical theorems the treatment of Pythagoras, though highly general, leaves us in much doubt as to the exact relation, in his way of thinking, between what we call the geometrical and the arithmetical. That he recognised this distinction we are definitely informed by Proclus: ${ }^{1}$ at all events, according to his account, the distinction must have originated at a very early period in the Pythagorean school. Nevertheless there is less distinction drawn between the arithmetical and the geometrical in the Pythagorean theorems than we are now accustomed to draw. If we seek for a definite answer to the question, were the elements which Aristotle calls numbers conceived by the

1 Proclus, Comm. in prim. Eucl. elem. librum, 35 ed. Friedlein. 
Pythagoreans arithmetically or geometrically? the decision is not easily reached. The answer, nevertheless, has some importance both in respect to the Pythagorean doctrine as a whole, and, as we shall see, in respect to the interpretation of those curious puzzles with which, soon afterwards, Zeno the Eleatic perplexed his hearers, and which have furnished a constant topic of discussion in later philosophy. My impression is that, so far as Aristotle is to be regarded as an authority, the primary position must be given to the arithmetical. For Aristotle repeatedly notes ${ }^{1}$ that the Pythagoreans attempted to give to their numbers space dimensions, the 1 being the point, the 2 the line, the 3 the plane, the 4 the solid, but that they were much perplexed as to how this incorporation of numbers in space came about. Moreover, we are informed that, according to the Pythagoreans, proportion was the connecting-link between arithmetic and geometry. Now, though the doctrine of proportion, which is for us proximately arithmetical, was undoubtedly in the elementary Greek mathematics worked out in reference to lines, yet it is evident that the Pythagoreans reached a point of view approximating to the arithmetical, and that particularly through their researches into harmony.

It may then be accepted as a provisional foundation for the general account of the Pythagorean principles that they are mainly a theory of numbers; that the distinctions which were regarded as of importance were primarily distinctions of number. Now, the distinctions which the Pythagoreans regarded as of most importance are indicated by the terms Odd and Even, Limited and Unlimited. Aristotle says: "The first elements of number are the Odd and Even, which again are regarded as the Limited and the Unlimited. The One, on the other hand, combines both these as being at once odd and even." 2

${ }^{1}$ Arist. Met. н 1028 b 15. (R.P. 76 a.) ${ }^{2}$ Arist. Met. A 986 a 17. (R.P. 66.) 
It is possible that the Pythagoreans combined with this general opposition of Odd-Even, Limited-Unlimited, a general conception of oppositeness or contrariety, as running through the whole structure of things.

On the side of geometrical or mathematical theory the attempt to develop the theory of numbers seems to have been singularly devoid of fruit. Only in the one case, the doctrine of harmonies, did the Pythagoreans lay the foundations for a later development of scientific worth.

To effect a junction between this very abstract theory of numbers and such scattered notices as we have of the Pythagorean cosmology is also very difficult. We learn that the Pythagoreans conceived of the world - that in which definiteness, order, and proportion to some extent prevailed-as being but, so to speak, a section of the totality of existence. There appears in them a threefold distinction, which considerably later acquires definiteness, which appears distinctly in Aristotle, and which is not without influence on the Platonic writings. The formed universe was regarded by them as falling into the three regions: (1) that which formed the boundary of the universe-the ultimate Olympus, the region of elemental fire, what is purest, in perfect order, admitting of no change or variation: (2) the region of the heavenly bodies, excluding the earth; here there was law and order, combined with multiplicity and movement: and (3) the region under the moon, the earth and its immediate surroundings, the realm of indeterminateness, what later was called in Plato and Aristotle the world of generation. ${ }^{1}$

The Pythagoreans in a dim way seem further to have regarded this threefold distribution as coming about through the gradual subjugation of the void, or rather of the relatively void, under the component of order, pure fire, or

1 The Pythagoreans are said to that below the moon oujpavos.-R.P. have called the middle region $\kappa \delta \sigma \mu o s: 81$. (Stob. Ecl. i. 488.) 
something resembling fire. What they meant by the void is a point much debated. Aristotle clearly says that

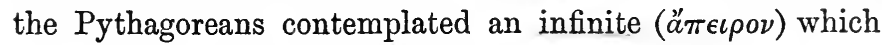
was outside of the heavens (oúpavós); and he also tells us that according to the view of the Pythagoreans the heavens, the ov pavos, drew in the void, and that thereby the numbers were separated from one another. ${ }^{1}$ Now, the conception of an absolute void hardly became clear before the period of the later Eleatics and the Atomists, whose views in that respect are almost identical; and the two data supplied by Aristotle naturally suggest that by this indeterminate boundless void the Pythagoreans meant something like the Air which as principle of things was proposed by Anaximenes-not air as one element of the physical universe. For there can be no doubt about another datum we get, that according to the Pythagoreans the elements were formed from the regular solids: the earth being the Cube, fire the Tetrahedron, air the Octahedron, water the Icosahedron; while, as there still remained the Dodecahedron, the Pythagoreans added a fifth element, of uncertain or unknown name. ${ }^{2}$

It is possible, then, that they may not have advanced to any exact discrimination of this relative void, but contented themselves with assigning to it a function very importantthat of separating the numbers from one another. "Separating the numbers" seems only to be interpretable in terms of space, whence would follow the outlines of a broad conception, doubtless never made precise by the Pythagoreans, that the formed universe is reducible to figures in an all-• extending space. Figured space would become their general

1 Arist. Phys. iv. 213 b 22. (R.P. Plato. Cf. Plato, Tim. 55 c. Aristotle 75 a.) recognises in addition to the elements

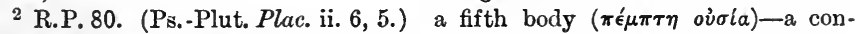
[Probably the view ascribed to the ception from which the word 'quintPythagoreans is really borrowed from essence' is derived.] 
idea of the physical universe; and, as the two are quite distinct from one another, the possibility of infinite division would be assigned to the relatively void (the vague indeterminateness of space), while indivisibility would be the characteristic of the figures or numbers in space. There are certainly traces of some such view among the Pythagoreans. In accordance with it, as can be seen, the line would be conceived as made up of a number of indivisible points, while the indivisible point itself might fairly be said to be in the realm of abstraction what the atom in the realm of physics was for the later Atomists-an indivisible quantum. We shall consider later whether the puzzles of Zeno have not express reference to some such way of representing geometrical magnitudes.

Later authors have naturally tended to interpret this cosmical view of the Pythagoreans in the light of ideas with which no doubt it is logically and chronologically connected. They have represented the universal fiery vapour as a soul of the world animating and sustaining it, and embodying itself in individual form in living beings. Even to Philolaus ${ }^{1}$ there are ascribed certain utterances respecting the soul and its parts which are supposed to confirm such an interpretation of the primitive theory. These are all of later date, however; and what Philolaus has to say of the soul has certainly been corrupted, as we have it, from Stoic sources. The Pythagoreans really cannot be said to have had the conception of a soul of the world; and, with one exception, their doctrines of psychology are rudimentary, little more than a commentary on the doctrine of transmigration. Aristotle says only of the Pythagoreans, (1) that some of them seem to have thought of the soul as in itself a principle of movement, for they thought that the soul either

1 A contemporary of Democritus, born perhaps about 470 B.c. 
was or was like the motes seen in a sunbeam, ${ }^{1}$ and (2) that according to the Pythagoreans-and it was a view which to Aristotle seemed ludicrous-any soul might go into any body. ${ }^{2}$

With this latter notion of the transmigration of the soul, and therefore its separability from the body, there is no doubt connected the Pythagorean opinion to which Plato. refers, that during our earthly life the soul is, as it were, in a prison. ${ }^{3}$ Some of the Pythagoreans seem to have spoken of the body as the grave of the soul, ${ }^{4}$ and such a view is in the direction of that antithesis, prominent in later Pythagoreanism, of the soul as the principle of good and the body as the principle of evil.

Something a little more scientific in regard to the soul may be found, however, in the scanty fragments of Alcmæon of Croton, said by Aristotle to have been a rather younger contemporary of Pythagoras. ${ }^{5} \mathrm{He}$ seems to have been a physician. The view is ascribed to him that the brain is, of all the parts of the body, that which is properly the seat of all psychical activities ${ }^{6}$ and he seems to have expressed himself in regard to the action of outer things on the soul in the familiar mechanical fashion. Moreover, there can be no doubt that a very interesting reference to a theory of the generation of knowledge in the $P h{ }^{2} d o^{7}$ has Alcmæon in view.

Even less can be made out of the early Pythagorean records with respect to ethics than to psychology. They are said to have attempted certain generalisations or definitions of virtues; but, so far as we know, these consisted simply in selecting a numerical equivalent or symbol for the

${ }^{1}$ Arist. $D e$ An. i. 404 a 17. (R.P. 86 a.)

${ }^{2}$ Arist. De An. i. 407 b 20. (R.P. $86 \mathrm{c.})$

3 Plato, Phcedr. 62 в. (R.P. 90.)
4 Plato, Crat. 400 c. (R.P. 89 a.)

5 Arist. Met. A 986 a 29. (R.P. 66.)

6 R.P. 85. (Iambl. Theol. Arithm. 22.)

7 Plato, Phcedo, 96 в. 
virtue. Thus justice was a square, and a just man a perfect cube. It is very doubtful whether the Pythagoreans themselves applied to excellence of character their own general notion of harmony - a notion most easily adapted to it. The same doubt attaches to the application of this notion to the soul: that also was current in later Pythagoreanism. In the Phcedo a definition of the soul is ascribed to two interlocutors obviously Pythagoreans (for they knew Philolaus in Thebes), in which the term harmony occurs. ${ }^{1}$ But there the notion is of soul as the harmony of the body, which has a suspiciously un-Pythagorean ring about it.

The Pythagoreans contributed one important thread to the web of Greek philosophical thinking, and their influence will be found in all the later developments.

1 Plato, Phccdo, $85 \mathrm{ff}$. 


\section{CHAPTER III}

\section{THE ELEATICS}

We turn next to another system of a very characteristic kind in Greek thinking - that of the Eleatics, "the first metaphysicians." In general the Eleatic school is said to have been founded by Xenophanes of Colophon, to have had its principles formulated by Parmenides, applied rather negatively or dialectically by Zeno, and finally rather corrupted in their exposition by Melissus. It is to be borne in mind that these four names cover among them a considerable portion of time, and that therefore such changes as occur in what may be at bottom the same doctrine may find natural explanation from the conflicting views with which that doctrine was successively confronted. Modern researches have rather tended to diminish the importance of Xenophanes and to rehabilitate to some extent the reputation of Melissus, who is an object of sharp and somewhat contemptuous criticism to Aristotle.

1. Xenophanes, ${ }^{1}$ younger, but not much younger, than Pythagoras, is known to us from some fragments of his own poems as a rbapsodist, one who travelled about reciting poems. It is possible that his travels, which were mainly in Sicily, may have originated in the Persian conquest of Greek territories in the East. So far as the frag-

1 Born about 569 B.c., died about 480 B.c. 
ments of Xenophanes go, they indicate much more a severe criticism of the follies of anthropomorphism than a definite strain of philosophical thinking. "There is one supreme God, greatest among gods and men, like to mortals neither in body nor in thought." 1 "As a whole he sees ; as a whole he thinks; as a whole he hears." 2 "Without any labour his thought directs all things." 3 "Mortals indeed believe that the gods come into being as they do, that they have senses, voice, body, like their own. . . . But if oxen or lions had hands, could draw and produce works of art like men, oxen would make gods like oxen, horses gods like horses; they would give to them the bodies they have themselves." 4

These fragments, then, no doubt mainly expressing a judgment strongly adverse to polytheism, may quite reasonably be said to be in harmony with the more precise philosophical doctrine which is not in any of his fragments but which is ascribed to him-for example by Aristotle. Aristotle writes, "There are some who express themselves about the universe as though it were one single nature, though they are not alike either in regard to the merit. of their account or in their way of defining this nature. ... Parmenides, for example, seems to have viewed the

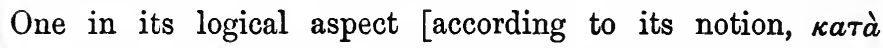
Tò $\nu$ óyov], Melissus, on the other hand, from the point of view of matter ( $\kappa a \tau \grave{a} \tau \dot{\eta} \nu v^{\prime} \lambda \eta \nu$ ), wherefore the former: said that the One was limited, the latter that it was unlimited. Xenophanes, indeed, the first of those who adopted the theory of the Unity of things, for Parmenides is said to have been his pupil, did not make any clear statement in regard to either of these natures; but, looking to the whole universe, he said, "The One is God." 5

1 R.P. 100. (Clem. Strom. v. 714.)

${ }^{2}$ R.P. 102. (Sext. Emp. Math. ix. 144.)
${ }^{3}$ R.P. 108 a. (Simpl. Phys. 23, 18.)

${ }^{4}$ R.P. 100. (Clem. Strom. v. 714.)

5 Arist. Met. A 986 b 10. (R.P. 101.) 
Aristotle, then, ascribes to Xenophanes the first definite statement of the Unity of Existence, obviously understanding thereby something which is different from any view of the One-ness of existence which might naturally be ascribed to any of the earlier Ionic thinkers. Xenophanes, moreover, is said by Aristotle to have left the doctrine of the unity of existence in an indefinite condition, neither saying that it was limited nor that it was unlimited. Later authorities tend to turn this into the more precise but more doubtful and difficult statement, that according to Xenophanes the One was neither limited nor unlimited, to which they add, 'neither in rest nor in motion.' ' (This does not fit Xenophanes at all, nor does it go with what Aristotle says. Xenophanes distinctly says that this One God does not/. move from place to place. ${ }^{2}$ )

There is indeed a fragment which seems to run counter to the statement that he did not define the One as being limited or unlimited, for he certainly speaks of the earth as extending below our feet to infinity. ${ }^{3}$ It is possible that

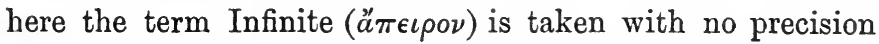
of meaning. It is possible too that in all that Xenophanes says about the physical world, he is proceeding upon the distinction which became explicit in Parmenides between truth and mere opinion, or, in other words, using the distinction between the real world and the world of mere appearance. There are many of his fragments which refer to the generation of things out of earth and water, ${ }^{4}$ and others which very pointedly enforce the doubtfulness of all human views respecting things. ${ }^{5}$ All of these are more intelligible if we assume that the distinction between real existence (the One) and apparent or unreal existence (the Many) was

\footnotetext{
I R.P. 109. (Simpl. Phys. 23, 4.)

${ }^{4}$ R.P. 103. (Simpl. Phys. 189, 1.)

2 R.P. 110 a. (Simpl. Phys. 23, 6.)

3 R.P. 103. (Achill. 1sag. Arat.

5 R.P. 104. (Sext. Emp. Math. vii.
} 128 ed. Pet.) 
approached (however vaguely) by Xenophanes. But all this leaves in the dark what exactly is to be understood by the 'One God,' the 'One Real Existence'; and from Xenophanes, indeed, nothing is to be had in respect to that. Only in Parmenides do we get the explicit statement that is required.

2. Parmenides ${ }^{1}$ is said by Aristotle to have been a pupil of Xenophanes; this may have been so, for apparently he was a younger contemporary. Of Parmenides, fortunately, we possess much more complete information as regards his doctrine than in the case of Xenophanes. Considerable fragments of his poem have been preserved; and Plato and Aristotle frequently refer to and criticise his views. The poem consisted of an introduction and two parts, the first treating of truth, and the second of opinion: "Come, then, I will tell thee-and do thou attentively hearken-the only ways of search that are given to man." 2

With the proposition that 'only Being is,' that Being is the matter or object of knowledge, the philosophical doctrine of Parmenides at once begins and ends. Being is and Non-Being is not, that is the goddess's reiteration. Being, that which is, must by reason of its very nature exclude from itself all

- qualification, all relation, all multiplicity, all change : it is in its nature absolute: thought, which apprehends it, and which can apprehend nothing but it, apprehends in it nothing but pure, absolute, unmoved existence: "Birthless it is and deathless, . . . for ever it stands a continuous One. . . . All is full of being. . . . No defect is there in it." 3

It will be noted that the various predicates here assigned - to Being are all really negative in character; they do not express any positive feature of Being which could be distinguished from Being itself : there is no such feature. They

\footnotetext{
1 A native of Elea, who flourished about 480 B.c.

2 R.P. 114. (Procl. Tim. 105.)

3 R.P. 117 f. (Simpl. Phys. 144, 25.)
} 
serve only to exclude from the notion of Being what ordinary experience and opinion lead us to assign to existence. (This is a very abstract expression of the Ionian doctrine, that in the last meaning of the terms there was no such thing really as an act of Becoming, or of Generation. This was recognised by later thinkers, who all assign to the Ionians the authorship of the maxim, "Out of nothing comes nothing.")

With this fundamental view as regards truth it might seem impossible-and it has always been found inexplicable -that Parmenides should proceed further, and append to his treatment of truth a treatment of opinion. It is certainly not easy to make out his meaning on this point from the fragments of the poem itself.

As regards the account given in the second part, it begins thus: "Two forms men have established; and in this they err, for one is sufficient." 1 These opposites, according to Parmenides, are the components of the world of phenomena; and their intermingling underlies all natural objects, man included. Parmenides repeats a good deal of Anaximander, and probably some Pythagorean material, in these his cosmical fancies. One of the fragments of this second part deserves more particular notice. The general idea of mixture is applied to man and to the mind of man. ${ }^{2}$ "As is at each time the condition of the well-jointed limbs, so is constituted the mind in men. In all and in each that which thinks is the same, namely, the nature of the body, for according to that which predominates is the general character of the mind."

It remains to consider to what extent we can interpret further the rather obscure proposition that 'Only Being is.' Zeller-and he has been supported by several recent writers -thinks that the all-important point in the antithesis between Being and Non-Being is the difference between the space-filling and the void. He insists that Parmenides, like

\footnotetext{
${ }^{1}$ R.P. 121. (Simpl. Phys. 39, 1.) ${ }^{2}$ Arist. Met. $\Gamma 1009$ b 22. (R.P. 128.)
} 
all the early Greek thinkers, was occupied with the general structure of nature, that we have no right to ascribe to him the conception whether of abstract thought or of the incorporeal; and he attaches much importance to the oftenrepeated statement of Aristotle that the reality with which the pre-Platonic thinkers occupied themselves was just what is perceived by the senses. ${ }^{1}$

As against this it may be urged, in the first place, that Aristotle, in speaking of the pre-Platonic thinkers, has always in mind the distinction most familiar to him, and first made explicit in Plato, between the intelligible world and the world of the senses. It is perfectly natural that he should be found saying that the pre-Platonic thinkers did not contemplate another world of existence, so to speak, over and above that of the senses, for he means the other world as represented in Plato. Moreover, when Aristotle has occasion to deal more in detail with the Eleatic doctrine (as in the first book of the Physics ${ }^{2}$ ), we find him expressly saying that, although the Eleatic doctrine is there considered, in point of fact it does not concern the physical at all. It lies outside the - range of physics, deals with general notions that go beyond the physical, and is of service, so far as investigation of nature is concerned, only because of the value that criticism of general notions always has for special purposes.

- Again, beyond a doubt it would be erroneous to identify the abstract notion of the Eleatic doctrine with the conception of an incorporeal reality, if by that be understood, as Zeller throughout seems to understand it, something of the nature of thought, mind, or spirit. No one questions that - the first approach to this discrimination of the incorporeal as psychical from the corporeal as space-filling, was made by Anaxagoras. But it is not necessary that the only antithesis should be that between the corporeal and the incorporeal

${ }^{1}$ Zeller, Pre-Socratic Philosophy, i. 589 ff. $\quad{ }^{2}$ Arist. Phys. i. cc. 2 f. 
in the sense of psychical or mental. Something must be done to fashion the general conception, however dim and obscure, of the non-corporeal, before it can be further defined as in its own nature mental or psychical; and the terms of the Eleatic discussions leave no doubt that they at least approached the highly abstract notion of the NonCorporeal. If Parmenides is not very explicit in that respect, we shall find Melissus and Zeno explicit enough.

Finally, as regards the view that 'space-filling' con-1 stitutes the ultimate character of the Eleatic Being, it is impossible to reconcile this view with the insistence with which the Eleatics affirm the Unity of Being; and if any stress is laid on the expressions in Parmenides which seem to imply a spatial form of Being, due consideration should be allowed both to the imperfection of terminology at the time, and to the impossibility which even a developed terminology finds of expressing a distinction of thought, a logical distinction, in terms that are not redolent of external nature. Aristotle contrasts Parmenides and Melissus in regard to their way of conceiving Being. According to him, Parmenides, in characterising it as limited, was more correct than Melissus, who insisted that it was unlimited; and Aristotle's reason is that Parmenides

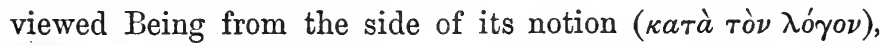
while Melissus regarded it from the side of the matter

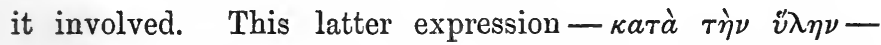
implies no reference to the corporeal. 'Matter' with Aristotle is a much wider notion than corporeality; there

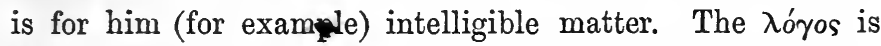
the abstract notion, the complete representation of what is essential to the thing. In regard to it $v^{\prime} \lambda \eta$ is always involved, but only as a subordinate factor or element. If a thinker looks exclusively to this subordinate element, this cornponent of a complete notion, he would in Aristotle's 
phraseology view the thing $\kappa a \tau \grave{a} \tau \grave{\eta} \nu$ í $\lambda \eta \nu$. In the Physics ${ }^{1}$ he says: "'Whole' (ö $\lambda o v)$ and 'complete' ( $\tau$ ć $\lambda_{\epsilon \iota o \nu)}$ are the same or akin. Now nothing is complete which has not an end, and an end is a limit. Therefore Parmenides was more - correct than Melissus . . . for ' unlimited' and 'whole' are incompatible. ... The unlimited is indeed the matter within which size may become complete, and potentially a whole but not actually so."

Thus, then, none of the arguments seem to carry with them of necessity the conclusion that Parmenides was - contemplating as the Existent a motionless, changeless, indivisible plenum, something which we must say extends through space, even though thereby we do violence to our own position. On the contrary, it would seem as though the Eleatic doctrine is correctly described as metaphysical. It arises from reflexion on the single predicate, Being; and in itself it has the permanent interest for us, that it marks one of the perplexities in which human reflexion is always involved when it attempts to employ its own notions in working out a completely intelligible scheme. It is evident that the effect produced by the Eleatic argument lay quite outside the region of physics, that it played no part in the development of the early Greek cosmology, and that its influence is altogether logical or dialectical.

3. The later development of the Eleatic school in ZENo ${ }^{2}$ and MELissus ${ }^{3}$ adds but little to the fundamental idea; and it is somewhat hard to interpret, because we are ignorant of the precise opponents against whom their arguments were probably directed. Some recent writers have laid great stress on a supposed definite antagonism between these later developments of the Eleatic school and a doctrine

1 Arist. Phys, iii. 207 a 13.

2 Born at Elea about 489 B.c.
${ }^{3}$ Of Samos, flourished about 440 B.c. 
they ascribe to the Pythagoreans: that space, and therewith figures in space, consisted of a combination of discrete elements resembling the geometrical point. It must be said, however, that there is not such divergence between the popular conception of a plurality of real things, which Zeno (for example) is usually supposed to have attacked, and the more scientific or mathematical conception of discrete quantity, as would be required to substantiate this view; also, that there is no very conclusive evidence for ascribing this conception of figures in space as made up of discrete points to the Pythagoreans. That such a conception is to be discerned early in Greek thinking is beyond a doubt. It was explicitly held by Xenocrates, an early head of Plato's school; is ascribed by Aristotle in general terms to Plato himself, and probably therefore was anticipated in the prePlatonic thinking. But on the ground, among others, that the Pythagoreans themselves are credited on good authority with having first brought out the doctrine of Incommensurability, one must hesitate to ascribe to them as a fundamental position the view that the line (for example) is made up of points: for then all lines would be commensurable, as the points would be in number definite.

In Plato's Parmenides there occurs the well-known passage in reference to Zeno: "In reality, this writing is a sort of reinforcement for the argument of Parmenides against those who try to turn it into ridicule on the ground that, if reality is One, the argument becomes involved in many absurdities and contradictions. This writing argues against those who uphold a Many, and gives them back as good and better than they gave; its aim is to show that their assumption of multiplicity will be involved in still more absurdities than the assumption of unity, if it is sufficiently worked out." 1

Zeno then is rightly to be regarded as the first of the -

${ }^{1}$ Plato, Parm. 128 c. See Burnet, Early Greek Phil. 325 (\$157 2nd ed.) 
dialecticians or logicians. In him first appears a certain perception of the general structure of argument itself; and we shall find his method, that of attacking the conclusion rather than the premisses of a counter-view, revived in the Megarian school, and intimately connected with the Platonic. Of the arguments assigned to Zeno, a quite satisfactory summary is given by Zeller. ${ }^{1}$ They consist of the following:-

A. Arguments against Multiplicity :-

(a) Were being manifold, did it consist of a plurality of existents, it must be at once infinitely small and infinitely large: the former, because every plurality consists of units, which, if units, are indivisible, and no indivisible unit as such possesses magnitude; the latter, because its parts, to be at all, must have magnitude, and the parts possessing magnitude can only be distinct from one another by an endless interposition of parts between them. This infinite quantum of units must be itself infinitely large. ${ }^{2}$

(b) Were being a plurality, it must be at once numerically finite and numerically infinite: the first, because there are evidently just as many units as there are; the second, because no one unit can be distinct from another save by interposition of a third something, and so ad infinitum. ${ }^{3}$

(c) A plurality of being implies extendedness in space; but that the existent should be in space is a contradiction; for if all that is is in space, space either is not, or is in space, and so ad infinitum. ${ }^{4}$

(d) A measure of corn when thrown out makes a sound. Each grain and each smallest part of a grain must therefore have made a sound; yet no sound is made by a single grain..$^{5}$

\footnotetext{
1 Zeller, Pre-Socratic Philosophy, i. $\quad{ }^{3}$ R.P. 133. (Simpl. Phys. 140, 28.) $614 \mathrm{ff}$.

4 R.P. 135. (Simpl. Phys. 562, 3.)

${ }^{2}$ R.P. 132. (Simpl. Phys. 139, 5.) ${ }^{5}$ R.P. 131. (Simpl. Phys. 1108, 18.)
} 
B. Arguments against Movement :-

(a) Before a moving body can reach any point it must pass over half the distance; and before it can reach the half-way point it must do the same; and so ad infinitum. But an infinity of spaces can be passed over in no given time; therefore movement of a body is impossible. ${ }^{1}$

$\sqrt{ }(b)$ This is the old puzzle of Achilles and the tortoise, and a popular repetition of the first. It assumes that both move. ${ }^{2}$ $\sqrt{ }(c)$ "The flying arrow." To be at any moment in a place is to be for that moment at rest; but at any moment in its flight an arrow is in a place; therefore at any, that is, at every, moment of its flight the arrow is in a place and at rest. ${ }^{3}$

(d) The fourth argument may have been intended to obviate an evasion of the force of the above by laying stress on velocity as transition from point to point of space and as involving likewise change in time. Zeno appears to desire to make out that the notion of velocity involves the same contradiction as that of simple movement.

Take a line $\mathrm{AB}$. We have to draw two lines $\mathrm{CD}$ and $\mathrm{EF}$ equal to $\mathrm{AB}$. $\mathrm{CD}$ is placed so that $\mathrm{C}$ is below $\mathrm{B}$, and $\mathrm{EF}$ so that $\mathrm{E}$ is below the mid-point of $\mathrm{AB}$, and $\mathrm{F}$ below $M$ the mid-point of $\mathrm{CD}$.

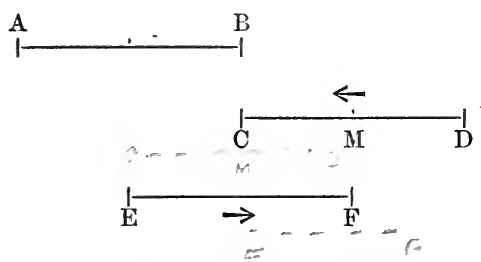

$\mathrm{CD}$ and $\mathrm{EF}$ move, $\mathrm{CD}$ in the direction from $\mathrm{B}$ to $\mathrm{A}$, $\mathrm{EF}$ in the direction from $\mathrm{A}$ to $\mathrm{B}$. Let them move for

I Arist. Phys. vi. 239 b 9. (R.P. 136.)

2 Arist. Phys. vi. 239 b 14 . (R.P. 137.)

3 Arist. Phys. vi. 239 b 30. (R.P. 138.) 
half the time required to pass over the whole space $A B$, then $C$ will be found below the mid-point of $A B$, and $E$ at $\mathrm{B}$ and below the mid-point, $\mathrm{M}$, of $\mathrm{CD}$. It is this point $\mathbf{M}$ to which Zeno attends. $\mathbf{M}$ in the time allotted has passed over a distance = half $\mathrm{AB}$, but during the movement it has passed along the whole of $\mathrm{EF}=\mathrm{AB}$; that is, $\mathrm{M}$, in the allotted time, has touched one half the points in $\mathrm{AB}$ and also every point in $\mathrm{AB}$, for it has passed along the whole of EF. ${ }^{1}$ (Obviously he is confusing absolute and relative movement.)

4. Melissus, the last representative of the Eleatics, has at least two points of interest apart from his attempt to expound the doctrine in a more systematic fashion: (1) he makes clear the non-spatial character of the One Being; ${ }^{2}$ - and (2) he applies the Eleatic argument not only to the prominent type of change-local movement-but also to the more vague form of change, qualitative alteration. ${ }^{3}$

As regards the first of these points, I do not think its force is at all affected by any doubt as to the precise reference in the relative passage of Melissus himself.

These later developments of the Eleatic position are subsequent in time to the utterance of a very distinctly opposed thought, which may not impossibly in its turn

1 Arist. Phys. vi. 239 b 33. (R.P. that we did not see aright after all, 139.)

2 "Now, if it were to exist, it must needs be one; but if it is one, it cannot have body; for if it had solidity ( $\pi$ á $\chi o s$ ) it would have parts, and would no longer be one."-R.P. 146. (Simpl. Phys. 110, 1: 87, 6.)

3 "We said that there were many things that were eternal and had forms and strength of their own, and yet we fancy that they all suffer alteration, and that they change with each perception. It is clear, then, nor are we right in believing that all these things are many. They would not change if they were real, but each thing would be just what we believed it to be; for nothing is stronger than true reality. But if it has changed, what is has passed away, and what is not has come into being. So then, if there were many things, they would have to be just of the same nature as the one."-R.P. 147. (Simpl. De Coelo, 558, 21.) 
have affected them. In Heraclitus the emphasis is laid exclusively on the element of change or process. The notion no doubt is conceived in a very general, and indeed somewhat obscure, fashion; and Heraclitus, on the whole, exhibits more of the meditative tendency towards religious mysteries than of the clear abstract thinking which generally characterises Greek philosophy. The spirit of his utterances is more ethical or religious than speculative or scientific; but in his own way he gives expression to a thought as fundamental as that of the Eleatics, and, so to speak, the supplement which their reflexion imperatively demands. 


\title{
CHAPTER IV
}

\author{
HERACLITUS
}

OF Heraclitus ${ }^{1}$ there remain considerable fragments of a work which probably made its appearance about 480 B.C. or earlier. The work is said to have fallen into three sec-

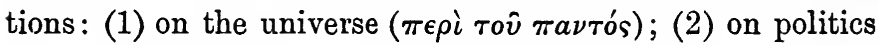

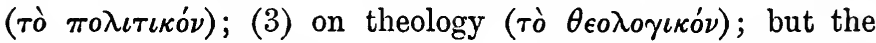
fragments now cannot so be reconstructed. From the earliest time the work was celebrated for its obscurity, which indeed, Aristotle hints, was to some extent intentional. ${ }^{2}$ One source of obscurity is certainly Heraclitus's predilection for rather strained verbal analogies-a circumstance of small significance in itself, but of some interest in connexion with a remarkable development of what may be called the Heraclitean school. Plato notices as a feature of the Heracliteans in his time that they indulged to excess in obscure enigmatical terms. ${ }^{3}$

The fragments as they come before us, while they un. doubtedly contain much of the same large cosmology which characterised the earlier Ionic philosophy, breathe a spirit of deeper reflexion than is present in those earlier speculations. It is difficult to find a word to express the tone of this meditation. It is not strictly ethical, in our sense of that

1 A native of Ephesus, who flourished about 500 B.c.

2 Arist. Rhet. iii. 1407 b 15. (R.P. 30 a.) ${ }^{3}$ Plato, Theret. 180. 
word; nor is it theological or religious; but on the whole the broad ideas which elsewhere are applied to the changing phenomena of outer nature are in Heraclitus extended, and even applied with greater force, to the changes of human life and destiny. In him, perhaps more than in any of the other Greek thinkers, we find it difficult to bear constantly in mind that for them symbol and thing symbolised were not distinct, that a general thought whose import is of the utmost width was formed in intimate union with the more external perceptions of natural change. For example, we find in him a series of utterances regarding fire and its transformations by which all the cosmos is constructed, which looks little more than a cosmology of the ordinary Ionian type; but we find in him also a series of thoughts, pictorially expressed, but very abstract in themselves, which bring forward the several aspects of the root idea of change or process, and its law. We can hardly avoid keeping these apart, giving pre-eminence naturally to the latter. Even with Plato and Aristotle the abstract implication of Heraclitus's doctrine begins to be isolated from the cosmological applications with which at first it was conceived.

The fragments in all probability began with certain utterances which indicate a profound conviction on the part of Heraclitus that the ordinary ideas of things were altogether confused and without foundation. We fortunately know, from a reference in Aristotle, what was the first, or all but the first, fragment in his work. ${ }^{1}$

This ignorance of the many, on which Heraclitus dwells, has a general source, which the fragments lead us to express thus: we incline to take the surface-view of what is given in experience as being the whole truth. No doubt this general expression has more than one particular application in

1 "Though this discourse is true stand it."-Arist. Rhet. iii. 1407 b 14. evermore, men are unable to under-

(R.P. 32.) 
Heraclitus's views. On the one hand, it implies that what the senses directly give is not without further consideration to be taken as the truth, and that not even a copious supply of such sense-perceptions will be equivalent to an insight into the truth: the truth lies hidden; it is underneath the obvious.

On the other hand, there is doubtless implied, though not explicit, a reference to what in the long-run constitutes the essential weakness of the surface-views of sense-perception. They do not bring us to understand the true underlying principle or law ; nay, they rather disguise that from us. It is perhaps not too much to say that the senses tend to give us the notion of the fixity of things, and therefore to hide the truth that the law of all things is change: there is no permanent in things, save only, as we shall see later, the law of all change.

Thus, then, the first general conception in Heraclitus's meditations on things is that which we express by the term process or change. Heraclitus, says Plato, seems to say that all things flow and nothing stands still, and, likening existence to the flow of a river, he says that you cannot go down twice into the same river. ${ }^{1}$

Such change is at the same time for Heraclitus the reality which forms the very structure of things: it is not change but the changing, and the changing is Fire. The wholeworld of existence is the exhibition of the constant transformations of Fire.

This conception or thought of constant process is in itself but a half-thought; and the remarkable feature in Heraclitus is the clearness with which he appreciates the other. side which is implied in the thought. Pictorially, this is represented in him through the thought of all change as a counter-change or opposition, a counter-flow: in all things there is a coming-and-going, a strife, and yet this counter-

$$
{ }^{1} \text { Plato, Crat. } 402 \text { A. (R.P. 33.) }
$$


flow, this strife, is only one side of real concord or harmony. In all things opposites not only are, but are united: a thing, so to speak, is not merely itself and again its opposite; its very nature consists in the union of these two opposites in itself. Harmony is implied in all opposition. It is a con- cord only through opposition; without opposition it would cease to be concord. The whole system, even though its law be change, is a system which continually preserves itself through these very changes. "This order ( $\kappa o ́ \sigma \mu o s)$ which is the same in all things no one of gods or men has made, but it was, is now, and ever shall be an ever-living fire, kindled and extinguished in due measure." 1

The soul is in no way conceived by Heraclitus as distinct from the other transformations of the ever-living Fire. It is one of the forms into which that passes. Although this is a sufficiently crude conception of the nature of soul, yet Heraclitus is also to be credited with the more important view that, since man has the capacity for apprehending both the outer surface of things and the inner law, it is in the recognition of this inner law - of what is objective, therefore-that his true nature is to be found. The law of harmony is therefore extended in its scope: it has not merely the significance, as we put it, of a law of external nature; it possesses at the same time all those attributes summed up in the term 'the Divine.' "Wisdom is one only, is willing and unwilling to be called by the name of Zeus." 2

Thus it becomes obvious why at a later time the Stoics, who sought to overcome the dualism of the Platonic-Aristotelian conception, and to identify physical and psychical, should have returned to the work of Heraclitus, and appropriated almost all its fundamental features. Some part, indeed, of our difficulty in reaching the original thought of Heraclitus is due to the fact that his theory passed through

1 R.P. 35. (Clem. Strom. v. 14.)

2 R.P. 35. (Clem. Strom. v. 14.) 
the Stoics and has come to us coloured by the Stoic ideas and expressed in the Stoic terminology.

Certain points in the Heraclitean doctrine call for further examination: First, what exactly is to be included within the idea of constant change? Conceivably this might mean either that every possible object for our apprehension is in constant flux, or that in the stream of existence there is a cycle of change-the elements, as it were, changing into one another, but preserving throughout their changes what we must call a kind of total equilibrium. In Plato's Thecetetus, ${ }^{1}$ where the doctrine is criticised, the first of these two interpretations is pressed on it as its necessary and only consistent expression. This probably indicates that in the original statement the question was left in some obscurity, and that the later Heracliteans, following out the path indicated, had been forced to a more precise statement than that made by Heraclitus himself. Indeed it may be thought that the second interpretation, if rigorously handled, and if it be borne in mind that according to Heraclitus the change of the great elementary components was of the nature of transformation, not mere alteration of relative position, would lead to exactly the same result as the first interpretation. .

Connected with this is a second point. The Stoics, and with them the Church Fathers, always understood Heraclitus to speak of a final reduction of all things to the state of Fire $\left({ }^{\epsilon} \kappa \pi t \hat{v} \rho \omega \sigma \iota s\right)$ : just as Fire is the original element from which all are formed, so in due order all things will again be resolved into Fire, and so on endlessly. There is only one passage which can be appealed to as in any way decisive $;^{2}$ and it certainly appears to favour the view that

2 "Fire will come upon and lay Burnet, Early Greek Phil. 135 hold of all things." - R.P. 36 a. (149, 2nd ed.) 
in the cycle of existence the path upward and the path downward (which are, according to Heraclitus, one) begin and end in the one element, Fire, which, however, being itself subject to the law of constant change, immediately and in endless cycles produces the series of transformations into the other elements.

Thirdly, the utterances of Heraclitus about the senses are somewhat ambiguous; and no doubt the ambiguity indicates the want of any definite distinction between perception and understanding. The senses fail to convey the whole truth because they give the fictitious impression of fixity in things, and, moreover, what the senses have to deal with is the relatively less mobile, less living part of the universe. This view about the senses, and, in particular, the general ground for it, that no fixity in the objects perceived can be assumed, is singled out by both Plato and Aristotle in their criticisms of the Heraclitean doctrine. In their view that doctrine involved, though in a different way, the same fatal consequence to predication that must be drawn from the Eleatic principle. According to the Eleatic view, seeing that no element of difference is admissible, the only predication possible is the same of the same: indeed, in strictness only one judgment is possible, 'Being is Being.' From the other view-it follows with equal force that no predications at all are possible, for they imply that somehow $\mathrm{a}_{\text {? }}$ definite character can be assigned to the subject. Is it possible that the Heracliteans did not perceive this difficulty and find some means of evading it? We might conjecture, following certainly more modern ideas, that the escape would be made by contrasting the fixity of a law with the flux of the particular cases. The general Heraclitean doctrine contains something to which the appeal could be made: it contains some notion of the unity which

${ }^{1}$ Cf. Lucretius, De Rerum Natura, i. $690 \mathrm{ff}$. 
is exhibited in and through multiplicity or change. But this is only conjecture.

It is still more conjectural to connect this difficulty with the remaining point in the Heraclitean teachings-the importance attached to names. There is here an approach to the same doctrine of the peculiar function of names as is found among the opinions ascribed to Antisthenes, though the theory of knowledge with which Antisthenes connected it is not identical with that of the Heracliteans. We shall find that Antisthenes combines in a curious way an empirical reading of the Eleatic doctrine with this rather startling conception of the function of names. 


\section{CHAPTER V}

\section{ANAXAGORAS}

THE speculations which next present themselves have two marks in common, which they exhibit in different degrees. In the first place, they are profoundly affected by the Eleatic maxim: in one way or another they accept that maxim in its abstract form:-Out of nothing comes nothing; and they endeavour to accommodate thereto their view of existence. And, in the second place, they show a decided tendency towards biological speculations. These characteristics are shared by Anaxagoras, Empedocles, and the earlier Atomists.

Anaxagoras ${ }^{1}$ has a doctrine which falls into two portions : (1) his view respecting Matter; (2) his theory of Mind

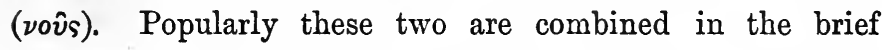
statement: "At first all things were together in an indiscriminate mixture. Then came $\nu$ ovs and arranged them in order." 2 But this is a very imperfect view of Anaxagoras's idea, and quite conceals the real points of interest.

First of all, what were the things that "were all together"? To this question Anaxagoras offers a very peculiar answer. The things are the innumerable seeds of whatsoever is qualitatively distinct. Qualitative dis-

1 A native of Clazomenæ; born about 500 B.C., died about 428 B.c.; a friend of Pericles.

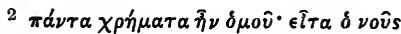

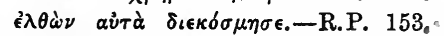
(Diog. Laert. ii. 6.) 
tinctness is therefore taken as an ultimate fact; and, as Anaxagoras frankly accepts the Eleatic maxim, no qualitatively distinct thing ever changes into another. If then an empirical fact, such as the assimilation of nutriment, appears to show us the conversion (say) of corn into flesh and bone, we must interpret this as meaning that the corn contains in itself, in such minute quantities as to be imperceptible, just that into which it is transformed. It veritably consists of particles of flesh, and blood, and marrow, and bone.

Although Anaxagoras does not appear to have used the word, this conception of a relation between a qualitatively distinct whole and the minute parts qualitatively like the whole, of which it is made up, may very well be expressed by the term Aristotle applies to such a whole and has made current, ó $\mu о \iota \mu \mu \epsilon \rho$ śs.

The All, then, consists of an infinite number of qualitatively distinct kinds of matter; but to this we must add: (1) that the division of each kind of matter into its parts goes on ad infinitum, there being no smallest part; (2) there is no void; the infinitely small particles of all things are therefore in the relation of parts of a continuous whole; wherefore (3) this whole is rightly described by the term $\delta \mu o \hat{v}$ - they are all together; meaning by that, so mixed up that no portion of the whole can ever consist of representatives of one, or even of a few, of the distinct kinds. We name the parts of the whole as though they were made up of things of one quality only because we notice only the preponderating elements.

Aristotle says very definitely that, in his conception of matter, Anaxagoras was entirely under the influence of the Eleatic principle $;^{1}$ and it is not difficult to see in detail how

$$
{ }^{1} \text { Arist. Phys. i. } 187 \text { a } 26 . \text { (R.P. } 151 \text { a.) }
$$


the broad outlines of his theory of matter are drawn with a view to meet the difficulties which seemed to follow from the Eleatic principle. In the first place, that principle had shown that logically what is called the transformation of one thing into another was just as inconceivable as what may be called absolute generation. Accordingly, if the phenomenal be 'preserved'-an expression which Aristotle uses in a similar reference in the case of the Atomists ${ }^{1}$-it must be assumed that the qualitatively distinct is uncreated, and exists from the beginning and throughout in its qualitative peculiarity. '

Again, the Eleatic principle, thoroughly developed, involved the rejection of absolute parts. Accordingly, if a multiplicity be admitted at all, it must be held to consist of infinitely numerous, infinitely divisible, particles.

Further, the Eleatic argument was fatal to the admission of void space; and Anaxagoras, accepting this rejection of the void, which also carries with it the previous assumption of infinite divisibility, is compelled to conceive of the material as being a continuous whole in which the mixture is so complete that no absolute severance of kind from kind is possible.

Accordingly infinite divisibility, infinite qualitative distinctness, infinite mixedness of the elementary parts, are the characteristics of matter according to Anaxagoras.

The original condition, then, of this matter may very well be described by the term early applied to it-Chaos. And the description at once forces on the second problem which Anaxagoras tries to answer:-What is it that gives rise to such a change in the Chaos as is required to account for its actual appearance to us?

Proximately the cause is Movement; and Anaxagoras, though perhaps without clear consciousness, attempts, by

1 Cf. Arist. Gen. Corr. i. 315 b 9, 325 a 23. See below, p. 59. 
his selection of the type of movement involved, to solve a difficulty which comes to the surface when the movable is represented as a continuous whole. How can there be movement where there is no void? The answer is that the movement is one of rotation-a whirling movement: $\delta i v o s$ or $\delta i \nu \eta$ is the word currently applied to this vortexmovement. But the rotatory motion itself requires explanation; and its ultimate ground seems to have been defined by Anaxagoras through reflexion on one consequence of his conception of matter. No part of the continuous whole, no portion of the mixture, has any such independence as is required for the source of movement. Whatever that source may be, it must, metaphorically, be outside the mixture, be unmixed; and, as connected with the mixture in this sense, it must itself be independent, pure, simple. Were it mixed at all, it would have to be mixed throughout. These characters seem all to be condensed in the single notion or term, $\nu o \hat{s}$ or Intelligence; and indeed they constitute all that is definitely predicated of it by Anaxagoras himself. ${ }^{1}$

Beyond a doubt Plato and Aristotle interpreted this

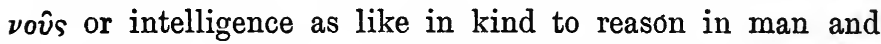
the animals; and it is to be admitted that Anaxagoras expressly says that some things share in vov̂s. We must, then, allow the justification of the view generally taken, that by assigning the origination of movement to vov̂s, Anaxagoras did mean to postulate intellect, something psychical in its nature, as the principle of change. It must be said at the same time that what really constitutes the radically new and distinct feature in such a conception is the isolation of vov̂s, the principle of change, from the changing. The principle is thus conceived as, so to speak, transmundane; for, in respect to the two functions which all

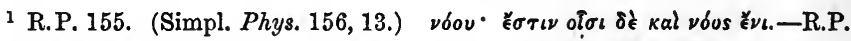

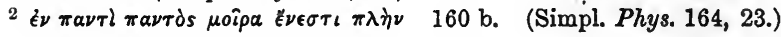


early Greek thinking was in the habit of assigning to the soul-namely, that it is the initiator of motion and that it is cognitive-Anaxagoras makes use only of the first. Both Aristotle and Plato are forward in condemning Anaxagoras for having failed to carry out the consequences of his view that the arrangement of things is due to intellect. ${ }^{1}$ They blame him for his persistent tendency to explain mechanically; and Aristotle says he has resort to vov̂s only when he can find no other explanation.

What kind of effect, then, does this action of vov̂s produce? Broadly speaking, it is called 'setting things in

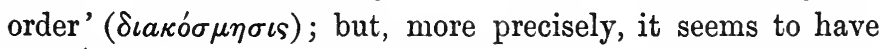
been represented as a process of separation and combination; and probably we shall not be far wrong in saying, further, that this means the drawing together, so far, of like particles, and the separating off of unlike. The revolving motion/ itself was conceived as beginning at a certain point of the chaos and extending itself gradually. ${ }^{2}$ Its velocity is represented as having been far beyond any velocity known to us.

In this representation there is a trace of the principle of attraction among similars; but it must be noted that, according to Anaxagoras, the element of difference is even more important. It is unlikes or dissimilars that influence one another, ${ }^{3}$ and, from what Aristotle says, he may be thought to have held that in what we call qualitative change the process is always the sequence of two opposed facts.

The whole view was much affected by consideration of the phenomena of animal life; and, to all appearance, Anaxagoras must have speculated on the application of his view to such phenomena. We know, however, extremely little of his teachings in this line.

1 Plato, Phcedo, 97 f. Arist. Met. A 985 a 18 . (R.P. 155 d.)

3 R.P. 161 c. (Theophr. De Sens.

2 R.P. 155. (Simpl. Phys. 156, 13.) 27,29 .) 
Of the senses he seems to have said that they are in one way quite untrustworthy, for they cannot penetrate to the real qualitative distinctions among things. ${ }^{1}$ Obviously in this the way is prepared for the distinction which the Atomists soon after drew between so-called primary and so-called secondary qualities of things.

Aristotle selects Anaxagoras as an example of those who reject the law of contradiction, on the ground, of course, that the infinite mixture rendered any definite predication impossible. It may be that in this Aristotle is drawing a consequence which was neither admitted nor contemplated by Anaxagoras himself.

The line of speculation of Anaxagoras in Athens was continued by Drogenes of Apollonia, who, however, seems to have tended rather towards a kind of eclectic combination of the principle of Anaxagoras with that of the earlier Ionian teaching. According to him the fundamental fact was Air, which he insisted was full of intelligence and knowledge-a fact in support of which he appealed to the regular order of the seasons, and of day and night. ${ }^{3}$ (The Greeks always considered that order anywhere implied reason.) He held that the whole cosmos is formed by the gradual transformation of Air, and that its most refined type is the soul of man. Perhaps Diogenes is most deserving of note for the clearness with which he brings out a fundamental idea of method: there must be unity of nature if there is to be actiou and reaction among things. The parts, as it were, or what we generally call independent things, can only be in relation to one another in so far as they are really parts-that is, members of a whole. ${ }^{4}$

1 R.P. 161. (Sext. Emp. Math. ${ }^{4}$ R.P. 208, 208 a. (Simpl. Phys. viii. 90.)

2 Arist. Met. $\Gamma 1007$ b 25. 151, 30 ; Theophr. De Sens. 39. Cf.

3 R.P. 210. (Simpl. Phys. 152, 11.) Arist. Gen. Corr. i. 322 b 13.) 


\section{CHAPTER VI}

\section{EMPEDOCLES}

Considerable fragments remain of two poems by Empedocles $^{1}$ : one on Nature ( $\left.\pi \epsilon \rho i \phi v i \sigma \epsilon \omega s\right)$, another called the Purifications ( $\kappa a \theta a \rho \mu o$ ) -more mystical and Pythagorean in character than the former, and expressing a very strenuous belief in the doctrine of Transmigration. The poem on Nature indicates pretty clearly what seem to have been the important influences determining his line of thought. These are partly the abstract arguments of the Eleatics respecting generation, partly the results of considerable meditation on the phenomena of animal life. Under the first influence, Empedocles interprets coming to be and ceasing to be as in reality only a combination and separation of what already is. There follows at once the more precise determination of what it is that is combined and separated: the four 'roots' of all things, as he calls them, are the four elements, Fire, Air, Earth, Water. These are permanent in their nature: they undergo no qualitative change: all that happens is the expression or result of such external changes in them as are indicated by the terms Combining ( $\mu \imath \xi \iota s$ ) and Separating $(\delta \iota a ́ \lambda \lambda a \xi \iota \varsigma) .^{2}$

1 Of Agrigentum, in Sicily; born about 492 B.c., died about 432 B.c. 3,20 .)

His history is legendary.

2 R.P. 164 f. (Ps.-Plut. Plac. i. 
Obviously this view demanded as its next position that some ground or cause of the change should be introduced distinct from the elements changed. This ground of change is with Empedocles twofold: Love-the combining force; Hatred-the separating force. ${ }^{1}$ It is hard to define his conception of these. If his poetical expression be taken quite literally, Love and Hate must be represented as somehow components of the physical All, extending throughout the whole, and mingled with the elements. And it is probable that his conception reached no greater degree of clearness than is involved in the statement of the functions which he ascribed to these agents.

As to their mode of operation-their way of bringing about changes in the world of elements-Empedocles goes a little more into detail. He uses of course the general idea of rotation; but what is essential and peculiar in his doctrine is the view taken of the cycle of generation as coming about from the varying preponderance of one or other of the two active agents. At first the whole is held together in one complete undivided mass by the all-embracing power of Love: the whole forms a sphere. As Hate gradually finds its way in, this perfect unity is broken up, and Hate gradually acquires the upper hand, until the unity is wholly broken up, all mixture is destroyed, and apparently each of the elements is drawn together and sundered from the others. (It is impossible here to avoid the use of a term-'drawn together,' $\sigma v \gamma \kappa \rho i \nu \epsilon \sigma \theta a \iota$ - which Aristotle had already noted as indicating a serious inconsistency in the view of Empedocles; for obviously an effect is ascribed to Hate which, on the surface at least, is identical with that otherwise ascribed to Love. ${ }^{2}$ )

No sooner has the epoch of complete dissolution or separa-

1 R.P. 166. (Simpl. Phys. 158, 1.)

2 Arist. Met. A 985 a 21. (R.P. 166 i.) 
tion been arrived at, than Love again begins the work of drawing together. Here, again, it is hard to make Empedocles consistent, for he employs throughout the conception of like being drawn to like, which, if applied to the elements, would lead just to the result of perfect dissolution. Love gradually getting the upper hand, all things are brought back to the state of perfect union, and the cycle is ready to begin again, for the process is endless.

Individual existence is of course possible only in the two intermediate stages between perfect unity and absolute separation (aggregation and segregation); but whether it is possible for such individual existence as we experience to take place equally in both the intermediate periods is a question to which the fragments allow of no definite answer. The general idea is undoubtedly involved that what we call individual existences are gradually formed from less perfect types; but in detail Empedocles, so far at least as the formation of plants and animals is concerned, seems to regard these imperfect types also after the fashion of parts, which may be put together to make the more perfect whole. ${ }^{1}$

Even in this quaint fancy, however, is involved, though in very crude fashion, another thought already foreshadowed by Anaximander. Of the varied combinations that thus come about, only those go on surviving which are able to maintain themselves in existence: all others are destroyed. ${ }^{2}$

The mode in which the several parts operate on one another brings in a conception of some interest, which Empedocles, indeed, extends to a specially important mode of action-as it may be called-that of sense-perception. All action is of the nature of contact. There is no void

1 See Burnet, Early Greek Phil. An. iii. 430 a 30; Phys. ii. 198 b 29. 260 f. ( 279 ff. 2 nd ed.)

(R.P. 173 a.)

${ }^{2}$ Arist. De Celo, iii. 300 b 29 ; De 
space. When bodies which, as we say, are at a distance from one another act on one another, they do so by means of effluxes (ámoppoaí); and all so-called solid bodies are full of pores, into which such effluxes may be received in so far as the pores are adapted to them. Sense-perception is a case of such receptive action; and vision, for example, is effected by a stream of light from the eye to the object seen ${ }^{1}$-an idea which was soon afterwards modified by the additional hypothesis that there was also a stream of some kind from the object seen. ${ }^{2}$ In a general way Empedocles applies to the action of the senses his maxim that like is drawn to like: like is drawn by like: it is because and in so far as the elements are in us that we are able to apprehend them in the world about us. By fire we know fire, by water water, and so with love and hate. ${ }^{3}$

What Empedocles would have felt inclined to say of the soul, one can hardly make out from the fragments. $\mathrm{He}$ is taken by Aristotle as representing the view that all psychical activity is sense-perception, that thought and sense are identical $;^{4}$ and he certainly expresses himself much after the fashion of Parmenides, declaring that a man's mind or thought varied with the composition of his body, and altered from moment to moment according to the changes of what is presented in experience. Coupling this view with what is involved in the general notion of cyclical change, it would seem hardly possible for Empedocles to retain in any form the doctrine of an individual soul, a soul in any special way connected with the individuality of the person; and yet no doubt it is hard to reconcile this negative result with what is said of Transmigration.

7.)

1 R.P. 177 b. (Theophr. De Sens.

2 The problem in this form was debated till late in the Middle Ages.
${ }^{3}$ Arist. De An. i. 404 b 7. (R.P. 176.)

4 Arist. De An. iii. 427 a 21. (R.P. 177.) 


\section{CHAPTER VII}

THE ATOMISTS

Along with Empedocles I think we may take the Atomist doctrine: even though in so doing we have to some extent to transgress the strictly chronological order of exposition; for the developed doctrine of the Atomist view must be ascribed to Democritus.

The Atomist school is said to have been originated by Leucippus, of whom we know in detail nothing. $\mathrm{He}$ is said to have been an adherent of the philosophy of Parmenides, and there can be little doubt that there must have been the very closest relation between the speculative doctrine of the Eleatics and the more physical conceptions of the Atomists. ${ }^{1}$ From the statement of Aristotle ${ }^{2}$ it is obvious that in his view the Atomist doctrine had two roots: (1) The appeal to experience, the assumption that the multiplicity and change presented in experience must be accepted, and that any explanation offered must be made to square with it-more than once in reference to the Atomists he uses ${ }^{3}$ the expression, 'to preserve phenomena'; (2) The Eleatic doctrine, both in its most abstract form and in one of its special applications. There is no

1 See Burnet, Early Greek Phil. in Aristotle. It is frequently used 353 ff. (c. 9,2 nd ed.)

2 Arist. Met. A 985 b 4 ; Gen. Corr. his commentary on Arist. De Ccelo) i. 324 b 35 . (R.P. 192 f.)

3 [The actual phrase does not occur from Eudemus or from Callippus.] 
generation, no absolute coming into being or passing out of being, and there is no movement-which is one form of generation - without the Void. What the Atomists proceeded to say, then, was that (to put it paradoxically) both Being and Non-Being must be admitted as real; that is, they in terms contradict the position of Parmenides that only Being is and Non-Being is not. The admission of Non-Being carried with it the further consequence that Being was not One: it was divisible; and, more particularly (since the Non-Being referred to was, in the concrete, Void Space) the All was regarded as made up of Void Space and the infinite multiplicity of what was directly the opposite of Void Space-the Full. The Full ( $\tau \dot{o} \pi \lambda \hat{\eta} \rho \epsilon s)$ and the Void (rò $\kappa \epsilon \nu o ́ \nu$ ) - the Full being conceived as numerically infinite-are for the Atomists the components of existence; and from that view methodically, and appealing only to one ground of explanation, they maintained that it was possible to account for experience.

Democritus, ${ }^{1}$ a native of Abdera, seems to have been, like Aristotle, profoundly learned. His fellow-citizens - thought him mad, and sent for Hippocrates to cure him. He himself laid claim to a wider knowledge, a more manysided acquaintance with facts, than any of his contemporaries, and in particular claimed to have pushed his researches far in the region of geometrical science. ${ }^{2}$ The catalogue of his works may be taken as bearing out this claim to an all-comprehensive study of nature, a study of which the fragments convey but an imperfect impression. There is one section of the catalogue and of the fragments specially noteworthy. It is evident that Democritus included within the scope of his general research the practical side of human experience. $\mathrm{He}$ might fairly be called the first

1 Born about 460 B.c., died about 370 B.c.

2 R.P. 188. (Clem. Strom. i. 69.) 
systematic exponent of a general ethical theory. We might gather from this what will become abundantly evident from other sources, that in and about his time speculation was beginning to be greatly exercised on the problems of. Conduct, whether viewed on the side of the State or on that of the individual. Let us try then to put the general development of the Atomist position in some systematic order.

The atoms are represented as indivisible bodies so small as to escape perception. They are devoid of qualitative differences; but among themselves they differ in figure (with which, I suppose, must go magnitude), arrangement or grouping, and position. ${ }^{1}$ The atoms, therefore, are to be conceived of as presenting practically infinite variety in these three respects; and, in particular, much of the possibility of grouping or combination is made to depend on the figures or shapes of the atoms (size being also included with these).

Did the atoms differ in weight? It is natural to suppose that in accordance with the two characteristics, homogeneousness of stuff and difference of size, there would go difference of weight; for we naturally tend to think that weight is in some way proportional to the quantity of stuff in the body concerned, and this quantity (assuming equal density) would then vary with the size. There is evidence, too, that Democritus recognised the difference of density, but confined it to what we may call composite bodies. ${ }^{2}$ On the other hand, there can be no doubt that some of the later authorities ${ }^{3}$ expressly say that the atoms were not in themselves distinguished by differences of weight. In the absence, then, of any decisive evidence it seems erroneous to incorporate into the earlier Atomist view the very natural, and rather popular, explanation of the varied

1 Arist. Met. A 985 b 13 . (R.P. the atoms composing them.

192.) Strictly, it is complex bodies that differ according to the arrangement or to the relative position of
2 R.P. 199. (Theophr. De Sens. 62.)

3 E.g. Ps.-Plut. Plac. i. 3, 29. 
movements of the atoms which is given by referring them to their varied weights.

The Atomist view, recognising, as it did, an infinity of void space, in which therefore there was no up or down, could hardly have admitted this determined direction of movement of the atoms as a consequence of their weight.l But having said this, we are confronted with the problem, What did the Atomists say about the movement of the atoms? Figure, combination, position of the atoms-these alone will not suffice to account for phenomena. The broadest and most important feature of experienceChange - is not explained by them alone. Undoubtedly the Atomists placed alongside of these fundamental marks of the atoms the explanatory ground-movement of the atoms themselves. And by this movement (which they followed out in a rather unscientific pictorial fashion) they sought to account for the arrangement of things-for the cosmos and its changes. What explanation, then, did they give of movement? To this I think our answer must be that in one sense they gave no explanation. They insisted that no explanation was possible or necessary; that is, they postulated constant movement as an ultimate. Our authority for this view is Aristotle, who not only tells us that the Atomists declined to offer any explanation of the initial movement, but also blames them for not seeing that their account of movement was thereby rendered altogether imperfect. $^{1}$ Later writers have always sought to give this want of explanation a more positive content by introducing the name Necessity.

I am inclined to conclude that the originai Atomist doctrine started from the postulate or conception of constant movement as a characteristic of the whole multiplicity of atoms. It may be stated that in this they were misled by reading in somewhat too positive a fashion the Eleatic

\footnotetext{
${ }^{1}$ Arist. De Calo, iii. 300 b 8. (R.P. 195.)
} 
doctrine that motion was impossible without a void, and they may all too readily have converted that into the proposition that if there is a void there is therefore motion.

Assuming, then, the constant movement of the atoms, Democritus seems to have proceeded to explain how, as a consequence of the different forms and magnitudes of the atoms, there originated a variety of types of movement. Through their collisions the atoms were driven hither and thither, but in different directions according to their size. Democritus ${ }^{1}$ especially fastened on a kind of sideway pushing as giving a key to the great type of movement - the rotatory or vortex motion-which had already begun to be employed in cosmical explanations. All the later formations were ascribed in a very general way to the vortex motion set up in the whirling crowd of atoms.

The atoms being infinite in number, and void space being infinite, the rotatory motion (1) did not exhaust or include the whole at once, and (2) was not necessarily one only: the rotation might be started at infinitely numerous points; and there would follow an infinite number of worlds ( $\left.\kappa^{\prime} \sigma \mu \circ\right)$, with interspaces between them. ${ }^{2}$

Democritus is probably also to be credited with the very definite distinction between what we call primary and secondary qualities. The secondary qualities, as they are called, such as hot, bitter, colour, exist only by convention ( $\nu$ ó $\mu \omega)$; in reality $(\dot{\epsilon} \tau \in \hat{\eta})$ there are only atoms and the void with their inherent characteristics. ${ }^{3}$ Moreover, Democritus made a valiant attempt to point out how the varieties of these secondary qualities, which fluctuated according to. the condition of the body, were also correlated with various combinations of their real causes-the atoms. It must be

1 R.P. 197. (Diog. Laert. ix. 31.)

${ }^{3}$ R.P. 204. (Sext. Emp. Math.

2 R.P. 198. (Hippolyt. Ref. Har. vii. 135.)

i. 13.) 
noted here that Democritus ran a certain danger of inconsistency - a danger pointed out by Theophrastus. ${ }^{1}$ For on one side he uses as an explanation of the merely conventional or subjective and non-real character of the secondary qualities their dependence on the constitution of the body, while on the other hand he points out certain objective or real differences which determine the varieties of the subjective affections. There is no inconsistency in the longrun; but it is quite possible that Democritus did not go far enough in the direction of explaining the secondary qualities as complex effects dependent on the varying combinations of two sets of real antecedents-those in so-called external things, and those in the body itself. .

Another feature of Democritus's psychology is his theory of $\epsilon^{\prime} \delta \omega \lambda a$ (simulacra). Owing to the constant activity of the atoms and of their combinations, every body is always throwing off from itself an efflux or simulacrum, which is to be conceived as a stream of finer particles, retaining to some extent the same arrangement as the original body from which it is thrown off. By these Democritus explains the process of perception, and it is perhaps part of his doctrine that the same effluxes were taken to explain the phenomena of dreams, and also many of the beliefs of popular mythology. ${ }^{2}$ The gods were represented as the effluxes of really existent objects, which were naturally formed in the generation of the world. ${ }^{3}$

With atoms and the void must be included those attributes which define the nature of the atom. Now, Aristotle more than once takes the Atomists as representative of the view that the phenomenal is the only reality apprehended;

1 R.P. 204 1. (Theophr. De Sens. Plac. iv. 8.) 69.)

3 R.P. 203. (Sext. Emp. Math. ix.

2 R.P. 202 and note. (Ps.Plut. 19.) 
insists, therefore, that they identified sense and reason, ${ }^{1}$ and condemns their theory of knowledge as altogether subjective and ultimately sceptical. On the other hand, there is abundant evidence that the Atomists did insist on a distinction between the perceptions of sense, in so far as these had to do with the qualities of things, and some form of knowledge which had to deal with the ultimate original properties of the atoms. Sextus Empiricus professes to quote from Democritus ; ${ }^{2}$ and, according to his statement, Democritus declared that there were two types of knowledge

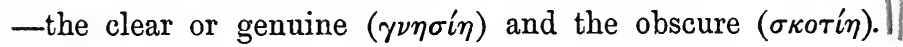
To the obscure belonged all the five senses: the clear was quite distinct from these; and he advances a further quotation which seems to imply that the special pre-eminence of clear knowledge was that it dealt with what lay beyond the limits of the senses. The senses could not penetrate to the minute realities, the atoms, and therefore, he concludes, the criterion of truth was reason ( $\lambda$ óyos), which Democritus called 'clear knowledge' ( $\left.\gamma \nu \eta \sigma^{\prime} \eta \eta \gamma \nu \omega \mu \eta\right)$.

I think we must accept this, although allowing that for the Atomists it must have been difficult or impossible to offer any explanation, consistent with their general view of perception, as to how clear knowledge came about. So far as the distinction between sense and reason is concerned, Aristotle is doubtless right in saying generally that the Atomists identified these. From their point of view the difference of the powers could only have been one of degree; but it must also be admitted that, in so saying, they left unsolved the difficulty arising from the difference in function and value of the two kinds of knowledge.

As to the last point, that the Atomist theory of knowledge could be identified with the Relativism of Protagoras,

1 Arist. De An. i. 404 a 27. (R.P. 204 k.)

2 R.P. 204. (Sext. Emp. Math. vii. 135.) 
we have reason, and some historical evidence, for the statement that the Atomists at all events did not so regard their theory. They did maintain that in the apprehension of the ultimate properties of the atoms we had objective knowledge. The historical evidence is to the effect that Democritus throughout opposed the relativist doctrine of knowledge of his townsman Protagoras, and in particular wrote against a thesis ascribed to Protagoras that the line did not touch the circle in one point only, which obviously we must interpret as meaning that Democritus defended against Protagoras the objective universal character of mathematical propositions. ${ }^{1}$

A somewhat similar perplexity - a conflict of two hardly reconcilable positions-may be detected in the fragments of Democritus's ethical theory. A considerable number of these fragments remain to us; and undoubtedly they give one a high impression, not only of the practical sagacity of Democritus, but of the elevated tone of his ethical teaching. Certainly, in accordance with his general position, one would have expected that in ethics his position would have been much the same as that of the Cyrenaic school, who regarded the momentary pleasures and pains as the only motive forces, and who, if they admitted at all a judgment on these pleasures and pains, thought that such judgment concerned only the quantities involved. But Democritus: insists that the end of life is not pleasure, but a state of thought and feeling. only to be attained by a due control exercised over pleasures and pains, and further, that this control is only exercised in its best form by the philosophically trained or cultivated nature. The final end, he considers, is Tranquillity ( $\epsilon \dot{v} \theta v \mu i a){ }^{2}$

\footnotetext{
1 Sext. Emp. Math. vii. 389.

2 See Plato, Rep. ix. 583 в, where the statement that only the wise man

has real pleasures seems to be a reference to Democritus.
} 


\section{CHAPTER VIII}

THE SOPHISTS AND SOCRATES

WITH Democritus we have already stepped into the historical period that lies outside the traditions of the first Greek philosophy. The problems he discusses differ much in character from those of the early Greek philosophers of nature. Discussions on knowledge, and its validity and kinds, attempts to connect the practical side of life with philosophical views, - these all indicate a profound modification in the general turn of reflexion in the Greek mind. On the whole, the modification is not inadequately expressed in the contrast between the terms objective and subjective. The period within which most of Democritus's work falls is emphatically a time of subjective reflexion; and there were abundant historical circumstances which led to, and which explain for us, the change which had come about in Greek culture. Representing such a change, expressing in various ways the separate currents which together made up the main movement, are the Sophists. Of them I purpose to speak only in the most general way. It is matter of familiar knowledge what the conditions were in Greek life which led, at the period of the Sophists, to the demand for a more extended and more systematic intellectual training than had previously been found necessary. We know also that, as an inevitable result of the 
character of Greek public life, the main end of this more complete intellectual culture was found in political activity. It is quite intelligible, therefore, how a large share of the special teaching of those called Sophists should have consisted in rhetorical training,- for Rhetoric meant the art of speaking on public affairs.

The name Sophist, even in the times to which I am referring, had no fixed connotation. It applied to groups of individuals who differed in many important respects from one another. Such fixity of significance as the term has come to acquire, it got unquestionably from Plato and Aristotle, whose interests were concentrated on certain important features of the whole movement, and who interpreted these features in the light of, and in the contrast supplied by, principles of their own. It was inevitable that they should represent the Sophists as having collectively an aim and method with something of the same identity of nature, the same homogeneousness, as they found in their own philosophical views on the main topics of human interest. They tend, therefore, always to represent the Sophists as more or less of a philosophical sect, pursuing by imperfect and even tricky methods a quite unworthy end, and exposing themselves to risk by selling their instruction.

It must be admitted that to the contemporaries of Plato and Aristotle the term Sophist had not precisely this connotation; and it must further be said that the meaning attached to the term by Plato and Aristotle is too narrow. The Sophists were not a philosophical sect. There was among them no community of aim and method. To the ordinary citizen, the philosopher-Socrates, for examplewould have been, and was, quite undistinguishable from the Sophists; and it cannot be thought that there is any founda- 
tion for the view that the Sophistic teaching exercised a detrimental influence over the Greek character. Plato, in the Republic, ${ }^{1}$ shows very emphatically that in his opinion the blame to be attached to the Sophists arose only from the fact that they adapted themselves to the current state of ideas and feelings on matters practical, and did not try to reform human nature and society. Even in Plato we can see very clearly that the term 'Sophist' must have fluctuated in meaning merely by being applied to historically different types of teacher. More than one generation brought forth Sophists, and these differed very considerably from one another in type. ${ }^{2}$

Among these types of Sophist, distinguished from one another in order of time, one must note: first, the earliest type, in which almost exclusive stress is laid on rhetoric and the acquirement of political power; secondly, a type of Sophist more philosophical in character, represented, for example, by Protagoras, where the interest seems mainly to have lain in questions about the possibility of knowledge and the natural foundations or conventional sanctions of morality; thirdly-quite distinct from these, and probably of later date-the Eristics, a rather contemptible species, whose stock-in-trade seems to have consisted of a collection of dialectical puzzles, mainly Eleatic in origin, but to some extent originating in the teaching of Socrates. We must also recognise Sophists whose business was entirely that of teaching, whether natural science, or grammar, or the like.

1 Plato, Rep. vi. $487 \mathrm{ff}$.

2 See Plato's Gorgias, where Gorgias, Polus, and Callicles represent three generations of thought and action. Callicles represents a type of character distinct from any earlier type-an historically new generation : he is not a Sophist. In the Republic (Bk. i.) Thrasymachus $=$ Polus in the Gorgias, while Glaucon and Adimantus represent a new and deeper set of thinkers. 
Among the problems, whose rise we can trace in the period of the Sophists, prominence must be given to the practical. The circumstances of the time were doubtless sufficient to attract attention to the study of, or speculation on, the causes which effected the union of the human race in states, to the origin of civilisation or culture, and to the ultimate ground of distinction between right and wrong. Our evidence, of course, is fragmentary ; but there is enough to show that this sort of speculation was abundant at that time, coinciding thus, it may be noted, with the origin of historical composition among the Greeks. A branch of the same speculation is that concerning myths; and of this too we have traces. ${ }^{1}$

Again, it is impossible in following out such inquiries to avoid coming on questions that concern the nature of education, training, or discipline; and, as can readily be understood, the Sophists in particular showed an interest in questions belonging to the theory of Art. Protagoras and others were evidently inclined to endeavour to reduce to codes of rules the matters of practical teaching with which they dealt.

Running through all these problems of civilisation, becoming of pressing moment so soon as they are considered, is the distinction between nature and convention, the natural and the artificial-a distinction already emphasised in the theory of knowledge and existence by the Atomists. We have evidence to show that the application of this distinction-even to such a problem as that of the significance and origin of words - fell within the scope of the speculative work of this time. It is not impossible that on this topic the counter-views of the Heraclitean school and of the Atomists were brought with Protagoras to a sharp issue.

1 Speculations, e.g., of Prodicus ; see Sext. Emp. Math. ix. 18, 51. 
Of the Sophists the most interesting philosophically is Protagoras of Abdera, ${ }^{1}$ to whom is assigned the familiar maxim, that Man is the measure of all things. ${ }^{2}$ It can hardly be doubted that Protagoras meant by this-man taken in his concrete individuality. It is probable, therefore,-though one can hardly say it is certain,-that Protagoras united this maxim with the view that sense-perception was the only mode of apprehension. It may have been the case-but it is much less probable-that Protagoras brought to the support of his thesis such portions of the earlier philosophy of Heraclitus as seemed to fit into it.

Protagoras is said to have applied his view in a general way to the question about the existence of the gods, and indeed to have been banished from Athens on account of the rather scéptical character of the exordium of his treatise on the gods. ${ }^{3}$ Whether the interesting attempt at building up a kind of natural history of the social virtues in Plato's dialogue Protagoras, which is there ascribed to Protagoras, has historical foundation, cannot be determined with absolute certainty. It seems probable, however, that it does represent in the main the views of Protagoras. Further, Protagoras seems to have speculated on the foundations and possible radical alterations of certain fundamental social relations, such, for example, as marriage.

Gorgias was a Sophist of a somewhat different type from Protagoras-a type less easy to define. He was a native of Sicily, ${ }^{4}$ who came to Athens on an embassy about 427 B.c., and thereafter spent the rest of his long life of varied and distinguished activity in Greece. $\mathrm{He}$ is known to us in part through fragments of a writing definitely speculative, but more

1 Born about 480 B.c., died 411 B.c.

2 Plato, Thecet. 152 A; Diog. Laert.

3 R.P. 226. (Diog. Laert. ix. 50.)

4 Born perhaps about 483 B.C. ix. 51. (R.P. 227.) 
as a rhetorician. His speculative work, probably a youthful production, might be called an Essay in the Eleatic Metaphysics. It put forward three theses. The first thesis was: Nothing exists. This was established by an ingenious modification of the Eleatic argument; but, on the whole, may be said to exemplify only the common, often repeated, confusion between the existential and the propositional significance of the word 'is.' 1 The second thesis was: If anything existed, it could not be known or apprehended in any way. The basis of this was evidently the insistence on the total opposition between the subjective and the objective. That is, so far as thought is concerned, it is just as possible to think a non-existent as an existent. In thought, therefore, there can never be a guarantee of the objective. ${ }^{2}$ The third thesis was: If there were anything, and if there were knowledge of it, that knowledge could never be expressed at all. The basis for this is the impossibility of identifying where there is difference. Apply this maxim, for example, to the case in which we say a word expresses a visual presentation. The word is wholly distinct from the visual presentation; they can never be identified; the one can never take the place of the other. ${ }^{3}$

Sharing to a very large extent in the general tendency of thought exemplified in the Sophists, but altogether deeper and more serious than they, is Socrates. ${ }^{4}$ Of him at present I purpose saying only what concerns immediately those features of his philosophical activity which are of importance as bearing on the Platonic doctrine. The points, therefore, to be considered are, first, the general conception

1 R.P. 236. (Ps.-Arist. De Melisso, 979 a 13.) 77.)
${ }^{3}$ R.P. 238. (Ps.-Arist. De Melisso, 980 a 19.)

4 Born at Athens about 470 B.c.; died 399 B.c. 
of method which we find in Socrates; secondly, the nature of the end towards which this method was directed; thirdly, the restriction of the range of philosophy to practice; and fourthly, the characteristic doctrines of Ethics which form the substance of his practical philosophy.

1. As regards the method, we first note its external feature-cross-examination in the form of a dialogue. This cross-examination, although it finds natural expression in the dialogue (a colloquy of two at least), is in its own nature quite general. Reasoning or thinking on the part of the individual himself is just a kind of inner conversation. ${ }^{1}$ The peculiarity of such conversation (and to Socrates the peculiarity stood out most prominently by contrast with the method generally adopted by the Sophistic teachers) is that the result finally attained is, so to speak, 'evolved.' The selfquestioner is only making explicit what is implicit from the first. The method of the Sophists rather consisted in supplying to the pupil a quantity of methodised knowledge; and they therefore by preference followed the method of exposition or lecture. The Socratic method, even if conducted by Socrates himself, did not even imply that either interlocutor was from the start in possession of the complete knowledge which was sought for. Some precognition must indeed be supposed, but such precognition consisted only in the general idea of what was required in order to constitute a satisfactory result. The knowledge made explicit must conform to those requirements which on reflexion we can determine as necessary in order to constitute knowledge. Now, such requirements are simply fixity and generality; a view, an opinion, a judgment, if it is to constitute a part of knowledge, must be general in nature and have a certain stability in it. The Socratic method, therefore, may fairly be said to involve the rather far-going thought, that in the thinking

1 Cf. Plato, Thecet. 189 E. 
nature of man there is contained that which renders possible the marks of knowledge. It would be going far beyond the Socratic speculation to employ in respect to it the term a priori; but undoubtedly the line on which Socrates is proceeding is that which leads directly to the view that all true knowledge is but the explicit expression of what is a priori, what is implicit in human thought.

2. The Socratic method, moreover, had its definite processes-processes determined by the nature of the marks of true knowledge. The questions are not put at random, but with a view to reaching in each special case an end, the general outlines of which are known. In concrete material these processes are two in number: (1) the collection for critical comparison and sifting of a number of instances; and (2) the determination from these of the identical common fixed element, the attainment of a general notion or definition.

If the first process be called Induction, then we may accept Aristotle's remark that to Socrates must be ascribed the in-

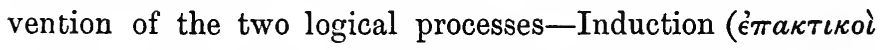

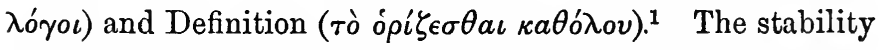
and generality of the results thus reached is what in the view of Socrates distinguishes his own method both from that of the Sophists and from that of ordinary unreflective experience; for it seemed to him that the Sophist inevitably was led to regard as the standard of knowledge and the guide of practice merely individual opinion, which, as such, was deficient in a general ground and in fixity. So unreflective experience proceeded under the guidance of hastily picked up notions whose limits were ill-defined; and it was constantly liable to be thrown into confusion when these crude notions were confronted with discordant facts of experience.

The general notion, then, is the only form of knowing which has the characteristics of objective worth; and it is

1 Arist. Met. M 1078 b 23 . (R.P. 249.) 
perhaps the great contribution of Socrates to the development of philosophy that he should thus have singled out the generalising function in the mind as that whereby most completely, if not exclusively, truth is to be attained.

3. On the surface the end was always practical. Even in his emphasis on self-knowledge Socrates had the problems of conduct in view. In the rational element in man he thought there would be found the basis for all rules of conduct that could claim authority. There can be no doubt that Socrates himself did thus restrict the range of application of his method; but it is quite uncertain on what he based this restriction. It may have been the conviction that the process, which is essentially that of making explicit what is implicit in the thinking nature, was on that account alone to be restricted to human conduct. The Cosmos lay, so to speak, outside of man; and it could perhaps never be assumed that knowledge of the kind sought for, but relating to the Cosmos, was implicit in the rational nature, the thinking function, of man. On the other hand, the restriction may have had merely the practical basis which is more than once definitely put forward by Socrates, that conduct is infinitely more important than cosmical speculations, and that, so to speak, a man must first learn to know and govern himself before he extends his view to the wider region of external nature. I cannot think that there are sufficient grounds for insisting on the first of these possibilities; and therefore I think it an exaggeration to ascribe to Socrates, even in a tentative fashion, a theory of the essential limits of knowledge.

In this connexion I think it may be said that there is no evidence entitling us to connect the restriction of the Socratic method with any view on the part of Socrates regarding the failure of previous speculative philosophy. That is to say, I do not think we can hold that Socrates was sceptical as to knowledge of nature because he was profoundly impressed by 
the failure of previous efforts in that direction. The fairer interpretation of the only reference which could be understood in this way, the passage in Plato's Phoedo ${ }^{1}$-even if we assume that what is there given is historically sound -would be that Socrates was convinced that the previous cosmical speculations did not find a rational application to the problems of more pressing human significance-those of conduct. ${ }^{2}$

4. As to the ethical docirines, practically they are summed up in the one fundamental position: Virtue is Knowledge; a proposition which, if elaborated, is found to carry with it the consequences that Vice is Ignorance, and therefore involuntary (as no man is voluntarily ignorant), that virtue can in some sense be taught, and that all the virtues are one,-also with a certain limitation of the sense in which the term 'one' can be used.

Another consequence very easily drawn depends on the contrast implied in the Socratic view between the happiness which a man enjoys from right action and such happiness as may come from good fortune. About the relative positions of these the Socratic ethics is clear: the happiness of man, as also his virtue, is wholly independent of external fortune; happiness, like virtue, is an inner possession, a joy of the soul. Thus we must note in the Socratic ethics the first trace of that ascetic tendency which is almost invariably the concomitant of a rationalist or intellectualist view of morals. It was an easy step to the position which the Cynic school occupied, that virtue is really identical with the strength of will of the individual, his power of maintaining himself in independence of all surroundings. This rapidly develops into Antinomianism-all outer enactments being regarded as purely indifferent to the virtuous man.

${ }^{1}$ Plato, Phredo, $95 \mathrm{ff} . \quad 2$ [But cf. Xenophon, Mem. i. 1, 14-16.] 
The final question which appears throughout all the minor discussions of the Socratic ethics, what is the Good the knowledge of which constitutes virtue? never is answered by Socrates himself. At times under the pressure of it he seems to approximate to a kind of utilitarianism; at other times a thing is held to be good when it fulfils its function; but no definite answer is anywhere given, and it is obvious in Plato that a sense of this deficiency in the Socratic ethics lay at the foundation of much of the theory of Ideas. 


\section{CHAPTER IX}

\section{THE MINOR SOCRATIC SCHOOLS}

THE minor Socratic schools undoubtedly exhibit the profound influence of the Socratic teaching; but it is an influence in each case exercised on foreign material. The Cyrenaic, Cynic, and Megarian schools show us earlier types of thinking modified by the Socratic teaching, and adapting themselves to the treatment of problems which had been first made definite by the teaching of Socrates.

1. The Cyrenáics are the least important philosophically of these three schools. They are represented by Aristippus, ${ }^{1}$ who, in the history of ethics, presents the first and still the most logically coherent exposition of Hedonism. The doctrine was further systematised by his grandson, also named Aristippus. Even in the elder Aristippus there is to be traced, alongside of the hedonism which is his main doctrine, the influence of Socrates as exhibited in the curious position, that man is not to be mastered by his pleasures, not to be the slave of circumstances, but must, so to speak, make his pleasures for himself, and be superior to circumstances.

The Cyrenaics appear to have continued the traditions of an earlier school, which we shall probably not be far

1 A native of Cyrene, and follower of Socrates. 
wrong in saying was partly the Atomist, partly the Protagorean. Something in it may be the result of the Heraclitean views. They pushed to an extreme the relativism which easily arises as a generalisation from the facts of sense-perception. ${ }^{1}$ The Cyrenaics insisted that, while the sense-impressions might be affirmed as veritable, no such affirmation could be extended to the supposed real objects which give rise to the perceptions. Thus knowledge was reduced to a series of individual sense-impressions; and the Cyrenaics consistently enough maintained that therefore the general terms we use are not names of any common permanent element, but are entirely conventional.

If the Cyrenaics extended to sense-perceptions generally what they said of pleasure and pain, the sense-perceptions which serve as motives for action, - that these are the results of movements, and, apparently, movements from without which set up movements from within,- the inference might be allowed that it is to the Cyrenaic doctrine of knowledge in some of its developments that Plato is referring in the first part of the Theotetus. ${ }^{2}$

2. The Crnics.-I treat these thinkers solely with the view of extracting from our very scanty data the traces of a certain fairly elaborated theory of knowledge. Antisthenes, ${ }^{3}$ the founder of the Cynic school, a devoted follower of Socrates, lived probably for thirty years after the death of Socrates, and was therefore for long a contemporary of Plato. It has always been known that a certain opposition of principle obtained between Antisthenes and Plato. I think there is good ground for supposing that this opposition was much more detailed than is generally suspected; that Antisthenes advocated a theory of knowledge in all respects

1 R.P. 272, (Sext. Emp. Math. vii. 191.)

2 Plato, Thecet, 151-187.

3 A native of Athens. 


$$
\text { Tomilotogy. }
$$

opposed to the Platonic; that they mutually criticised ones, (another's views; and that in the working out of his own theory of knowledge Plato has repeatedly the counterdoctrine of Antisthenes in view. Aristotle says: "Antithenes was under a misconception in thinking that nothing could be predicated of a thing except the expression peculiar

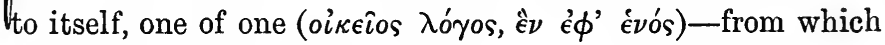
it followed that there could be no contradiction, hardly even error." 1 "So the difficulty which Antisthenes and some others-like him ill-trained in logic-used to start, has some point in it, namely, that it is not possible to define the real nature of a thing (for a definition is merely

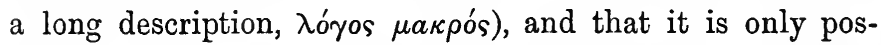
sible to affirm the quality of the thing: as, for example, we cannot define 'silver,' but we can say that it is like tin. Of what really exists, then, a definition and formula ( $\lambda$ óyos) is possible in part-of that part, namely, which is composite. . . But there is no such possibility with respect to the elements of the composite." 2

We know otherwise-from Isocrates ${ }^{3}$ - that Antisthenes did defend the proposition that there could be no contradiction. (Clearly, if there can be only identical propositions, there can be no contradiction: ' $A$ is $B$ ' is mere sound without meaning. Antisthenes accepted the doctrine that names were by nature, not by convention.)

What kind of thing had Antisthenes in view as the element out of which the compound is formed? We know from the titles of his works that he handled the question, which was beginning to become a stock problem, of the difference between Opinion ( $\delta o^{\prime} \xi a$ ) and Knowledge ('́ $\pi \iota-$ $\left.\sigma \tau \eta^{\prime} \mu \eta\right)$; also that he treated of the relation between Senseperception ( $a \iota \sigma \theta \eta \sigma \iota)$ and Knowledge. If, now, we bring

1 Arist. Met. $\Delta 1024$ b 32 . (R.P. 286.)

2 Arist. Met. H 1043 b 23. (R.P. 286.)

3 Isocr. Hel. i. 1. 
to our aid such additional light as is given through the remarkable passage in Plato's Thecetetus, ${ }^{1}$ we may conjecture that, according to Antisthenes, the Ultimates $(\pi \rho \hat{\omega} \tau a)$ were directly given in sense-perception. Each element or ultimate had its own individual nature, an individual nature which obviously could be adequately conveyed by no term or proposition which expressed the nature of any other element. This extreme atomism in the doctrine of knowledge is of course a perfectly helpless doctrine. It must involve itself in inconsistencies; and I think it is these inconsistencies in the actual working out of the doctrine by Antisthenes which cause us perplexity when we try to piece together the scattered fragments of his view.

"Some of the ancients denied abstract qualities altogether, though they allowed the quale; as, for example, Antisthenes, who once, disputing with Plato, said, 'Plato, I see a horse; I do not see horseness." '2 Accordingly, then, we must assume as a fixed point in our judgment of Antisthenes that he proceeded on the basis of the rather far-reaching conception of existence as made up of isolated individual elements, corresponding to which were isolated indivisible acts of apprehension. Psychologically these acts of apprehension were of the nature of perception. Such a view always comes forward as the final refuge of extreme nominalism. The isolated individual is the extreme counterposition to that of (it may be) the equally exaggerated and false representation of the abstract essence seized by thought. The position is an untenable one, and Antisthenes evidently found it so. Pushed resolutely, it involves the consequence which we find ascribed to Antisthenes, that there can be no contradiction, and that one individual element never can be another. We must assume (it is the more obscure part in our knowledge of Antisthenes) that

1 Plato, Thecet. 201 D ff. ${ }^{2}$ R.P. 287. (Simpl. Cat. 66 b 45 ed. Brandis.) 
somehow he allowed that these percepta had their namesa postulate which would become very hard to fulfil if in some way there were not combined with it the curious Heraclitean view that names are natural, not conventional. (There seem to me to be references quite unmistakable in Plato's Cratylus to Antisthenes as sharing this view with the Heracliteans.)

This consequence-that contradiction, nay, almost falsity, is impossible-is just one demonstration of the untenableness of the position. We are bound to think that Antisthenes did not remain consistent to it, but that with the help of distinctions, as, for example, between simple and composite, between sensation and opinion, between opinion and knowledge, he endeavoured to bring his view a little more into conformity with actual facts. Of the nature of these distinctions unfortunately we know very little: it is evident both that distinctions of the psychological kind-between sensation and opinion, opinion and knowledge-were current topics of discussion, and in particular that the problem that forced the discussion on was the problem of Error. Obviously with regard to the simple indivisible apprehensions of simple indivisible elements, error is impossible-a position which will appear less surprising when we find that, differently expressed, it represents the final view in regard to knowledge, implicitly of Plato, and explicitly of Aristotle. Such a position, however, can obviously only be maintained with respect to these supposed Simples. Wherever there is composition on the side, let us say, of the object to be apprehended, there will be a corresponding complexity of character on the part of the act of apprehending, and therewith the possibility of error.

If we ask what is the first type of this complexity on the side of the process of apprehending, a conjectural 
answer may be given. It is the combination, somehow, in one and the same act, of a perception and an image or idea. The conjecture is based on the two facts,-(1) that such a theory is subjected both to general and to detailed criticism by Plato in the Theotetus, ${ }^{1}$ and (2) that such a theory is adopted and elaborated later by the Stoics, who not only shared in the practical tenets of the Cynic school, but also represented an elaborated form of the dimly discernible theory of knowledge of Antisthenes. Even the literal gross analogies to which Plato refers as illustrating the explanation of false opinion were later used by the Stoics, who completely ignored Plato's criticism of them.

Such a mechanical explanation, as the criticism in the Thecetetus makes plain, does not really account for false opinion; much less does it make clear the nature of true opinion; and yet somehow true opinion, together with the statement of some ground or reason or definition, is what we can hardly doubt Antisthenes finally settled on as making up Knowledge ('́ส

3. The Megarians. - When we find two schools agreeing in a startling position,-as, that predication must be only of identicals, - it is certain that the basis is the same in the two cases. The Megarians and the Cynics exhibit this agreement. The common basis here is that the Ultimates are isolated and unrelated, whatever be the process by which they are known.

Of the Megarians, unfortunately, we know almost as little directly as of Antisthenes: their theory has to be reconstructed; and in their case the Platonic reference ${ }^{2}$ is much more ambiguous and doubtful. Euclides ${ }^{3}$ was the founder of the school-a great personal friend of Socrates, and also of Plato, though older than the latter.

\footnotetext{
${ }^{1}$ Plato, Thecet. 191-195. $\quad{ }^{2}$ Plato, Sophist, 248. $\quad{ }^{3}$ Lived at Megara.
} 
Of Euclides we only know in a general way that he accepted on the whole the Eleatic position. We may, I think, reasonably assume that what is ascribed to the whole school, and marked as that in which they agreed with the Eleatics,- that they rejected sense and admitted only reason,-was part of the general attitude of Euclides. As to details, all that we definitely know comes from Diogenes Laertius-a very poor authority. According to Diogenes, ${ }^{1}$ Euclides insisted on identifying the Good and the One, though allowing that the Good was called by many names: that is, real existence and the good are one and the same.

According to Diogenes, ${ }^{2}$ also, he attacked arguments not from the side of the premisses but from the side of the conclusion (evidently the carrying out of Zeno's method of indirect refutation), and he rejected any argument by analogy, saying that it must proceed either from similars or from dissimilars (meaning, I imagine, that that which is used to illuminate the obscure must either really resemble the obscure or not); if, he adds, from similars, it is very much better to keep to the things themselves than to turn to what resembles them; if from dissimilars, then the argument becomes void.

To another member of the school, Diodorus Cronus, a contemporary of Aristotle, probably also of Plato, are ascribed two rather important types of arguments.

The first argument ${ }^{3}$ is directed pointedly against the Aristotelian doctrine of potential existence, and, briefly, is to the effect that possible and actual are one and the same. It consists of three propositions any two of which will destroy the third:-(1) Every past reality is necessary : (2) The impossible cannot be a consequence of the possible:

1 R.P. 290. (Diog. Laert. ii. 106.)

${ }^{3}$ R.P. 295. (Cic. De Fato, 17.)

2 R.P. 291. (Diog. Laert. ii. 107.) 
(3) That is possible which neither is actual nor will be. Now Diodorus, accepting and uniting (1) and (2), destroyed by their means (3): concluding, therefore, that that only is possible which either is or will be. Practically his argument amounts to this:-It is admitted that what is past could not have been otherwise; but both present and future will become the past, and they therefore are equally necessary; that is to say, the possible and actual are one and the same.

The second is rather a group of arguments than a single argument. ${ }^{1}$ But they are all directed against motion, and are to be described broadly as repetitions of the older arguments of Zeno. They have, however, certain features of particular interest. They imply a conception of what might almost be called intelligible atoms - whether Diodorus uses this conception hypothetically only or not. The argument which has become best known runs thus:-A body must move either where it is or where it is not: it cannot move where it is, for 'being where it is' means filling a certain portion of space; clearly it cannot move where it is not, for it is not there to move. But this argument, though it turns on concrete movement, is and was known to be perfectly general, and to apply wherever division into parts is possible, whether the divided be concrete substance or time or space; and its general principle is to insist on the exclusiveness of each unit or individual part that can be separated in thought.

Of the immediate followers of Euclides one, Eubulides, is well known in the history of logic as the author of most of the captious fallacies which illustrate one or other of the forms of Fallacy of Accident. All these fallacies wrn on one and the same general position, that any element

1 R.P. 296. (Sext. Emp. Math. x. 85.) 
of difference is fatal to identity: there can be no identity where there is difference.

Now, it does not seem unfair to say that, if the Megarians insisted on this position, that identity excludes all difference, they must, first, have accepted in full the Eleatic denial of the world of generation ( $\left.\gamma^{\prime} \nu \epsilon \sigma \iota s\right)$ : according to their view, however they expressed it, the characteristic of the world of generation was non-existence.

In the second place, they must in some way have rejected any interpretation of the intelligibilia which assimilated them to class - notions. It is impossible to represent the class-notion without introducing as components the one and the many-points of agreement and points of difference. The Megarian position admitted only absolute units ; their atoms of predication, even if intelligible, excluded each within itself any multiplicity.

This will probably enable us to understand a little better a rather obscure utterance ascribed to Stilpo." "He said that if one says 'man', one is speaking of no single man, for one says neither 'this man' nor 'that man.' For how 'this' rather than 'that'? Therefore not 'this.'” 2 This passage appears to imply an objection of a rather subtle kind to the Idea as a generic notion: for the simple intelligible unit cannot contain in itself any such element of difference as would be required to determine this or that individual representative of it.

In the third place, the Megarians must have accepted (as we are expressly told they $\operatorname{did}^{3}$ ) the same view of predication as Antisthenes-the curious view that it is possible only in so far as the predicate repeats the subject,

1 Died about 300 B.c.

2 R.P. 300: Еँ

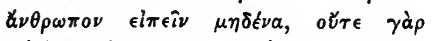

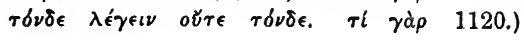

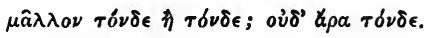

(Diog. Laert. ii. 119.)

3 R.P. 299. (Plut. adv. Colot. 23, 


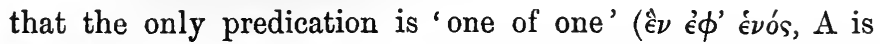
A). But it seems necessary to assume that the Megarians did not throughout adhere with rigorous consistency to the Eleatic conception, according to which multiplicity is excluded not only from each unit as within itself but from units as such. For it seems to me impossible to understand the Megarian view of predication without allowing that they accepted as the intelligible existents a plurality of units isolated, unrelated. Perfect consistency would have led to the conclusion not that predications are possible only 'one of one,' but that only one predication is possible, if even that, only the predication of Parmenides, "Being is."

That the Megarian theory works out with great consistency we cannot suppose. From its' very nature it not only stood in violent opposition to experience, but, as a combination of really independent thoughts, was certain to work out into a conflict. The Socratic view of notions is evidently to some extent accepted; there is united with it the Eleatic doctrine of simple unrelated being; and these will not combine.

In the Sophist ${ }^{1}$ Plato, describing discussions-and, obviously, more or less contemporary discussions-about the nature of real existence, opposes to each other, first, the materialists who maintain that only what can be touched, or is object of sense, is real, that body is the sole reality; and, on the other hand, those who are described as 'friends of the Ideas,' who are said to maintain that real existence consists of certain intelligible and incorporeal forms, while, negatively, they are said to break up by their. arguments the asserted corporeal realities of the materialists, and to insist that, instead of constituting real existence, these bodies are only a process which is constantly going on. Moreover, separating thus real being and process (ovं ía

1 Plato, Sophist, 246-248. 
and $\left.\gamma^{\prime} \nu \epsilon \sigma \iota \varsigma\right)$, these thinkers are said to maintain that we participate in real being by reason, and in process by sense, and, further, to maintain that the realm of real existence is wholly unchangeable.

The point in debate is: Are we justified in assuming that the thinkers here referred to are the Megarians? The point is one of importance rather as regards Plato than as regards the Megarian doctrime; for I do not think we gather any addition from it of real importance to our knowledge of the Megarian doctrine. In the face of the discussions in Diodorus in regard to movement, \&c., it cannot be held that the Megarians consistently and unambiguously maintained the Eleatic position of the singleness of Being. They certainly admitted a plurality of intelligible units, however inconsistent they might afterwards find such admission to be with their general doctrine. But if there be independent grounds for assigning the conception of plurality of being to the Megarians, then every reason disappears for refusing to recognise here the Megarian doctrine: there is no other doctrine known to us, not even any form of Plato's theory of Ideas, which could be described so accurately in the terms used in this passage. The Megarians, like the thinkers in this passage, distinguish between the intelligible and the sensible realms of existence: according to them, the only true existence is the intelligible; the realm of true being admits of no change, and therefore there does not apply to it the conception of activity, which is meaningless without change. The intelligible world, according to them, unquestionably admits of plurality: nowhere do we find the Megarians rejecting all predication, as rejection of plurality would involve. And, finally, it would be difficult to describe better the general character of the Megarian arguments about corporeal existence, movement, space, and time, than in the phrase used here, 'breaking up into fragments.' (The 
Megarian intelligible unit is isolated and individual, and is thus distinguished from the Platonic Idea, which is a (generic universal.)

A passage ascribed to Antisthenes ${ }^{1}$ declares that God is like no other, and that therefore it is impossible to understand Him from an image. No doubt this conjectural discussion begins in certain statements of Socrates-that the gods alone possess knowledge, and that it is a mistake to suppose that they do not know everything. I think this remark of Antisthenes is identical in general meaning with the passage from Euclides directed against argument from illustrations. But the position may be made more significant if we suppose that the remark has in view the distinction between the world of perception and the world of intelligible reality: for then Antisthenes would be saying that there is an absolute severance between these, and that what we know in this world can throw no light on the world of intelligible reality : we can know nothing of God from an image.

To a certain Polyxenus - a Sophist said to have been educated by Bryso (of whom it is fair to conjecture that he is the Bryso noted as a pupil of Euclides)-may perhaps be assigned the first form of an argument which became of great importance in discussions in the Platonic school, -the argument called 'the Third Man,' which seems to have been intended to show that the distinction and also the relation of the sense particular and the Idea led to an absurd conclusion. ${ }^{2}$

${ }^{1}$ R.P. 285. (Clem. Protrept. 61.) ${ }^{2}$ Alex. Aph. Met. 84 ed. Hayduck. 

In turning to the theory of Ideas, I desire to repeat the general statement that that theory does not in the history of Greek thinking present itself as absolutely new $c^{\prime}$ The form and the development it received from Plato ${ }^{1}$ are undoubtedly of such an original stamp as to give the theory of Ideas a position of quite exceptional significance in the history of Greek philosophy; but it ought to be admitted that the root conceptions from which it sprang are all to be discovered in the earlier types of Greek speculation, that the problems to which it was an answer had been already prepared in that earlier history, and that it is hardly possible to understand its full meaning without keeping it in constant relation to these earlier conceptions and forms. It is one of the great difficulties in interpreting Plato that we are apt to conceive of the general positions which constitute Platonism as being equivalent to

1 A native of Athens; born 427 B.c., died 347 B.c. 
the Platouic theory in its details. From such a point of view we are in danger of misrepresenting any evidence of a change or development which we may think we can discover in the Platonic theory itself.

That some such development must be discoverable might indeed be taken without further question. It is impossible that a mind like Plato's, receiving into itself all the influences of an unusually rich age of intellectual culture, busy during a long life in working out its philosophical conceptions, should not have undergone a development which assuredly will be reflected in the various expositions of his doctrine. Our means, however, of determining the order-even the nature-of such development are very indirect. Very little is known with certainty of the events of his life, and still less of the chronological order of his writings; and the external authority to which one would first turn-Aristotle-gives extremely little indication of any perception on his part of important changes in the Platonic doctrine.

There is perhaps no question, as regards this problem of the development of Plato's theory, which we find more difficult to solve satisfactorily than that of the weight to be accorded to the evidence of Aristotle. Aristotle's position with respect to the Platonic doctrine was both favourable and unfavourable. It was favourable, because certainly he had full knowledge of the Platonic work, and himself shared largely the Platonic views: profound as the differences are between the two, they are on a common basis. On the other hand, Aristotle's interest in the problems which the Platonic work involved is so intense that naturally he inclines to regard as calling for criticism or treatment on his part only the most matured results of Plato's thinking. Moreover, as his own reflexions somewhat modified the problems themselves, it is natural for him to take 
into special consideration only what Plato had to say on the problems as they were now contemplated from a slightly different point of view.

With all due allowance for the imperfections which Aristotle's critical position naturally entails, I think we are bound to consider that, if anywhere Aristotle does offer a statement which involves a comparison between earlier and later forms of the Platonic theory, it deserves to have the greatest significance attached to it. No theory which we may work out, on internal evidence, of changes in Plato's way of representing the Ideas ought to be allowed to outweigh a statement from Aristotle which constitutes external evidence in such a case. It is possible that there may be no "real conflict between the two representations of Plato, because Aristotle was in possession of a source of information bearing on Plato's development which is not now open to us. He knew the form of the treatment of Ideas which constituted the substance of Plato's teaching in the latest years of his life. It would seem that these teachings were not embodied by Plato in writings; but, on the other hand, among the works of Aristotle which we do not now possess there seem to have been abstracts, probably with criticisms, of these latest expositions.

Fortunately Aristotle, though evidently without ascribing much importance to the change of view, does with tolerable explicitness refer to a modification in the theory of Ideas. ${ }^{1}$

"Now as regards the Ideas, we must first consider the theory in its original form, not putting it in relation to the doctrine of numbers, but treating it in the way in which it was formulated by those who first asserted the existence of Ideas. The theory of Ideas was first reached from the basis of an acceptance of the Heraclitean view respecting things of sense, that all such things were in constant flux. If,

1 Arist. Met. M 1078 b 9. 
then, there were still possible science and knowledge of any thing, there needed to be assumed permanent existences distinct from the sensible, for of the ever-changing no knowledge is possible. Now, Socrates in his treatment of the virtues first sought to determine their nature by general notions, by definitions, for of the earlier physical philosophers Democritus alone had gone but a short distance in this direction. . . . It was Socrates who rightly directed his inquiries towards determining the Essential ( $\tau \grave{o} \tau i \dot{\epsilon} \epsilon \sigma \tau)$, for his aim was reasoned knowledge. Now the very principle of reasoning is the Essential. . . . To Socrates are to be assigned with justice (1) Inductive Arguments

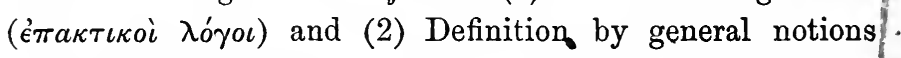

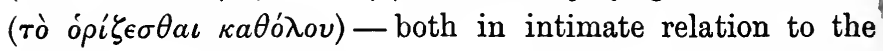
principle of knowledge. But Socrates did not regard Universals and Definitions as separate realities $(\chi \omega \rho \iota \sigma \tau a)$. The adherents of the doctrine of Ideas did separate them, and called such realities Ideas. It followed, as an almost direct consequence of their mode of argument, that there must be an Idea wherever there is a general term; and their procedure much resembled that of a man who, having to count a number of objects, should think could only manage if there were more of them-for the Ideas are just a reduplication of the things of sense. . . . For there is an Idea of the same name, answering to each group of sensible substances, and existing apart from them, and there is a One of Many, in the case of other things also, both in the case of temporal and in that of eternal things." 1

According to Aristotle, the theory of Ideas, in its first form, was more definitely connected with the problem

1 'Other things.' He apparently The 'things of sense which do not means by this that there must be change' are the heavenly bodies. See Ideas for qualities and relations. Plato, Republic, vi. sub. fin. and vii. 
respecting knowledge suggested by the two somewhat connected views, - that of Heraclitus with regard to the realm of perception, and that of Socrates with regard to the function of thought; and in its latest form was definitely connected with, and almost tended to become absorbed in, a theory of a somewhat mathematical kind, connected to some extent with the earlier Pythagorean doctrine. ${ }^{1}$ That is to say, at first the theory regards the Ideas as the

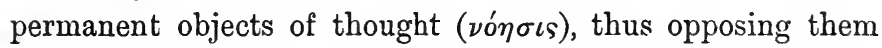
to the fluctuating matter of sense-perception ( $a \iota \sigma \theta \eta \sigma \iota s$ ), and bestows on them a kind of substantive existence superior in grade, so to speak, to the shadowy halfexistence allowed to the matter of sense-perception. In this its earlier form the theory naturally and inevitably views the Idea as the objective counterpart of the general notion: the Idea is a universal, but with the added attribute of substantive existence. In the later form the Idea, if not identified with a number or numerical ratio, is so closely assimilated thereto as to be hardly distinguishable from it; and, as a consequence, the systematic connexion of the Ideas with one another is explained in accordance with the principles by which the several numbers are brought into a systematic whole.

I think it fair from the statement of Aristotle to deduce one methodical maxim respecting the interpretation of the theory of Ideas as it comes before us in Plato's Dialogues. The Dialogues do not themselves contain, at least explicitly, the later form signalised by Aristotle. But, if we accept Aristotle's statement as authoritative (and I can see no sufficient ground for doubting it), then we are entitled to say. that wherever in the Dialogues we can find traces of an approximation to that form of the Ideal theory which Aristotle calls the later, we are justified in regarding that

${ }^{1}$ Arist. Met. M c. 6. 
portion of Plato's work as relatively the later in date. Wherever, on the other hand, the treatment of the Ideas remains within the limits of the earlier discussions respecting knowledge and its conditions, and advances no further than that modification of the Socratic view which Aristotle points out as peculiarly Platonic, namely, the objectifying of the Ideas, there we are justified in assuming that the work is relatively earlier.

No doubt this maxim gives us but a very general clue. Aristotle, to judge from his criticisms, bestowed no attention on what specially interests us-the steps through which the earlier form of the theory passed into the later. It is perhaps no great assumption to make, that these transitions were consequences partly of difficulties pressed on the Ideal theory from without, partly of difficulties experienced in working out the theory from within. Unfortunately the historical data for tracing the first of these influences are most unsatisfactory, while, as to the second, the real and insuperable difficulty which we experience is that of placing ourselves with complete satisfaction at the point of view of the Ideal theory itself.

This general maxim of method, if applied to the Dialogues, does not, as I say, give us more than a very general indication. Perhaps, pressing it as far as one may, it would justify us in selecting the representation of the theory of Ideas presented in a group of Platonic dialogues-Phodrus, Symposium, Republic, Phoedo-as belonging to the earlier form. In all these dialogues the idea is connected definitely with the process of generalisation. The basis on which the whole proceeds is that, wherever we collect together a number of individuals and designate them by a common name, there is involved, on the one hand, an act or process of mind, wholly distinct from sense-perception, and, on the other hand, an object which in all 
its essential features differs from the thing perceived by the senses. ${ }^{1}$

In such a view it is implied-the implication is often made explicit-that there is an exact correlation between knowledge and real existence. In fact here, more clearly than in the later Platonic work, we have to note the identification current throughout all Greek speculation, of truth and real existence. Discussions which result in this sharp distinction between knowledge, with reality as its object, and sense-perception, with its indefinable changeable object, naturally connect themselves with the distinctions, already familiar in the Socratic discussion, between perception, opinion, and knowledge; and it must at once be said that the fundamental importance of the distinction between knowledge on the one hand and opinion with perception on the other, is not in the theory of Ideas limited to this its earlier form. In the Timous, for example, which we have every reason for regarding as relatively late, the distinction is made the basis of the more constructive treatment that is there attempted. ${ }^{2}$

In the earlier dialogues there is little or nothing of an attempt to make out a systematic interconnexion among the Ideas. Each is considered primarily in relation to a multiplicity in the world of opinion and sense. But the nature of the process which obviously is involved in the transition from things of opinion to the Ideas, suggests a kind of connexion among the Ideas: they are in relation to one another of greater or less generality. Plato gives, as it were, a new reading to the Socratic doctrine of Induction and Definition. The process is both upwards and downwards: we generalise, and then we divide the genera obtained, and

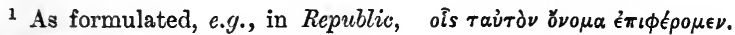

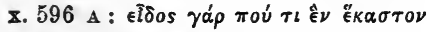

2 Timcers, $51 \mathrm{D}$.

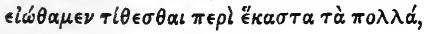


so complete our knowledge by connecting in a double way the lower with the higher generalities. It does not appear to me that the process here referred to-the only kind of classification alluded to in these earlier dialogues-is really identical with that special form of division which is more peculiarly connected with the name of Plato, which is frequently subjected to detailed criticism by Aristotle, and which is applied with wearisome elaboration in the Sophist and Politicus-the method of division by dichotomy. That type of division appears to me to have grown into significance in Plato's mind as a consequence of the necessity imposed on him of finding a general explanation, within the Ideal realm, of the element of Negation or Difference.

- If we seek for a definition of the Ideas from the point of view of this earlier form we have no difficulty in finding what looks positive, though in reality, perhaps, it never succeeds in being more than a series of negations. The Idea, viewed from the side of knowledge, is the rational essence of things: it is that which each group of things is in itself; the universal as in or beside the particular; the one in or beside the many; the common element in or beside the points of difference. Viewed more from the side of existence, the Ideas, we have to say, possess no property of sense-are invisible, intangible, incorporeal, formless, colourless : they form, taken together, absolute Being, that which is in every respect: they are eternal and immutable, self-identical, simple, unmixed, without parts, harmonious, pure.

The contrast between the Ideas so represented and the world of generation ( $\gamma^{\prime} v \in \sigma \iota \varsigma$ ) is certainly as absolute as possible; yet it must be remembered that Plato never regards the world of generation as the non-existent. Even in this earlier stage of the theory he is to be found allowing to the realm of generation a shadowy intermediate 
mode of being between being and non-being. As it is put in the Republic, ${ }^{1}$ if knowledge $(\gamma \nu \hat{\omega} \sigma \iota \varsigma)$ has being

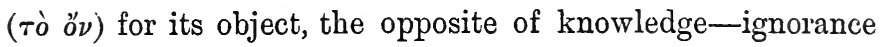

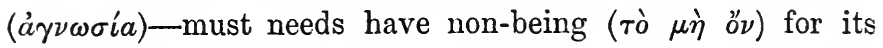
object. To opinion ( $\left.\delta^{\prime} \xi a\right)$, therefore, which is neither knowledge nor ignorance, there must be allowed some intermediate object, something whose mode of existence is very hard to determine. In truth, the greater portion of Plato's work is an attempt to define in what consists this shadowy half-existence of the world of generation; and I imagine that, historically, some part of his earlier dialogues will be found to be occupied in distinguishing his position in this respect from the somewhat similar doctrine of the Eleatics and their successors the Megarian school, who cut the knot of the difficulty by denying that the world of generation existed at all.

The general distinction which thus appears in the Platonic theory between real being (ovं ía) and process or change ( $\gamma \in \dot{v} \nu \sigma \iota \varsigma$ ) runs parallel to the distinction between reason or intelligence on the one hand and sense-perception and opinion on the other. The simplest point of contrast in the opposed couples is that of permanence as opposed to change, determinateness as opposed to indeterminateness. In the Cratylus, one of the earlier dialogues, in which the doctrine of Ideas, though referred to as no novelty, plays but a very small part, the doctrine is based upon the necessity of some permanent, determinate element on both sides - both as regards the act of knowledge and as regards the object known.

The contrast, however, if based solely on this feature, tends readily to become too absolute. It was never Plato's purpose so to define the realm of process and opinion as

${ }^{1}$ Republic, v. 478. 
to put it out of all conceivable relation to the world of true being and thought. In these earlier dialogues Plato shows himself always aware of some such connexion between the two as is involved in the generalising process by which the notion is reached. An Idea, as it is put in the Republic, ${ }^{1}$ is assumed wherever we collect together a number of individuals, and, recognising their common nature, bestow on them one and the same name. Our intelligence, as it is put in the Phoedrus, ${ }^{2}$ proceeds synthetically from a collection of particulars to a unity. It is perfectly true that Plato never succeeds in satisfactorily clearing up the relation which is thus shadowed forth between perception and opinion on the one hand and thought on the other; for it is always his view that thought is perfectly independent, a pure unmixed energy of the soul and, indeed, were we interpreting after more modern fashion, we should be compelled to say that according to Plato the apprehension of the Ideas is not so much a result reached by the activity of intelligence, as the presence in the intellect of, or the illumination of the intellect by, the Ideas. (This modern interpretation is in fact the view, lineally descended from Plato, of St Augustine and of Malebranche.)

But from the outset there appears-and we have to trace its progress-the desire to bring together into some rational form of connexion the two realms of objects and the two modes of apprehension. A somewhat similar development might be traced on the side of Plato's practical philosophy, where the first sharp opposition between the Good and perfect virtue on the one hand, and every form of pleasure and virtue of the lower type on the other hand, is gradually removed-a place being finally found for the lower type of virtue, and pleasure being recognised, not merely as a concomitant of the highest excellence, but also as an all-

${ }^{1}$ Republic, х. 596 A.

2 Phadrus, 265 D $\mathrm{x}$. 
important fundamental instrument for the training of a character to its highest excellence. In the Republic, among the earlier dialogues, we find the most definite of the attempts to connect in some way the two contrasted objects and processes. $^{1}$ The whole realm of opinion is allowed to possess a shadowy kind of half-existence ; that is, in Platonic language, it corresponds to imperfect knowledge; but there is a gradation of imperfection, a gradation in which the connexion seems to be of the nature of imitation or copying $\left(\mu i^{\prime} \mu \eta \sigma \iota\right)$. The whole realm of process is an imperfect copy of the realm of real existence; and in both realms a certain subdivision is indicated, a subdivision which in one of its parts proved of decisive importance for the development of the whole theory.

The realm of the intelligible is subdivided into two types of intelligible object, two types of mental act of apprehension: (1) the mathematical aspect of objects with, as its appropriate act, understanding, what we might call 'discursive' reason (Sıávoıa); and (2) the Ideas proper, with pure intellect, 'intuitive' reason ( $\nu$ ovs), as the mode of their apprehension. These two subdivisions are themselves in some kind of relation of imitation; that is, in Platonic language, he who apprehends the mathematical relations of objects knows truly and to a certain extent their ultimate nature. The true relations of things are, so to speak, reflected in their mathematical relations, whence, indeed, follows the consequence familiar in Plato, that the appropriate discipline of the intellect, that which leads it most effectually to knowledge of the true world of existence, is mathematics. The mathematical sciences themselves exhibit somewhat of the twofold character which constitutes the link we are in search of. The mathematical elements are not absolute being, not ov́ria in the full

1 Republic, vi. $509 \mathrm{ff}$. 
sense; but they effect the transition to true being - a relation which seems to me to explain to some extent the very remarkable term in the Philebus,' 'generation into

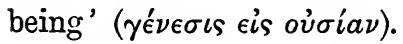

Again, the same relation of imitation connects the two grades of the world of generation, of which the first-natural bodies-are the higher in the scale of existence, and the second-the images or reflexions of these-are obviously their copies. Nay, one might say that there is a closer relation, that is, more of imitation, between the natural objectsthings, plants, animals-and the mathematical ratios, than between the latter and Ideas. Thus, it will be observed, the first simple thought of a contrast or opposition between being and process is crossed and modified by the more subtle conception of a gradation or scale of existence, from the highest, the most perfect, to that which is on the point of passing into the non-existent.

The processes of mind enumerated in the Republic play no great part in any other portion of Plato's exposition; and there is one of the earlier doctrines which rather tends to emphasize the distinction of kind between them, and so runs counter to the idea of a graduated connexion-the familiar doctrine of Reminiscence (á $a \dot{\mu} \mu \nu \eta \sigma \iota s)$. In three of the Platonic dialogues-Phoedrus, Meno, Phoedo-this doctrine is prominent. $^{2}$ It is connected in Plato's exposition with quite ordinary facts of association of ideas, but it goes far beyond them; and in the Phoclo particularly the account given of it comes very near the doctrine of Innate Ideas in its modern

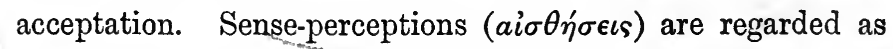
suggesting an idea ( never furnish: for example, nowhere among percepta can we

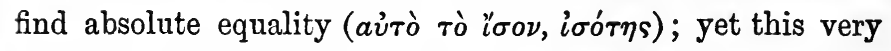
judgment that percepta do not contain absolute equality
1 Philebus, $26 \mathrm{D}$.
${ }^{2}$ Phecdrus, 249 ff. ; Meno, 80 ff. ; Phocdo, 72 ff: 
proves that the idea of the absolutely equal is present in mind." So with all other ideas: they are not produced but must already have been possessed; and the doctrine so interpreted is used as at least one ground for ascribing immortality to the soul.

The doctrine of Reminiscence in the long-run connects itself with the highly peculiar Platonic doctrine of the Soul $\left(\psi v \chi \eta^{\prime}\right)$. The soul, as we shall find in Plato, has two functions, which, indeed, enable it to play the remarkable part assigned to it by him of serving as the real intermediary between the world of generation and the world of true existence. Its functions are Knowing and Moving; by 'moving' being meant 'initiating change.' These are its functions, and its nature-inseparable from it, forming, one might say, its very idea: although in truth, according to the Platonic theory, there is no Idea of the soul. In its function as knowing, according to its nature as intellectually apprehending, the soul is in no way dependent on the body or on the accidental circumstances of time. As knowing,-and that is its nature,-the soul is always apprehensive of the Ideas. Only as having this constant, or rather timeless, vision of the true realities, the Ideas, does soul exist at all. The doctrine of Reminiscence, therefore, is but an imperfect way of expressing the more important notion of the ultimate nature of the soul. Evidently, when so conceived, the soul is quite independent of the body - at all events, in its function as knowing. And therefore, from that point of view, it would appear impossible to effect any junction between pure intellect and sense-perception or opinion. In order to do that, some relation, external or internal, between soul and body becomes necessary. 


\section{CHAPTER II}

LATER METAPHYSIC: THE PARMENIDES, SOPHIST, AND PHILEBUS

THE Parmenides presupposes much discussion on the Ideas. The Ideas, so far as we have seen, present themselves as a series of objects corresponding to the particulars of senseperception, but quite distinct from them in nature. Little, if anything, is determined respecting their interconnexion; and indeed, from the mode in which they are at first represented, each as a unit with its own indefeasible nature, connexion or interrelation of any kind in respect to them presents a difficulty. There are thus two features to be kept in view: (1) the contrast and yet relation between each Idea and its corresponding particulars; and (2) the unique character of each Idea when looked at by itself. In this second feature it is obvious that the Platonic Ideas resemble strikingly the Intelligibles of the Megarian school; and it is but a little assumption to make, that in historic fact the Megarian philosophers and Plato did for a certain time find themselves in agreement. On the other hand, the difference between the two becomes apparent as soon as the questions are raised, what constitutes the relation between the Idea and the particulars? and, in what way is it possible that among the Ideas themselves there should be relation? The Megarian thinkers took a negative attitude with regard to 
both questions. They did not admit that the particulars in any way existed; and they altogether refused to allow even of such mode of connexion among the Ideas as seemed to be involved in the fact of predication. That these questions had begun to press at a very early period in the working out of the Platonic doctrine, is evident from the Euthydemus and Phocdo. (The Euthydemus is generally acknowledged to be early in date.)

Understanding, then, that questions touching very deeply the theory of Ideas were current topics of discussion, we turn to the first part of the Parmenides, ${ }^{1}$ where Socrates is represented as bringing forward the theory of Ideas with the view of asking whether the subtle dialectical arguments of Zeno, on, for example, the One and Many, would apply if the objects considered were the Ideas. ${ }^{2}$ In reply to this Parmenides proceeds to put a series of questions respecting the Ideas, with a view to extracting a more definite statement as to how they are related to the things of sense, the Many; and, in the first place, he inquires whether the view of Ideas is perfectly general in scope, whether it is confined to such cases as likeness, the just, the beautiful, the good, or must be applied also to rather more concrete objects, such as man, and even to things which are in their nature imperfect. ${ }^{3}$

Assuming the wider application of the theory of Ideas, Parmenides then asks, ${ }^{4}$ in what way is this participation ( $\mu \epsilon \tau a \dot{\lambda} \eta \psi \iota \varsigma$ ) of the particulars in the Idea conceivable? and readily points out that the obvious superficial inter-

1 Parmenides, 126-137.

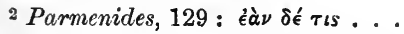

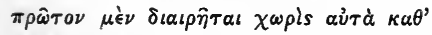

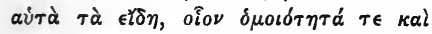
ả

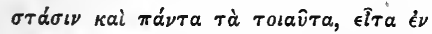

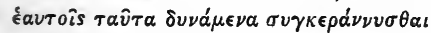

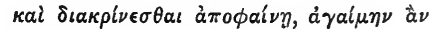
єै $\gamma \omega \gamma \epsilon \theta \alpha v \mu \alpha \sigma \tau \hat{\omega} s$.

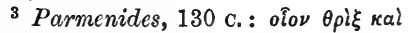

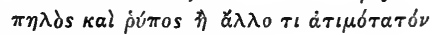

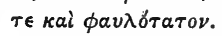

4 Parmenides, 131. 
pretation of participation leads to a hopeless perplexity. Socrates, admitting the difficulty, is confronted with the question, whether, as the Ideas evidently arise from the process of generalising, the hypothesis of the single Idea for each group of particulars is not confronted by the difficulty which results from the unlimited possibility of generalising. The argument points out, as it were, that there is something arbitrary in stopping at one Idea which contains the common features of the particulars: an infinite series of Ideas is possible. ${ }^{1}$

To this Socrates ${ }^{2}$ suggests as an answer that perhaps after all the Ideas ought not to be supposed to exist except

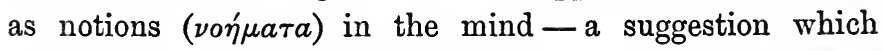
Parmenides at once refutes by the then accepted axiom, that a notion, being always the notion of something, implies the existence of that something.

The assumption that the Idea exists may, Socrates thinks, be defended by supposing that the participation is of the nature of resemblance: the Ideas are patterns ( $\pi a \rho a \delta \epsilon i \gamma \mu a \tau a)$ fixed in nature, and the particular things resemble them-a suggestion which Parmenides meets by bringing forward one of the forms of the argument later familiarly known as 'the Third Man.'

Socrates, in a kind of despair, gives up the attempt to defend further the hypothesis of Ideas; and Parmenides proceeds ${ }^{3}$ to point out a more formidable difficulty than all the others which the hypothesis would have to meet and overcome if it were seriously defended. Briefly, the difficulty is the impossibility of bridging over the antithesis between absolute being and absolute knowledge on the one hand, and relative being and relative knowledge on the other hand. The absolute existents will be related among

\footnotetext{
1 'The Third Man' argument: see above, p. 89 .

2 Parmenides, 132.

3 Parmenides, 133.
} 
themselves and to their own knowledge. Relatives will be related to one another and to their own knowledge. But relative knowledge will not extend to absolute existence, nor will absolute knowledge extend to relative existence.

This enumeration of difficulties must, I think, be understood as having reference to current discussions about the theory of Ideas which emphasised the points of difficulty in the elaboration of the doctrine. There is no necessity to suppose-no ground for supposing-that they constitute a criticism by Plato himself at a late period of his career on the earlier form of his doctrine of Ideas. It is possible to trace the genesis of all the objections urged, and that to sources outside of Plato. The important argument, 'the Third Man,' is often referred to by Aristotle.

The argument was evidently commonly recognised in the Platonic school; and we are fortunately able to trace its first appearance, though not, unfortunately, to date that. It is to be assigned to a certain Polyxenus, a Sophist. ${ }^{1} \mathrm{He}$ is said to have been a pupil of Euclides; and it seems reasonable to infer that the argument called 'the Third Man' was the product of the Megarian ingenuity. The Megarians could urge it; for they did not admit the existence of the Many alongside of the One, and the perplexity in this argument arises whenever the Idea is placed as the One alongside of the particulars as the Many. They altogether rejected the generic character of the intelligible units, and it is this generic character that lies at the root of the difficulty - naturally only when the generic character is supposed to possess of itself a substantive existence.

Again, the supposition that the Ideas may be only notions in mind undoubtedly originates with Antisthenes. It was his objection to the Platonic doctrine; and the terms in

1 See above, p. 89, note 2. 
which his objection is referred to by later authorities leave no doubt as to its purport and the kind of answer offered to it here in the Parmenides.

As to the third, the most important of the difficulties urged, that turning on the absolute distinction between the realm of real existence and the realm of relative fact, the sources are not so definite. The argument is a general one, and it connects itself, I imagine, with a certain doubt that we find Plato repeating, even in his latest works - the doubt whether it is possible for man to be completely in communion with absolute existence. Already Socrates had $d$ welt on the general distinction between wisdom, as the possession of the gods only, and the love of wisdom, or philosophy, as the possession of man; and Plato had repeated that distinction in his own way. ${ }^{1}$ But if we sought for something more pointed I imagine we should not be far wrong in looking, first, to the curious contention of Euclides already referred to, ${ }^{2}$ and then to the sharp distinction which Antisthenes appears to have insisted on, according to whom we could know nothing of God from an image. ${ }^{3}$

These objections, then, taken together, are to be regarded historically as a summary of current arguments against the theory of Ideas; and in the remainder of the dialogue the answer to them is of a twofold nature. First, and far the most important, is the general remark of Parmenides 4 that, except on the basis of the hypothesis of Ideas, reasoning

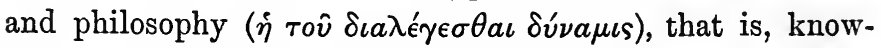
ledge, are impossible; and, secondly, the indirect demonstration, which the second part contains, that the insistence on the absolute severance of the One from the Many leads merely to self-contradiction.

1 Symposium, 204.

3 P. 89.

2 P. 84.

4 Parmenides, 135. 
The doctrine of Ideas found naturally much resembling itself in the earlier Eleatic metaphysic. The Ideas as a whole and individually occupy very much the position of Being in the Eleatic doctrine. Now, from the Eleatic position, it appeared quite impossible to offer any justification of the elements of Plurality and Otherness or Relation,terms which point abstractly to the more concrete distinction between true being (ovं $\sigma^{\prime} a$ ) and the realm of generation

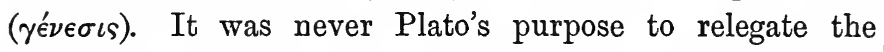
realm of generation to the indefinable sphere of Non-Being. There remained for him, therefore, always the difficulty of determining in what consisted the relation between the two distinct components-generation and true being. And this problem he appears to handle in two different ways: (1) quite abstractly, by a treatment of the notions involved, a treatment we might call dialectical; and (2) in a more concrete manner, by attempting to define the real principle of generation, to point out that element of absolute existence which from its nature constituted the explanation or ground of the relative or world of generation. The Parmenides seems to me the first step in the more abstract treatment, for in result it is almost wholly negative: it does no more than emphasise the contradictoriness of both positions-that which abstractly isolates being from everything else, and the opposite, equally abstract, isolation of a multiplicity of units. No doubt in this second alternative Plato has in view a variety of theories: the abstract argument applies equally well whatever conception may be formed of the nature of the units - whether they are intelligibilia (the Megarian view), or isolated percepta with their names (the view of Antisthenes), or physical units (the view of the Atomists).

The positive ground on which this negative argument rests deserves explicit recognition. It is the necessity for 
some other explanation in order to account for reasoning, that is, for knowledge. In the Parmenides this positive ground is no more than introduced. In the Sophist, on the other hand,-a dialogue which handles the same problem, but in a more developed fashion,- - the position is stated much more fully, and the solution there reached is altogether determined by reference to the necessities of knowledge or thought. The discussion remains in the region of abstract notions, but the result-that what is called Non-Being is but the inevitable element of Otherness or Difference which is necessary in order to render thought possible-prepares the way for a more concrete treatment. In the Sophist it is shown that the Ideas cannot be represented as wholly isolated from one another, as altogether excluding the element of Difference, Plurality, or Relation. Each Idea, while the same with itself, is different from every other, and such difference affords the only intelligible explanation of the predication of Non-Being; for, while every Idea can and must be said to be itself, it is not any other. This element of Relation-not, it is true, to be handled without caution -introduces interconnexion among the 'parts' of real existence.

Evidently, from this point of view, the systematic interconnexion of the Ideas is conceived in a way which differs from the result shadowed forth in the Republic and the other dialogues in which the Ideas are contemplated from the point of view of generalisation. The two representations are not indeed in conflict with one another; but the later imposes a certain limitation on the earlier. According to the earlier representation, the interconnexion was rather of the external kind, which is dependent on the play of our thinking. According to the later, the nature of the interconnected parts determines the extent to which they can be related one to the other. A way is thus prepared, as it 
appears to me, for excluding from the realm of real existence much that would have been included in it from the earlier point of view; and a hint is given of a method for tracing out the interconnexions which differs from that which would be supplied by the process of generalising. That is to say, applying what has been said to the all-important case,- the relation of the generated particulars to the Idea, - the way is prepared for modifying the first conception of it, in which they simply stand to one another as Individual and Class, Particular and Universal, Many and One.

If we look for this new or improved method of handling the relations through which the world of existence is a systematic whole, we seem to find something resembling it in the utterances of the Philebus. This dialogue is professedly on the nature of the Good, and consists largely of a discussion respecting the places of pleasure and knowledge in the Good or final end; but it is based on a representation of the elements of real existence which is very different from any offered in the earlier dialogues.

In the Philebus Socrates, after pointing to the nature of the difficulty which is involved in the conception of Ideas, and assimilating that to the general problem of the One and the Many, introduces a rather novel feature into the treatment of the problem. He seems to say that in earlier discussions of the difficulty it had been too easily assumed that the One and the Many just, so to speak, stood side by side, whereas in truth it is necessary to bear in mind that, as all things contain in their very nature the elements of One and Many, we should specially concern ourselves to secure completeness of system by the connexion of a One with its Many. ${ }^{1}$

Carrying out this more into detail, Socrates proceeds to

${ }^{1}$ Philebus, $16 \mathrm{f}$. 
enumerate the elements or kinds of existence. These are: First, the Infinite or Unlimited or Indeterminate ( $\tau \grave{o}$ ăm $\pi \iota \rho \rho \nu$ ) -a generic title which covers all cases in which there is simply the possibility of the more and less. The Infinite embraces, as it were, within its scope everything which is relative and capable of variation, but in which determinate amount or definite ratio is not visible. (We shall find Aristotle always asserting that the material principle in Plato was the Great and Small, or the Greater and the Smaller, or Excess and Defect; and this is what is named here 'the Indeterminate.')

Again, a second element appears as the Limit or Limiting (тò $\pi$ épas)-that which, when introduced into the Infinite, gives rise to definite quantity or ratio.

Thirdly, under one comprehensive head there fall to be grouped together all the products of this introduction of the limit into the indeterminate. The class is called the Mixed

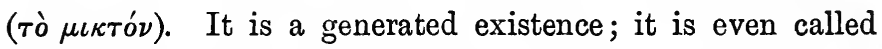

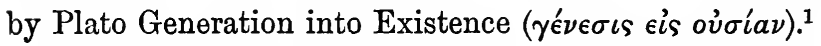

A fourth factor Socrates declares to be necessary - the Cause or Ground of the mixture (i aiтia $\tau \hat{\eta} s \xi v \mu \mu i \xi \epsilon \omega s)-$ that which brings about that the limit is imposed on the Indeterminate.

Apart from all other difficulties in the Philebus, the classification of the elements of existence has been felt to involve a special problem. In that classification the Ideas are not explicitly named. It is impossible to identify them with the Indeterminate. They may be thought to resemble the Limit, and have often been identified with it; but Plato's description of this element is quite fatal to such an interpretation. The limit is emphatically and exclusively numerical or quantitative, and we have no ground for asserting that at any period of his career Plato simply identified the

\footnotetext{
1 Philebus, $26 \mathrm{D}$.
} 
Ideas with numbers. He brought them very close together, so close that his immediate followers in the school identified them, and rejected one or the other as having anything special about it: they did not want more than one of them.

The Mixed Class, it has been thought, may perhaps contain the Ideas; but certainly, if so, the conception of the Ideas appropriate to that is out of harmony with anything that Plato elsewhere has said of them. If any one proposes to find the Ideas in the mixed generated class, he must, I think, accept Dr Jackson's interpretation, ${ }^{1}$ that Plato in the later development of his Ideal theory came to regard the Idea as the natural type which was imperfectly realised in the concrete individuals. But this interpretation will not really get over the difficulty, for it is the individuals in their imperfection which constitute the mixed class.

There remains, then, as the only possibility, that the aitia, the ground or cause of the mixture, is the Ideal realm, and that therefore we are to understand Plato as implying that in the world of generation a certain conformity to the Ideas, and therewith a certain share of existence, is obtained, wherever, and in so far as, there is quantitative definiteness. Numerical ratios constitute thus the connecting-link between the otherwise wholly fluctuating material of the world of generation and the real existents, the Ideas.

${ }^{1}$ In a series of articles, Plato's 7 Philology, vols. x., xi., xiii., xiv., xv., Later Theory of Ideas, Journal of $=\mathrm{xx \textrm {v }}$. 


\section{CHAPTER III}

BEFORE proceeding to the Timceus, perhaps the most distinctly expository of all Plato's works, it is desirable to consider the general position of Soul in the Platonic doctrine. The interpretations recently offered of the change undoubtedly discernible in the theory of Ideas, concur in attaching the main significance to the relation of Soul and Ideas,a relation which obviously admits of a great variety of statement. Jowett, for example, without expressly discussing the development of the theory of Ideas, indicates throughout his various Introductions to the Dialogues ${ }^{1}$ that in his view a change is to be discovered from the representation of the Ideas as transcendental objects to the more psychological view which finds certain analogies in the modern doctrines of innate ideas, categories of the understanding, and the like. Thus, on this view, the Ideas would come to be placed in a certain relation to the soul, almost in a relation of dependence upon it. Dr Jackson and others $^{2}$ have carried still further the same idea: interpreting rather freely from the point of view of modern Idealism, they suppose Plato finally to have reached the

1 The Dialogues of Plato, translated into English, with analyses and introductions, by B. Jowett.
2 E.g., $\mathrm{Mr}$ Archer-Hind in the introductions to his editions of the Phoedo and Timceus. 
conception of the Ideas as having a twofold mode of existence. On the one hand, they are the fixed ways of thinking of the Infinite Mind or Soul-the lines of the structure of Infinite Mind. On the other hand, the Ideas also appear as definite ways in which the finite soul exists, expresses itself, or thinks. The finite soul must therefore be said never completely to apprehend the Ideas: a certain element of imperfection attaches even to its representation of fixed types in nature.

If, then, we push the idealist interpretation further, we may regard objects of sense as a subordinate form of the limitations which finitude of soul or mind imposes on the apprehensions of the individual soul. In the same line may be put the deductions of the most recent of the writers on the chronology of the Platonic dialogues, Mr Lutoslawski, ${ }^{1}$ whose view briefly is, that in the later stages of the Platonic work the Ideas disappear and Souls take their place.

It is necessary, then, to consider rather carefully what place Plato assigns to Soul in his general scheme of existence. In the Phoedo the stress is mainly laid on the distinction between soul and body; but there are two points in the dialogue which will serve us in good stead for working out a more complete conception.

The first is the eternity of the cycle of generation. ${ }^{2}$ It is impossible to overstate the significance of this article in the Platonic theory; it is no novelty with Plato, and we shall find it reappear, and carry much of the same consequence with it, in the Aristotelian system. ${ }^{3}$ The world of generation is, in one sense at all events, eternal. There is no qualification of this in Plato; for even if it be said in the Timceus that that which is generated always comes into being, and if the action of the Artificer be pictorially represented as

1 Origin and Gronth of Plato's Logic : London, 1897.
2 Phcedo, 72.

${ }^{3}$ See below, pp. 161, 235, 240. 
fashioning an image which is the world of "generation, yet, in the same Timceus, ${ }^{1}$ we are carefully informed that time itself comes into existence only with the world of generation, and not even Aristotle-the harshest of Plato's criticsever misinterpreted Plato on this point.

The creation or coming into being of the world of generation must therefore be understood not as a temporal act, but as a way of representing the relation of logical dependence: the inability to understand the world of generation except by reference to something beyond itself. If the world of generation be eternal, equally eternal is the principle of that which is most characteristic of the world of generation -change, movement.

In the second place, the soul is placed in the most intimate relations to the Ideas. (But it is distinct therefrom : the soul is not an Idea.) The pictorial representation of Reminiscence is but a way of expressing the fact that on one side, at least, the very nature of the soul consists in its vision of the true realities, the Ideas. The soul is of kin with the Ideal realm, and through its intimate connexion therewith it is immortal.

The point at which the connexion with the Ideal realm is made most explicit is expressed by Plato as the relation between the soul and the Idea of life: the soul is, relatively to the Idea of life, the concrete which participates in the more abstract, in the Idea of life. ${ }^{2}$ What is the Idea of life? Nothing, I conceive, but the abstract essence of change; or, if that notion be thought too wide, of spontaneous change. In other words, Plato is but repeating here that in its own nature the soul is the first principle of all change.

In the Phcedrus most definitely we have-the-statement of the function of Soul as the principle of self-originating movement. Movement or change-so the argument appears 
to run-cannot be always produced change; ultimately there must be some first source of movement at once moving itself and others. On this is based the conclusion that the soul is immortal, for did the source cease from whence all change flows, therewith would cease the whole cycle of generation. ${ }^{1}$ In the same Phoedrus there is, with equal explicitness, ascribed to the soul the vision of the Ideas. In fact, the Phoedrus gives this vision in its most pictorial fashion.

In the latest work of Plato, and in the only book of it of speculative importance or value, the general argument of the Phoedrus is worked out at very considerable length. In the tenth book of the Laws the general position of the Phoedrus is elaborated; and the consequence is deduced from it that in the structure of things it will be found, seeing that soul $\left(\psi v \chi \eta^{\prime}\right)$ is most akin to mind ( $\nu$ ovs), that those arrangements prevail which are more of the nature of mind. It must be added that in this same discussion in the Laws there appears a still more startling division of Soul than that into immortal and mortal-the division into good and evil: the good soul directing all things in accordance with mind or reason, and the evil soul, the companion of folly, doing the very contrary. ${ }^{2}$

The various statements are so far in agreement. They justify us (1) in assigning to Soul a cosmical function; the soul is conceived to be in some way the principle of that which characterises all generation, namely, change: and (2) in holding that Soul is always distinguished from the Ideas, even when these are referred to only under the general term 'mind'; the soul acts, so far as it can, in the light of the knowledge it possesses by vision of the Ideas, or by participation in mind. (In the Timceus the expression is used, "mind or reason (vov̂s) is in Soul just as Soul is in body." 3 Now, according to the Platonic usage, this signifies
${ }^{1}$ Phredrus, 245 c.
${ }^{2}$ Laws, x. 896 ff.
${ }^{3}$ Timceus, $30 \mathrm{~B}$. 
just the reverse of the relation directly expressed: it means, body is intelligible, has reality, only through its relation to and dependence on Soul; in like manner Soul is intelligible and has existence only through its relation to, and dependence on, mind or reason.) So far, then, as the dialogues exclusive of the Timoeus are concerned, there seems no reason for assigning to Plato the view that the Ideas are in any way dependent on the soul: there is nothing to qualify the original statement, however pictorially expressed, that objective existence attaches to the Ideas. 


\section{CHAPTER IV}

FINAL METAPHYSIC : THE TIMAEUS

The Timceus presents first in general outline the familiar Platonic distinction between the realm of Ideas or of absolute existence, and the realm of generation or of merely relative being. Pictorially, the latter is represented as being that in which the divine Artificer ( $\delta \eta \mu$ rovprós) works out a design; and the point of view is taken that the Artificer of necessity keeps in view, as the model in working out his design, that which is in itself complete and absolutely existent. In order to secure that the copy shall, so far as it is possible for a copy, resemble the model, the first place in that which is produced is given to what of all things

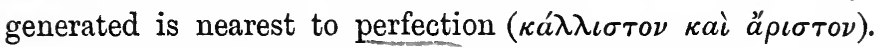
Now of all such things that is best which shares in reason ( $\nu$ v̂s), and nothing shares in reason except Soul. Thus it is through the soul in the world of generation that that world is brought as near as may be to be a resemblance of the Ideal world. The cosmos, then, is represented as a living creature $(\zeta \omega o \nu)$, possessing soul and reason by the providence or design of the divine Artificer. ${ }^{1}$

The soul, then, is that principle which holds together the

1 Timceus, $30 \mathrm{f}$. There is only one cosmos. Plato introduces his own way of dealing with 'the Third Man' argument, which appears in Atomist doctrine in view. 
whole world of generation. The other extremity of that world is at first specified as the elements, the elementary opposites-Fire, Air, Earth, and Water,-which are themselves represented as being to one another in a strictly determinable arithmetical ratio. ${ }^{1}$

Obviously, in order to discharge its functions of holding together the whole world of generation and making it a copy as far as possible of the perfect model, the soul must be in its nature composite; and Plato presents in the Timceus a statement, in very exact but incomprehensible terms, of the composition of the universal soul. ${ }^{2}$ Leaving the details, I accept from this the general indication that soul in some way unites the two natures, the purely ideal and the material; but while on the one hand it is akin to, and inexplicable except through reference to, the world of Ideas, on the other hand it is required as the explanation for the characteristic of the material world-its change. Undoubtedly one must admit that after having said this there still remains a characteristic of the world of generation which is not accounted for-just that which is "dimly indicated by our term 'materiality.'

It is not a little remarkable that in the Timous Plato first gives clear explicit recognition to this deficiency, and proceeds to add to his account of the whole scheme + of existence a third factor. ${ }^{3}$ The ground for recognising this new factor is expressed in a distinction between two forms of cause. "The generation of this universe is a mixed creation, by a combination of necessity and reason. . . If, then, we would really declare its creation in the

1 Timcus, $31 \mathrm{f}$.

${ }^{2}$ Its elements are (1) 'the un. divided and ever-changeless sub-

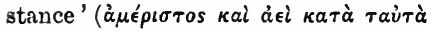

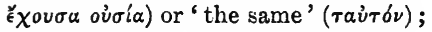
(2) 'that which becomes divided in

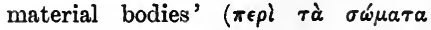
$\gamma(\gamma \nu 0 \mu \epsilon \in \nu \eta \mu \in \rho เ \sigma \tau \eta)$ or 'the other'

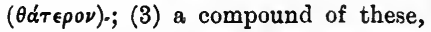
called simply oúría.Timceus, $35 \mathrm{\Delta}$.

3 Timceus, 48 E. 
manner whereby it has come to be, we must add also the nature of the Errant Cause and its inherent power." 1

This third factor, furnishing an explanation of the element of necessity, is metaphorically declared to be 'the receptacle

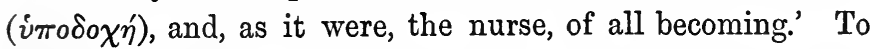
illustrate what is justly called an obscure saying, Plato raises the question, are we justified in speaking of even the elements-Fire, Air, \&c.-as having true Being? Do we not see them undergoing continual change? Is it possible, then, to speak of any one of them as an individual,

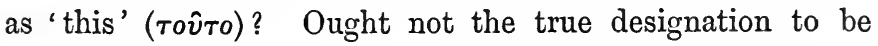

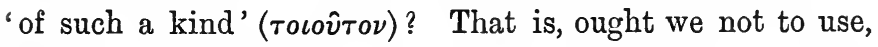
instead of the substantives, fire, \&c., which seem to point to individual subjects, predicative terms, all of which point to some subject quite indeterminate? We ought not to say that in the world of perception there is Fire, but that the subject, indeterminate $x$, is at such a time, under such conditions, of the nature of fire, fiery. So with all other sense-predicates. To do justice to the variability of what they express we must assign them all to some subject.

What, then, is this subject? It cannot itself have a definite form; it cannot be one kind of thing; it is rather all-receptive, capable of assuming all forms; and the forms it assumes, "which come in and pass out, are likenesses of the eternal existences, copied from them in a fashion wondrous and hard to declare, which we will follow up later on." 2 Positively its nature is further defined as Space

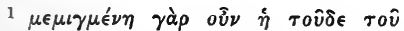

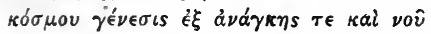

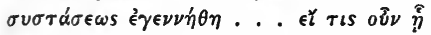

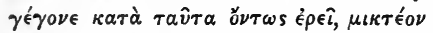

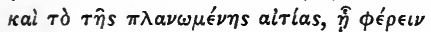

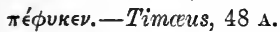

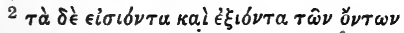

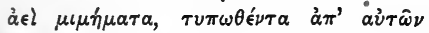

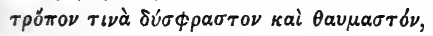

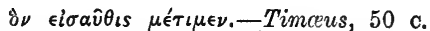
This promise is not fulfilled in the Timceus or in any other extant writing of Plato. It may be conjectured to refer to the efforts he seems afterwards to have made to show some connexion between the numerical ratios which constitute the definable character of these shapes and the Ideas. 
( $\chi \omega^{\prime} \rho a$ - -space (perhaps one ought to say) in the most abstract of its aspects, as, so to speak, the mere form of externality, that which enables thing to be distinguished from thing.

Space, regarded as the universal all-embracing form, at once suggests a reasonable ground for the determination of the nature of the elements of the world of sense through geometrical ratios. The elementary bodies are just determinations of space, according to a mathematical law, and such determinations are impressed on space because thereby space resembles as closely as may be the true natures, that is, the Ideas.

It is to be added here that not only does Plato fail thereby in his attempt to explain corporeality, but that he also, as we have seen, has to introduce alongside of space a form of mechanical movement which serves as a ground for explaining physical changes independently of the soul.

The visible perceptible world, then, finds at all events a certain amount of explanation in so far as the forms which enter into and pass out of the receptacle are geometrical, calculable. The less definite properties of objects are regarded very much in the light of secondary qualities: that is, they are supposed by Plato to arise as a conjoint result of (1) these fundamental geometrical properties, and (2) the character of the human body, which is itself fashioned to be the appropriate locus of an inferior grade of soul. The mixture which composes the world-soul is modified, when connected with the body of man, and Plato's account of the body is the most absolutely teleological ever offered. The quality of every part is determined with reference to the function it is required to discharge for the soul. ${ }^{1}$

The problem now arises, in what position does the Timceus leave the Ideas? 
First of all we may ask, what types of Ideas are unambiguously referred to in the Timceus? The answer to this question is to some extent indeterminate both because it must be given by enumerating, after the metaphorical manner of the dialogue as a whole, the components of the realm of existence, and also because the absence of some types of Ideas from the enumeration is not the same thing as their definite rejection by Plato.

Taking the enumeration, then, we have, in the first place, the heavenly bodies, the gods; and, in the organic world, man, animals, and vegetables-types, therefore, or classes, of natural objects. As regards the inorganic world, it will be observed that Plato does not allow that the elementsfire, air, earth, and water-have Ideas. They are composite. The ultimate elements are in nature geometrical. Plato indeed endeavours to show how out of certain triangular forms the elements may be composed. Thus the whole inorganic world is to be regarded as exhibiting in a confused way an ideal structure that, strictly speaking, is mathematical in its nature. So far, therefore, there would not be Ideas for (let us say) stones and rocks, mud, \&c., such as were referred to in the Parmenides.

Now, there is no reference made to artificial things, no reference to relations or qualities-of all of which examples had previously formed the stock illustrations of the doctrine of Ideas. Even if the absence of reference to them is not to be identified with refection of them, it is at least significant when coupled with Aristotle's express remark that the Platonists did not admit such Ideas, while, nevertheless, the arguments they employed would compel the admission of them. ${ }^{1}$

Accordingly the Ideas in the Timceus are really of two types : first, the more concrete, where the Idea is the perfect

${ }^{1}$ Arist. Met. A 990 b 15; 991 b 6. 
representative of a class of natural objects; and, secondly, the more abstract, tending to become hardly distinguishable from mathematical ratios, from numbers. Now, the characteristic of the natural classes, belonging to the first variety, is that they are all informed in various measure by Soul. The visible and tangible world which surrounds them, belonging to the second variety, corresponds, therefore, very much to the object of all apprehension on the part of the soul.

Assuming, then, that we have so far a statement with respect to the composition of the ideal world, does the Timceus in any way define the mode of existence and interrelation of these parts of the ideal world? In one way it does. 'The unchanging Idea, unbegotten and imperishable, neither receiving aught into itself from without nor itself entering into aught else, invisible, and not in any wise perceptible, that whereof the contemplation belongs to thought'-such is Plato's description $;^{1}$ and it implies, and Plato steadfastly maintains, the 'transcendental' mode of existence of the Ideas. Whatever, then, may be the signification of the treatment given in the Sophist to the conceptions of Identity and Difference, these must be regarded as so far external to the Ideas themselves. Possibly Plato is only trying to express what his terms render it almost impossible to express satisfactorily, that on the one hand the true is always immutable, and on the other hand that the true is always intelligible, and is, therefore, always apprehended through sameness and difference.

Now, the Timceus undoubtedly confirms the conjecture we have already formed, as to the importance of the position assigned to Soul in Plato's explanation of the world of generation. That eternal world requires, as principle of the

\footnotetext{
1 Timceus, 52 A.
} 
changes which go on in it, something which spontaneously originates movement. Further, such spontaneous movement Plato will not and cannot conceive as proceeding haphazard without law, order, or end. The moving principle must, therefore, he thinks, be regarded as at the same time informed with intelligence-capable of apprehending and, so far as its conditions allow, reproducing in its functions what is apprehended as true and perfect. Undoubtedly in this conception there is still left an inexplicable element-the conditions which render it impossible for the soul to effect a perfect copy of its perfect original. So far indeed does Plato push this element of the inexplicable that, as we saw, he is compelled to allow, over and above the purely formal aspect of it, not only Space, which introduces multiplicity into the copies of the eternal ratios, but also the more material element of Movement.

A certain source of change lying altogether outside of Soul is undoubtedly admitted in the Timous; and it makes its appearance as constituting the ground for the final unintelligibility of much in the particulars of sense. It appears on both sides of the process of sensation - on the side of the perceiving agent, and on the side of that is perceived. On the side of the perceiving agent is connected with what Plato calls the 'mortal' part of soul, that part which has no share by itself in the apprehension of eternal truth. On the side of the sense-qualities it appears as the factor which renders impossible what we call objective knowledge of these qualities. Sensations come about through the tumultuous flow originated in the body by the influence of outside things. The sense - qualities, then, which we ascribe to things are, in the first place, largely, if not wholly, subjective. They indicate nothing of reality in the absolute sense. And, in the second place, in various degrees they tend to pass into the wholly indeterminate, having, one might con- 
jecture from references here and in the Philebus, as their lowest limit those changes of bodily condition which do not appear in consciousness at all.

Perhaps it is not too violent an interpretation of this position of Plato respecting sensation and the sense-qualities, to say that it corresponds to the recognised impossibility of reducing the sense-qualities to exact mathematical determination: for just in so far as the mathematical ratios involved in all of them make themselves apparent, as, for example, in figure, in so far the sense-quality has more of the character of objectivity; where, as in odours, and in pains and pleasures, little or nothing of the foundation appears, they become wholly subjective and indeterminable.

Thus, then, the Timceus in one respect simply repeats the earlier doctrine that sense-perception, as having to deal only with the transitory, does not constitute knowledge; in another respect it goes beyond the earlier position by defining what it is that constitutes the defect of senseperception, namely, the impossibility of seizing in the flow of sense the true mathematical ratios of the ultimate components both of the sense-thing and of the percipient organ, the body.

The Timceus in the long-run evidently succeeds no better than the early theory in accounting for that which constitutes the difference between the particular and the Idea. Indeed it names that as the inexplicable. But it explains more fully than any other dialogue, what would otherwise appear startling, that the immediate followers of Plato, the first Platonic school, entirely threw aside the earlier pictorial representation of the Ideas, and either identified the Ideas with numbers or substituted numbers for them. That this view of the Platonic school was mediated by the later work of Plato himself we have every reason for inferring from 
Aristotle's mode of criticising the latest type of the Ideal theory as known to him. Taken generally, indeed, these criticisms of Aristotle and his representation of the Platonic theory do not contain anything that is not foreshadowed even in the dialogues. The more important articles of his account $^{1}$ of the Platonic theory are the following:-

1. The Ideas are self-existent substances, having no position in space. There are just as many Ideas as there are groups of natural things.

2. Three grades of existent are to be distinguished: (a) the Idea; (b) the thing of sense; $(c)$ the intermediate (the mathematical), which is distinguished from the Idea in that while of the latter there is but one of each kind, of the former there may be many.

3. All that is has a twofold ground-the formal and the material. The formal ground is the One; the material is the Indeterminate, which is of a twofold nature, the Great and the Small. This third article is the most important of the three, and the most difficult to interpret. It appears to imply that, in Aristotle's view, Plato introduced the element of plurality into the ideal world as into the world of sense, and under very much the same title.

According, then, to this interpretation we shall certainly admit a material factor in the Ideal realm - extending, however, the meaning of 'material,' and understanding by it only that which contains the ground of multiplicity. In the realm of the Ideas this is pure quantity. In the world of generation it is, as we have seen from the Timoeus, Space; and space, as there defined, is just the copy of pure quantity, containing in some mysterious way the element of sense. Just as in the Timceus we see an approach to an explanation of the world of generation by a reduction of all compounds to simple ratios of figures in space, so we may fairly

1 Arist. Met. A c. 6. 
imagine that Plato proceeded to define the contents of the ideal world as the determined ratios of pure number.

Obviously in so doing there is left in regard to the ideal world the same problem which Plato solves partly by introducing Soul as the principle of movement in the world of generation, and partly by referring to the lawless force of nature. There is no ground offered for what we may call the generation of the Ideal Numbers from their elements; and it is at this point perhaps that we understand why it is that Aristotle should have said-and he has been frequently reproached for saying it-that Plato employed only two principles: the formal and the material.

There may have been in the later speculations of Plato something of an attempt to bring together this extraordinarily abstract result with earlier and more concrete conceptions, that appear, for example, in the Republic in the doctrine of the Form of the Good, and generally wherever Plato has to define the kind of order which the soul tries to reproduce. It is not without significance that in these latest speculations, of which we hear as Lectures, the title should have been indifferently "Of the One" and "Of the Good"; ${ }^{1}$ but we have no means of recovering the line of thought through which the connexion may have been approached.

${ }^{1}$ [The title is usually given (e.g. were disappointed when they found

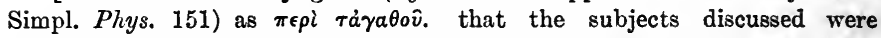
Aristoxenus (Harm. Elcm. ii. 30) 'good and unity as predicates of the relates, on the authority of Aristotle, finite, numbers,' \&c.]

that the majority of Plato's hearers 


\section{CHAPTER V}

\section{PLATO'S SOLUTION OF THE PROBLENI}

THE general problem with which the theory of Ideas is concerned may be defined as the explanation of the world of generation. It must never be forgotten that in Plato's view the world of generation not only has an existence, but that it is eternal. Its mode of existence certainly is of a kind hard to define in terms; indeed, we can express it only by changing the reference from objective being to knowledge. The leading idea of method in Plato is unquestionably the identification of absolute existence, existence in the fullest sense of the term, with perfect intelligibility. The world of generation, then, has not existence in the fullest sense of that term, because it requires for its explanation reference to something other than itself, something that possesses marks conspicuously wanting in it. The change, the constant cycle from coming to be into ceasing to be, which characterises every part of the world of generation, renders indispensable the reference to a ground which itself is characterised by the opposite predicates-Want of Change and Absolute Being.

The mode of existence which is here contrasted with even the indestructibility of the cycle of generation corresponds exactly to truth and logical validity; and it is the feature of the Platonic theory and of all Platonism that it identifies 
the existence of some subjects or objects with the nontemporal character of truth or logical validity. ${ }^{1}$

The world of generation-we might perhaps be ready to admit with Plato-requires a ground other than itself. But, after making the admission, we should probably find, as Plato found, extraordinary difficulty in connecting the world characterised by change and plurality with the explanatory ground which has just the opposite qualities. In making the admission we, so to speak, start from the world of generation as the datum. Is it possible to do what Plato seems to have contemplated as the very final problem of speculation - to start from the explanatory ground and deduce from it as necessary consequence the world of generation with its wholly antagonistic features?

When the problem is taken within the limits of those bare abstractions with which Greek philosophy first operatedthe One and the Many-it may seem capable of satisfactory solution. But we should have to say, as involved in the solution, that the antithesis implied in the terms 'starting from ' the one element or the other is quite misleading. We can neither deduce the Many from the One nor the One from the Many. If we separate them at all, the problem becomes insoluble. But it is altogether a different question when, in the place of the abstractions One and Many, we have the much more concrete related factors, the nontemporal unchanging realm of absolute existence and the changing cycle of merely relative being. It is then, I think, that Plato begins to find the necessity of introducing inter-

${ }^{1}$ Lotze, in a valuable chapter of his Logic (Book iii. chap. ii.), insists that Plato was perfectly aware of the confusion of thought which results from complete identification of these two, that he never intended more by the Idea than the logically valid or true, and that Aristotle's criticisms therefore miss the mark, for, taken altogether, they consist in pointing out the incompatibility of objective or substantive existence with the characters of logical validity or truth. 
mediaries, forcing together the opposites into some kind of union, so as to make the antagonism between them at least less obvious. I doubt whether he ever commits himself to the position that the world of generation is necessarily implicated in the world of absolute being. His nearest approach thereto is in the correlation he quite empirically makes between Reason ( $\nu \circ \hat{v} s$ ) - the one function of which is the contemplation of the Ideas, and which, itself unchanging and unchangeable, is informed by the unchanging and unchangeable Ideas-and Soul. Reason, he tells us, ${ }^{1}$ is in Soul; and he almost lays down the general proposition that Reason is actualised only in Soul. The indestructibility of Soul doubtless enables it thus to serve as that concrete in which the eternal Reason is made actual. But if a distinction obtains at all-and some distinction there must be - then precisely what constitutes the difference evades the scope of the general explanation.

We have here, in fact, an illustration-perhaps it is historically the first illustration-of the fundamental difficulty which attaches to any purely deductive construction of the universe of being. It is quite a mistake to suppose that the Universal completely explains the Particular. It explains no more than that in the Particular which does not differ from the Universal. It is with Plato as with Spinoza; and Plato's procedure in interposing these intermediariesthe Soul and Space - between the eternal Idea and the variable Particular is exactly parallel to Spinoza's interposition of the attributes and the infinite modes between the universal of Substance and the particular of the finite modes.

The intermediate that plays the most important part is, as we saw, Soul, which is generalised by Plato and taken to signify the principle of all change. But now and again, one must say, on empirical grounds, it is assumed

\footnotetext{
1 Timeus, $30 \mathrm{~B}$.
} 
that in the process by which this principle of change unfolds itself it follows the direction prescribed in and by contemplation of the Ideas. But the soul shares also the nature of the mutable; and in this finally Plato has to find a solution for that deviation from the perfect model which cannot but be allowed in the world of generation: so much so, indeed, that, as we saw, in the Laws he is ready even to distinguish between the good and the bad soul. Finally, the soul as principle of change, as working out a copy of absolute existence, has to operate under conditions that are so far foreign to its own nature. The element of externality is inexplicable from the explanatory ground, the Ideas themselves.

However Plato may endeavour, then, to bring into somewhat closer connexion the world of Ideas and the world of generation than seems possible from the first direct antithesis between them, it has still to be acknowledged that the effort is a failure: that the Ideas still remain in some obscure way external to the world of generation, and that not from them alone is any explanation offered of the first most important character of the generated, namely, Change.

Now, substantially these are the two objections which Aristotle is to be found persistently urging against Plato's theory of Ideas: (1) that just in so far as they are put outside of the particulars they serve to explain neither the existence of the particulars nor our knowledge of them; the universal, Aristotle consistently presses, cannot be said to exist outside of the particulars: and (2) that the Ideas, even if they did exist, furnish no explanation of real change, real process, in the world of generation. ${ }^{1}$

Aristotle's own theory with regard to the world of generation so strongly resembles that of Plato that we must, I take

1 Arist. Met. A c. 9, and M, N. 
it, assume that the distinction which he seeks so persistently to enforce had a real and important signification for him. According to Aristotle, the character of the several parts of the world of generation is determined by the presence in each type or class of things of a certain group of essential attributes. The distinction is thus implied between what we may call the objective universal, the real class, and the subjective universal, that which is the product of our comparing and abstracting thought. Accordingly we can see that part of Aristotle's objection to the Platonic Idea is that in it the subjective universal, the notion or concept, is identified illegitimately with the objective universal, the group of characters or marks which defines one special type of concrete things. Evidently, too, if this identification be made, it becomes more easy-seeing that the generic or subjective universal is never presented in concrete fashion - to assign to it a kind of existence which is wholly independent of the concrete particulars, and which constitutes it, according to Aristotle's habitual phrase, 'a One alongside of the Many' ( $\pi a \rho \grave{a} \tau \grave{a} \pi o \lambda \lambda a ́)$. The constitutive marks of a real class are only found in the concrete particulars. They may be predicated in the form of a notion of the

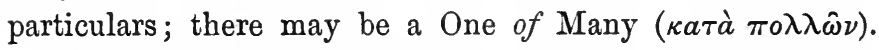

Aristotle would substitute, then, for the generic universal with which he identifies the Platonic Idea, the essential form-that complex of marks which constitutes the definite nature of any actual group of things in the world of sense. It is the constitutive nature of a group. (The isolated individual is for Aristotle, as for Plato, the unknowable.) It is the nature of actually existing things, that is to say, subjects of properties: there must therefore always go with the essential form that which performs the two indispensable functions, (1) of constituting plurality and (2) of conferring the ultimate characteristic of being a subject of properties. 
Aristotle, for his part, names this constituent Matter $\left(v^{\prime} \lambda \eta\right)$, and thereby involves his own theory in the same final perplexity in which the Platonic is entangled.

These groups of individuals, sharing in a common constitutive or essential character, are what Aristotle called

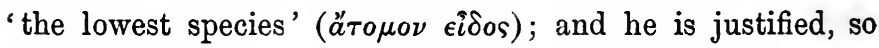
far as the terms allow of justification, in saying that in them the essence is inherent. Beyond them, outside of them, the essence, the form, has no existence. Sharing with Plato the view that the world of generation is eternal, Aristotle therefore regards the origination of these constitutive forms of the lowest species as not a problem requiring solution.

Our knowledge of the field of experience is completed when we have reached insight into the constitutive naturethe forms-and are able to deduce therefrom all that follows from the original nature of the things themselves. Such knowledge, then, must be regarded as having, so to speak, a number of quite independent roots. Each type of things has its own individual character; and consequently, according to the Aristotelian view, there are distinct sciences, each with its own ultimate principles; and it is therefore impossible that there should be any one all-comprehensive science such, for example, as Plato seemed to contemplate in his Dialectic. Common principles there may undoubtedly be, for the work or process of knowing is the same in kind throughout the several sciences; but from common principles no specific knowledge can ever be deduced. The hypothesis, therefore, of a science which deals only with abstract principles severed from things, and which attempts to deduce therefrom the specific character of the things themselves, is illusory - whether the abstractions be represented as generic universals in the fashion of the earlier Platonic view, or as mathematical ratios, in conformity with the later view. The severance of the Idea from the particulars, 
therefore, in Aristotle's view rendered knowledge of the particulars themselves quite inexplicable.

The second main objection which Aristotle presses is that the Ideas afford no explanation of what is above all characteristic of the world of generation-namely, Change. "All philosophy of nature," says Aristotle, "is cut off by the hypothesis of Ideas " $;{ }^{1}$ for from the permanence and unchangeability of the Ideas it is obviously impossible to deduce the counter-opposite - transitoriness and change. Nor will Aristotle acknowledge that anything is gained by the intermediary, the soul, with which in the Platonic theory explanation of change appears to be given. In so far as the soul operates in and through contemplation of the Ideas it ought to operate without change, if the expression be allowed. The Ideas, says Aristotle, are always there; why are the particulars not always there? Just in so far as the soul is supposed to operate apart from the Ideas, a ground of explanation that is not the Ideas themselves is resorted to. We have seen abundantly that Plato's theory is open to this criticism. Accordingly Aristotle insists that, in the long-run, the Platonic theory would be compelled to have recourse to a duality of active principles, and that therefore an explanation cannot be found in the Ideas alone.

Perhaps the nature of the difficulty which Aristotle here presses may become clearer if we follow out now, in a few words, his own attempt to find a solution in accordance with the view he takes of the world of generation.

The fundamental fact of movement or change in the world of generation Aristotle recognises; he recognises also that there cannot be an endless sequence of determined movements-that in some way the original impulse must be given by that which is not itself impelled. As such an original

1 Arist. Met. A 992 b 8. 
ground of movement cannot be found within the world of generation, it must be supposed to exist outside thereof. A $>$ First Mover who communicates movement to the world of generation-that is Aristotle's solution. The movement is communicated first of all to that external all-embracing sphere which closes in the world of generation, and is transmitted 'downwards,' becoming at each step more and more irregular, until in the terrestrial province it presents itself as the rather chaotic interchange of the elementary opposites, Hot and Cold, Dry and Moist.

This Aristotelian solution has very much the same difficulties as the Platonic, and leaves them in the same way unsolved. Even assuming it to be true that a first $>$ cause of motion is a necessity, the difficulty of the notion of an unchanging cause of change, an unmoved mover, is not diminished by putting it outside the world of generation. And, as regards the changes of the cycle of generation, the Aristotelian solution works out very imperfectly. In strictness it would imply a wholly mechanical conception of the universe,-a conception from which Aristotle always recoiled, and quite irreconcilable with his view of the essential forms.

Moreover, Aristotle shares with Plato the conception of a teleological direction of movement. Plato, as we saw, simply puts the teleological and mechanical side by side: the soul as principle of change works with purpose as contemplating the perfect model of the Ideas; alongside of it there is natural necessity, mechanical movement. So in Aristotle: in his view the most important changes that come about in the world of generation are purposive, those which constitute the development from the potential stage of existence to that of completed actuality. A type of objects, for example, exhibits to us a number of individuals passing through stages of development determined throughout as a striving towards 
the complete realisation of the typical form. Such purposive movement or change is wholly inexplicable by mechanical causes; and Aristotle, using more precise language than Plato, has to recognise, alongside of such change, Chance

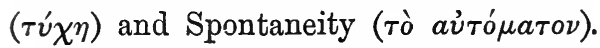

And if we ask further what explanation can be given of the purposive movement, the teleological connexion, Aristotle is able only to offer a confused reproduction of one element in the Platonic theory. Somehow the world of generation strives towards a perfection which lies outside of itself. It is to be regarded, therefore, strictly in the Platonic fashion as an imperfect copy, but animated by a desire to attain a completeness which it does not yet possess. 


\section{CHAPTER VI}

\section{THE SCHOOL OF PLATO}

SPEAKING generally, the philosophy of Aristotle has its roots in the Platonic doctrine. Despite the constant opposition to the Platonic philosophy in its main concepts and in many of its characteristic details, Aristotle's system is nevertheless to be regarded as a natural development from the Platonic position. Aristotle himself was for many years a member of the Platonic school. ${ }^{1}$ He was familiar, therefore, in particular with what we must call the latest tendencies of the Platonic thinking. Perhaps on this account we may explain the otherwise remarkable fact that Aristotle's criticisms of Plato refer so seldom to parts of the Platonic work which the modern world holds in highest estimation. In the later period of Plato's teaching it is probable that there were many discussions of fundamental points in the theory of Ideas; and it is possible that the opposition to the doctrine of ideas which is a salient feature of Aristotle's system had already made itself apparent while Aristotle was connected with the Platonic school. Indeed some recent critics ${ }^{2}$ of Plato have thought that there could be discerned in certain Platonic dialogues traces of the influence of criticisms so closely resembling those later advanced by Aristotle that

1 Aristotle entered the Academy Stagira; born 384, died 322. about 367 B.C. He was a native of 2 E.g., Siebeck. 
without undue straining of evidence they can be assigned to Aristotle himself. Thus, for example, the perplexity of attitude adopted to the theory of Ideas in the Parmenides and the Sophist in particular has been interpreted as a criticism from the side of Plato of objections to the doctrine of Ideas that had been raised in the Platonic school by Aristotle himself. There is little evidence in support of this view. For instance, the use in the Parmenides ${ }^{1}$ of 'the Third Man' argument does not justify a reference to Aristotle, as 'the Third Man' was a recognised shibboleth. On the other hand, in the Laws - in the book that sums up Plato's natural theology-there is an undoubted reference to the Aristotelian view that all things come about by nature. ${ }^{2}$

However this may be, we are entitled, I think, to assume that Aristotle's position in the Platonic school gave him the means of estimating precisely the lines along which the Platonic thinking was being gradually developed, and that his criticisms therefore may be taken as indicating what was the last form of the Platonic work. It is with special reference to this final form that Aristotle's opposed view is worked out. It would be dangerous certainly to attempt to extract from Aristotle's criticisms alone the main features of this later form of the theory of Ideas. Fortunately we have a certain supplement in what is known of the doctrines advanced by the immediate successors of Plato, who were regarded not as establishing a new and independent school but as continuing the traditions of the genuine Platonic school."

Of these leaders of the Academy-Plato's school-the first was Plato's nephew SPEusipPus, who presided over the school from Plato's death in 347 to 339 . Of his doctrine we get certain indications in Aristotle himself and in the later authorities, principally Sextus Empiricus and Clement. It

1 Plato, Parm. 132.

2 Plato, Laws, x. 889 E : cf. 891 c. 
is possible that these later authorities all drew from one source - the writings of Aristotle's immediate successor Theophrastus, who may fairly claim credit as the first historian of philosophy after Aristotle himself.

First, we gather that Speusippus modified greatly the fundamental position of the Platonic system - the antithesis, the almost absolute contrast, between rational knowledge and sense-perception. He admitted the existence of something intermediate, of a certain interconnexion, between these two. Sextus Empiricus writes:1 "Speusippus, dividing things to be known into the sensible and the intelligible, declared that the criterion of the intelligible

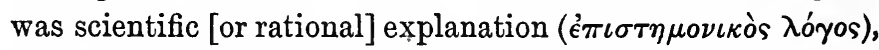
while that of the sensible was perception which is scien-

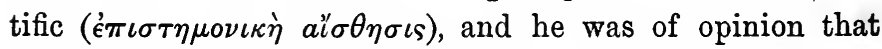
scientific perception came about by a certain participation in rational truth." 2

There seems to follow from this recognition of an intermediate form between reason and sense a further divergence from the Platonic principles. Speusippus apparently gave up the attempt to interpret the whole of existence from the point of view of the Idea of the Good. He tended, in other words, towards a separation of the parts of real existence from one another such as was incompatible with the Platonic conception of a complete explanation of all from the ultimate principle of the Good. It is possible that in this we must recognise the influence of that increased interest in natural phenomena which goes with a recognition of some measure of real knowledge, of rationality, in sense-perception. The pointed divergence from Plato comes in a very unexpected form. "Some," says Aristotle, "as,

1 Sext. Emp. Math. vii. 145. (R.P. ${ }^{2}$ Plato comes very near this view 354.) Cf. Zeller, Plato and the Older in the Timceus.

Acadcmy, 568.

${ }^{3}$ Arist. Met. $\Lambda 1072$ b 30. (R.P. 355.) 
for example, the Pythagoreans and Speusippus, are of opinion that what is fairest and best is not primordial

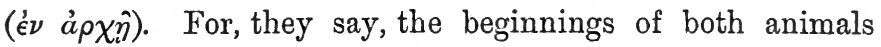
and plants are undoubtedly causes, but what is fair and perfect is the final form reached and derivative." 1 From this Speusippus appears to have drawn the very important metaphysical conclusion that the Good was not to be regarded as primordial, as the $\dot{a} \rho \chi \dot{\eta}$ or principle of things. The Good was to be regarded as derivative, as rather a final end than as the initiating cause or ground. Such rejection of the Good left Speusippus apparently with nothing but the more abstract conception of Unity or the One as the principle of existence; and from what Aristotle tells us it is evident that Speusippus felt to the full the impossibility of advancing a step further with the Parmenidean One. Accordingly he seems to have placed alongside of the One, as having equal value as an ultimate factor, the Many, from which he found it doubtless possible to develop number. But again he was compelled to make additions when advance was sought from number to geometrical forms, and finally an additional principle was required if advance was to be made to life and mind. We learn definitely from Aristotle ${ }^{2}$ that Speusippus placed alongside of the One other principles for different kinds of reality - first the principle of numbers, then the principle of geometrical magnitudes, and lastly the principle of soul. Aristotle's criticism of this is obviousthat it would make the universe like a bad tragedy, a string of unconnected incidents. ${ }^{3}$

How are the differences between these kinds of reality to

1 Aristotle's reply to this is that the seed is itself a derived fact-the egg is not antecedent to the hen,the dominant conception of his whole philosophy being that of fixed types in nature that have no beginning.
He would say that the question of the origin of any one definite type is meaningless.

${ }^{2}$ Arist. Met. Z 1028 b 21. (R.P. 353.)

3 Arist. Met. 1076 b 1; N 1090 b 19. 
be explained? Speusippus gives up the problem. As we have seen, he adopted in addition to the One a distinct principle which served to explain the second type of intelligible existence, namely, number. What this principle was we are not definitely told. It may fairly be conjectured from the very similar speculations of Xenocrates that it would have to be named the Manifold, or perhaps by the more Pythagorean title, the Indeterminate Dyad ( $\dot{\eta}$ áópıros $\delta v a ́ s)$. Further, a new principle was required to explain another type of intelligible existence, geometrical magnitude. Again we are left in doubt as to how this principle is to be named. Probably it resembled that factor which in the Timoeus is introduced as Space, a kind of receptacle for all changing forms. Still more indefinite are the principles which Speusippus found himself further obliged to postulate. One indeed is named to us as 'soul,' and as by soul is doubtless meant, in Platonic fashion, the principle which initiates all movement and change, it is possible that Speusippus is not in respect to this far from agreement with his successor Xenocrates, who as we know defined soul to be a self-moving number. Another principle is required, but is only referred to in the most general fashion by Aristotle, the principle which ex-

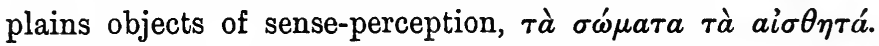

It will have been observed that Speusippus avoided identifying the One and the Good. This he appears to have done on the ground that he did not regard the element of multiplicity as being in itself evil. ${ }^{1}$ Again, it will be observed that Speusippus practically identified the Platonic Ideas with a certain kind of number, and, moreover, assigned to such numbers (seeing that they are generated from a unity that was more arithmetical in character and without the mystical significance of the Good) a distinctly

${ }^{1}$ Arist. Mct. N 1091 b 33. 
mathematical character. In both points there is marked divergence from the Platonic view. For Plato identifies the One and the Good, and Aristotle even makes a special criticism on the consequence involved, namely, that according to Plato good and evil are alike first principles (all duality being evil). Plato also distinguished the Ideas from the arithmetical numbers; and even though the Ideas tended to become more and more numerical in character, they were nevertheless characterised as being devoid of the special qualities of number. They could not be combined as mathematical numbers can be combined.1 Speusippus rejects this distinction, but nevertheless, as Aristotle points out, since he is compelled to introduce a certain distinction between the One-Unity-which is principle of all and the One which is a factor in all number, he implicitly allows a distinction of the Platonic kind.

One further doctrine is ascribed to Speusippus which has its own general interest. We find Aristotle ${ }^{2}$ contesting a position which seemed to threaten the possibility of scientific knowledge. To define, it was urged, requires absolutely complete knowledge. No one can define-that is, state completely the nature of what is defined-without distinguishing the defined from all else. In other words, there is no knowledge except absolute knowledgeabsolute quantitatively as well as qualitatively. Apparently Speusippus was the author of this argument, though I admit it is not easy to see in what way it connects with the other doctrines ascribed to him. It raises definitely for the first time the question whether reality is a whole at all.

Something more definite may be found in what is

1 They are non-addible ( $\alpha \dot{\alpha} \tilde{u} \mu \beta \lambda \eta$ Tot).

${ }^{2}$ Arist. Anal. Post. ii. 97 a 6. (R.P. 352 b.) 
known to us of the work of Xenocrates, the second head of the Older Academy, ${ }^{1}$ and a personal friend of Aristotle's, though our knowledge of him also is but fragmentary, and many of his sayings are of a mystical or allegorical nature. Xenocrates is credited with a restatement of the forms of apprehension-types of knowledge, they may be called-which it is of special interest to note he coupled with a correlative classification of the real world of existence. Xenocrates recognises senseperception, reason, and a third - a composite kind of knowledge to which he gave the Platonic title $\delta \xi^{\prime} \xi$, opinion. To sense-perception he allowed a certain measure of truth, but inferior in certainty to what was given in 'reason.' I suppose that the distinction here was more or less that previously hinted at by Plato, that senseperceptions were, so to speak, isolated. What is given is not connected with grounds or reasons which render it intelligible. It is only-so to speak-fact. Opinion, again, was held by Xenocrates to yield both true and false. Some opinions were true, some were false. With the distinction of these three forms of knowledge was conjoined a classification of corresponding objects to be known. To rational knowledge was assigned what was outside the oúpavós. Sense-perception had as its province what was within the oúpavós, while opinion had as its field the ov́pavós itself-meaning by that the various heavenly bodies. ${ }^{2}$ Obviously here there is a more definite formulation of the threefold division which must have been floating in popular ideas, and which we find ascribed, no doubt falsely, even to the Pythagorean Philolaus. The division is important, because it is

\footnotetext{
1 From 339 to 314 B.c. He was a native of Chalcedon.

358.) The object of $\delta \delta \xi \alpha$ is described as complex reality ( $\sigma \dot{v} \nu \theta \in \tau o s$ ov $\sigma i \alpha)$.

2 Sext. Emp. Math. vii. 147. (R.P.
} 
that which forms the ground-plan of all Aristotle's speculation.

What is outside the oupavós is for Xenocrates that which is wholly devoid of change. That which is within the oupavós (and there is little doubt that by this he meant pretty much what Aristotle calls the sphere under the moon) has the character of constant and, for the most part, incalculable change. The oúpavós itself partakes of change, for the heavenly bodies move; but it is change that is uniform and calculable. Xenocrates also gave these divisions of the real world the names of the three Parcæ -Atropos, Clotho, and Lachesis.

Like Speusippus, Xenocrates seems to have postulated as his fundamental principles in a metaphysical sense the One and the Indeterminate Dyad. ${ }^{1}$ From this point of view it becomes intelligible why Xenocrates should have rejected Ideas in the common Platonic sense and retained only the Ideas as numbers. $\mathrm{He}$ is supposed to have identified Ideal numbers with mathematical numbers, laying emphasis, however, on the features peculiar to the Ideal numbers.

In this connexion it is worth noting that we possess from Xenocrates a rather significant definition of what was meant in the Platonic school by an Idea-aitía mapa-

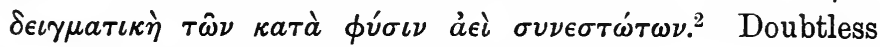
every term in this is carefully selected:-

airía ='ground' or 'cause'- perhaps the former is the more correct rendering.

$\pi a \rho a \delta \epsilon \iota \mu a \tau \iota \kappa \eta '=$ 'after the fashion of an example, type, or model.'

Hence 'a cause which serves as a model, an example.' $\kappa a \tau a ̀ ~ \phi u ́ \sigma \iota \nu=$ 'in or by nature' is obviously intended

1 Stob. Ecl. i. 62 . (R.P. 359.)

2 Proclus, Parn. 131 E (B. iv. 136 ed. Cousin). 
with respect to what is thereby excluded. Now, in Plato, that which would be excluded would doubtless be ex-

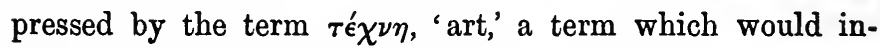

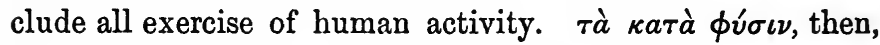
would mean things produced by the supreme organising power, as distinct from human activity-by the divine.

$a \dot{\epsilon} i$ $\sigma v \nu \epsilon \sigma \tau \omega \tau \omega \nu$ must again be taken as indicating a certain restriction. Not everything which subsists, which has substantive being in nature, is to be understood, but those things only which have a kind of universality of existence, by which I take it he can mean only the types, kinds, or genera of natural things.

Thus from the definition it will become apparent that Aristotle was strictly correct in asserting that in the later Platonic doctrine there were not admitted Ideas of artificial objects; and, doubtless, there must have gone with that the exclusion of negatives. For negatives can hardly be said to have existence in nature. It is not obvious, however, from the definition that we must exclude what may be called abstracts as compared with concretes, that we must refuse to admit as veritably Platonic, Ideas, for example, of relations and qualities. In respect to this some further distinctions are required, and probably the Platonists were prepared to reject on certain grounds some qualities and relations, while admitting others.

There is ascribed to Xenocrates definitely a doctrine to which certainly there are approaches in the Platonic

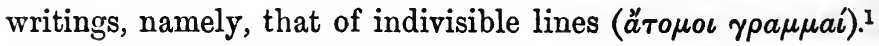
Possibly this doctrine is connected with the view of Xenocrates that the ultimate intelligibilia are number. $\mathrm{He}$ seems to have carried it to the full extent, and naturally involved himself in hopeless difficulties from the mathematical side.

1 Simpl. Phys. 138, 10. (R.P. 362.) 
Finally, to Xenocrates is ascribed the definition of the soul as a self-moving number. Obviously this is a direct deduction from the Platonic description in the Timoeus of the composition of the world-soul. The indivisible and divisible there were interpreted by Xenocrates as the elementary principles of number, namely, Unity and the Indeterminate Dyad; and the factors Same and Other, also assigned by Plato to the soul, Xenocrates interpreted as the principles of stability and change. 

PART III

\section{A RISTOTLE}

\section{CHAPTER I}

\section{PLATO AND ARISTOTLE}

THE Aristotelian system, taken as a whole, is most easily approached from a consideration of the relation in which it stands to the Platonic. The popular antithesis of Platonism and Aristotelianism exaggerates, no doubt, but does not altogether misstate, the nature of this relation. On some sides, unquestionably, there is so much identity of spirit and principle between the Aristotelian and the Platonic philosophies, that the former is rightly enough to be regarded, and can only be understood, as a development of the latter. Perhaps, even when the final statement of Aristotle's doctrine is reached, it may appear to the modern critic to express something so resembling Platonism as to be hardly distinguishable from it. On the other hand, it is impossible to overlook the continuous sense of opposition to Plato which runs through all the Aristotelian writings. Beyond a doubt Aristotle conceived himself to be following a line of thought antagonistic to the Platonic. 
We shall not err much if we connect this sense of opposition with an important difference in the intellectual equipment and training of the two thinkers. What most impresses the modern critic in Plato is the wholly abstract attitude of his mind with respect to the detail of external nature. The one writing in which Plato handles of set purpose the facts of nature-the Timoeus-is among the most mystical and least satisfying of his writings. It deserves, if ever any speculative treatise did deserve, the title sometimes given to Leibniz's theory of Monads-a philosophical romance. On the other hand, the most obvious external feature of Aristotle's method is its continual reference to a vast mass of empirical material, prevailingly, though not exclusively, of a physical nature. Accordingly, in the classifications of the sciences, as one may call them, offered by the two, the broad external difference is that in Plato metaphysics tends to absorb all the rest, while in Aristotle there is the clearest possible recognition of separate provinces as belonging to metaphysics and to the several natural sciences.

One might even say that Aristotle's constant objection to the Platonic theory of Ideas is the outcome of his superior knowledge of physical nature and his deeper conviction of its reality. In Plato's theory of Ideas, under all its many modifications, there seems to be involved, as the one characteristic of reality, that immutability which seems to attach to the objects of pure intellect: as contrasted with these immutable essences, the shadowy realm of the changeable was allowed only an imperfect, undefinable, almost selfcontradictory mode of existence. In Aristotle, on the other hand,-although in the long-run the distinction so prominent in Plato will be found to maintain a place in his system,the burden of his argument throughout is that the world of change has a reality of its own and is altogether inexpli- 
cable by reference simply to the immutable essences which Plato had called Ideas. However unsuccessful Aristotle may be in his final solution of the problem of change, it is the characteristic of his philosophy that he lays stress on the fact of change, and insists that something more than the unchangeable is required to explain it. 


\section{CHAPTER II}

\section{FUNDAMENTAL CONCEPTIONS}

WHEN we take into consideration only the generalities of the Aristotelian doctrine we are apt to misunderstand them: it is difficult to read into the abstract terms which Aristotle employs, the exact concrete meaning they possessed for him. A thinker's abstractions have meaning always, and only, in reference to such detailed and concrete picture of the world of fact as he carries with him. It would be impossible to bring together in a summary fashion the details of the Aristotelian representation of the world of fact: some of its broad features, however, it is all-important to keep constantly in mind.

\section{i. General division of the realm of existence.}

Aristotle gives precision to a distinction in the general realm of existence which had been gradually shaping itself through the speculations of his predecessors. In his general representation of fact the whole system falls into three members or groups: (1) the absolutely unchanged and unchanging final cause; (2) the realm of existents that are relatively unchangeable but which undergo a regular uniform series of changes, the heavenly bodies; (3) the region of constant mutation and change which locally is definable as that 
underneath the moon-the earth, that is, with its immediate surroundings, the atmosphere, \&c.

Keeping this very general distinction in view, I proceed to make the assumption that in any connected body of speculative views there is generally some central conception which will furnish a clue to the interconnexion of its parts. Some such dominating conception I think we find in Aristotle in the idea of End or Purpose. It is an idea so closely connected with that of change that it can only be expounded in close relation to the analysis of change. I purpose following out rapidly this conception of change as the embodiment of purpose or end in order thereby to get a first provisional view of Aristotle's system.

\section{ii. The conceptions of Change and Purpose.}

Aristotle lays down in the broadest terms the proposition : "Each existent in the realm of change comes to be from something, by something, to something." 1

What is this existent which undergoes change? On that Aristotle points out, first, that the existent is distinct from its qualities, quantity, and relations. These are its predicates; and, as opposed to them, it is definable by the - abstract term 'subject' (тò i $\pi \circ \kappa \epsilon i \mu \epsilon \nu o \nu)$. In the last resort, then, the existent which changes is a subject that is not predicate of any other. ${ }^{2}$

Secondly, Aristotle does not fall a victim, at all events not readily, to the line of speculation which naturally arises from the distinction between the subject and its qualities, quantity, and relations. That is to say, he will not, or, at least, will not readily, be driven to the supposition of a subject which, like Locke's 'substance,' is a mere cluster of negations. The existent subject, he maintains as well as he

1 Met. $\Lambda 1069$ b 36 : $\pi \hat{\alpha} \nu \mu \epsilon \tau \alpha \beta a ́ d \lambda \epsilon\rfloor$ a 13.

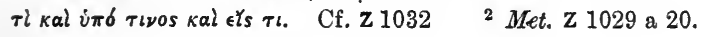


can, must be a concrete somewhat ( $\tau o ́ \delta \epsilon \tau i ́)$, an individual thing; generalities, universals, are not as such existent; the generalities which we may predicate of the existent subject

- do not themselves directly indicate existents.

Thirdly, the individual subject, though thus opposed to its universal predicates, must nevertheless have a definite nature, a character, that which is essential to it, that which makes it to be what it is, that which it is in itself : without such character it could not be or be known.

Fourthly, this group of characters, whereby the concrete individual existent thing is defined, coincides with the last or ultimate specific difference which we arrive at in classification.

Thus, fifthly, the ultimate subjects, in the region in which change is most of all involved, are the individuals composing an infima species or natural kind-one in nature, therefore, but many in number. In regions where change is uniform ${ }^{1}$ the ultimate subjects are single eternal existents, changing by constant law-one both in kind and in number.

I call attention here to the all-important identification in Aristotle's system of the essence of the individual with the essence of the infima species or natural kind. Undoubtedly this rests on, or, at all events, coincides with, the idea which Aristotle throughout accepts, that nature in the broad sense is a system of fixed types of existence. Such a representation of nature lies in the background of all Aristotle's thought, and only by constant reference to it can we make the details of the Aristotelian logic internally consistent and intelligible.

The definite nature which makes the thing to be what it is, is also that whereby each thing has its place in the whole, by which it plays its part in the whole, discharges its function, and therefore is what each existent has to be, what it

1 That is, among the heavenly bodies. 
has to realise. In the realisation of this, its inherent determined nature, the true being of each thing consists. The whole world of change, therefore, may be regarded as a system of realised ends, or as the constant process of the realisation of ends. From the one point of view each concrete thing is entitled by Aristotle a completed Actuality

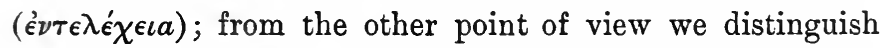

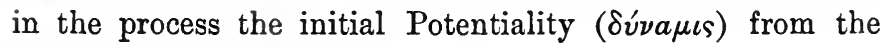
Actuality itself ('̇ं $\left.\hat{\epsilon}^{\prime} \rho \gamma \epsilon \iota a\right)$.

The distinction of actuality and potentiality involves a third conception, that of Process or the actualisation of the potential. Aristotle calls it $\mu \epsilon \tau a \beta o \lambda \eta^{\prime}$ (Change), and uses

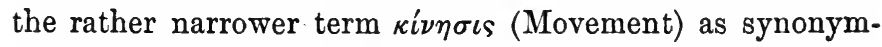
ous with it. ${ }^{1}$ It is best to keep in mind not this more specific form of change (movement), but change or process in general, which is to be defined as the actualisation of what exists potentially: it is the transition from the potential stage to that of completed actuality.

In this transition it will 'be noted that the completed actuality assumes a definite form, the presence of which distinguishes it from the antecedent potential condition. All change, therefore, involves the negative element: it is a transition from what is not yet to what is. The negation, however, is not, so to speak, of the absolute kind. The potential, as not possessing what the actuality manifests, is not absolute negation. "Aristotle uses to designate this aspect of it the technical term $\sigma \tau \tau^{\prime} \rho \eta \sigma \iota s$ (privation). The potential may have abundance of actuality when looked at from another point of view. It is negative or privative only as regards the higher form into which it is capable of

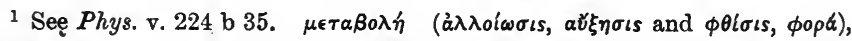

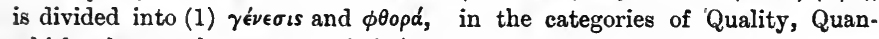
which relate to the category of ouria; tity, Place, respectively.

(2) $\kappa i v \eta \sigma$ s, which has three species 
developing. In the complete gradation of nature there is thus, as it were, a scale of ascent and descent, descending towards privation of all that is determinate, ascending towards completed perfect actuality.

Further, from its position as a realised end, an actuality, the concrete existent must always be regarded as in itself a compound ( $\sigma \dot{v} \nu \theta \epsilon \tau o \nu)$, of which it is easy to distinguish as elements the familiar Form and Matter. It is a compound because the actuality is not an absolutely new formation; there is carried out in it, manifested in its fulness, what is also in a way present in the antecedent condition. There must therefore be a common basis, the foundation for that identity in difference which connects the potential and the actual. This common basis is called by Aristotle $v^{\prime} \lambda \eta$ (Matter), a notion much wider than that which we

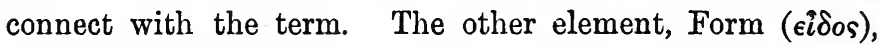
is easily identified with the $\tau$ é $\lambda$ os or final cause, for it is the same as that which the thing is capable of being, that which when attained constitutes the complete existence of the thing. The Form is equivalent to the end or purpose of the thing in an explicit or direct way, when the existent thing comes about by Nature ( $\phi v \dot{\sigma} \sigma \varsigma$ ). The same holds good, though the relation is implicit or indirect, when the thing

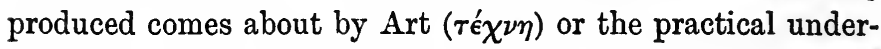

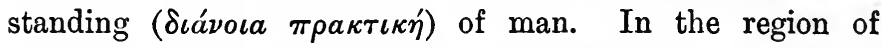
generation, then, there are two main types of cause: Nature, which Aristotle vaguely enough regards as the immanent activity or form; and Art, whatsoever springs from the soul or mind, in which latter case the form is distinguishable in its antecedent condition from its realisation in the concrete thing. ${ }^{1}$

It is worth noting here that Aristotle connects with these two types of causes two mysterious and treacherous

1 Phys. ii. c. 1. 
factors which play a part in his theory of nature,-

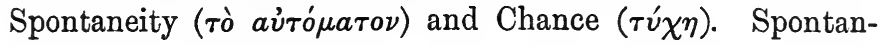
eity relates mainly to nature as a cause, chance rather to art. The connexion between chance and art is the more obvious of the two. In carrying out a plan, says Aristotle, it often happens that the actions requisite for the end in view have consequences that were not foreseen, and that did not enter into the consideration of the agent. On the analogy of this relation he seems to have conceived of spontaneity or the spontaneous as holding a similar place with respect to the operations of nature. Nature also has to employ means in order to realise its ends, and from such means may follow effects which are not, so to speak, in the plan itself. ${ }^{1}$

Evidently the conception of Spontaneity is irreconcilable with any scientific view of nature as an interconnected whole; and perhaps it is not unfair to insist on the essential relation between the notion of the spontaneous and Aristotle's fundamentally unscientific conception of nature as a gradation of fixed types of concrete existents. Now experience forces on any one the admission of deviations from such fixed types. Even in the realm of organic life, where Aristotle's picture of nature has most to support it, we are presented with innumerable deviations from the type. Aristotle himself considers only the extreme cases of such deviation-monsters as they are

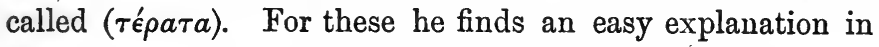
this notion of a possible deviation from nature, a possible interference with the operation of nature, which, as he conceived it, is always directed towards the realisation of ends. ${ }^{2}$

I The effects or consequences in mechanical way, it is said to be the question are always such as might result of spontaneity or chance. See have been the object of nature or art. In other words, when what might have been intended results in a purely Phys. ii. cc. 4-6.

2 Phys. ii. 199 b 1 : cf. Gen. An. iii. 759 b 10. 
iii. The conceptions of Form and Matter.

These notions of Form and Matter admit of and require somewhat more detailed analysis; and the analysis will yield us some of the characteristic technical notions with which Aristotle operates. Matter, quite generally, is the substratum of change. Change is, as Kant later expressed it, not vicissitude, a series of perfectly disconnected events; there is involved in it an element of identity, of continuity; the differences which are too easily taken to constitute change are possible only as differences in some common substratum, which therefore constitutes the necessary complement in the whole notion of change. ${ }^{1}$ Matter then, so regarded, is that which is not in itself the individual concrete existent, but is so only potentially; it is what may or may not possess this or that quality. Such potentiality of becoming a concrete existent is still more clearly manifested in another aspect of matter, that in which it presents itself as capable of being, or of not being, an individual. This or that individual cannot be called necessary. Now that in the individual which has this characteristic of non-necessity, or contingency, is its matter.

If, now, recognising the strictly relative character of this notion of matter, we carry our view downwards to that which is the last remainder after abstraction, we have the wholly indeterminate final matter $\left(\pi \rho \omega^{\prime} \tau \eta v^{\prime} \lambda \eta\right)$ which is the bare potentiality of all that is actualised in the realm of changeincognisable by itself, known to us only by analogy, a point in which Aristotle is borrowing freely from Plato.

In the realm of change, wherever there is numerical multiplicity, there is the element of contingency, the element of matter. Where there is no element of the material, no

1 Phys. i. c. 7 .

${ }^{2}$ Met. z 1036 a 9 ; Phys. i. 191 a 8. Cf. Plato, Tim. 52 в. 
potentiality, only completed actuality, there is no numerical multiplicity,-a proposition which furnishes Aristotle with one of the main determinations of the Divine Nature. It enables him to assign to the Divine the all-important feature of unity. (There is considerable difficulty in clearing up the relation of matter and form in the case of those concrete existents which are not included in the realm of constant change, namely, the heavenly bodies. In so far as they undergo change in the sense of motion, they contain matter in the correlative sense. But they do not contain matter in the proper sense of the word. Each one of them is the sole and complete representative of its type,-it is sui generis.)

The element of form is that which constitutes the nature of the concrete thing,- that, therefore, which when known discloses to us its essence. For this Aristotle uses a very

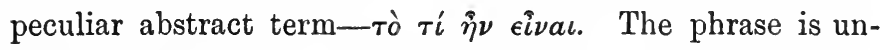
doubtedly framed on analogies common enough otherwise

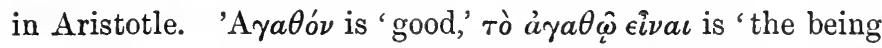
good' or 'goodness.' Consequently our phrase here means 'what was the being of the thing,' or otherwise 'the abstract nature or essence of the thing.' 1 This abstract essence or, as we might call it, the notion of the thing, is its determinate character divested of all element of matter. It is therefore, as can readily be seen, what appears expanded

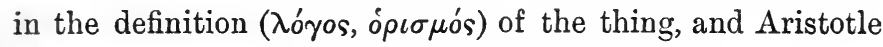
expressly calls this notion of the thing its 'form.'

\section{iv. The First Cause.}

The process of transition or development from the potential to the actual always involves an Efficient Agent (rò

1 The imperfect $\hat{\eta} \nu$ is explained as an idiom by which the permanent nature of a thing is expressed; or perhaps it refers to a supposed con- text of discussion, and means what the thing really was throughout the investigation of its nature. 
$\kappa \iota \nu \circ \hat{\nu} \nu)$, whether nature in some one of its concrete manifestations, or art as embodied in some concrete agent. And it is a fundamental proposition with Aristotle that the Efficient, that which gives rise to the process of transition, must always be in itself an actual existent. The potential as such does not give rise to the actual. It is necessary, so to speak, that the potential should be stimulated into energy, and it can be so stimulated only by the operation of a completely existent thing-something which, as Aristotle puts it, exists in actuality. From this proposition it was evidently easy for Aristotle to proceed to an important conclusion from his general doctrine, namely, that there must be for the whole connected sequence of changes a First Efficient, a First Mover ( $\pi \rho \hat{\omega} \tau o \nu \kappa \iota \nu \circ \hat{v} \nu)$; there must be, as he says, a first beginning, a principle ( $\left.\dot{a} \rho \chi \eta^{\prime}\right)$; the series of causes cannot be endless. Thus, in spite of the apparent priority of the potential to the actual, Aristotle insists that in fact the actual always precedes the potential,-another of those features which absolutely distinguish his conception of development from any of the more modern interpretations of that notion.

To recapitulate: Process or Change is the notion under which Aristotle brings all forms of transition from the potential to the actual. In it, therefore, we find what corresponds most closely to the all-important notion of efficient causation; and Aristotle takes occasion to define very accurately one element in his theory of real causation. The Efficient, that which gives rise to the transition from potential to actual, must always itself, before the transition, be in the condition of actualised existence. Ultimately, therefore, however far back we may push the regress from effect to cause, we must land in an efficient which is itself in completed actuality, and which therefore is not itself in the condition of process or transition. Even if we look at change 
in the rather limited though important sense of local movement ( $\phi \circ \rho a^{\prime}$ - - and Aristotle sometimes goes the length of maintaining that all forms of change involve local movement ${ }^{1}$ - the result is the same in kind: there must be postulated a first unmoved mover. Along this line, then, Aristotle works out perhaps the most obvious connexion between the realm of mutation and the immutable, or, as he otherwise calls it, the Divine (

It would perhaps be an exaggeration to say that the characters by means of which he further defines the notion of God are negative; but certainly they come very near being mere explicit denials of what is the general aspect of the realm of mutation. These defining marks of the Divine are most easily unfolded from the notion of the first unmoved cause of motion. The following ${ }^{2}$ is a summary of them :-

(1) God is in His essence pure actuality; there is ' not in His being anything merely potential.

(2) The essence of the Divine is eternal, for the series of transitions making up the process of the world of generation has neither beginning nor end. (This proposition of the eternity of the world of generation caused the greatest trouble to the scholastic Aristotelians. They found difficulty in accommodating it to the Christian doctrine of Creation.)

(3) The nature of the Divine is immaterial.

(4) The nature of the Divine, being immaterial, is unchangeable and free from every element of passive affection. It is not by motion of Himself, or, in the more general way, by change of His own being, that the Divine Agent gives rise to movement or change. This position, however necessary from the premisses of Aristotle's system, only

1 Gen. Corr. i. c. 5.

2 Taken from Schwegler, Handbook of the Hist. of Phil. 109 (14th ed.) 
accentuates the difficulty there latent of representing in any intelligible fashion the manner in which the operation of the Divine on the world of generation comes about. Aristotle himself hardly gives any explanation of it beyond a reference to the analogous case in which change of emotion or desire may come about from contemplation, say, of the beautiful. Thus, in a way, the series of changes in the realm of mutation would be represented as originating from, and expressive of, a certain striving of the changeable towards the perfect model of the unchanging. ${ }^{1}$

(5) The nature of God, being devoid of every element of matter and therefore of all multiplicity, must further be characterised as single. The Divine is one. The same result, indeed, would follow from the unity of the world of mutation; for the sequence of changes there is continuous, and such continuity can find explanation only in the singleness of the first cause. ${ }^{2}$

(6) Finally, as the Divine is wholly devoid of any element of the material, its essence must be defined as throughout intelligible, and its mode of existence, therefore, must likewise be defined as the exercise of pure unmixed intelligence. The Divine is pure continuous activity of thought, altogether devoid, therefore, of the practical or productive energies which characterise the rational life of man, and having for the object of its contemplation nothing beyond itself. It is therefore pure self-conscious reason ( $\nu$ ó $\eta \iota \varsigma$ $\nu o \eta \sigma_{\epsilon} \omega$ ) - to strain the expression a little. It is impossible from the scanty utterances of Aristotle on this point to give greater exactness to the all-important notion which here emerges-that of the intelligible object of the continuous contemplation of the divine reason.

1 Met. $\Lambda 1072$ b 3.

${ }^{2}$ [But at the same time it must be kept in mind that Aristotle recognises also as many unchangeable Divine Intelligences as are necessary to explain the movements of the planets.] 


\section{v. The Soul.}

Returning now to the realm of the mutable, I note that Aristotle proceeds, in viewing the types of change, on a distinction easily arrived at from a broad contemplation of the world of fact, and already recognised more or less definitely in the pre-Aristotelian thinking-the distinction between movement which is, as we should call it, the mechanical result of a preceding movement, and movement or change which is, so to speak, self-generated. Nature, in the narrower sense of that term, is regarded as the principle of all self-generated movement, and such movements constitute the more important element in the world of change: merely induced movement is accidental.

Now, the principle of all such self-generated movement had been called by Plato $\psi v \chi \eta^{\prime}$ (Soul); and, though Aristotle perhaps restricts to some extent the range within which soul is recognised, he yet does not depart widely from the Platonic position. (For him as for Plato there is no distinction in essence between life and soul. Only, in accordance with the method provided by the important distinction between potential and actual, and the cognate notion of a gradually ascending scale of actuality, Aristotle is enabled to connect life and soul by the relation of potential and actual. Soul is the actuality of the organised body or living being. The completion or complement of the living being-which apart from it possesses merely the potentiality of life-is called by Aristotle $\psi v \chi \eta^{\prime} .^{1}$

Soul, then, is not only always related to body, but it is more specifically related to that type of body which from the arrangement of its parts is adapted to the kind

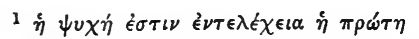

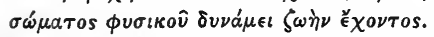

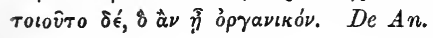

ii. 412 a 27 . For a more precise statement of the relation of $\zeta \omega \dot{\eta}$ and $\psi v \chi \eta$, see below, pp. 199-202. 
of function which we call 'life.' Thus in strictness soul in the world of mutation presents itself only in the realm of organic life. It is not, as with Plato, extended over the whole region of the material universe. Only where the arrangement of parts exhibits the peculiarity of organic connexion can we say that the completed actuality which is thus made possible is of the nature of soul. Wherever that arrangement is provided there may be soul; and in truth the term 'organic connexion'-the significance we attach to the term 'organ'-can only find application when the activity called 'life' is really brought into existence. Thus, for example, Aristotle steadfastly maintains that a hand or arm when cut off ought not to have applied to it the same name which it bears when the same portion of matter is veritably an integral part of the living whole.

The same general conception, which enables us thus to define the soul as the actuality of what is potentially in the organised living body, may in its turn find application to the soul itself. That is, the soul may exhibit to us a gradation of ascending functions related in somewhat the same fashion as respectively potential and actual.

Aristotle, following out this thought, proceeds to ask, What is the simplest set of functions in which the organic life is manifested in actuality? They are, he says, the nutritive or vegetative. ${ }^{1}$ The living being preserves its existence only by assimilating nutriment. The function therefore of nutrition is the first grade of the activity of the soul. Without it none of the higher forms can be exercised.

The next of the higher forms are, in the first place, sense-apprehension (ai $\sigma \theta \eta \sigma \iota \varsigma)$; in the second, motor activ-

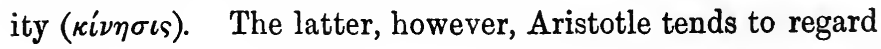

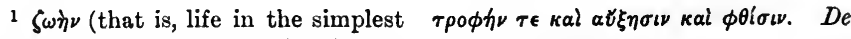

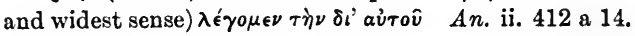


as dependent on the former. Here he shows genuine psychological insight.

Aristotle regards sense-perception as the specific characteristic of the animal soul. It is the foundation for a variety of closely connected higher functions, which on the whole Aristotle tends to group together with senseperception, and which the later scholastics almost unanimously named 'the animal soul.' They constitute the representative function ( $\phi a \nu \tau a \sigma i a)$, which includes (1) the capacity for retaining images of past sense-apprehensions $\left(\mu \nu \eta^{\prime} \mu \eta\right)$; (2) reminiscence or voluntary recall (ává $\mu \nu \eta \sigma \iota$, a function which Aristotle thinks belongs chiefly to man); and (3) imagination, in the fuller sense, as the representation of a concrete individual.

Closely allied to these, and not, as we shall see later, very accurately defined by Aristotle, are the functions of judging, believing, and even reasoning-a group constituting altogether what might be called the functions of understanding; and on the whole the Platonic term Sıávoıa is suitable here.

The soul, thus represented as the actuality of the body, as constantly correlated with the body, is, like the body, part of the realm of the changeable. ${ }^{1}$ Like the body, it is strictly individual. It is nonsense to represent any soul as capable of inhabiting any body. ${ }^{2}$ The soul therefore is mortal or immortal in the same sense in which the body is. That is to say, just as the world of generation is eternal and the types of existence in it equally eternal, while the individuals are transitory, so with the soul. It is only in the endless series of generations that man has immortality. ${ }^{3}$

${ }^{1}$ [Though Aristotle regards the investigation of $\psi v \chi \dot{\eta}$ as a department of $\phi \cup \sigma \iota \kappa \dot{\eta}$, and therefore as dealing

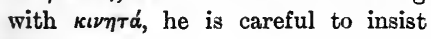

that the affections of $\psi v \chi \eta^{\prime}$ are not strictly $\kappa \iota \nu \eta^{\prime} \sigma \in \iota s$.]

${ }^{2} D e A n$. i. 407 b 23.

3 De An. ii. 415 b 3. 
Nevertheless Aristotle recognises, and from the positions of his metaphysics was bound to recognise, something in or connected with the soul whereby an explanation could be given of the apprehension by man of what is not mutable, what is eternal, even in a sense in which the cycle of generation is not eternal-the Divine. There is in the soul something of the Divine, and to this Aristotle gives the name of intellect or reason ( $\nu$ ov̂s).

In considering Aristotle's general view of the soul two points require attention.

1. The whole life of the soul, regarded as the actuality of some potentiality, might be looked at either from the side of the organic body of which it is the completion, or with respect to that more abstract idea, the purpose, end, or aim which is realised in the life of the soul. From this second point of view the life of the soul is, in one way at least, the realisation, the concrete actual apprehension, of truth. The function of the soul, on its theoretical side at least, is to know, to apprehend what is. The development of the soul, then, through the several grades or powers, may also be regarded as the gradual approximation in actual conscious experience to the ideal of theoretical apprehension,-that is, completed knowledge of the real. Perhaps from this point of view it is most easy to understand some of the characteristic positions of the theory of knowledge to which we shall presently advert. The reality which is to be apprehended, so far as the realm of generation is concerned, exists always as a combination of matter and form. Correspondingly, our apprehension of the world of fact must exhibit a combination of the universal, the notion, with the particularising elements marking off the individual of sense-perception. Even in the cases where it is most of all possible to separate the 
form from the matter in what is known, namely, in mathematical science, there will still be found as constituting the real object known an embodiment of form in matter. Mathematical relations are apprehended only in the typical individuals-figures or numbers-in which is involved an element of matter. ${ }^{1}$

So if we carry our consideration farther back, corresponding to this combination of the perceived and the notion in what is known, there will be, as respects the psychical functions, the co-operation of sense-apprehension and the higher activities extending up to reason. In that combination, and corresponding to the gradation of completeness in our knowledge, there will be a graduated scale of ascent from the stage in which passive sense is the predominating factor to the highest intellectual exercise, that of reason, where the function of sense seems almost absent.

2. The peculiar perplexity in which Aristotle's psychology is left through the apparent want of continuity between soul and intellect or reason is the correlate of the corresponding perplexity in the theory of existence, and also in the logical theory of knowledge. Whatever explanation Aristotle may have to give of the relation between intellect ( $\nu \circ \hat{v}$ ) ) and the soul, he is at least clear and emphatic in declaring that vovs is not the realisation of any corporeal potentiality; it is not dependent on the body, and has no specific organ. ${ }^{2}$ It comes, as he puts it, from without into the soul. ${ }^{3}$ (Aristotle denies that the soul possesses immortality in a sense different from the immortality of the body. The soul may have the inmortality of continuous unending generation, but it does not follow

\footnotetext{
1 The material factor in mathe- a 33 . matical objects is called by Aristotle

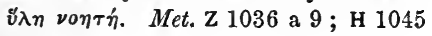


that the individual soul has. Nov̂s, on the other hand, may claim immortality in the fullest sense, that is, nontemporality; but it may not claim individuality.)

But this is precisely the kind of position in which the Divine stands in relation to the world of generation. It is wholly distinct from it in character, determinable really by predicates which are just the negations of the fundamental features of the world of generation. For example, it is evident that the unity assigned to the Divine is not a positive predicate, but only the negation of that plurality which characterises the concrete world of generation. It is quite impossible to represent the unity of the Divine nature as numerical singleness. However much the Platonic and Aristotelian conception of the ultimately real existent may have deepened, however much of richness and concreteness it may have gathered as compared with the original abstract conception of the Eleatic One, there must be said of it just what was pointed out in the case of the Eleatic doctrine. The various predicates by which the One is determined do not in any way unfold the positive nature of the One. They are no more than varied ways of denying that real existence belongs to any part of the manifold changeable world of phenomena.

There is thus the same hiatus in the psychology as in the metaphysic. Corresponding to it we shall probably find, when we are engaged in considering the relation between the first principles of knowledge and derivative truths, a breach of continuity which renders the problem of knowledge insoluble. These first principles must to some extent at least be the apprehension of pure forms; and such apprehension in various degree must be reached with the help of, on the basis of, the particulars of sense- 
perception. But the question in what relation the apprehended first principles stand to the knowledge which is supposed to result from the apprehension of them in the concrete facts of perception raises a difficulty similar to those which we find in Aristotle's psychology and metaphysic. 


\section{CHAPTER III}

\section{THEORY OF KNOWLEDGE}

\section{i. Demonstration and Opinion.}

IN dealing with knowledge Aristotle proceeds on a modification of the familiar Platonic antithesis between opinion ( $\left.\delta o^{\prime} \xi a\right)$ and science $\left(\dot{\epsilon} \pi \iota \sigma \tau \eta^{\prime} \mu \eta\right)$. What Plato called 'opinion' is called comprehensively by Aristotle 'dialectic' ( $\delta \iota a \lambda \epsilon \kappa \tau \iota \kappa \eta)$; what Plato called 'science' Aristotle calls

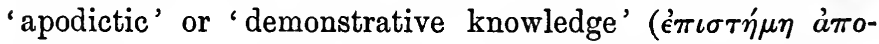
$\delta \epsilon \iota \kappa \tau \iota \kappa \eta)$. 'Dialectic' is a term which Aristotle employs with considerable uniformity of meaning to signify judging, reasoning, or thinking, which proceeds on grounds merely assumed as true without the careful investigation required in order to establish their validity. Ordinary experience supplies us in abundance with these commonplaces of thinking, merely probable propositions. On the other hand, science or demonstrative knowledge employs only premisses which are themselves universal and necessary. In both cases, whether in the material of dialectic or in the material of apodictic, we reason in one and the same form. ${ }^{1}$ There

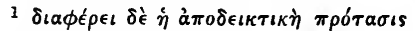

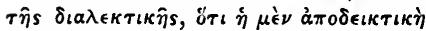

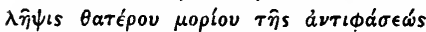

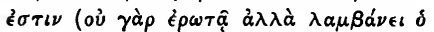

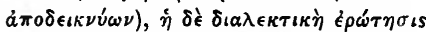

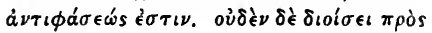

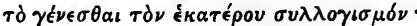

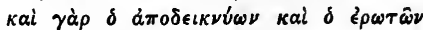

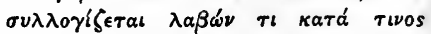
vidá $\rho \chi \epsilon เ \nu \hbar \dot{\mu} \eta \dot{v} \pi d \rho \chi \epsilon เ \nu .-A n a l$. Prior. i. 24 a 22 . 
is a unity of structure in our connected thinking, whether dialectical or scientific. It is this common structure which Aristotle was the first to analyse in greater detail, and which constitutes the specifically logical aspect of knowledge.

'Apodictic,' employing the syllogism as its form, inevitably suggests the question as to the necessity or possibility of first principles of knowledge. If there is demonstration at all, then it seems to Aristotle obvious that there cannot be an infinite regress of proof. Ultimately we find ourselves attaching all demonstrated conclusions to certain primitive, absolute, simple, immediate data. Such principles are of two distinct kinds; and the distinction is of the utmost importance. They are either common or general principles

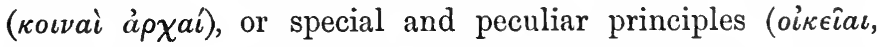

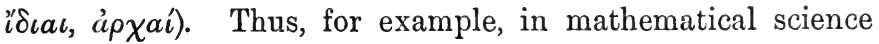
the axiom 'if equals be taken from equals, equals remain' is general, applying indifferently to quanta of different kinds. On the other hand, there are certain fundamental truths with respect to figures which cannot be regarded as also truths with regard to numbers; nor is it possible always to transfer a fundamental truth in respect to one kind of quantity to another kind of quantity. Each distinct type of concrete existence, having its own permanent essential nature, involves a certain number of primitive, immediate, simple data or truths, on which all demonstration respecting it must be based, or about which all demonstration turns. ${ }^{1}$

Aristotle puts very concisely another important feature of difference between these two kinds of ultimate primary truths. Besides the essential attributes which are demonstrated, every science involves (1) principles from which

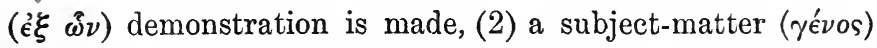
cencerning which ( $\pi \epsilon \rho i$ ó) demonstration is made. ${ }^{2}$ The

1 Anal. Post. i. 76 b 37.

2 Anal. Post. i. 75 a 39, 76 b 11. 
former are the common axioms or principles; the nature of the latter is expressed by the special, peculiar, axioms or principles; and all demonstration which does not proceed upon special peculiar principles is empty, void of significance. $^{1}$

No doubt, underlying this distinction, there is the characteristic Aristotelian view of the fixed types of concrete existence. As we saw, the concrete thing is what it is by reason of the general character, its form or essence. Thus complete knowledge about a thing is obtained when we are able to connect all its features ( $\tau \grave{a} \kappa a \theta^{\prime}$ aí $\left.\tau \grave{a} \sigma \nu \mu \beta \epsilon \beta \eta \kappa o ́ \tau a\right)$ with the primitive components of its essence. Demonstration, where possible in respect to any one type of existence, would present itself as a syllogism or series of syllogisms in which the ground or reason for all that is known respecting the thing is shown to be the essential, primitive, or ultimate components of its essence.

On the other hand, nothing is demonstrated from the general axioms alone. They indicate conditions in the absence of which demonstration is impossible, but they furnish no concrete data for knowledge. This peculiar character of the common principles is most clearly exhibited in the most important of them, the axiom of Contradiction - the principle that two contradictorily opposed judgments cannot be at once true, or, that a thing cannot both be and not be under the same conditions and in the same relations.

\section{ii. The Principle of Contradiction.}

The principle of contradiction is selected by Aristotle as the supreme and most important and fundamental common axiom. ${ }^{2}$ The consideration of this principle falls within the scope of metaphysic, which, more specifically, is regarded 
by Aristotle as having for its object being-as-such ( $\tau$ ò ô $\nu$ $\dot{\eta} \not \nu)$. The treatment of common axioms in general is regarded by him as forming part of metaphysic; but, in particular, the principle of contradiction falls within that part of philosophy because it connects directly with beingas-such. The principle itself is formulated by Aristotle with a rather definite objective reference-'The same thing cannot belong and not belong to the same thing at the same time and in the same respect.' ${ }^{1}$ Such an axiom is also the most firm principle of knowledge or thinking; for it implies that it is impossible for the human mind to think that what is true is at the same time, in the same sense, in the same reference, false. ${ }^{2}$ The fundamental opposition between true and false has the double reference. It is incompletely expressed if not taken both with respect to the nature of things and at the same time with respect to apprehension of that nature of things. These, in Aristotle's view, are always correlative; but, if a priority is to be assigned to either, it must be accorded to the objective aspect, the nature of things.

The same axiom, when due attention is paid to the notions of truth and falsity occurring in it, implies a further generality-that which later logicians separated off as the law or principle of Excluded Middle. When they are properly defined there is no third possibility between the true and the false. ${ }^{3}$ Aristotle, in handling this implication of the principle of contradiction, approaches the highly important speculative proposition that all assertions which have as their apparent subject the universe, the sum-total of reality, are meaningless.

The principle of contradiction from its nature cannot

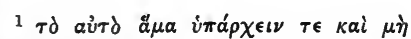

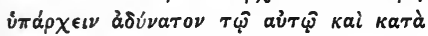
$\tau \dot{~ a u ̀ \tau b .-M e t . ~ \Gamma ~} 1005$ b 19.
2 Met. $\Gamma 1005$ b 24.

3 Met. Г 1011 b 25. 
admit of proof. Those who seek for such, says Aristotle, ${ }^{1}$ exhibit only their ignorance of what is meant by proving. He who rejects it, then, cannot be dislodged from his position by a demonstration which shall directly establish the truth of the principle. He can be refuted only indirectly ('ं $\lambda \epsilon \gamma \kappa \tau \iota \kappa \hat{\omega} \varsigma)$, by showing that it is either impossible or absurd for him to retain the position of rejecting the principle. For the purpose of this indirect confirmation of the principle it is sufficient to insist that its opponent shall allow that the terms or notions he employs have a definite meaning. If he uses any term at all, with the admission that it has a meaning, then, Aristotle thinks, it is possible to make clear to him that he must admit the truth of the principle of contradiction. If he will not allow that terms or notions have any meaning, then it is evident that he rejects thinking in toto, must resign the use of speech, and is no better than a plant. For if his terms or notions have a meaning, whatever they mean is distin. guishable from their corresponding negatives, and it must therefore be impossible that one and the same term or notion can at the same time mean both the positive and negative. The possibility of thinking at all, Aristotle seems to say, depends on the admission that there is a certain fixity of significance in terms or notions, and this in the long-run is equivalent to the fixity of the nature of that which is. Thinking, in other words, is but the apprehension of what is; and, if there be no distinction between what a thing is and what it is not, thinking becomes impossible, and we are not even in a position to reject the principle of contradiction. We have neither thoughts nor terms whereby to express our rejection, if such thoughts and terms have no fixity of meaning. ${ }^{2}$

Thus the principle of contradiction is an axiom of thought

1 Met. $\Gamma 1005$ b 2, 1006 a 5.

2 Met. r c. 4. 
only on account of the intimate correlation between thinking as a process of apprehending and the nature of things to be apprehended. Aristotle is far removed from the position sometimes taken in purely formal logic, according to which the principle of contradiction is the expression only of a condition under which the subjective activity of thinking proceeds. It is, indeed, and has always been found, impossible in any way to extract from the notion of thinking as a merely subjective activity the principle of contradiction. In the Aristotelian view, however, that principle manifests its fundamental character only when thinking in general is taken as an element, it may be an all-pervading element, in the process of apprehending reality. A severance of thinking from reality is altogether foreign to Aristotle.

If the terms in which the fundamental opposition between true and false is referred to in the principle of contradiction are clearly conceived, they lead us back, Aristotle points out, to the fundamental conception of the final subjects of predication. It is primarily with respect to such final subjects - concrete existents, each with a definite nature-that the principle has its application. Aristotle is therefore on the one hand making a distinction between subjects and their predicates, and on the other hand rejecting any view which extends the conception of subject beyond the sphere of the concrete existent.

Consider the first of these points. Aristotle points out that we must define carefully the terms of our opposition, as, for example, man and not-man. The principle of contradiction is to the effect that the concrete existent cannot at the same time have the nature of man and not have the nature of man. But, it was evidently urged, of the concrete existent man I may predicate that he is white, educated, and so on; and evidently, it was insisted, white is not man, 
educated is not man; therefore it is possible to predicate not-man of man. ${ }^{1}$

Such accidents, Aristotle maintains, do not constitute the negative of the nature of the subject from which we start; and, were we to endeavour by means of them to express exhaustively the opposite of the concrete subject with which we start, we should be compelled to try to complete the impossible enumeration of an infinite series. In the longrun all assertions about accidents are valid only in so far as they refer to the fundamental subjects; and it is the fundamental subject that must be taken as that of which the negative cannot be true at the same time with the positive. Even when we look to the accidents the axiom may receive confirmation: for certainly 'white' is different from 'educated'; and, if we deny that 'being man' is the same as 'being white' or 'being educated,' we must allow that the difference is infinitely greater between 'being man' and 'not being man.' The opposite, the negative, is thus regarded as, so to speak, the final term in a chain of differences. ${ }^{2}$

The principle of contradiction, then, must be admitted by any one who allows the possibility of apprehension at all. Apparent rejection of it-for Aristotle maintains that its rejection cannot really be thought-must depend on the denial of the possibility of apprehending reality. Such a denial, in the previous history of speculation, had come forward in three varieties at least: ${ }^{3}$ (1) the Heraclitean, according to which, because of the constant flux of things, no apprehension of any one definite truth was possible; ${ }^{4}$

1 Met. $\Gamma 1007$ a 8.

2 Met. $\Gamma 1007$ a 4.

3 Met. r c. 5.

4 Aristotle maintains that if this view be strictly adhered to, it must involve the thinker either in contra- diction of himself or in absolute cessation of thought, whence, therefore, he refers with approbation to what was said of Cratylus, one of the followers of Heraclitus : that he had given up the use of speech and con- 
(2) the Protagorean, according to which, from the purely relative character of apprehension, it was possible and necessary to say that no one proposition was more true than another; and (3) finally, from the doctrine of Anaxagoras, that all things were so intermingled that it was necessary to say each thing is as much one as the other.

iii. Metaphysical Principles of the Theory of Knowledge.

The consideration of the special or peculiar axioms carries us at once into the Aristotelian theory of knowledge. It is impossible to understand the position accorded by Aristotle to these special axioms except in connexion with the general outlines of his view of knowledge as a whole. In that theory of knowledge we are able to recognise distinctions of aspect which have become more definite in modern philosophical treatment. The theory has a logical, a psychological, and a metaphysical aspect; nor is it possible to give a statement of Aristotle's view of knowledge in any one of these aspects without consideration of the others. I shall first take into account certain of the metaphysical doctrines which bear most intimately on the view of knowledge. As a preliminary it is to be borne in mind that Aristotle's terminology shows an increasing consciousness of the ambiguity which always attaches to the term 'knowledge.' $\mathrm{He}$ accepts in his own way the Platonic antithesis between opinion and knowledge, an antithesis which implied that by knowledge was meant the clear final insight into truth and reality-what we should call the final result of scientific investigation. In a similar fashion Aristotle contrasts dialectic and apodictic; defining the former as reasoning

tented himself with wagging his finger, and that he had proposed to amend the statement of Heraclitus, "No man can go down twice into the same stream," by saying "No man can go down even once into the same stream." 


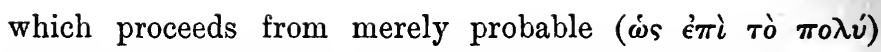
premisses and which attains therefore merely probable conclusions, whereas in the latter the start is made from principles which are themselves necessary truths and the conclusion is likewise necessary. But Aristotle's more comprehensive view of experience leads him greatly to reduce the force of the antithesis as presented in the Platonic doctrine. Not only does Aristotle recognise a community of form in reasoning within the two distinct provinces,-a community of form in the more elementary processes as well as in what is fundamental, the connective operation of syllogising,-but he also recognises a variety of intermediaries which bridge over the gulf between the region of opinion and the region of scientific insight.

Nay more, one might say that to a certain extent the modification thus introduced almost amounts to a denial of the distinction of kind which seems to be implied in the Platonic antithesis. Aristotle keeps so constantly in view what we call the development of knowledge-the gradual advance from the imperfect stage of merely probable judgment to that of final, assured, scientific insight-that his first contrast tends to become less and less absolute. Certainly this statement must be made with qualification; and the qualification requisite points directly to what we shall find to be the final insoluble difficulty in the Aristotelian treatment. The antithesis never finally vanishes. There always appears at a certain point a transition of kind-the transition which in the metaphysical sphere is indicated in the opposition between the variable and the immutable, in the psychological sphere between the functions of the soul and the mysterious activity of $\nu$ vos or reason, in the logical sphere between the apprehension of mediated truth and the intuition of first, special, peculiar principles.

Turn then to the metaphysical characteristics which are 
of most importance as determining the theory of knowledge. Aristotle opposes strenuously to the Platonic doctrine of Ideas, taken as separate from the particulars, the view that the only existent is the concrete individual. The Platonic Idea he regards as a class-universal which as such can possess no substantial existence. The universal as such does not indicate an independent entity, but a property or quality common to many individuals. ${ }^{1}$ No doubt such universals indirectly indicate what exists, for they point to the common attributes of really existent subjects. Moreover, universals are absolutely necessary for knowledge: there is no knowledge of the isolated or abstract individual. A distinction is thus indicated between two senses of the term 'individual.' On the one hand, it would appear as though the individual were necessarily the ultimate, unqualified, undetermined unit, the final result left after the withdrawal of all that constitutes its agreement with others. On the other hand, if the individual enters at all into knowledge, it must have an aspect or character which has in it something of universality.

Aristotle shows himself fully aware of the difficulty involved in his antithesis between the individual and the universal, and more than once formulates it with the utmost definiteness: "Knowledge is of the universal." ${ }^{2}$ Individuals are infinitely numerous and distinct from one another. How is it possible that if knowledge be of the universal, which is on one ground necessary, it should also be of the individuals, which on another ground is equally necessary?

It can hardly be said that he succeeds in giving a solution as clear as the difficulty to be solved. An approach to a solution, however, is made through the metaphysical analysis

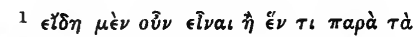

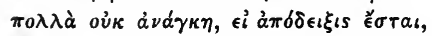

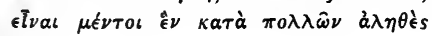

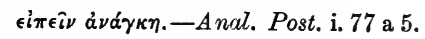

${ }^{2}$ E.g. De $A n$. ii. 417 b 23. 
required in order to clear up the notion of the individual. Numerical plurality is not the ultimate feature which characterises the individual for Aristotle. Things, the subjects of predication, may be many in number and yet possess singleness of character. In fact, within the realm of generation it might be said to be necessary that what is really one should be manifested in a plurality of numerically distinct individuals. Numerical plurality is thus regarded by Aristotle as the final accident attaching to the real subjects of predication by reason of their existence in the world of generation.

The true individual is not the numerically distinct unit, but that which is manifested within the region of alternate coming to be and ceasing to be in a plurality of separate units. The separate units are cognisable only in so far as they have that fixity of character which enables them to be recognised as units of one and the same kind. Aristotle does not explicitly say, but he might very well have said, that the subject which is only characterised by numerical unity, and the indeterminate substratum which has no qualification at all, are alike beyond the range of knowledge and existence. Thus the concrete individual, though always manifested in numerical plurality, is more properly to be conceived of as the common character which finally connects together the multiplicity of numerically distinct units.

Much depends in this statement on the term 'finally'; and we must accept as Aristotle's view that it is not merely possible but necessary to recognise in what is offered to us in experience the final characters which distinguish one type of many units from all others. When expressed logically this postulate is to the effect that there are and are discoverable ultimate specific differences. It is Aristotle's view in general, expressed in the most pointed way, that the 
ultimate real subjects of predication are fixed by the last specific differences which determine one type of numerically distinct individuals. What is called logically the ultimate specific difference coincides therefore with what metaphysically is termed by Aristotle the essence or form or notion of the concrete individual. Nothing exists which has not in addition to its numerical distinctness a fixed character or nature. Individuals numerically distinct exist therefore only as manifestations of a fixed character or type. Logically and metaphysically Aristotle's theory is dominated by this conception of fixity of character, nature, or type, in the subjects of all possible predication. I think he regarded it as almost an axiom that, if there be knowledge and existence at all, there must be fixity of character in that which is and is to be known.

Aristotle's treatment of the principle of contradiction proceeds on this assumption. The interpretation which on the whole is given by him to this axiom detracts somewhat from its generality. There can be no doubt that in his mind what corresponded to it, and gave it definiteness of meaning, was the representation of nature as an arrangement of fixed types, natural kinds. In practice Aristotle takes as too easily accomplished the heavy task which is necessary in order to carry out fairly the requirements of the term 'final ' or 'ultimate.' $\mathrm{He}$ is too ready to accept, as obviously final or ultimate, differences which are no doubt prominent in the appearance of natural objects as presented in experience. A modern thinker might accept the axiom in all its generality; but much experience would have taught him how difficult it is to be assured that in the analysis of concrete fact we have succeeded in finally determining the differences; and the new turns of investigation which were but little appreciated by Aristotle would further lead him to doubt whether the 
final result would take expression in the only form contemplated by Aristotle-that of a complete classification of natural objects.

\section{iv. The Concrete Individual.}

According to the account in the Metaphysics, the ultimate subject of predicates is no doubt the concrete individual, but not the concrete individual as a mere unit with no characteristic save that of numerical distinctness from all others. Even numerical distinctness presupposes, Aristotle seems to say, a certain common basis. The many are always a plurality of the same kind. To be concrete, to be, therefore, the possible subject of predication, the individual must be conceived of as the numerically distinct member of a class, and, moreover, of a class or kind which itself consists merely of individuals. (Aristotle as frequently employs the term 'the individual' to indicate the infimce species as the numerically distinct members of them. ${ }^{1}$ ) Thus the final existent, from the metaphysical point of view, is the lowest class, that which is marked out by a property or complex of properties peculiar to itself. It is, indeed, implied in Aristotle's account-which is expressed with reference proximately to the world of generation, of alternate coming to be and ceasing to be-that numerical plurality is a necessary aspect of these final classes, fixed types, or natural kinds, and that the numerical plurality is a consequence of the fact that there the single, numerically one, form receives realisation only in the potentially manifold matter.

So far, then, a certain solution of the problem is attained. The basis for a reconciliation in knowledge between the two features - universality and concrete individuality - is so far secured. But the solution has its own difficulties.

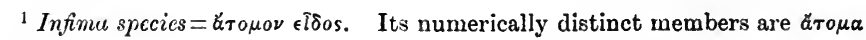
$\tau \hat{\varphi} \epsilon \hat{I} \delta \epsilon \iota$. 
Though expressed proximately with reference to the world of generation, it contains nothing otherwise to limit its generality; and yet it is obvious enough that it is not, without important modification, applicable to either of the other realms of existence contemplated by Aristotle. Perhaps in the intermediate sphere where there is change but perfect uniformity-where change does not imply alternation, the ceasing to be and coming to be of numerically distinct representatives of a type, where therefore type and individual coincide-a little straining might make the expression appropriate.

On the other hand, there is no possibility of applying the suggested solution to the ultimate existence, the Divine nature, in which there is no feature of numerical difference, no feature dependent upon matter, no vicissitude or alternation at all, in which therefore individuality seems altogether wanting. Yet Aristotle for his part seems to regard this perfect activity, this form devoid of matter, as possessing in the highest degree concrete individuality. Were we to proceed from this position, we should be compelled to regard the forms in the world of generation in their abstraction from matter as the true element of existence, and the numerically distinct subjects as a kind of falling away from the perfection of existence peculiar to the form. Such a view is a kind of feeble reproduction of Platonism, and later became the familiar, almost the characteristic, doctrine in the Neo-Platonic metaphysics. That it should thus present itself as a necessary consequence, if we reasoned from the Aristotelian theology, is another of the many indications that the whole Aristotelian metaphysic is a combination of quite incongruous and incoherent parts.

Even, however, from the point of view which at present we have to occupy-namely, the extent to which the solution enables us to lay out a coherent doctrine of knowledge- 
there is something a little doubtful in the conception of the concrete individual as the ultimate species, the fixed type, or natural kind. The numerically distinct individual is in that theory viewed merely as the embodiment or bearer of the specific marks constituting the form or intelligible essence of the natural kind. But experience forces on us the lesson that we do not immediately apprehend numerically distinct individuals as being thus merely the embodiment of an essential intelligible nature. Such apprehension of them is rather the final result of completed insight, that with which we rest contented as the terminus of investigation, not that with which we start. Now Aristotle is far from ignoring this lesson of experience. It is the characteristic feature of his theory of knowledge-what most of all distinguishes it from the Platonic-that it recognises and places in the foreground the development of our apprehension from the crude, vague, imperfect beginning to the final completed insight. Yet, evidently, whoever contemplates such development is bound also to contemplate a type of individual perfectly distinct from that which in the final apprehension is known as the manifestation or expression of the intelligible essence or form. Aristotle beyond all question admits such a distinction; but he nowhere furnishes a satis? ( factory account of the relation between the individuals in the two senses in which they are considered. The term which he employs for the individuals in this new sense, as occurring in the first stage of our progress towards knowledge, itself increases the ambiguity of the whole exposition. It is the term familiar in logic for the particular, to $\kappa a \theta$ ' ध̈ $\kappa a \sigma \tau o \nu$. Our knowledge always starts with 'the particulars ' ${ }^{1}$ and repeatedly Aristotle offers summaries of his view of knowledge which accommodate themselves most readily to what is commonly recognised as the empirical

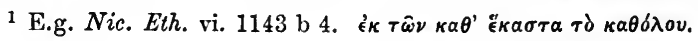


doctrine of knowledge: first, particulars apprehended in sense-perception; then, just in proportion to the degree and scope of retention, the formation of certain crude generalities which furnish the basis for what he calls é $\mu \pi \epsilon \iota \rho i a$ (experience)-meaning by that the kind of generalised knowledge which is adequate to recognising a new specimen of a kind already familiar to us. ${ }^{1}$ It corresponds almost to what we call empirical knowledge; and its crudest form is no doubt the familiar reasoning from particulars to particulars. It does not involve knowledge of the cause or ground ( alı by induction, ${ }^{2}$ we have universal propositions ( $\left.\tau \grave{a} \kappa a \theta o ́ \lambda o v\right)$, which furnish the basis for art and science; and Aristotle seems almost continually to lay down the general position that the universals are known from the particulars, and very commonly to declare that the process by which they are reached is induction. (In nine cases out of ten, Aristotle

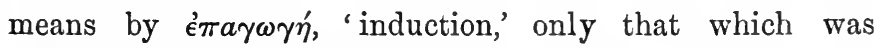
perhaps first designated by that term-the collection of a number of resembling cases, - a collection made, no doubt, with an end in view. The term does not indicate any theory as to the nature of the process whereby from the collected instances the universal is to be gathered. Aristotle indeed seems often to think that if a sufficient number of particulars have been collected, the universal will just be seen by immediate inspection.)

Moreover, Aristotle proceeds with very definite consciousness of the difference between the kind of apprehension of individual things with which we begin and that with which we terminate. There runs all through his theory of knowledge the important distinction first adequately recognised by him and designated the distinction between prior to us

${ }^{1}$ Met. A 980 b 28 ; Anal. Post. ii. 100 a 5.

${ }^{2}$ Anal. Post. ii. 100 b 4. 


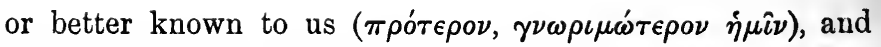
prior in nature or better known in nature ( $\phi \dot{v} \sigma \epsilon \iota)$. 'Relatively better known' and 'absolutely better known' express the distinction fairly well; but its full significance is only to be understood if we add what are also recurring expressions in Aristotle: the particular is the relatively better known, the universal the absolutely better known; and that which is perceptible to the senses is relatively better known, that which is apprehended by reason is absolutely better known. ${ }^{1}$

\section{v. Place of the Syllogistic Forms.}

Aristotle is perfectly in earnest with the conception of development in knowledge, and through that conception is enabled so far to overcome the absoluteness of distinction which in the Platonic view had separated the region of opinion from that of knowledge proper. In accordance with the conception of development Aristotle is ready to maintain that the same general structure, the same fundamental character, which constitutes knowledge, is exhibited, though in very different degrees of completeness, throughout the whole range, from the first collection of particulars up to the final insight into the essential as contrasted with the accidental. Perhaps on this ground we may explain-what would otherwise cause us some difficulty in the Aristotelian logic-the recognition of the common form of the Syllogism as, so to speak, independent of the difference of matter in dialectic and apodictic.

Two different views are possible here. The first view is that syllogism, in its nature and rules, is dependent only on the formal character of the faculty of thinking, which faculty may be employed either about probable matter, in dialectic, or about necessary matter, in apodictic. That the

\footnotetext{
${ }^{1}$ Anal. Post. i. 71 b 33.
} 
syllogism therefore presented itself in both, would be regarded as a consequence of its connexion solely with the subjective conditions of our thinking. This is the point of view familiar in the later developments of Formal Logic. It rests on an interpretation of thinking altogether foreign to Aristotle. Aristotle never makes a distinction between the formal conditions of thinking and the actual constitution of the manifestation of thinking in knowledge. As we saw, even the axiom of contradiction is taken by him to be not merely the expression of a subjective necessity, a law of our way of conceiving of things; for him it primarily had signiticance only in the complex of real knowledge, in which, therefore, thinking and the objects thought of are equally necessary components. Moreover, as we also saw, it is Aristotle's view that from maxims of such generality nothing can be deduced.

The other view regards syllogism as expressing formally, or in respect to its typical manifestation, what is essential in the real process of knowing. Now, according to Aristotle, that process of knowing is always the complex act in which a universal is apprehended as determining the character of the particulars in and through which it is realised. Explicitly stated, the act of knowledge is always syllogistic in its structure; and, therefore, whatever be the nature of the matter within which our thinking moves, whether that matter be probable or necessary, the general structure will be the same, and the probability of the premisses in dialectical reasoning on this very account does not affect the reasoning itself. We proceed to reason about what is merely probable on the assumption that it contains the truth. Our conclusion is drawn as necessary; but, in so far as the hypothesis does not correspond with fact, our conclusion likewise requires qualification. 
vi. Syllogism and Induction.

The distinction which Aristotle draws between the better known relatively and the better known absolutely he connects not only with the contrast between sense-perception and intellection or reason but also with a contrast between syllogism and induction. The contrast between these latter, expressed in the most general way, is that of method of procedure. In syllogism we proceed from that which is prior in nature, better known absolutely; in induction we proceed from what is prior relatively to us. The distinction therefore corresponds to procedure from the universal or from the particular. ${ }^{1}$ Aristotle, however, makes an attempt to exhibit the process of reaching a conclusion by induction in the syllogistic form. His attempt, while throwing some light on the terms of his own doctrine of knowledge, can hardly be said to clear up very successfully the process whereby a conclusion is reached inductively. In the syllogism, whether the premisses be merely accepted for the purpose of argument or be necessary truths, the conclusion is reached through a middle term which constitutes the ground or reason for the assertion there made. The middle term and the conclusion are therefore related in the general way of ground and consequence. Syllogistically, therefore, we proceed from the ground to the consequence. Now the ground is always more universal than the consequence, and is therefore prior in nature though less easily apprehended by us. If induction be in any sense a form of proof, it must likewise involve the relation between consequent and ground; but, as in it we proceed from the relatively better known, the particulars, it is evident that even in form the process must differ from that of the ordinary syllogism. What syllogistically would appear in

1 Top. i. 105 a 13. 
the premisses must in induction appear in the conclusion. Technically, in the inductive argument, or, as Aristotle calls it, the inductive syllogism ( $\dot{o} \dot{\epsilon} \xi \dot{\epsilon} \pi a \gamma \omega \gamma \hat{\eta} s \quad \sigma v \lambda \lambda \sigma \gamma \iota \sigma \mu o^{\prime}$ ), the conclusion attaches the major term to the middle and employs as intermediary what syllogisticaily would be the minor term. ${ }^{1}$

Aristotle indeed at various times indicates that induction never succeeds in establishing a truth of the same kind as presents itself in the premisses of a scientific syllogism, and it is possible that in his account of the inductive syllogism we misunderstand the point at issue by introducing our own more modern interpretation of the terms 'universal' and 'particular.' The particulars which Aristotle has in view in the inductive syllogism are not individual cases from which in our modern interpretation of induction our reasoning begins. They are always species of a genus. The inductive syllogism, as he conceives it, therefore, proceeds by showing that in a variety of species there is a constant co-existence between two marks or attributes, and approaches therefore - on the ground of the assumption that the enumeration of species is exhaustivea universal proposition which would imply that the two attributes thus found constantly co-existing are in the relation of ground and consequent to one another. All that induction proper can achieve is the exhibition, by enumeration of cases, of this constancy of co-existence. It can only lead the mind to the assumption or apprehension of an essential intelligible relation corresponding to what is constantly exhibited in conjunction as a matter of fact.

Quite in accordance with this, as we shall see, is Aristotle's mode of defining the mental process or act by which principles are extracted from the enumeration of instances. Aristotle always introduces as supervening upon the in-

${ }^{1}$ Anal. Pr. ii. 68 b 15. 
ductive enumeration the rather undefined act of intellectual insight, reason, or intuition ( $\nu$ ov $s$ ). It would therefore be strictly correct to say that, according to Aristotle, the process of apprehending an essential necessary truth by enumeration of instances is not completed even when we either know or assume that the enumeration is exhaustive. There is still required the peculiar unique act of intellectual insight, the function of which, as one may put it, is to transform mere conjunction of fact into rational connexion.

\section{vii. The Ultimate Data of Knowledge.}

In the demonstrative syllogism, that is, in the process of reasoning as it appears in true knowledge, the fundamental characteristic is to be found in the kind of premisses from which the start is made. All scientific knowledge, and any syllogism which is employed in demonstration, rests on premisses which are true, prior, immediate, better known in themselves, grounds of the conclusion drawn from them, and therefore peculiar or specific, that is, of the same kind as the conclusion drawn. ${ }^{1}$ It is assumed therefore that, in knowledge strictly so-called, there is a regular connexion whereby thought may proceed, in respect to each definite object of inquiry, from fundamental data, themselves indemonstrable, to conclusions in which are gradually unfolded all that belongs to the particular object by reason of its own nature. There cannot be in proof, in knowledge strictly so called, an infinite regress; nor is it possible that proof should be circular in form. ${ }^{2}$ There must therefore be accepted as constituting the basis of all knowledge certain indemonstrable truths, not common axioms but

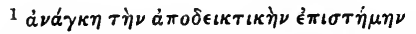

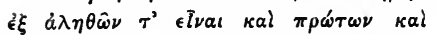

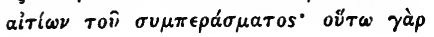

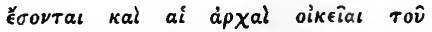

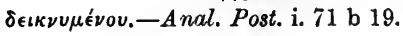

${ }^{2}$ Anal. Post. i. c. 3.
} 
peculiar principles, statements therefore of what is essential in the nature of the object known.

The data, then, in all genuine knowledge are the exposition of what constitutes the essential nature of the object known. The essential nature we have already seen to be in its own way universal. The object known, that which is the material about which demonstration turns, is not the abstract individual but the concrete individual, the manifestation in numerically distinct units of a common essence or fixed nature. All demonstration concerns itself with some kind of existent, and must therefore start from the expressed, explicitly unfolded, nature of that kind. If there is true knowledge with respect to any object in nature (and knowledge, be it remembered, implies universality and necessity in the propositions composing it), such knowledge must consist in a series of statements all of which can be shown to follow from the given essence or fixed nature of the object known. Demonstrative knowledge, science, is thus contemplated as occupying the point of view which is not nearest to us, the point of view, as we should put it, of absolute intelligence rather than that which is occupied by the individual observer. From that point of view, in Aristotle's system, the essence or intelligible nature, that which is expressed in the complete notion or definition of the object, is the basis, the foundation, for all reasoning. Whatever is attached to the object necessarily and universally must be attached to it because, such being the essence or nature of the object, the predicates must be so-and-so.

It might appear, now, that from this absolute point of view there should be, and must be, included in the complete notion of the object all that can necessarily and universally be asserted of it. This is not, however, Aristotle's conception of the connectedness that holds good in the world of 
the intelligible. The notion of the thing consists only of what is peculiar to the one type of object; formally, as we have seen, it is the complex of differences marking out a lowest species. Aristotle, then, conceives of a natural gradation of predicates some of which belong to the species, the unit of knowledge, by reason of its nature, but which do not constitute part of that nature. It appears to me extraordinarily difficult to maintain this point of view, and it is undoubtedly one of the perplexities in Aristotle's general view of things that the connexion between the specific individual character of the units of knowledge and more general predicates is in no way cleared up.

The subject of demonstration must therefore, as known, be intelligible; and the indemonstrable, immediate, primary data from which demonstration starts consist merely in the statement of this intelligible essence or notion of the subject of demonstration. The attributes possessed by a subject by reason of its nature are those which follow immediately from that nature, which are, in other words, implications already contained in its essential notion. From this point of view it seems clear that Aristotle is approaching a view of knowledge which can hardly ever be evaded when the position is taken of absolute insight,- - the view that knowledge consists merely in the analysis of ultimate notions. The only qualification which Aristotle supplies is contained in that contrast which he makes, but which he fails to utilise, between the points of view of absolute knowledge and of the individual observer. Actually his theory of demonstration holds a position of unstable equilibrium between the two conceptions of knowledge,- as it presents itself to completed insight, and as it is gradually built up in the mind of the individual observer who starts with the particular, with the things of sense, not with the universal and rational. 


\section{viii. The Immediate Object of Apprehension.}

Relatively to us, then, the particulars, the individuals, are the nearer and the better known. Such particulars are in the first place apprehended by sense-perception. Keeping in the background for the moment the inquiry as to the psychological character of this sense-perception, we may ask, What is the logical aspect of the individual thus taken to constitute relatively to us the immediate object of apprehension? Much of the confusion in Aristotle's theory of knowledge is due to the want of distinctions which might quite well be introduced without departing from his point of view. Perhaps naturally he tends too much to take for granted that the transition from the individual immediately apprehended to the essential in which the determining nature, or form, of the individual is contained, is simple and almost forced on us by inspection of a number of particulars. Just as he overlooks in his logical analysis the real difficulties of the inductive procedure, so more generally he takes it for granted that a collection of the isolated particulars of sense will enable us at once to become aware of the essence involved in them.

Only in one direction does he indicate a sense of the difficulties which must surround such a transition. It is an important part of his general view of knowledge that what is immediately presented is in a certain way the vague, confused, unanalysed. From this point of view the immediately apprehended might indeed continue to be designated for one reason the 'individual,' but it would be distinguished in its logical character from the individual which is known in its particularity only as correlated with the essence or universal form, and which is therefore rather the final than the initial term in knowledge.

It can hardly be said, however, that on the line of logical 
treatment Aristotle successfully introduces this more fruitful conception of the immediate object relatively to us. We shall see later the appearance of a somewhat similar distinction in the account given of the psychological process.

ix. Induction and the Universal.

The transition from the particulars of sense to the apprehension of the essence or intelligible nature is always by Aristotle designated 'induction,' and repeatedly in words he seems to say that our knowledge of these generals, universals, intelligible forms, is reached by induction;-but it must be remembered that these terms have a meaning in Aristotle's system very different from the meaning they have in our modern theories of knowledge. Indeed, the necessity of interpreting them in accordance with the peculiarity of Aristotle's system is forced on us by the occurrence side by side with them, in Aristotle's treatment of knowledge, of the definite and repeated statement that induction never establishes universal propositions. Obviously, then, the description of the attainment of first truths from induction means something special in Aristotle's doctrine. We should quite misconceive the whole character of it if we put out of sight the fundamental article in Aristotle's general scheme of things, that which gives its special colouring to all his metaphysical and logical system.

Aristotle means by the universals which are reached from induction the ultimate determining characters of the primary subjects of all predication. Given, as it were, the fixed types of concrete existents, then the end to which our, at first, imperfect apprehension of their features may gradually be led is equally direct immediate apprehension of these determining marks, an insight into the intelligible notions or essences. Such ultimate characters are not themselves capable of proof. They cannot be demonstrated; much 
less can they be established by induction, in the logical sense of that term. The function of induction is wholly relative. The collection of instances makes it possible for intellect to become aware of its appropriate objects, the simple, immediate, primary data; and the all-important metaphysical consideration that these data, the intelligible essences, are realised only in the material of concrete fact renders necessary the collection of instances, which is the business of induction. Neither instances per se nor intelligible form per se, neither sense-perception per se nor intellect-per se, would yield the knowledge of the real essential characters determining the fixed types of concrete existence. Thus then the apprehension of primary truths from induction means with Aristotle that, so soon as a sufficient collection of empirical material has been made, it becomes possible for the function of intellect to be called into exercise, it becomes possible directly, immediately, intuitively, to seize upon the universal or intelligible essence.

Thus Aristotle almost in the same sentence can speak of induction and of intellect as being the source of first principles, of primary data.

The difficulties inherent in Aristotle's view are not finally overcome by this assignment to induction and intuition, perception and reason, of functions equally necessary in building up knowledge. It still remains a puzzle, first, in what consists the element of imperfect apprehension which is allowed to the inductive collection of particular cases, and, secondly, in what precisely consists the activity of intellect whereby intuition of first principles is reached?

\section{x. Intuition and Discursive Thought.}

Leaving this for the moment, I draw attention to a further perplexity which besets Aristotle's doctrine of knowledge. Demonstration, as we have seen, proceeds from first prin- 
ciples which are themselves necessary to a conclusion which is necessary; and in accordance with this a distinction of an ultimate kind is made between primary data and conclusions from them. The intermediate process is obviously the realm within which the logical processes of judging and inferring find their place; and evidently the definite view that there must be first principles, that there cannot be an infinite regress of proof, nor an infinite number of middle terms between the first principles and the conclusions deducible from them-these are all not so much results established on independent foundations as explications of the fundamental view that absolute knowledge consists in apprehension of the determining intelligible character of the types of existence, of the ultimate subjects of predication.

But if this be so, then it would appear as though our mode of apprehending the primary data must be quite distinct from the processes in the intermediate stage of demonstration-assuming for the moment that the distinction here implied can be maintained. What can be demonstrated of the individual type is no doubt apprehended by us through the intermediate processes of judging and reasoning, but the primary data cannot so be apprehended. So we must introduce-and Aristotle does introduce, though not very explicitly - a distinction which we may fix in language by the terms 'intuition' and 'thought' or 'elaboration.' The primary data-not, be it remembered, merely such common axioms as the law of contradiction, but the content of the peculiar axioms, that is, the definite determining marks of the essence,-these are immediately grasped; and with them the opposition fundamental to thought or elaboration has no place. Our attitude to them is not that of judging their truth or falsity, but that of having them or not having

$$
1 \text { Met. } \Theta \text { c. } 10 .
$$


them. We either possess or do not possess the primary data.

Intuition, then, is not only distinct from the discursive elaborative act of thinking as a process; it is distinct in respect of the kind of object with which it is concerned, the kind of content that is apprehended. The definition, which is the explicit statement of the content thus apprehended by intuition, is therefore only in form a judgment. Strictly speaking, there is not in it the distinction which in discursive thought appears as that between subject and predicate. The element corresponding to judgment in ordinary definitions lies really, in Aristotle's view, outside the definition proper, and is of the nature of an assumption or postulate. We may, for example, in certain cases assume that something exists which has the defined marks summed up in our notion of it. This assumption lies outside of the definition proper.

It is evident that in this Aristotle is introducing a rather doubtful distinction. In definitions strictly so called there can be no question about existence. In them abstract essence and its realisation in concrete form flow together and are indistinguishable. The moment we recognise that there may be definitions in respect to which the postulate may or may not be made that the defined object exists, we have passed from the region of intuition, of absolute knowledge, to that of relative progressive apprehension: we are occupying the point of view of the finite subject who is gradually making his way towards completed insight.

Thus, then, knowledge exhibits a further mysterious separation. We have intuition wholly distinct from the discursive operation whereby the ultimate subjects are connected with the last predicates in which their nature is unfolded, and both again are distinguished from the less developed func- 
tions of mind based on, growing from, sense-perception. It remains to be seen whether in the detailed psychology of these processes any further light is thrown on the rather perplexing question of their relation to one another or on their combination in the intellectual life of one and the same subject. 


\section{CHAPTER IV}

\section{PSYCHOLOGY}

\section{i. The General Nature of Soul.}

THE psychology of Aristotle begins with a careful and elaborate determination of the notion or fundamental nature of the soul. Proceeding from a critical survey of antecedent views, mainly those of the Platonic philosophy, ${ }_{1}^{1}$ Aristotle brings to bear on the problem of determining the nature of the soul the fundamental metaphysical notions of his own system. These he combines and applies in his ordinary fashion, with due attention to empirical detail, or, at least, to such broad characteristics of empirical fact as seem to him of decisive significance in the classification of objects of nature. Thus he accepts as an empirical basis for his treatment the important distinction in the concrete realm of natural things between those that possess life and those that do not. ${ }^{2}$ With the help of this distinction he at once effects the first limitation of the notion of soul. It seems to him inappropriate to extend the scope of soul beyond the realm of living beings: it is, in fact, one main ground of his adverse criticism of the Platonic psychology that it had extended the notion of soul to the cosmos at large, and had therefore assigned to soul certain functions necessary no doubt in respect to the cosmos, but incompatible with

\footnotetext{
${ }^{1}$ De $A n$. i. cc. 2-5.
}

${ }^{2} D e A n$. ii. 412 a 13. 
that which experience shows to be involved in the operations of the soul. Movement, for example, is no doubt so obvious a feature of the cosmos that, if the soul be taken as the animating principle of the whole, it must have assigned to it the function of local movement. Plato accordingly had identified the revolutions of the heavenly bodies with psychical changes, - an identification which seemed to Aristotle wholly incompatible with what was likewise assigned to soul as a function-namely, thinking. ${ }^{1}$

Soul, then, presents itself most obviously within the range of natural bodies that possess life; and it may be said to be coextensive with life. It is an obvious fact of experience that what are admittedly functions of the soul are exhibited only in conjunction with life in its simplest sense as the function of nutrition. Only the living being shows the power of perception, desire, thinking. It was natural, then, to assume some intimate connection between the principle through which explanation of life is to be given and the soul. Indeed, if the functions which specially characterise the realm of living beings be enumerated, they form a kind of scale-understanding, sense-perception, movement of the body, and that kind of change which may be called internal movement, involved in the assimilation of nutriment, and in the growth and decrease of the organic body. These characterise the various forms of living being. Taken together, they constitute a kind of empirical survey of the functions of the soul. Soul, on the other hand, is just the vital principle-the principle in virtue of which living beings perform these functions.

From this empirical foundation Aristotle proceeds, with the help of his fundamental metaphysical ideas, to deter-

I [At the same time it must be kept is the cause of the uniform cosmic in mind that in Aristotle's own sys. movements.]

tem vov̂s, which is in some sense soul, 
mine more accurately the essential intelligible characterthe nature-of the soul. Just as the living being must be said to exist, to have a place among concrete realities, so in some way it must be said that the soul exists, has a place in concrete reality. But what place? Concrete reality itself exhibits always a distinction-a notional or conceptual distinction, one made by thought-corresponding, no doubt, to some difference of aspect, but not to be confused with a separation into parts or an isolation of independent wholes. It is the familiar distinction between matter and form. ${ }^{1}$ The animated concrete existent is obviously a kind of compound - a compound, we may assume therefore, in its general character resembling that in which the constituents are matter and form. The body in this compound is matter; the soul is form. ${ }^{2}$ But, as we have seen, this distinction of matter and form is identical with, is but an imperfect expression of, the distinction between the potential and the actual. ${ }^{3}$ The body, in so far as it is the body of the animated being, is necessarily organised, is a system of which the parts are subordinate to the whole. ${ }^{4}$ Such an organised body has potentially life; is adapted, therefore, by its structure to the discharge of certain functions. Our distinction, of course, is only in thought; it is not actually the case that the body, although we call it an organised whole, is potentially possessed of life in its own nature.

Only when the organised body is in the condition to discharge the functions for which its structure adapts it, can it be said, strictly speaking, to be living. No doubt a finer distinction must here be introduced. We are not entitled to say that the potential is potential only when its powers are in active exercise. There is conceivable and, as experience shows, real, a stage in which the potential is
1 De An. ii. 412 a 7.
3 De An. ii. 412 a 21.
${ }^{2}$ De An. ii. 412 a 16.
4 De An. ii. 412 a 28. 
capable of exercising its functions though not at the moment in full activity, just as, for example, a rational being would be said to have knowledge even though at the moment he may not actually be contemplating this or that object of knowledge. ${ }^{1}$ This finer distinction Aristotle fixes by the technical terms First and Subsequent Realisation ( $\left.\pi \rho \omega \dot{\tau} \tau \eta, \delta \epsilon v \tau \dot{\epsilon} \rho a, \dot{e} \nu \tau \epsilon \lambda \epsilon^{\prime} \chi \epsilon \iota a\right)$ of Potentiality.

If the body, as organised, potentially possesses life, then life in its varied functions of nutrition, bodily movement, sense-perception, understanding, will be the active exercise, the realisation, of that potentiality. Soul taken generally, therefore, may be defined as the realisation, the actualisation, or rather, more strictly, the first actualisation of that life which the organised body possesses in potentiality. ${ }^{2}$

Thus, then, if we put it in slightly more modern fashion, the concrete subject about which all predications which concern activities of mind are made is the living being, the animated body. As a concrete subject the living being, the animated body, has always the twofold aspect. It is not a mere composite of soul and body, nor can these be really independent of one another. ${ }^{3}$ The complete fact is the life, the expression in activity of the nature of this concrete subject, and that nature may be described in either of two ways: (1) by enumerating the potentialities of the body, or (2) by enumerating the functions discharged in the course of its existence. Soul, therefore, is the intelligible essence, the form of the organised living body; and what is said of soul in general may equally be said with respect to its separable functions. Each of them is similarly the realisation, the actuality, of what some part, some subordinate system, of the animated body is potentially. ${ }^{4}$ Sense-perception, for example, taken as a whole, is the actualisation

I De An. ii. 412 a 22.

2 De $A$ n. ii. 412 a 27.
3 De An. ii. 412 b 6.

4 De An. ii. 412 b 17. 
of what the perceptive system is potentially. Seeing is the actualisation of what the organ of vision is potentially, and in strictness the concrete subject about which predicates relating to vision may be made is here neither the eye taken in abstraction nor the activity of seeing taken in abstraction, but the seeing eye.

The functions of the soul, like soul itself, are to be regarded in the closest relation to the body. In all of them, in some more obviously than others, the operation is one in which soul and body are equally concerned. Just as, then, we find in experience a gradation of organised bodies, so we find a gradation in the forms of psychical activity which they exhibit; and, generally speaking, we may contemplate this gradation as ascending from what is the minimum necessary to constitute animal life, and the several forms as holding to one another the general relation of potential and actual. Aristotle is no doubt influenced here largely by the broad empirical classification of living beings into plants, animals, men. Such classification enables him to make the first grouping of the stages of soul, a grouping not always made in uniform fashion, but of which the most common form is the following:-

(1) Fundamental to life as such are the functions of nutrition and generation, necessary in order $(a)$ to preserve the individual, and $(b)$ to continue the species or natural kind-nutrition being the sine qua non. ${ }^{1}$

(2) Sense-perception ${ }^{2}$ characterises animal life as distinct from vegetable. With sense-perception there go as accompaniments or necessary consequents, on the one hand, what gives rise to movement ( $\kappa i \nu \eta \sigma \iota s)$ - namely, feelings of

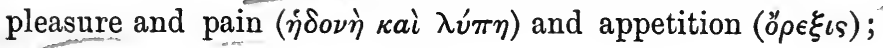

\footnotetext{
1 De An. ii. 413 a 31. The 'soul' ( $\mu$ ópเov). or 'part' of soul corresponding to this ${ }_{2}^{2} \mathrm{De} A n$. ii. $413 \mathrm{~b} 2 . \quad \psi v \chi \grave{\eta}$ ai $\sigma$.

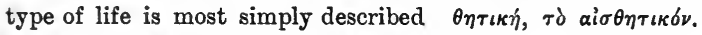

as $\psi v \chi \grave{\eta} \theta \rho \epsilon \pi \tau \iota \kappa \dot{\eta}$ or $\tau \dot{\partial} \theta \rho \in \pi \tau \iota \kappa o ́ \nu$ 
and, on the other, what lies at the foundation of all

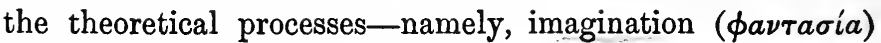
and memory $\left(\mu \nu \eta^{\prime} \mu \eta\right)$. Sense-perception, again, exhibits within its own range a gradation; and Aristotle naturally adopts here, as throughout, the teleological view. The fundamental essential sense which all animal life exhibits is touch $\left(\dot{a} \phi \eta^{\prime}\right){ }^{1}$ and next-and equally necessary in view of the function of nutrition-taste ( $\gamma \epsilon \hat{v} \sigma \iota \varsigma)$, which is a kind of touch. ${ }^{2}$ Some animal forms seem to have little more than these rudimentary functions. Others exhibit the

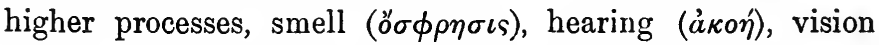
(ö $\psi \iota \varsigma)$. Not all animals exhibit the consequences of senseperception which lie at the foundation of understanding. In most of them images, the relics of sensation, may exist; in some of them these cohere and give rise to memory

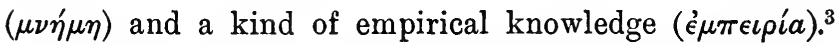

(3) In man the basis of sense-perception supports the higher functions of reminiscence ( $\dot{a} \nu a ́ \mu \nu \eta \sigma \iota \varsigma)$, judgment ( $\delta \delta^{\prime} \xi a$ ), and reasoning; while in man, and in man only, there appears also reason or intellect ( $\nu$ ovs). ${ }^{4}$

ii. The Sensitive Soul.

Under the general title Sensitive Soul ( $\left.\psi v \chi \grave{\eta} a i \sigma \theta \eta \tau \iota \kappa)^{\prime}\right)$ Aristotle groups together a number of activities of which sense-perception is the basis and the most characteristic. It is peculiar to animal life to possess sense-perception, and concrete animals possess sense-perception in different amount and in different degree. All of them possess the

1 De $A n$. ii. 413 b 4.

2 De An. iii. 434 b 21.

3 Met. A, 980 a 30 ; Anal. Post. ii. 99 b 36 .

${ }_{4}$ Man is distinguished from the

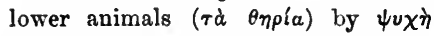

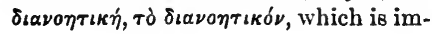

plied in $\pi \rho \hat{\alpha} \xi \iota s$, as distinct from $\kappa l \nu \eta \sigma \iota s$. ŏ $\rho \epsilon \xi$ is is a genus which includes two

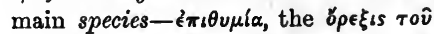
$\dot{\eta} \delta$ tos, manifested, in the case of the lower animals, in $\kappa i \nu \eta \sigma \iota s$, and Bou $\lambda \eta \sigma \iota s$, the ${ }^{\circ} \rho \in \xi \xi s$ rov $a \gamma \alpha \theta 0 \hat{v}$, manifested in $\pi \rho \hat{a} \xi$ เs. 
fundamental sense of touch. In the higher animals, and in man, there is the complete apparatus of the five senses, and the perceptions of these senses Aristotle treats from a number of different points of view, some of them of no great importance.

Of no importance, perhaps rather misleading; is the attempt to demonstrate that the apparatus of sense in man is exhaustive, that no qualities of the sensible are not correlated with organs or functions of sense in man. ${ }^{1}$

In the second place, however, importance belongs to the attempt $^{2}$ to regard the functions of sense from what may be called the teleological point of view-that is, to view them systematically as contributing towards the complete existence, the self-preservation and progress, of the animal life. This is undoubtedly a fruitful point of view; but perhaps it was not possible for Aristotle to work it out satisfactorily, and this for two reasons: (1) the special limitation which always attaches to his view of end or purpose, invariably a preconceived or predetermined end; and (2) the very scanty supply of empirical details at his disposal.

In the third place, Aristotle proceeds to deal with the senses as furnishing knowledge of objects which without them would remain unknown. Here he advances the important psychological doctrine that each sense apprehends its own specific object; and with some detail he works out an account of the specific sensible for each of the several functions of sense-perception. ${ }^{3}$

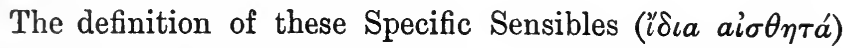
naturally suggests a distinction of them from what are

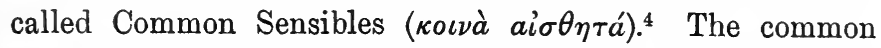
sensibles - motion, rest, magnitude, figure, number (with

1 De An. iii. 424 b $22-425$ a 13.

${ }^{2}$ De An. iii. cc. 12, 13.

3 De An. ii. cc. 7-11.

4 De An. ii. 418 a 10. 
which is sometimes included unity)-are said in a general way to be apprehended by all the senses, although in fact Aristotle refers for the most part only to sight and touch as alike perceptive of magnitude and figure, with which motion is included. It is difficult to determine what weight is to be assigned to his statement that, as each sense in each moment of perception apprehends its own specific sensible, it apprehends it as a unit, and that unity therefore (and therewith, no doubt, would go number) is a common sensible in the strict acceptation, as being involved in every operation of sense-perception. ${ }^{1}$

There is something perplexing in Aristotle's account of these common sensibles. Speaking of sense-perception generally, ${ }^{2}$ he distinguishes three objects, as they are commonly called: (1) the appropriate or specific sensible, (2) the common sensible, and (3) that which is perceived per

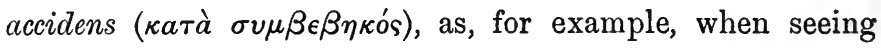
a white object I am said to perceive the individual-son of Diares. Now, Aristotle insists that the individual object-by which I take it he means the concrete existent -is not apprehended by sense-perception in one indivisible moment. The concrete existence is perceived per accidens. As we should say, what is perceived by sense suggests the complex characterising the concrete object.

As opposed to this third acceptation of the perceived, the common sensibles are said to be perceived, but not per accidens. 'Accident,' unfortunately, is a term which plays a most ambiguous part in Aristotle, and it is therefore not at all surprising to find him in another connexion expressly saying that the common sensibles are perceived per accidens. ${ }^{3}$

1 De An. iii. 425 a 20.

2 De $A n$. ii. 418 a 6.

3 De $A$ n. iii. 425 a 15 . Here ката̀

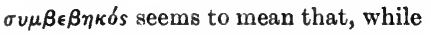
an $\{\delta เ o \nu$ ai $\sigma \theta \eta \tau \delta \nu$ can be perceived

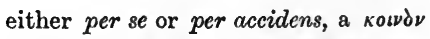
ai $\sigma \theta \eta \tau \delta \nu$ is always perceived secondarily-i.e., along with an $1 \delta ı \nu$ ai $\sigma \theta \eta \tau o ́ \nu$, which as such is the primary object of perception. 
Evidently, however, he desires to make a distinction; and this raises the question, therefore, what is the difference between the suggestion, on occasion of one sense-perception, of other sensibles belonging to other senses, and the process which takes place when, as in the case of sight, a specific sensible and a common sensible are apprehended together? So far Aristotle's answer is clear enough. There is not a special sense for the common sensibles. The common sensible-magnitude-is not merely united with colour, the specific sensible, in vision, as (say) yellow and bitter are united together in our perception of gall; there is no special organ for the common sensibles. What explanation, then, is to be given of them?

Aristotle undoubtedly recognises alongside of, or rather in, the special senses a common sensibility or common sense to which he assigns certain definite functions-namely, (1) making us aware that we are perceiving, ${ }^{1}$ and (2) enabling us to distinguish between the perceptions of the several senses. $^{2}$ Hence it was not unnatural to assume that he assigned to this common sense a third function, that of apprehending the common sensibles. At the same time, he seems expressly to insist that there is no special sense the objects of which are the common sensibles. We must suppose him, then, to mean that the recognition of the common sensibles, and the discrimination of them from the specific with which they are conjoined, is somehow a manifestation of the other functions assigned to common sense; and in fact (though it is expressed in a somewhat confused way) this seems to be his theory. There is a unity in the sensitive soul which is not destroyed by the multiplicity of the specific senses. The function of the sentient soul is by no means exhausted in the operations of the several senses. Sense taken in its entirety involves not only

1 De An. iii. 425 b 12-25.

2 De An. iii. 426 b 12. 
apprehension of the specific sensible, but also, as we should express it, consciousness of the act of perceiving and recognition of differences in the content of what is perceived. It is to be said that Aristotle does not offer in detail any explanation of how these functions of the sentient soul in its entirety are realised; and not much is to be made of that part of his theory in which the organ of the common uniting sense is defined as the heart. ${ }^{1}$ It will be observed, however, that, according to his general acceptation of senseperception, it is not to be represented as a merely passive receptivity of impressions. Indeed, Aristotle specifically calls it an innate or natural discriminative faculty, ${ }^{2}$ and he is always ready to insist that discrimination implies, requires for its possibility, a certain unity. ${ }^{3}$ The sentient soul cannot distinguish unless it is itself the all-embracing whole within which the differences are exhibited.

Aristotle proceeds to apply to the operation of senseperception those general notions by which he always seeks to define a faculty and its realisation. ${ }^{4}$

(Sense-perception is characterised as a power of apprehending the forms of sensible objects without their matter; thereby, indeed, a kind of distinction is made between the sensitive and the nutritive functions. ${ }^{5}$ What constitutes sense-perception is just this power of receiving the sensible form without the matter of the sense-object perceived; and an organ of sense is whatsoever portion of the animal body is so capable of receiving the form without the matter. If this is the case, then the process of sense-perception involves a certain change in the percipient and in the organ whereby perception comes about. ${ }^{6}$ But the change is not of the kind

1 De Juvent. 469 a 10 , etc.

2 Anal. Post. ii. 99 b 35.

3 De An. iii. 426 b 20.
4 De An. ii. cc. 5, 12, iii. cc. $1,2$.

5 De $A$ n. ii. c. 12.

6 De An. ii. 416 b 33 . 


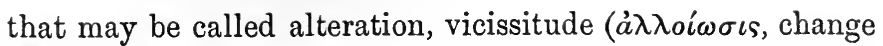
of quality); it is not the transition from the negative or privative to the positive. ${ }^{1}$ The animal confronts the world of sense-material with capacities conferred on it through the process of generation. ${ }^{2}$ The change, then, which occurs in sense-perception is to be interpreted, not as change in its proper acceptation, but as the realisation of a potentiality. By the impression of the object on the sentient soul the sentient soul no doubt nndergoes something ( $\pi a ́ \sigma \chi \epsilon \iota \tau \iota)$, is in one respect passively affected, but such passive affection is only one side of the whole process, which in its more important aspect is the actualisation of what the sentient soul is potentially. Seeing, for example, may be expressed as the passive affection of the faculty and organ of vision by the visible; but more correctly it would be described as the transition into full activity of what that faculty and organ involved potentially. Seeing as an actuality exists only when by the appropriate impression the potentiality of vision is called into, and continues in, exercise. A very similar distinction requires to be drawn with respect to the objects of sense-perception. In their case also what they are potentially is fully realised only in and through the process of sense-perception. ${ }^{3}$ Only in the actual exercise of vision can sight and the visible be said to be fully realised. Thus the actual process of perception, the activity of the senses under their appropriate impressions, may be described as the realisation of the relation, adaptation, to each other of sense and object of sense, as therefore the completion of their respective functions in the scheme of existence.

The common sensibles, as we have seen, are not by

1 De $A$ n. ii. 417 b 6.

3 De An. iii. 425 b 26.

2 De An. ii. 417 b 16. 
Aristotle assigned as objects to one sense which could be placed alongside of the others. Apparently, then, each sense, in the exercise of its function, yields at once the specific and the common sensible. The special senses, therefore, are in some way to be conceived of as manifestations of the single uniting activity of sense as such. Nevertheless, in the process of sense we discriminate the common from the specific sensible, and Aristotle seems to indicate, but rather obscurely, a teleological ground for this discrimination. ${ }^{1}$

Even with this explanation it still remains very obscure in what special relation the separate functions of sense stand to common sensibility. Some additional light is got from consideration of the other functions assigned by Aristotle to the common sensibility.

"In addition to actually seeing and hearing we perceive also that we see and that we hear. We must then perceive that we see either by means of sight itself or by some other sense. In the latter case, however, there will be one and the same sense relating to sight and to the colour which is its object: and thus there must either be two senses concerned with one and the same object or the sense must itself possess the perception of itself. Further, if the sense supposed to perceive sight were different from sight itself, this would either involve another sense ad infinitum, or there must at last be a sense which perceives its own action. We must therefore ascribe this faculty of self-perception to the original sense itself." 2

The sense, then, in some way perceives its own activity, and Aristotle's special ground for this conclusion is worth noticing. Practically it comes to this. Take the case of vision with white as the object. The object 'white,' the realised specific sensible, is not a separate fact existing

${ }^{1}$ De An. iii. 425 b 4-11.

${ }^{2}$ De An. iii. 425 b 12-17. 
independently of the realised activity of vision. As we should put it in modern phraseology, the content of a senseapprehension is not a fact separate from the apprehension itself ; therefore, says Aristotle, if it were a separate sense which apprehended this act of vision, the supposed sense, which, ex hypothesi, is not vision, must also apprehend the white colour which is the content of the act of senseapprehension. But this is impossible. A faculty is defined by its object, so that there cannot be two faculties corresponding to the same object. Hence it is vision only that is capable of the apprehension of vision.

On this account, then, Aristotle rejects the needless duplication of function in what we should call that expression of consciousness-sense-perception. (The act of sense-perception is in its own nature a mode of consciousness) and, therefore, in Aristotle's language, each sense may be said to perceive itself. But now, just in so far as each sense perceives itself, it presents a common nature, distinguishable from what is specific in its operation, and this common aspect or element Aristotle connects with the common sense or uniting function of sensibility in the soul. The work of sense is not completed when what concerns the specific sensible only is taken into account. (Therefore the special senses must all be regarded as in some way definite expressions of a common uniting sense, It is the unity of the sensitive soul that lies at the foundation of this common feature, this element of consciousness in the special forms of sense-perception.

The same foundation in a common uniting centre is implied in another characteristic feature of sense-perceptionthe discrimination of sensibles from one another. In the De Anima ${ }^{1}$ and in the minor psychological tractates ${ }^{2}$ Aristotle deals separately with two prominent types of this discrimination-in the former mainly with the discrimination 
of heterogeneous sensations, ${ }^{1}$ in the latter mainly with the discrimination of sensations belonging to one and the same kind. ${ }^{2}$ The general solution, however, applies in the same way to both. What is necessary in order to render possible such a discrimination is a combination of unity and plurality in one and the same function; for, as Aristotle points out, recognition of a difference implies unity in the subject recognising it. Were the subject of the two different impressions not single there would be no more possibility of recognising the difference, of effecting a comparison, than in the case in which the impressions are produced in different subjects.

At the same time, it is not less necessary that the said uniting single subject should in some way exhibit plurality; for, otherwise, the difference which is to be recognised would become unintelligible. The subject, then, must be at once one and many, indivisible and divisible, uniting and distinguishing. Aristotle attempts, without much success, to apply to this apparent puzzle his general categories of

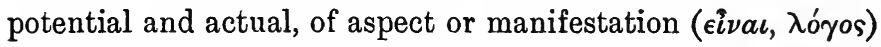

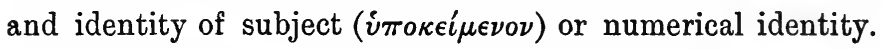
In manifestation the activity of the central sense is divisible, plural, many, capable of application to this and that; but, at the same time, it is always numerically one, indivisible, and acts as a unit, even with respect to the point of time at which it operates. It is not an additional sense which has for its specific object differences, whether of quality, number, or time, but the fundamental central activity of sense-perception, manifold in its operation, but also operating always as a unit at one and the same time.

This discrimination which is assigned to the central sense is evidently involved in the apprehension of the difference between the common sensibles and the specific sensibles;

\footnotetext{
${ }^{1}$ E.g., of the white from the sweet. ${ }^{2}$ E.g., of the white from the black.
} 
and it would seem, therefore, on this ground also, needless to regard the common sensibles as being in any special way the objects of the common sense,-an expression, indeed, which can hardly be employed without the implication which Aristotle rejects, that these common qualities are perceived by a sense distinct from the special senses. It is to be admitted, at the same time, that the more we insist on this the more evident we make the lacuna in Aristotle's account of the common sensibles; for no explanation is offered of the way in which they are actually perceived.

iii. Intermediates between Sense-perception and Reason.

In the De Anima Aristotle treats rather briefly and imperfectly of certain intermediates between sense-perception and reason. A certain supplement to this account is contained in the tractates on Memory and Reminiscence, on Sleep and Dreams, and the others making up the Parva Naturalia; but even with this supplement it is very difficult both to define the several types of intermediates and to assign their relation to sentience on the one hand and to reason on the other. The simplest of the intermediates, that which lies nearest to sense-perception, is what Aristotle

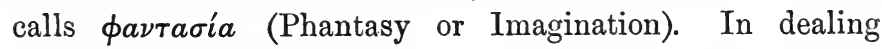
with this in the De Anima ${ }^{1}$ he proceeds mainly by the method of distinction, pointing out that imagination in the strict sense is not identical either with sense-perception or with variously-named functions of understanding. His nomenclature is far from scientific. He enumerates among

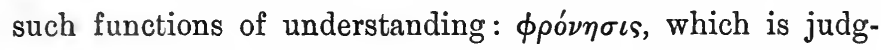
ment exercised about practical matters; $\delta \delta^{\prime} \xi a$, which is opinion, and which naturally must find expression in some assertion, explicit or implicit; and what he calls $i \pi o ́ \lambda \eta \psi \iota \xi-$ a puzzling and baffling term, corresponding to our use of the

${ }^{1}$ De An. iii. c. 3. 
word judgment in its generic sense. It is 'holding for true, taking for granted.' It is, as one may say, an assertion made without the claim that it is so grounded as to be beyond reach of question. It is possible, too, that Aristotle desires to introduce another function which might have assigned to it the specific term Sıávoıa, and which would mean rather a judgment based on grounds. From all of these he dis-

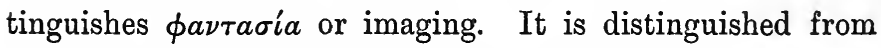
sense-perception on the ground that the image may present itself without any stimulation of sense; also on the ground that imaging does not always seem to accompany senseperception, there being, he thinks, animals which have sense-perception and imagination, while others have only sense-perception; and, further, on the rather ambiguous ground that sense-perceptions are always true, whereas the pictures of imagination may be to a great extent false. ${ }^{1}$ From the various functions of understanding imagination is discriminated on the broad ground that it involves no assertion, not even a combination of ideas such as is involved in assertion. ${ }^{2}$ Thus, then, negatively, the image, the $\phi a ́ \nu \tau a \sigma \mu a$, is defined by its singleness of character. ${ }^{3}$

But in the minor tractates Aristotle supplies some more positive characteristics; and it would seem as though his view might be expressed in the following way. (The stimulation of the sense-organ involves a certain alteration of the state of the organ itself, which in actual sense-perception is propagated to the central organ. For the complete perfect act of sense such co-operation of the central organ is necessary. The stimulated condition does not necessarily

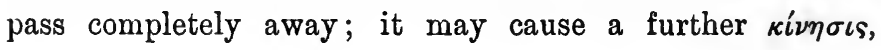

1 De $A$ n. iii. 428 a 5 .

2 De An. iii. 428 a 18.

3 It corresponds very much to what Dugald Stewart named Conception, by which he meant the mere reproduction in idea of what had been given in actual perception. 
though possibly impeded by many circumstances, partly physiological, partly psychological. When this occurs we have a $\phi a ́ \nu \tau a \sigma \mu a$ or image.

The $\phi a ́ \nu \tau a \sigma \mu a$, then, is conceived of by Aristotle on the one side as determined in the most mechanical fashion. It is a relic of sense-perception, a sequel which follows in accordance with the merely mechanical principle that movement once excited tends to propagate itself. Nevertheless Aristotle is never oblivious of the other side of all such processes. Neither sense-perception nor imagination, however dependent on the body, is wholly corporeal. The body only contributes in so far as it is animated, that is, is the vehicle or medium of the soul. Just as in sense-perception the act of sense is the realisation of the inner power of sentience, so in imagination the relic of sense-stimulation is only the means of calling forth an activity of the soul itself. What that activity is, and in what on its inner side it differs from sense-perception, Aristotle does not define. His expressions seem to justify us in regarding it as a function-an additional function-of the central faculty

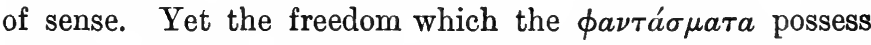
in respect to the immediate conditions of sense-perception enables them to be utilised by the thinking faculty of the soul; and they are specially utilised in two directions, theoretical and practical. The theoretical activities-judging, reasoning, and so on-are always dependent for their

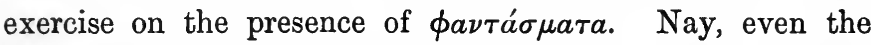
supreme function of reason, at all events in man, operates only in and through images. ${ }^{1}$

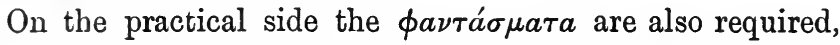
because it is through them that the functions of desire obtain a field of operation going beyond the immediate present. Even the animal has desires and appetites because

${ }^{1}$ De An. iii. 431 a 16. 
of the pleasure and pain which accompany its sense-percep-

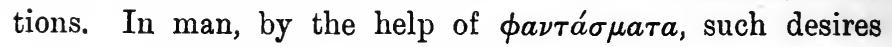
come under the scope of understanding and reason. Man can pursue an aim, can plan and deliberate. Thus we must

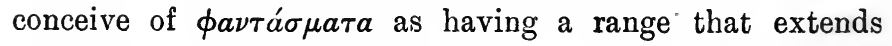
somewhat beyond the mere relics of sense-impression, although Aristotle in no way defines the relation between the more restricted and the more extensive types of imagination. $^{1}$

Memory ( $\left.\mu \nu \eta^{\prime} \mu \eta\right)$ and Reminiscence (ả $\left.v a ́ \mu \nu \eta \sigma \iota s\right)$ Aristotle distinguishes from each other and from Imagination. Memory is distinguished from imagination only by the feature, not further explained, that the images ( entering into it are accompanied by the sense of time, and therewith by the reference to the previous really perceived object. $^{2}$ From reminiscence memory is distinguished as the involuntary or mechanical in contrast with the voluntary or deliberate. Reminiscence, as he understands it, implies the resolution, the effort, to remember. ${ }^{3}$ The typical case is that of the mind trying to recall an experience which it had once had. Such a typical case had greatly exercised the early Greek psychologists $;^{4}$ and Aristotle's solution of the puzzle they discovered in it is a very practical one. The mind in trying to remember is no doubt not in possession of the image to be recalled, but it is in possession of something connected with it. It knows, so to speak, in part; and the business of reminiscence is effected by dwelling on this connected part that is known, and so stirring up into activity the movements which originally brought about the connexion.

\footnotetext{
1 De An. iii. 432 a $10-14$ (reading forgotten a thing, how could he, $\tau \alpha \hat{i} \tau \alpha$ for $\tau \hat{a} \lambda \lambda \alpha)$.

${ }^{2}$ De Mem. 449 b 26.

3 De Mem. 453 a 14. 4 Their difficulty was, if a man had but had forgotten? after recollecting it, be said to recognise what he was said to recollect as that which formerly he had known
} 
We call them now the links of association. Reminiscence, then, according to Aristotle and in our phraseology, is attending to an idea which has been associated with that to be recalled and thereby given occasion to suggestion. It is in this part of his work that Aristotle makes the first classification of what have since been called the Laws of Association. ${ }^{1}$

iv. The Rational Soul.

Nov̂, Reason or Intellect, is first considered by Aristotle with a view to the settlement of the question as to whether it is separable or not. By 'separable' no doubt is meant 'not dependent on corporeal conditions'; practically therefore the question is, in what relation does $\nu o \hat{s}$ stand to the soul? For soul, so far as its generic character is concerned, is not separable; it is dependent on corporeal conditions. ${ }^{2}$

The fact to which Aristotle appeals as furnishing some decision of this question may be called the universality of reason. The scope of reason is all-embracing, and on this account it must be, says Aristotle, using a term employed previously by Anaxagoras, ' unmixed.' 3 This universality of intellect which constitutes its sole nature (it is the potentiality of all apprehension) clearly shows that intellect is not dependent on corporeal conditions. To this it may be added in confirmation that, even if, as is no doubt the case, the operation of $\nu$ ovs resembles that of sense in this respect that it is affected by its objects, yet there is the difference that, whereas sense fails when the object is in too great excess, $\nu \circ \hat{v} s$ is the more perfect the more intelligible its object is. In other words, whereas sense operates only within a limited sphere or scale of degree which implies a qualitative determination, reason is free and not subject to degree. ${ }^{4}$

1 De Mem. 451 b 22.

${ }^{2}$ De An. ii. 413 a 3.
${ }^{3}$ De An. iii. 429 a 18.

${ }^{4}$ De An. iii. 429 a 29. 
Thus then, as Aristotle says, those who defined the soul as the place of forms (тómos $\epsilon i \delta \hat{\omega} \nu$ ) were on the right track, only their statement must be qualified. It is not the soul in its entirety but the noëtic soul that is the place of forms; and it is their place only in potentiality, not in actuality. ${ }^{1}$ Nov̂s does not possess the forms except it be in fulness of act-a state corresponding to that of realised knowledge in our minds.

Again, the real distinction between $\nu$ ovs and what depends on corporeal conditions may be illustrated by pointing to the difference between a concrete fact and its essence-the abstract notion corresponding to it. Where there is such a difference, where the concrete and its abstract notion are distinguishable, the apprehension of the two must come about either by the operation of different faculties, or at least by different applications of one and the same faculty. ${ }^{2}$ And this holds good even when the objects concerned are themselves of a very abstract nature, as in mathematical forms; even there-for example, in the straight line -we may distinguish between the concrete, the continuous space, and the abstract notion which is there embodied.

The operation of $\nu$ ovs is said to be in its general nature like that of sense-perception. ${ }^{3}$ Now, it has already appeared that sense-perception is not rightly conceived as, so to speak, passive reception of impression. What sense-perception does is no doubt rightly expressed on one side by the term reception; sense receives the form of the sensible. But in its own nature it is essentially the calling forth into actual exercise of a potentiality. Sense-perception is so related to the perceptible that it may as faculty, prior to impression, be called the perceptible potentially, so far, that is, as form is concerned; while, when actually stimulated, it is this per-

${ }^{1}$ De $A$ n. iii. 429 a 27.

${ }^{3}$ De An. iii. 429 a 14.

${ }^{2}$ De An. iii. 429 b 16. 
ceptible form in actuality. In a quite similar way reason

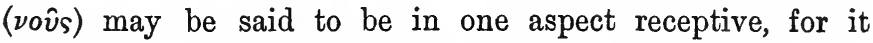
receives the intelligible forms; but as operative it is, like sense-perception, the calling forth into activity of what it is potentially. Just as sense, then, in its actual exer-

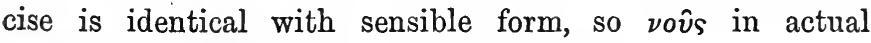
exercise is identical with intelligible form.

There is a certain limitation of the treatment here which deserves attention. Nov̂s is not only spoken of generally, but there is a definite reference to the $\nu$ ov s wich is said to belong to the soul. ${ }^{1}$ Without exaggerating the importance of this distinction, it appears to indicate two things: first, that Aristotle attempts, at all events, to maintain what may be called the unity of the whole soul: $\nu$ ovs, that is to say, is not to be represented as somehow just superadded to the soul, but as in some way working into a unity with the other functions of the soul; and in an earlier passage ${ }^{2}$ Aristotle has rather expressly made reference to the concrete subject, the individual, as that which possesses the intellectual capacity. And in the second place the reference may be taken to imply that, while there is a fundamental identity between vovs in the human soul and vov senerally, there may be a difference connected with the special conditions under which vovs is realised in the human soul.

Aristotle proceeds to point out that the broad distinction of potential and actual must be applied to the soul and, more specifically, to vov̂s or reason. Now, it is to be borne in mind that this distinction, however absolutely expressed, holds good only within the realm of change,and of change, moreover, of the type that is determined by the presence of matter. Obviously, then, we are entitled

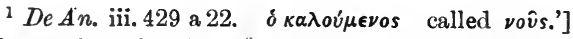

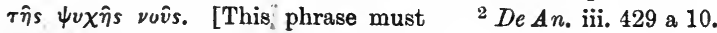

mean?" the part of ithe soul that is
} 
to assume that such distinction as Aristotle is proceeding to draw between the potential and the actualised aspects of $\nu$ ovs is taken with reference to $\nu o \hat{s}$ s as belonging to the soul, as in some way connected with the soul. ${ }^{1}$

This being so, then, Aristotle thinks it is obvious that

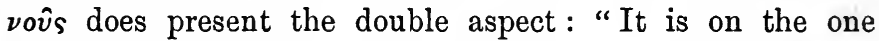
hand of such a nature that it becomes all things; it is on the other hand of such a nature that it produces all things after the fashion of a kind of active power such as, for example, light, for light also in a way makes what are colours in potentiality become actual colours." 2

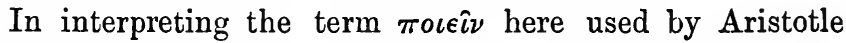
to describe the action of vovs (from which term indeed has been derived the current though non-Aristotelian de-

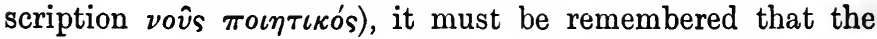
realm of generation is eternal. Novs, whether in man or otherwise, does in no sense create objects. The types of existence in that realm of generation are fixed eternally.

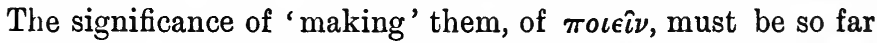
analogous to that which is involved in the action of light. Light makes the colour visible, nay, even, as Aristotle calls it, makes the colour actual; so the presence of reason makes possible the real apprehension of the intelligible essences of things in the world of generation, and thereby, as Aristotle would put it, makes them actual.

Aristotle goes on to say in words which have caused much trouble to the interpreters: "This vovs is separable

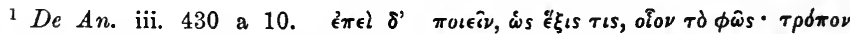

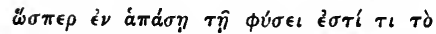

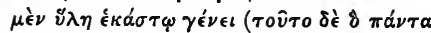

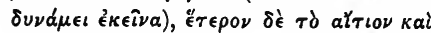

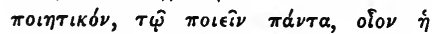

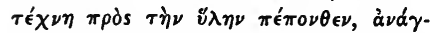

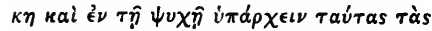

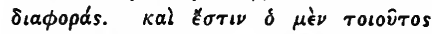

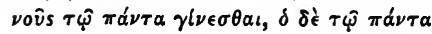

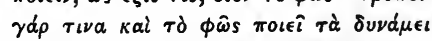

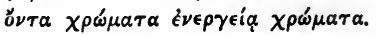

2 De An. iii. 430 a 14 . Cf. Plato's parallel between the act of vision and the act of intellection : the analogy of eye, visible objects, and

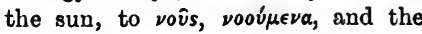

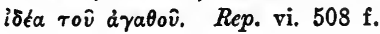




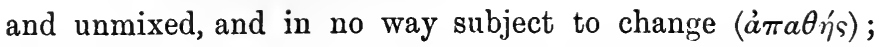
its very essence is pure activity. ... When it is separated, it is nothing but what it essentially is, and this alone is immortal and eternal. But we do not remember because

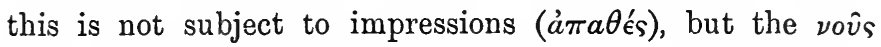
that is subject to impressions ( $\pi a \theta \eta \tau \iota \kappa o$ s) is perishable." 1

Nov̂s, then, is in some way to be regarded as eternal and immortal; and the reason is not far to seek. What Aristotle has in view is the apprehension of the intelligible essences

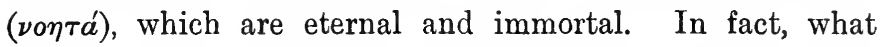
he seems to be saying is that the apprehension of truth presupposes, as connected with the human soul, an activity cognate to truth-with the same freedom, therefore, from temporal conditions, and hence to be described as a power which in its own nature is free from corporeal conditions, which is immortal and eternal.

Evidently there is something yet to be done in the way of explaining in what the connexion between soul and this higher power consists. I understand the following chapters ${ }^{2}$ as on the whole the attempt made by Aristotle to define this connexion, at least on one of its sides.

Intellect ( $\nu \circ \hat{v} s$ ) is definable only in correlation with the

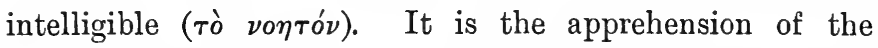
intelligible, and thereby gives to the merely potential existence of the intelligible, in matter whether corporeal or incorporeal, a higher form, an actualisation. But if this be so, then in accordance with Aristotle's whole theory of knowledge the act or operation of vovs is essentially the

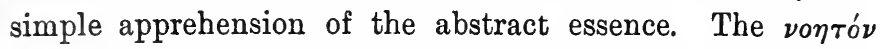
may from one point of view present itself as a complex,

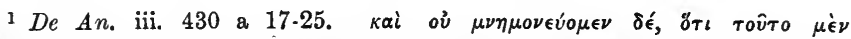

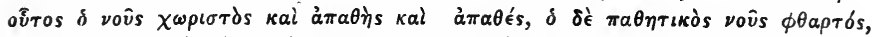

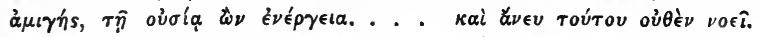

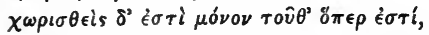

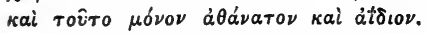

${ }^{2}$ De An. iii. cc. 6, 7, 8. 
but just in so far as it constitutes the essential nature of one type of existence it is a unit; and the action of $\nu$ ovs can only be represented as the simple direct grasping of this intelligible unit. So conceived, the action of vov̂s resembles that of simple sense-perception, - that is, the action of sense when occupied with the proper or specific sensibles. In both the act of apprehension is direct, simple: in both there is no question of truth or falsity; what is given is always true. Thus our actual knowledge has at its lowest and at its highest extremities the same peculiar characteristic form, the direct immediate grasping of the truth.

But this same form is discernible even in those intermediate stages which constitute the discursive work of understanding. There both on the theoretical and on the practical side we discover that the business of understanding, expressed on the one hand in affirmations and negations, on the other hand in striving towards or aversion from, always involves the reduction of a multiplicity to unity. Every judgment, whatever complexity it involves, whether of subject and predicate merely or of subject and predicate with qualifications of time or the like, involves a unity of conception-a unity even when the judgment is negative. In such uniting conceptions is throughout displayed the work of reason. It is reason which gives the unity apparent throughout all the discursive operations of understanding, both theoretical and practical.

It cannot escape attention that, in dealing with senseperception and even with imagination, Aristotle seemed to assign the same function of uniting, which is here ascribed to reason, to the common central sense; and it is remarkable that here, in dealing with the work of reason, he introduces again ${ }^{1}$ the conception of the central sensibil- 
ity in such a manner as would almost lead us to conclude that he was desirous of connecting the fundamental activity of $\nu$ ovs with that of the central sensibility as the higher form is connected with the lower. The central sensibility discharges functions which are preparatory to the higher activity of reason; and, in particular, such preparatory work is achieved by the combination-retention together, as we might put it-of images, wherein vovs or reason is able to see the intelligible form or abstract essence.

Even where the objects are of a very abstract kind, such as the mathematical, reason apprehends the essence with

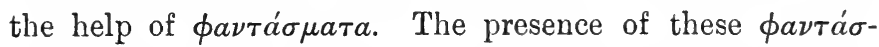
$\mu a \tau a$ is necessary in order to enable the mind to apprehend the distinction between the essential form and the matter in which it is embodied.

So far as the functions of vovs in the soul are concerned, I have tried to follow out a line which seems to be indicated in Aristotle's treatment, and which enables us to a certain extent to connect the special functions of vovs with those of the subordinate powers of the soul. Taking knowledge in the widest sense as equivalent to any apprehension, we saw that the extremes, immediate sense on the one hand and the direct insight or intuition of $\nu \circ \hat{v} s$ on the other, had one point of resemblance-simplicity. Neither presented that complex, which may be named either synthesis or analysis, and which is exhibited most clearly in the judgment. Nevertheless throughout all this intermediate stage, with its gradations, there was also clearly to be discerned a certain operation or series of operations of which the general character may be said to be unifying. In the region of sense-perception a certain approach to unification is given in the central function of sensibility as such. In the higher processes - whether theoretical, as in opining, believing, 
judging, inferring; or practical, as in desiring, deliberating, resolving-there is also a unification, of which the material

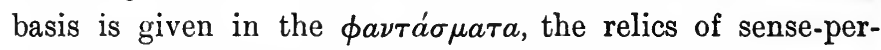
ception, and in which there is traceable, though not sharply distinguished by Aristotle, an advance from a uniting which hardly goes beyond the scope of central sensibility up to a range in which the unity is evidently due to the grasping, the apprehension, of intelligible forms.

With what consistency it is possible for Aristotle to work out this conception of $\nu$ vis as that which finally gives unity to our cognitive and practical experience, it is hard to determine. Probably much of the difficulty we experience depends on our ignorance as to the limits within which Aristotle thought right to confine participation in vovs. Is it, for example, only in the human race that participation in $\nu$ ov s is to be found? If so, the problem of adjusting the uniting functions assigned respectively to vovs and to the central sensibility becomes an insoluble one. Perhaps the most reasonable conclusion is that Aristotle did not definitely determine these limits, but that vaguely he allowed of the presence of $\nu$ ovs only where there was evident the power of appreciating intelligible essence, the power of thinking in concepts or notions. Such a result would imply in the case of Aristotle's psychology a hiatus such as confronts us in his metaphysic and in his theory of knowledge-a distinction of kind in that which forms a composite whole in the concrete.

A certain contrast is implied between the functions of the discursive understanding, theoretical or practical, and

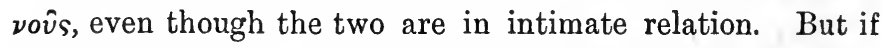
the special function of $\nu$ ovs be to give unity to our thought, to our knowledge, what kind of unity is it that is thereby conveyed? For evidently the representation of the several

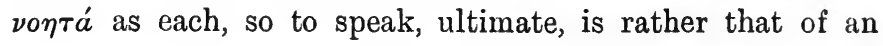


aggregate than that of a systematised whole. Is there,

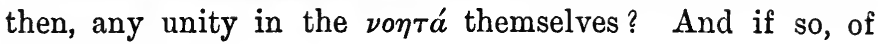
what kind?

Now, it appears to be a question of this nature that Aristotle is starting when he raises the problem, ${ }^{1}$ how does vovis apprehend itself? We have already seen that the unifying central function of sensibility involved this apprehension of itself in the diversity of its operations. Is there anything resembling the consciousness of sensation, assigned to sensibility, in the operation or activity of $\nu$ ovs?

Aristotle's answer to this question is presented in the $D e$ Anima so abruptly and enigmatically that little can be extracted from it, and even the fuller treatment, in the Metaphysics, ${ }^{2}$ leaves much to be desired. Nov̂s or reason taken generally is in its realisation identical with the intelligible; just as sense-perception in its realisation is one with the perceived, as far as form is concerned, so knowledge in its realisation is identical with the intelligible form, and the more the form is capable of abstraction from the material in which it is presented, the more perfect is this identification of subjective activity and objective truth. ${ }^{3}$

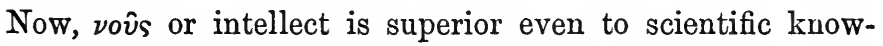
ledge; it is intuitive, while scientific knowledge is in part at least discursive. Nov̂s, therefore, most perfectly of all is

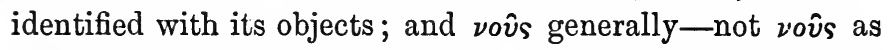
it may exist in, that is, under the conditions of, the soul-is always active: it has no other essence than to be the immediate apprehension of the truth ; it is perfectly correlated with its object, and becomes itself intelligible in and through such apprehension of the intelligible. When devoid of matter, and vov̂s in its own nature must be such, there is no distinction possible between it and the intelligible: itself is

${ }^{1}$ De An. iii. 429 b 26.

2 Met. $\Lambda$ cc. $7,9$.

3 De An. iii. 430 a 3. 
its own object, and thought, the highest thought, is the thinking of thought. ${ }^{1}$

Formally, no doubt, this statement is satisfactory enough; but it really leaves untouched all the questions of importance. Evidently what Aristotle is referring to in this description of the pure unmixed continuous energy of reason is the First Mover, that Absolute which in his system plays the part of ultimate cause of all change-change whether in the intermediate realm of the eternally moved, or in the transitory world of matter and sense-particulars. But no means of connexion is supplied between the pure unmixed energy (and, therefore, the continuous and systematic character of the intelligible) in this first cause, and the variety of forms embedded in matter in the world of generation. Such forms so far share the character of the original cause that they are eternal, uncreated. The causal energy transmitted to the world of generation is exercised not in producing such forms, but in effecting the constant variation of individuals. Neither, therefore, can the eternal forms find explanation in the supreme reason, nor is there furnished any ground of explanation for the other factor, the condition of all plurality, individuality, development-namely, matter.

One is almost inclined to characterise the theory as a mistaken attempt to turn a purely abstract theorem into a concrete and apparently scientific explanation of facts. The abstract theorem is no more than the representation of the objective, non-temporal, eternal character of truth, which naturally, obviously, and, as it was assumed by both Plato and Aristotle, without qualification, might be correlated with knowledge. Truth and knowledge imply one another, and their non-temporal character is easily translated into this representation of a first simple continuous activity of reason whose object is its own perfectly intelligible nature.

${ }^{1}$ Met. $\Lambda 1074$ b 34. 
What Aristotle adds to this is the apparently more concrete, more scientific, explanation of movement or change in the world of generation as due to the original initial impulse conveyed from the first moving cause through a series of intermediaries, the sphere of the fixed stars, the planets, and so on, down to the elementary components of the sublunary world. But the two pieces, the abstract theorem and the concrete representation, are in no necessary connexion, nor is it indeed possible for us to put them together into a coherent whole.

If this, now, be the nature of vovs in general, in what relation does vov̂s in the soul stand thereto? There are two closely connected questions which Aristotle raises which directly concern this problem: ${ }^{1}$ (1) Why is it that if the

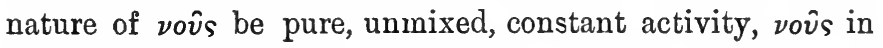
man sometimes thinks, sometimes does not think? What is it that constitutes the potentiality, or potential and

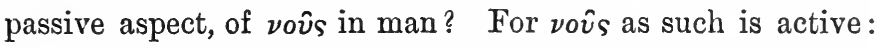
it is only in vovs as in the soul that we have to distinguish the potential and the realised aspect.

\section{v. Reason in Man and the Absolute Reason.}

From the broad outline which precedes we should certainly seem justified in saying that all parts of the universe have something of the Divine in them; for they all stand, so far, in the same relation to the absolute ground and final end of the universe. But such divine element or aspect may be presented in very varied degree by the parts of the universe; and in the world of generation it is natural to suppose that in man, the highest of these natural forms, the relation should be the most intimate and fully developed. This, however, can only mean the greatest possible approximation to what constitutes the nature of reason, that is, apprehen-

${ }^{1} D e A n$. iii. 429 b 22 . Cf. 430 a 22 (omitting où $\chi$ after $a^{\lambda} \lambda \lambda^{\prime}$ ). 
sion of the intelligible, the constant activity of that thinking which is occupied solely with the intelligible. Within the limits of the world of generation such approximation to the highest activity of reason can only be imperfect, and in particular it must be subject to the general conditions which constitute the character of the world of generation. Of such conditions the most general again is that expressed in the opposition between potential and actual. Man does not reach even such approximation to the divine reason as is possible for him except through the processes whereby he is enabled actually, as far as his powers extend, to seize the intelligible and to become aware of that function which is manifested in such apprehension. Prior to actual thinking he does not possess reason; but, nevertheless, since it is possible for him to a certain extent to grasp the intelligible, it must be said that in him intellect or reason exists potentially.

Now the intelligible, though in the world of generation always manifested in the material (and though what is intelligible in the world of generation does not exist save as expressed in the material), is nevertheless in its notion distinct therefrom; nor is it to be said, without the restriction to the world of generation, that the intelligible only exists in its material embodiment or manifestation. There is an intelligible, a pure form, which is not restricted to any matter, which is not dependent for its existence on the material, which is at once abstract and concrete, at once universal and individual.

Consequently, in respect to the power of apprehension of that which is intelligible, it is natural and reasonable to conclude that the function, power, faculty, is not dependent on material conditions, not dependent thereon at least so far as its essential character is concerned, though it may be that in its operation it is variously conditioned by the material. 
Thus, just as we have to contemplate a scale or gradation of the embodiment of the intelligible in matter from the lowest form in which the intelligible is embedded in the matter of sense through the intermediate stage, where the intelligible is manifested in a matter which is itself intelligible in kind, to the highest where form and matter are identified, so with respect to reason or its operations; we have to conceive of them as passing through a gradual development to the stage at which the final perfection of self-apprehension is reached.

It would follow, then, since the nature of reason implies no dependence on material conditions, and since the soul is obviously dependent on material conditions, that vovs is in its own nature distinct from the soul, and not a part thereof : though as realised in man it attains its full perfection only in and through the processes which are functions of the soul. Aristotle is quite explicit in his severance of $\nu o \hat{v} s$ from the soul. ${ }^{1}$

Is it then to be supposed, as some expositors have assumed, that $\nu o \hat{v} s$, or reason, in man is but the Divine thinking in him? The ground for this assumption is to be found in the passages in which Aristotle describes vovs as eternal, immortal, and wholly separate from the soul, and in which he raises the question, why it is that, although the activity of $\nu$ ovs is unceasing, we the human subjects should be aware of its activity only from moment to moment.

But there is no reason why we should ascribe to Aristotle a doctrine which would conflict so absolutely with his view of the total distinction between the first cause and the world of generation. Rather we must assume in accordance with his general scheme of existence that there is given something in the world of generation, as well as in the intermediate sphere where change is uniform, distinct from the Divine but partaking more of its nature than any other constituent

${ }^{1}$ [This statement seems hardly justified by any passage in Aristotle.] 
of these realms. Now, Aristotle does give a hint in this direction. He does place alongside of the four elements in the world of generation a fifth factor-æther-with properties very different from those of the elementary opposites. ${ }^{1} \mathrm{He}$ does tend to identify this fifth substance with the material substratum of the intermediate region, the celestial bodies, and be does indicate that it is through the conjunction of some portion of this superior element with the inferior ingredients forming the soul that a basis is provided for the

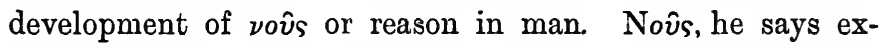
pressly, is the only thing in the human composition that comes in from without $(\theta \dot{u} \rho a \theta \epsilon \nu){ }^{2}$

With this introduction $a b$ extra of reason or intellect into the soul is undoubtedly connected also Aristotle's term which we translate 'spirit'- $\pi \nu \epsilon \hat{v} \mu a$. The $\pi \nu \epsilon \hat{v} \mu a$ is in fact the highest and finest form of the ethereal element, and it is what we might call the material basis of reason. This element whereby reason obtains a place in the concrete life of man is not described by Aristotle with any great definiteness. He will, however, assert of it that though relatively small in bulk it is the most important, - that of it may be said, 'there man is most himself.' ${ }^{3}$ It is, then, in connexion with a fact or element of the world of generation which, nevertheless, does not present the opposites which in that world make generation a process of coming to be and ceasing to be; it is by sharing in the one element which is pure, simple, with no contrary, which is therefore most of all akin to the Divine, that reason finds a place in the soul. For this element, though not identical with the functions of the

${ }^{1}$ De Celo, i. 269 a 30. oúría

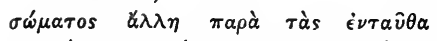

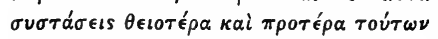
¿் $\alpha^{\prime} \nu \tau \omega \nu . \quad$ Cf. Gen. An. ii. 736 b 29.

${ }^{2}$ Gen. An. ii. 736 b 28.

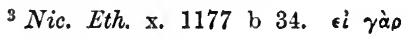

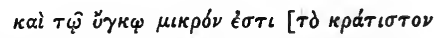

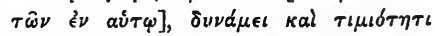

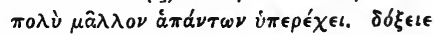

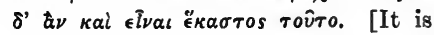
vov̂s that Aristotle refers to here metaphorically as 'small in bulk.'] 
body, is yet invariably connected with them, and seems to require conjunction with them for the exercise of its own activity. Its functions exhibit throughout features which reflect its original peculiarity of character. Its energy is simple, uninterrupted, without contrary; its mode of apprehension does not involve or require that synthesis and analysis which is characteristic of the work of understanding.

Thus it must be said that, though the development of vovs is gradual, it yet, as part of the complete whole, the human subject, is independent of the body; and when it has reached its final stage of development exhibits most clearly of all in its self-apprehension freedom from the conditions of the body.

According to this view, then, vovs in man would be by no means identified with the primal vov̂s or absolute reason, although in its nature it is identical therewith: its concrete mode of existence is wholly distinct from that of the primal

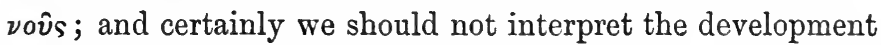
of $\nu$ ovs as though it were an illumination of the finite soul by some divine power. It is quite true that the view taken cannot get over the fundamental difficulty that $\nu$ ov is still in an obscure incomprehensible way severed from the soul, that there is a transition of a quite absolute kind; but I do not regard the difficulty which is ordinarily expressed, of accommodating the position of $\nu$ ov s with the unity of the subject, as insuperable. Aristotle did not define the unity of the subject from the point of view that we occupy; and for him the concrete whole, the animated being, which is the vehicle of vovs, constituted, I think, the individual subject. 


\section{CHAPTER V}

\section{REASON AS THE FACULTY OF FIRST PRINCIPLES}

Nov̂s is correlated with the ápxai or first principles; and these, as we have seen, stand in a peculiar relation to the discursive processes of demonstration or opinion: they are not themselves matters of demonstration: they stand at the head of the demonstrative process, are presupposed there. Moreover, in a general way it has been indicated that even these immediate principles, the pure intelligible essences, which find expression in complete definitions, are always apprehended in conjunction with the material setting of

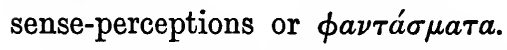

Is it possible to make somewhat clearer the way in which the apprehension of such principles comes about in the soul?

The Posterior Analytics closes with a chapter ${ }^{1}$ in which this very problem is formally propounded and discussed. The answer given is one of the many in which, dealing with the same kind of question, Aristotle seems to lay such emphasis on the empirical factor as to give some justification to those who have always claimed him as the first exponent of a completely empirical theory of knowledge.

"Now we have already seen that it is impossible to have demonstration except by already knowing the primary, im-

1 Post. Anal. ii. c. 19. 
mediate, principles. Two difficulties may be raised with respect to the apprehension of these immediate principles: (1) as to whether it is the same in kind with demonstration or not, - that is, whether we have scientific knowledge $\left(\epsilon \dot{\epsilon} \tau \sigma \tau \eta^{\prime} \mu \eta\right)$ in both cases or have in the one case $\dot{\epsilon} \pi \iota-$ $\sigma \tau \eta^{\prime} \mu \eta$, in the other an apprehension of a different kind; and, again, (2) as to whether the faculty [of apprehending the principles], not being innate, comes about in us, or, being innate and possessed from the first, is latent.

"There is something absurd in supposing that we from the first possess these apprehensions; for it would follow from that, that while we actually possessed a knowledge more adequate than demonstration itself, we remained in ignorance of it. On the other hand, if we attain to such apprehension, not having had it from the outset, how is it possible that we can have and acquire knowledge except from some knowledge which precedes? For this, as has been already said in respect to demonstration, involves an impossibility. Obviously, then, it is neither the case that we possess these apprehensions, nor do they come about in us as wholly devoid of some kind of apprehension. Necessarily, then, we must possess some capacity ( $\delta \dot{v} \nu a \mu \iota$ ), even though that be not of such a kind as to transcend the others in completeness and accuracy. ${ }^{1}$ Now such a capacity seems to be possessed by all animated beings; for they all have by nature a certain discriminative capacity which is called sense-perception. But in some living creatures possessing sense-perception there comes about a certain survival of the percepts; in others this does not happen. When it does not happen-whether in respect to perception in general or to a ceŕtain set of perceptions-then in such cases no knowledge is attained beyond the immediate act of sense-perceiv-

1 By 'the others' Aristotle means ciples and demonstration. the immediate apprehension of prin. 


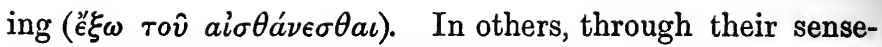
perceptions there comes about a certain unity ${ }^{1}$ in the soul. When many such sense-perceptions are given, a certain difference manifests itself in such a way that in some, from the survival of such percepts, there arises $\lambda$ óyos, in others, not. [The crux is just here.] From perception, then, arises memory, as we say, from repeated remembrance of the same

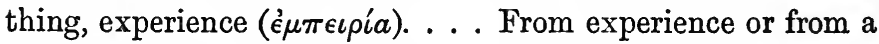
whole universal that has settled in the soul, from the One which is beside the Many, the point of identity in all the particulars, there arises the principle of art or science ('ं $\left.\pi \iota \sigma \tau \eta^{\prime} \mu \eta\right)$, -art when it refers to the changeable, science when it refers to the unchangeable. [I give up the attempt completely to understand this.] Thus, then, the acts of apprehending first principles do not exist in us completely determined and separate from all else, nor are they generated from other apprehensions, which themselves contain more insight than they do, but from sense-perception. For just as in a battle when a rout has occurred, first one makes a stand and then another until a certain order is re-established, so the soul has a faculty which enables it to undergo a somewhat similar experience. What has been said before, but not distinctly enough, must here be repeated. For when one of the individuals stands, then in the soul there comes about, first, a universal (for the act of sense-perception is directed to the individual, but sense-perception is of the universal: it is, for example, of man, not of the man Callias). Next, in these a stand is made until the indivisibles and the universals are reached, as for example, from animal of such-and-such a kind up to animal in general, and so on in like manner. Evidently, then, the ultimates must be made known to us by induction, for in this way perception implants the universal. Now, in regard to the faculties of the understanding

${ }^{1}$ Reading $\ddot{\epsilon} \nu \tau$ $\tau$. 
by which we apprehend truth, some of these are always true; in others, as opinion and reasoning, there may be

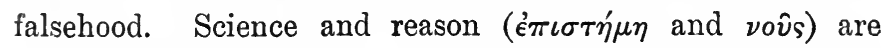
always true, and no kind of apprehension is more perfect than science except reason. Again, the principles from which demonstration proceeds are always the better known, and all scientific knowledge involves reference to a ground or reason. Hence it is evident that there cannot be scientific knowledge of first principles; and since nothing is more true than scientific knowledge except reason, reason must be our mode of apprehending first principles; and also because there cannot be scientific knowledge as the basis of scientific knowledge itself, since it is evident that the principle of demonstration is not itself demonstration. Since, then, over and above scientific knowledge, we have no other kind of apprehension which is unfailingly true save reason, reason is the principle of scientific knowledge."

I imagine that as much consistency as can be brought into Aristotle's theory of knowledge will result, if we view it as we now are able to do, in relation to the general positions of his system. Among these general positions there is one characteristic of the Aristotelian, and indeed of Greek philosophy in general, which has so entirely lost significance for us that we are apt to put it out of sight in interpreting special portions of Aristotle's work. I mean the doctrine of the eternity of the world of generation. By this eternity Aristotle meant, not merely that the generated, the changeable, is an ultimate and finally inexplicable component of the world of existence, but also, first, that the typical forms, which define as far as is possible the character of the world of generation, are eternal; and secondly, that the actual process whereby development or change within the world of generation comes about is always an efficient 
causation on the part of a definite individual-the cause of change is always an individual in full activity, fully real. Thus, for example, nothing could be farther from Aristotle's view of the world of generation than any thought of the gradual evolution of the human species from a lower animal type: the race of man is as eternal as the world of generation; the development of any one man has always as its initiating circumstance some action on the part of an already fully developed human being. So in all other cases. It must therefore be carefully borne in mind that Aristotle's phrases 'coming to be' and the like, whether in respect to nature or to the soul, are to be interpreted with reference to this permanence of the types of existence, of the causes of change, and of the series of changes they originate.

Aristotle's view of development, then, is that it naturally proceeds from the highest to the lowest. He has no conception corresponding to the modern view of Evolution.

The representation of the world of generation from this point of view naturally suggests the relation of the forms in which its characters are defined to the thinking power. Knowledge has for its correlate such fixed forms, and is perfect in so far as they are completely known and in so far as they are separated from the material contingent factor always associated with them in the world of generation. But the forms neither exist nor can be known except as realised in individuals; each type of existence exhibits an indefinite number of individuals in respect to whom it has to be said, first, that each of them is contingent, relatively at least; and secondly, that each of them passes through a series of changes forming the indispensable process towards its realisation of what is essential to it. Such process is longer or shorter, more or less varied, according to the rank of the existence in the scale of being: in man, for example, the process is the longest and most varied; not merely his physical but also 
his intellectual and practical development involve changes more numerous, more difficult to apprehend, than in the case of any other existence.

The intelligible forms are then always presented in a multiplicity of concrete individual cases with varying circumstances attaching to them, and with a variable history of the changes of each individual. Our knowledge, then, of any one type of existence must contain (1) the apprehension of the form, the intelligible essence; (2) the apprehension of the relations between that intelligible essence and what necessarily follows therefrom in the circumstances of each concrete individual; and (3) the apprehension of the variable contingent incidents which accompany each individual, whether as it stands or throughout its development.

From the point of view of the developing individual man, it is certainly not only possible but necessary to say that he only by degrees attains to a knowledge, an insight, into the intelligible essences of concrete things : for a human being is a part of nature, and can apprehend only in so far as his own capacities enable him, and must therefore in his apprehension be limited, on the one hand by those ontological conditions, the admixture of form and matter, of the intelligible and the contingent, and on the other hand by whatsoever conditions depend upon the structure of his own nature. Say for the moment that it is by means of the soul that man knows; then his knowledge will be conditioned by the structure of the soul as well as by the ontological conditions of existence as such-meaning by 'existence' the world of generation.

Thus the individual man is not only compelled in his thinking to clothe the intelligible essence with material accompaniments ; but, by reason of the structure of his soul, he can only apprehend this intelligible essence with the help of the concrete imagery of imagination and sense-perception. Thus, even though we can trace the development of know- 
ledge in man from sense to reason, laying stress on the confused relative character of the first data in mind, it is to be remembered that according to Aristotle there is no evolution of reason from sense. The whole scheme already pre-exists; and what happens is but the gradual attainment, on the part of the contingent individual, to what is already predetermined for him in consequence of his form, or intelligible essence, or nature.

That Aristotle should regard the apprehension of the intelligible forms as a process of thought, and thereby repeat in his own way the Platonic view, is not surprising. The difference in the long-run between the Platonic and the Aristotelian view does not concern this ultimate generality. What Aristotle objects to in the Platonic system is the want of mediation, - of complete, detailed, systematic working out. In the Platonic view the world of generation is just put alongside of the Ideas, and the general reference to the Ideas is taken to be sufficient explanation of the world of generation. Aristotle, for his part, emphasising the eternity of the world of generation, desires to see worked out in detail the structure of that world, and declines therefore to regard it as a sufficient explanation to say that there the Ideas are manifested.

At the same time he perhaps deviates from the Platonic conception in another point. The apprehension of the intelligible essences is immediate, each stands by itself; mediation, synthesis, finds a place only in the derivative work of demonstration or reasoning from the first principles. Accordingly, from the point of view of the human spirit, one must say that, according to Aristotle, there is not possible one ultimate comprehensive insight or knowledge which will explain the whole: indeed, from any such position his strenuous adherence to the eternity of the world of generation would have debarred him. That is to say, Aristotle 
accepts difference as ultimate: there is not on his side any effort to deduce the element of difference. (This is at the basis of his criticism of Platonism.) Consequently there is left for Aristotle in the description of his ultimate cause only a series of negatives; for the terms by which he expresses the action, the life, the mode of existence, of this ultimate cause, however positive they may appear, are negative in fact. It is simple, unmoved, unvarying energy, pure activity, single, not even through consciousness of itself having the element of plurality-all predicates, as one can readily see, which are but negations of the characters of the manifold world of generation.

From this survey it would seem impossible to accept the interpretation of reason, particularly the active reason, as being the divine nature-an interpretation which was first introduced by Alexander of Aphrodisias. According to him,

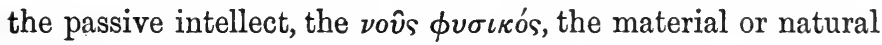
intellect-in itself a mere potentiality - was brought into activity by the action upon it of the divine; and the intellect

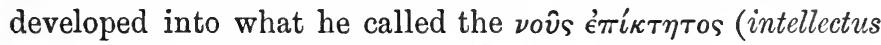
acquisitus). Throughout the Middle Ages this interpretation is to be found in constant conflict with a fundamentally distinct, rather Neo-Platonic, exposition which found its chief exponents among the Arab commentators on Aristotle, in Averroës especially. According to their view, the active intellect was a separate spiritual agency (of such agencies in their view there were many) which operated upon the minds of finite subjects, enabling their apprehensions to rise from the limited and sensible to the intelligible, or introducing into their minds the intelligible form. As Averroës expounded this, not only the active but also the material or passive intellect was regarded as a separate agency with which the minds of finite subjects were connected or related, and which was therefore one and the same for all minds. 


\section{CHAPTER VI}

FINAL CRITICISM

WITH these few data we proceed, in conclusion, again to ask, What, more precisely, is the nature of the problem which we may suppose Aristotle to have before him? I imagine that it would be an error to regard Aristotle as dealing in his discussion of the nature of $\nu o v s$ with the possible metaphysical problem, how does the world come to have the form of intelligibility? The solution of that problem is taken for granted.

There lies in the background of Aristotle's treatment the general representation of the whole universe as a system. In regard to the part which more immediately concerns us, the world of generation, the systematic character is fixed by the features (1) of its eternity, (2) of the eternal types of real being which are found therein, and (3) by the constant support of the whole sequence of changes in that world of generation through the eternal activity of the first mover. What is it in respect to such a system that constitutes intelligibility? It would be hard, I believe, to say what answer would be given to this by a modern thinker. The answer which is undoubtedly in the minds of both Plato and Aristotle, though perhaps requiring a supplement, is very definite. Constancy, regularity, uniformity, are for them intelligibility. From their point of view, the constant move- 
ments of the heavenly bodies may more properly be said to be intelligible than to be the manifestations of intelligibility, as we perhaps might be inclined to express it. The intelligible is then the constant element in the manifold, the law in what changes; and such laws, such constant elements, as we have seen, are taken by Aristotle on metaphysical grounds to be already established.

It is true that openly in Plato, less explicitly in Aristotle, there is a supplement to this thought of constancy, or of universality. In Plato the supplement appears in a form familiar to us-the subordination of all the parts of the system to the Good. But we also know that from Plato it is impossible to extract any other determination of the Good in this its metaphysical aspect than just this, that it is the symmetrical, harmonious, constant, universal. In Aristotle similarly there is doubtless raised the question of the way in which the ultimate cause is related to the system which it supports; and, as is natural, Aristotle applies to this ultimate the identification of the different meanings of cause which forms part of his whole treatment of that notion. The divine control of things may be compared, he says, to the command of a general over his troops or to the order among the troops themselves: the good is found in the universe both as a separate divine being and as the order of the universe. ${ }^{1}$ So the action of the divine sustaining cause may be regarded as proceeding from that cause; it may equally well be regarded as a straining upwards from what is said to be acted on towards the first cause as a final end. ${ }^{2}$ In the ultimate analysis efficient and final cause pass into one.

Nevertheless, just as little in Aristotle as in Plato are we able to discover anything which would enable us to connect the universal constant elements of the whole system of

1 Met. $\Lambda 1075$ a 14.

2 Met. $\Lambda 1072$ b 3. 
generation with any higher conception from which they should be, so to speak, deduced. Indeed, in the case of Aristotle, the principle to which he adheres of the eternity of the whole system would be hard to reconcile with such deduction. Such being the metaphysical conception, Aristotle's special problem must be regarded as this:-In what way is it possible that in the case of man, one of the types of existence in the world of generation, there should be knowledge of the constant and universal elements and of their systematic interconnexion?

Such knowledge, as we have seen, he will allow to man only; and even in the case of man it is a kind of knowledge different from that which he obtains by means of the faculties which he has in common with the other animals. The universal which he has to apprehend may be preceded in order of time by something in some respects resembling it, but insight into it as constituting the ground or reason, the final explanation, of the variable and transitory-that demands an activity different in kind from the lower faculties. Thus, for example, sense-perception undoubtedly in Aristotle's view gives us something resembling the universal. ${ }^{1}$ In like manner the processes of retention and imagination may give added definiteness to this first universal of sense, may give us apprehension of the individual with qualities; but we do not thereby reach the peculiar apprehension of the universal as the ground of, as that which determines, the properties of the individuals in which it is found.

Aristotle, then, seems to demand a kind of mental action which is unique, which in its own nature therefore cannot be explained by assimilating it to, still less by deriving it

1 This is very much what Lotze calls the primary universal, the universal of sense. Cf. generally what
Lotze says about concepts in his Logic, B. i. c. 1. 
from, the lower faculties of the soul. Yet, on the other hand, two things have to be borne in mind: (1) that this universal ground, cause, or principle is only a ground, cause, or principle, in reference to the varied individuals, the multiplicity of contingent fact; the forms, as he says, do not exist per se, they exist only in matter: and (2) that it is equally true in respect to knowledge in man that apprehension of the form is possible only in and with the concrete representations of the material individuals. Thus in one way reason may be said to be dependent on the lower faculties, and therefore, as Aristotle puts it, reason is in the soul or connected with the soul, ${ }^{1}$ and on the other hand the peculiarity of its mode of exercise is such as to compel us to say that in its own nature it is quite unlike the lower faculties, and that it does not, like them, seem to be conditioned by or dependent on any state of the body. This difference may be illustrated by the consideration that in the exercise of sense-perception there is discrimination, and that this discrimination involves something which we must call a unity. In sense-perception and imagination such central function is discharged by, and its discharge is dependent on, the central organ. In the case of intellectual action the chief fact is not so much discrimination. In it there is not even the need of unification which is exhibited in judgments; the peculiarity of the apprehension is that it is the apprehension of an indivisible ultimate term. ${ }^{2}$ There is no distinction of true and false. Such absolute unity, such appropriation of the indivisible, argues, Aristotle seems to say, a total independence of bodily conditions. Moreover, these indivisibles, the ultimate terms, the pure essences, form themselves in thought a series or whole, which Aristotle says has unity like that of the series of numbers-a unity which is wholly independent of space or time, an interconnected, systernatic

\footnotetext{
${ }^{1}$ [But see above, p. 219, note 1.]
}

2 De An. iii. 407 a 8. 
whole, as we should say. This exercise of thought, unique in its own way, is dependent for its occurrence, though not for its nature, on the conditions of the life of the soul. Once it has been realised, or actualised, in man, then it is indeed unnecessary that it should be always in exercise: the man possesses reason and may be said to have it potentially-not merely in the way in which we say an intelligent being has intelligence potentially, but in the sense in which we say that a man who has acquired knowledge which is not at present before his mind has that knowledge potentially. ${ }^{1}$ When intellect has been called into exercise, when it has been realised, then, and indeed in and through this realisation, intellect becomes capable of knowing itself. ${ }^{2}$ Apprehension of these intelligible forms is at the same time the knowledge of them as apprehended or grasped by thought.

Near the end of the Ethics Aristotle suddenly turns to the contemplation of the highest form of wellbeing or happiness

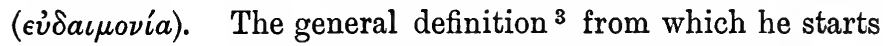
in the Ethics-that wellbeing is the conscious life (ėvé $\rho \gamma \epsilon \iota a)$

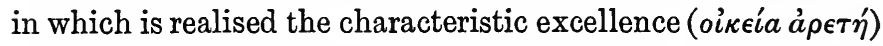
of man-is followed by a detailed treatment of the practical life and the so-called moral excellences or virtues ( $\dot{\eta} \theta$ ıкai $\dot{a} \rho \epsilon \tau a \hat{i})$. A rather detached isolated treatment is given of the

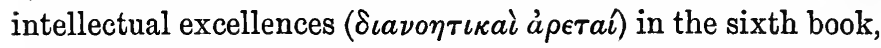
but on the whole the bulk of the treatment is devoted to the consideration of the realisation of the good in human conduct. Now suddenly, in the tenth book, ${ }^{4}$ the problem is resumed from a more abstract point of view. Referring to the general definition, Aristotle proceeds to point out that, if that defini-

1 Potential intellect ( $\nu$ ôs $\pi \alpha \theta \eta$.

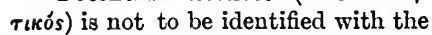
sum of the lower powers, as it is by Zeller and Trendelenburg.
2 De $A$ n. iii. 429 b 5.

3 Nic. Eth. i. 1098 a 16.

4 Nic. Eth. x. c. 7. 
tion hold good, then the absolutely highest happiness and welfare of man must lie in the realisation of what is highest and best in him. What, then, is this highest and best in him? It is $\nu 0 \hat{s}$, reason, pure contemplative intellect-the divine in man, or that in him which is most like the divine. The realisation of it, the contemplative life, has all the advantages in which the practical life is in large part deficient. It is independent of circumstances. It is essentially reposeful. No regrets can ever accompany it. It is occupation with the best and highest objects. Moreover, in a very special way, it must be said to be the life in which man realises himself. For surely that which is best and noblest in him, however small it may be in bulk, is to be called most truly the man himself. The practical life in its best mode of realisation must be regarded as only a preparation for the supreme happiness of the contemplative life. In that life, if man is not immortal, he is at all events most like the divine and immortal.

In this account two things deserve attention: (1) the sharp contrast in which the contemplative life is placed to the life of temporal effort, of practice; they are so disjoined that real union of them is hard or impossible: (2) the emphasis laid upon the contemplative life as the realisation of what is highest in man. From this emphasis the natural conclusion ought to be that in the Aristotelian conception of man, taken as a whole, there are united both reason and those lower faculties or powers which are occupied, we might almost say, both with the details of practical life and with the processes of discursive thinking.

In some way, then, Aristotle desires to regard pov̂s or reason as forming part of the concrete whole of human life, and from this point of view we may again resume his theory of reason. We should not perhaps be in error in applying to 
that theory the dominating conception of purpose or end. The existence of that type of concrete reality, man, is determined by reference to his end, and that end is incompletely represented without the inclusion of that all-important factor

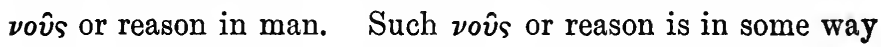
in man even though, as we have seen, it is not to be regarded as part of or as dependent on the soul. In so far as concerns logical dependence, reason is separable from the soul.

Is it equally separable from man? Aristotle, in the distinction which he draws between the active and passive reason, undoubtedly uses expressions which would imply that the intellect in its actual exercise has an existence independent of man. But is it necessary to interpret this literally? Independent of man intellect certainly is on the Aristotelian principles, for it is undoubtedly independent of this or that man. But man generically is eternal, part of the scheme of things-it may be a subordinate and determinate part, with its own end or purpose-but still forming an integral part of that scheme; and one might say (though I would acknowledge that one might appeal in vain to Aristotle for definite authority for the statement) that knowledge as being the actualisation of what is a component part of man as a member of the whole is in like manner to be regarded as eternal. Aristotle, we must bear in mind, shares with Plato the confusion between the notion of truth and that of concrete existence.

The eternity or, as we should better express it, the timelessness of Truth is what I think serves as the correlate in his view to the continuous perfect energy of reason when represented as existing separately. The determination of things, their natures, their intelligible essences, nuust on his principles be regarded as so far incomplete, in the state of potential being rather than actuality, in so far as they are not actually apprehended by reason. The fulness of being 
of these intelligible forms, and the actual existence or reality of reason, are one and the same thing. It is true, and Aristotle admits it, that such reason is not continuously realised in the individual subject; but Aristotle will not admit on this account that actual knowledge is even chronologically posterior on the whole-that is, with reference to man generally: to do so would be to contradict all that is involved in his conception of the system of things as an eternal organism, a graduated interdependent scheme of existence. If, then, we speak of reason as being potential, our reference is to the temporal conditions under which the necessary contact between man and the objects of his knowledge comes about. "Reason is potentially its objects, but actually none of them unless in actual operation." 1 Prior to the exercise of thinking, it may, as Aristotle says, be compared to a writing tablet $^{2}$ on which nothing is yet written; and we should be compelled to add that the writing is not a process exercised upon it ab extra, but resembles the calling forth into energy, or supply on appropriate occasion, of what is already there potentially. So far I think we can go.

There remain-apart, indeed, from the fundamental perplexity that Aristotle in no way enables us to understand the part played by the necessary preparations for the exercise of reason; they are simply stated as fact,- - there remain two further metaphysical difficulties.

First, what relation does Aristotle represent vov̂s in man as having to the divine vovs which is represented as by its continuous unmoved activity supporting the whole scheme of things? To that question I am convinced no answer can be extracted from Aristotle himself. The conception of the divine reason is framed by the help of general notions too abstract to bridge over the interval between the divine and

1 De An. iii. 429 b 30.

2 De An. iii. 430 a 1. 
the human. Aristotle bases his theology on the physical proposition (we might call it) that there must be a first cause of movement, and then proceeds to apply general notions to determine the nature of this first cause of movement. It is by a series of what we might call negations that he passes to what looks like a positive result, namely, that the nature of the divine first cause is the pure energy of thinking which has for its object itself, the perfectly and purely intelligible.

The second difficulty, which is indeed a form of the first, concerns the relation between the intelligible and vovs or intelligence, and that in more than one way. What is the intelligible for the divine intellect? Aristotle tells us it must be pure, unmixed. It can therefore be only intelligence itself. In what way, then, does the divine reason contain, embrace, or be in any kind of positive relation to, that intelligible which is assumed to have a place in the world of generation? For the intelligibles there are not really separable from matter, and cannot be apprehended except in the concrete things. Just as the unmoved mover is really and logically, whatever Aristotle may say, in no conceivable connexion with the chain of subordinate movernent, so we are bound to say that the Aristotelian divinity-the divine mover-is put beyond all conceivable connexion with the world of the concrete; and one can hardly regard as a sufficient explanation the reference to the striving of all things towards the divine. From this striving it must also remain impossible to derive their characteristic natures. Thus it seems impossible to reconcile the unity and absoluteness of the divine mind with the multiplicity and relativeness of even the intelligible essences of the world of generation. The two worlds still, as in Plato, fall apart without the possibility of rational connexion.

The difficulty is equally pressing on the side of the human 
reason. For there also, by its nature, reason is wholly severed from the lower faculties, which nevertheless have a constraining and limiting influence on it. We should also, I think, be inclined to doubt whether there is not a confusion involved in that identification, which is needed, of the form apprehended by reason with the act of reason itself. We might allow, indeed, that knowledge being a fact, a process in the world of fact, its completion involves this representation of the object for the thinking mind. But we should hesitate to regard that representation of the object as constituting the actuality, the fulness of real being of the thing apprehended or represented.

It is worth while to note very briefly what have been some of the main ways of understanding or interpreting

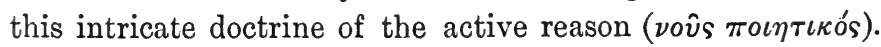
Perhaps there is no one of these interpretations-however widely we may think they depart on the whole from the Aristotelian doctrine-which does not retain some part of the confused material which comes together in Aristotle's statement of it. There is confusion both as regards the facts and the terms used.

Aristotle describes the reason in its active form as making all things, and seems at times to imply that what

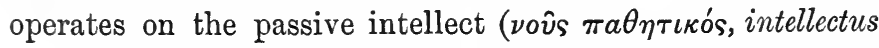
passibilis) is reason as an agent. It was natural that among

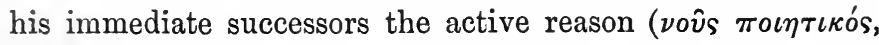
intellectus agens) should be identified with God; and Eudemus, one of his immediate successors, - his contemporary indeed,-identifies them. The tendency, however, in the Aristotelian Peripatetic school was steadily towards a rejection of the absolute distinction between reason and the lower faculties. This tendency fell in with the fundamental views of the Stoic school, whose main effort was 
to interpret the supposed differences of kind as differences of degree, and who therefore found it easy to transfer to their own doctrine with the requisite changes the apparently Aristotelian view of reason. Reason, according to them, was the controlling, directing, sustaining force spread throughout the whole universe, a force combining the two features of being natural and being rational. This force was spread in varying degrees of intensity through the various types of existence. Its highest form is represented by reason in man, the controlling, directing part of the soul, and of this the lower functions of the soul were but degraded or enfeebled forms. Others, again, of the Peripatetics wholly rejected the notion of a supreme reason; and the Peripatetic metaphysical doctrine may be said to have been worked out to its naturalistic conclusions in the work of Strato of Lampsacus, who flour. ished about 270 B.c.

Among the most important interpretations as regards the history of the subject is that of Alexander of Aphrodisias, the great commentator on Aristotle. ${ }^{1}$ Alexander proposes at once to identify reason with the lower faculties of the soul,--that is to say, to regard it as their highest development, and at the same time to preserve the separate existence of reason by introducing a more vital distinction between active and passive reason than Aristotle had done. According to him, reason in man presents itself in two forms: (1) that in which the abstract essences of things are, so to speak, abstracted from their matter-a process which he regards as not different in kind from the functions of the discursive reason. In this aspect he calls Reason

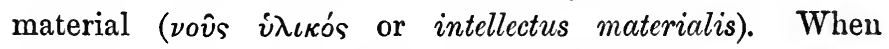
such abstractions have been sufficiently accumulated, there is formed in man (2) that higher type of intellect which

${ }^{1}$ Head of the Peripatetic school about 200 A.D. 
works, so to speak, with and among abstractions. Alexander

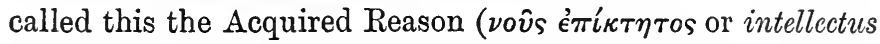
acquisitus). But Alexander thought it necessary to call in a ground of explanation for that illumination of the soul of man which it obtains by disengaging the abstract essences and dealing with them. This power operating $a b$ extra, bringing reason in man into living relation to the intelligible in things, he called God, and identified God with the

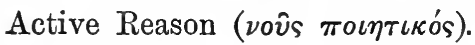

A different view was worked out by Averroës (Ibn Roschid), ${ }^{1}$ the Arab commentator on Aristotle. Averroës uses the accepted Aristotelian distinction between active and passive intellect, naming the contrasts by the terms which had been introduced by Alexander of Aphrodisias. But he seems also to be inclined to add to what is implied in that contrast a further type of intellect which in some way he distinguishes from the intellectus materialis. There is a form of intellect lower than that-such as is exemplified in the processes of discrimination and comparison. Even animals are capable of this. In man it is more developed. The characteristic mark of this lowest form of intellect is

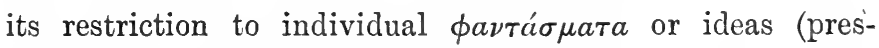
entations). The function of the whole process is to prepare a sufficient quantity of ideas for the work of the two higher types of intellect-intellectus materialis and intellectus agens.

Now with regard to both these higher forms, the characteristic turn of Averroës' doctrine is the denial that they form any part of the individual soul. Not only the intellectus agens is held to be separate, and therefore im-

${ }^{1}$ Born at Cordova, 1126 ; died in Morocco, 1198. Averroës does thorough justice to Aristotle's doctrine of the eternity of the world, though
Thomas Aquinas calls him the corrupter rather than the interpreter of Aristotle. 
personal: this had been held by others. But the intellectus materialis is regarded as separate from the individual soul. It is therefore one and the same for all individual souls. Its function is to receive, and, so to speak, to hold in potentiality the intelligible forms, apprehension of which is prepared by the collection of ideas ( $\phi a \nu \tau \alpha \dot{\sigma} \sigma \mu a \tau a)$, real apprehension of which is always due to the vitalising, realising, of the potential intellect by active intellect. This active intellect is in like manner eternal, single, separate. It is identified, indeed, by Averroës with one of those intelligences the hierarchy of which takes the place in the Arab philosophy - probably under NeoPlatonic influences-of Aristotle's saner conception of the series of heavenly bodies interposed between the prime mover and the world of generation. The function of both intellects is defined by reference to the universal; and, indeed, it is as dealing with the universal that both intellects are held by Averroës to be incorporeal and nonindividual. These intelligible essences, the abstract forms of things, the universals for all knowledge, are not dependent on this or that thinker or soul. Shall we say, then, that, as the receptive intellect is eternal and impersonal and all individuals share in it, they share in it always and alike? No, Averroës answers, the condition for such participation is preparation. Through the lower faculty

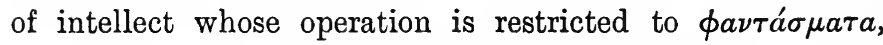
each shares in accordance with his preparation, and also in

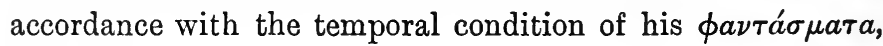
his ideas.

And now Averroës proceeds to take two further steps, neither of which can be said to be absolutely un-Aristotelian, but both of which may fairly be called exaggerations of Aristotelian doctrine.

(1) By participation in active intellect the individual 
acquires what we may call a certain formed power of retaining and dealing with abstractions. This is what Averroës, following Alexander, called the intellectus adeptus. In more familiar terms, it is the share which each individual has of knowledge, what he possesses of knowledge, and according to the principle of the doctrine this also is to be regarded as in a way impersonal and universal. It is so, because truth, knowledge, science, does not depend upon the individual thinker, and its eternity is rightly to be regarded as actually maintained by the eternity of the human race. "It is a necessity," says Averroës, "that there must always be some philosopher." 1

(2) The second step is based on reference to a function which is assigned to intellect, and which is not, in terms at least, identical with the realisation of the intelligible forms of material things: it is the apprehension of what is not material, that is, according to the crude representation in the Arabian philosophy, of the superior intelligences up to the divine. Of such apprehension reason is capable. We make our way towards it by abstract thinking, and the highest reach of that thinking is what in modern language we should call possession of absolute knowledge-an identification with the absolute intelligence so complete that the whole becomes intelligible. Such a state Averroës called unio. Obviously it is the same conception that is described in the Neo-Platonic doctrine as unification, absorption into the absolute. It is the same result that in many other less definitely philosophical doctrines is supposed to be attained by less honourable methods than abstract thinking. ${ }^{2}$

In this second extension of the Aristotelian doctrine we come across a rather curious deduction from Aristotle's views which has also had a notable history in speculation. The

1 Averroës, De anim. beat. 354 .

2 E.g., the hypnotic state of the dancing dervishes. 
intelligences are conceived as forming a hierarchy or graded scale; each has, so to speak, its end or the completion of its being in the apprehension of what is above itself. Each in like manner is to be conceived of as not having what specially characterises the mode of intelligence of what is lower than itself. Thus the divine intelligence, strictly speaking, has no other than absolute thoughts: its object is itself. In it there is no distinction of universal and individual: all is one. So, if we regard, as Averroës does, the active intellect as being in its nature divine, we are bound to say that the divine does not know more than the general or abstract. It does not know the concrete or individuala theoretical position which can be immediately translated and was translated into the very important practical doctrine that God's providence extends only to the general laws of things, not to the particular events. ${ }^{1}$

All these interpretations, I think, only combine to show that in the doctrine of Reason as it is left by Aristotle we have perhaps the most instructive instance of the difficulties into which he is forced by the fundamental dualism of his doctrine. However much Aristotle may object to the Platonic statement of the two worlds, he retains the feature which is of fundamental importance in that doctrine. $\mathrm{He}$ recognises a difference of kind. The perplexity in which this involves him appears at every one of the critical points in the exposition of his doctrine.

Do we turn to the doctrine of movement, we are there confronted with the baffling conception of a mover himself unmoved, and of an influence wholly physical in character exercised upon a physical world, which influence neverthe-

1 The speculation is just touched its apotheosis in Malebranche. on by Plato (Parm. 134); it reaches 
less is not itself physical and does not come from a physical agent.

Do we turn to his theory of knowledge, we are presented there with an instructive survey of the processes through which bit by bit separate conceptions are made more precise, retained, compared, and made into material for thinking. But the final step, apprehension of the universal itself-that is assigned to a process (we may call it intuition) distinct in kind from all others, so distinct that even the analogy with sense-perception does not enable us to form any true conception of its nature. It is to grasp indivisibles which nevertheless are invariably compounds. It is not to have the nature of judgment while nevertheless what is represented is always of the nature of a combination or separation of the parts of a whole.

Do we ask how knowledge is actually attained by the individual, there are the various faculties, powers, or grades of the soul laid out, each dependent on the conditions of concrete corporeal existence, and then there is added the supreme faculty of Reason, distinct in kind from all the rest, not dependent on corporeal conditions, and to be connected in no intelligible way with that which is otherwise called the preparation for its exercise.

Do we turn to what may be called Aristotle's theology, then there also, emerging unexpectedly as the result of an argument in which the first steps are the concrete changes of the world of generation, there comes a pure immaterial unchanging agent the nature of which is indeed called Reason, but which we find no means of identifying with or assimilating to reason as it is described in man. 



\section{PART IV}

\section{THE STOIC PHILOSOPHY}

\section{CHAPTER I}

THE STOICS

IT is characteristic of the Peripatetic work that it tends steadily to reduce the extreme oppositions which appear in Aristotle's own statement; and in this respect it must be said that the Peripatetic school was worked on lines practically identical with those of the Stoic philosophy. It is evident from the rather scanty relics we possess of the immediate followers of Aristotle that they recognised some at least of the fundamental difficulties of his system; and we can trace among them, as perhaps the most important tendency, a movement in the same direction as that which we find in the Stoic system. ${ }^{1}$ One might allow that with

1 Strato of Lampsacus, called Physicus, was a leader of the Peripatetic school, and therefore officially as it were an exponent of its doctrines, but in him we find a departure so wide from the fundamental principles of Aristotle as to imply their radical transformation. Negatively he is op- posed to any dualism. Nature and soul and reason are all like in kind. Also no explanation of nature is to be given by calling in the operation of what is supernatural. The divine constitutes for Strato no explanation. Positively he insists that nature is in itself the cause of all its character- 
Aristotle Greek philosophy in its purest form finds its culmination; one might give as much influence as they deserve to the general social and political changes which certainly tended to affect the whole temper and method of Greek thinking after Aristotle; one might even allow a certain measure of truth to the proposition that in these post-Aristotelian philosophies there is a prevailing tendency towards the practical, a tendency which is perhaps expressed more accurately as that of emphasising the subjective element; but there must not be forgotten the continuous tradition which, as regards material, problems, and method, connects these later schools-the Stoic in particular-with the Platonic-Aristotelian philosophy. The Stoic philosophy is altogether misapprehended if we take as its complete exponents those later representatives of it, the Stoics of the Roman Empire, of whom it must be said that in their hands philosophy has become altogether a way of life or practical discipline.

The early Stoics can only be understood by connecting their work in the most intimate fashion with the Aristotelian. Briefly, they endeavour with the help of the abundant material and excellent instruments provided by Aristotle to work over the problems of philosophy from a point of view which may fairly be named Monist. Their constant effort is to overcome the dualism that is inherent in the Platonic-Aristotelian philosophy.

In physics and in logic the Stoics were influenced by Heraclitus as well as by Aristotle. The Stoic ethics beyond all question connects with the earlier teaching of the Cynic school; and indeed we know that historically Zeno, the first

istics, and this nature again he identifies with the physical properties of things; pre-eminently with the fundamental elementary opposites, the warm and the cold. All the processes of the soul are movements. Sensation and reason are the same in kind. They are only the different ways in which one fundamental energy expresses itself. See R.P. 440-442. 
of the Stoics, was educated in the Cynic school $;^{1}$ and he is said to have written a treatise, the Republic, ${ }^{2}$ which the Stoics later found great difficulty in accommodating to their principles. For what the Stoic ethics did was to give an objective complement to the rather one-sided and subjective individualism of the Cynic doctrine. Further, the Stoics, since they were bound to recognise no differences of kind in knowledge and to place sense-perception on the level of reason, were inclined towards the empirical side in their theory of knowledge. (This statement will be qualified subsequently.) It was not unnatural, therefore, that they should have borrowed largely from Antisthenes, and should have accepted much that was characteristic of his exaggeratedly nominalistic position.

The Stoic school taken as a whole has a long history. For nearly five centuries it held its place as wellnigh the dominating system of human thinking. In this long history it is convenient to recognise a division into three tolerably well-marked periods :-

I. The period of the early Stoic school, in which the principles were formulated and a definite body of doctrine put together.

II. The period of the middle Stoic school, essentially a period of compromise, the attempt being made to accommodate the Stoic doctrine to the Peripatetic or Platonic.

III. Finally, the period of the later Stoic school, where Stoicism has for the most part only a practical significance.

The representative names of the early Stoic school are Zeno, $^{3}$ Cleanthes, ${ }^{4}$ and Chrysippus. ${ }^{5}$ These in succession

${ }^{1}$ Zeno was a pupil of Crates. See Diog. Laert. vii. 2. (R.P. 477.)

2 Diog. Laert. vii. 4.

${ }^{3}$ A native of Citium, in Cyprus; born 336, died 264 B.c.
4 A native of Assos in the Troad; born 331, died 232 B.c.

${ }^{5}$ A native of Soli in Cilicia (or perhaps of Tarsus); born 280, died 206 B.C. 
(from about 300 to 206 B.C.) presided over the school which was called the Stoa, from the painted colonnade ( $\sigma$ rod $\left.\pi \circ \iota \iota \lambda \eta^{\prime}\right)$ where it met. There is perhaps a little uncertainty as to the share each took in laying the foundations of the doctrine. There is little doubt, however, that to Chrysippus must be assigned the credit of working out the main ideas which determine the Stoic doctrine into a systematic shape.

The Stoic school, it must be borne in mind, was confronted throughout its whole career with rival schools, and subjected to continual criticism, not only from the Peripatetics, but also from the new schools,-from the Epicureans, ${ }^{1}$ and from the Sceptics, ${ }^{2}$ who fade away later into the Platonic school, the Academy. The Stoic doctrines must be conceived of as undergoing continual testing from the criticism of these outside schools. In particular, the fundamental positions in the Stoic theory of knowledge were topics of discussion among the Academic thinkers, and in all probability we must assign to the severe hostile

1 The chief names among the Epicureans are Epicurus, 341-270; Phædrus, c. 125 ; Philodemus, a contemporary of Cicero. Philodemus was the only Epicurean who tried to work out in detail a treatment of reasoning - a logic. Had this been preserved we should have been in possession of an ancient treatise on empirical logic. His

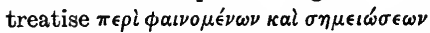
(ed. by Gomperz in Herkulanische Studien, Erstes Heft; see W. Scott's Fragmenta Herculanensia) seems to have been an attempt to lay down the rules by which from isolated individual expressions we can argue to objective fact-a view of the purpose of logic which is practically the same as J. S. Mill's. The greatest exposition of Epicurean doctrine is that given by Lucretius, who lived 95-51 B.c.

2 The leaders of the Sceptics (in. cluding those who were called the Academics as belonging to the Platonic school) were Pyrrho, 375275 ; Simon, $325-235$ (full of acrimonious discussion); Arcesilaus, 315240 (an Academician); Carneades, 219-129 (by far the acutest mind in antiquity-a regular Hume); Cleitomachus, 175-110; Philo of Larissa, c. 150 ; Antiochus of Ascalon, 125-65 ; Enesidemus, middle of first century B.c. ; Agrippa, first century A.D.; Sextus Empiricus, third century A.D. (.Ie sums up all the sceptical arguments, and is full of material about the Stoics. The only other real authority for Stoic doctrine is Stobæus.) 
criticisms of Carneades the character of compromise which is noticeable in the writers of the middle Stoic school. ${ }^{1}$ The criticisms of the Epicureans were of least importance.

The latest Stoic school, ${ }^{2}$ that which is relatively most familiar to us, is, as I said, prevailingly practical in character. The Stoic ethics had found a new home and indeed even more congenial soil in the Roman world than in the Greek. No philosophy proved itself so consonant to the Roman temper and genius as the Stoic; and it is to this connexion with Roman life that we must trace the continuance of the influence of Stoic conceptions-especially of those which became embodied in the Roman system of jurisprudence.

Turning back now to the philosophy of the early Stoic school, I note first, as regards external form, that philosophy was regarded by the Stoics as falling into logic, physics, ethics. $^{3}$ On the precise relations of these three to one another not even the early Stoics were in agreement. Generally speaking, the Stoics, who had a strong sense of unity, maintain steadfastly the interdependence of the three $;^{4}$ but they varied to some extent in their view as to their several worth, and the order in which they should appear in a connected exposition. On the whole, there are good general grounds for selecting as the fundamental

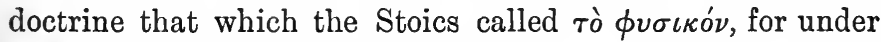
that title is included not merely such treatment as they gave of the detailed phenomena of nature, but the underlying doctrine of general principles. Physics in their view includes both physics and metaphysics. It is a statement

I Mainly Panætius, c. 180-110, and Posidonius, c. 130-46 B.c.

2 Seneca, 3-65 A.D. ; Epictetus, c. 40.100 A.D. ; Marcus Aurelius, 121-180 A.D.
${ }^{3}$ See, e.g., Sext. Emp. Math. vii. 17.

${ }^{4}$ Sext. Emp. Math. vii. 19. (R.P. 482 b.) 
of the principles and elements of existence. The only

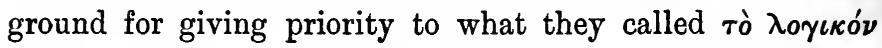
would be that the development of the theory of knowledge (for with the Stoics logic includes the whole theory of knowledge) led to a problem-the problem whether knowledge is possible at all-which, were it answered as the Sceptics desired, would have removed the ground from all the general philosophy. ${ }^{1}$

The second place in systematic exposition should be given to the Stoic logic, and there the fundamental problem we shall find is that regarding the criterion of truth. Ethics occupies the third place. There is no doubt of its dependence.

The three branches might again with advantage be subdivided:-Physics into physics in the narrower sense, and theology; logic into dialectic or logic in the narrower sense, and rhetoric (for the Stoics insisted on the intimate connexion of thought with expression); and ethics into ethics proper and politics. ${ }^{2}$

1 For a discussion of the order of the three parts of philosophy, see Zeller's Stoics, Epicureans, and Sceptics, 67 ff.

${ }^{2}$ Cf. Diog. Laert. vii. 41. ' $\delta \delta \dot{\epsilon}$

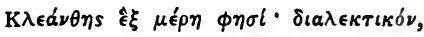

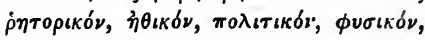

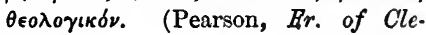
anthes, 1.) 


\section{CHAPTER II}

\section{PHYSICS}

THE general philosophy of the Stoics no doubt presents a character which has frequently caused it to be regarded as a kind of eclectic reproduction of the pre-Platonic Greek systems. Beyond a doubt they largely drew on Heraclitus. They tend to regard the cosmos as one, as continuously developing, as being in its fundamental nature fire, and as developing in the fashion of transformation. There is to be found in the Stoics also much that recalls Anaximenes and Diogenes of Apollonia, in both of whom fundamental importance was ascribed to air. In the Stoic theory of the constitution of matter, in their theory of mixture $(\kappa \rho \hat{a} \sigma \iota)$, there are unmistakable evidences of Anaxagoras. But it would be historically an error to regard the Stoic work as essentially a revival of these earlier views. The real substratum of the Stoic system is in the Aristotelian system. There is no violent breach between Aristotle and the Stoics, nor did the early Stoics at all events subordinate theoretic speculation to practical ethical interests. That may be said, indeed, with truth of the Roman Stoics, for whom speculative philosophy had value only as providing weapons of defence against attacks on their ethical doctrines. But the original Stoic system has all the marks of a comprehensive speculative view. It was an attempt to work over the Aristotelian 
philosophy from the point of view of unity, of system. Its general lines are all determined by those of the Aristotelian philosophy. It starts from a general picture of reality, which sums up the broad results of Aristotle's philosophy: Stoicism is a truly Greek system.

In Aristotle two fundamental doctrines stand out. The first is the eternity and unity of the whole system of existence. For the world of generation, while itself eternal, exists as part of that larger whole which is made up of the great divine first cause, the intermediate realities, and the world of change itself. The other fundamental doctrine is that the world of generation at all events is explicable through and by means of the correlative notions, form and matter. What exists has, and has eternally, its definite form or character: eternally-for if it has not individual eternity, it is eternal in type. Indeed it was hard even for Aristotle not to extend the scope of this comprehensive relation-form and matter-to the whole of his system beyond the world of generation; and to define, therefore, as what one may call the extremes, pure absolute form or activity and wholly indeterminate matter or passivity. The first considerable step in the Stoic development is made by this very extension, which was impossible for Aristotle on account of his total separation of the world of generation from the divine. The Stoics extended the correlation of form and matter to the whole. To the universe as a whole, and to every part of it, the distinction is made applicable. It is not a distinction of two elements, but rather of two principles, two aspects of one and the same thing. Form and matter are inseparable. The Stoics do not adopt in so many words Aristotle's equivalents for form and matter-évé $\rho \gamma \epsilon \iota a$

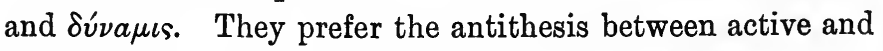
passive, which gave them the means of expressing in a single comprehensive formula the unique and universal mark 
of all that exists. The existent is that which is capable of being acted upon and of acting. ${ }^{1}$

Neither acting nor being acted upon exists separately. Everything presents both aspects, although from the point of view of knowledge it may be said that the important determining aspect is that of acting. It is the form which gives definiteness to what in abstraction is wholly indeterminate. The form at the same time is that which gives the existing thing its unity. ${ }^{2}$

Thus the Stoics start with a quite definite view of real existence-one might even call it a definition of reality. That view or definition may be given in two forms:-

(1) In more concrete expression, the view is that the real is corporeal: nothing is real that is not extended and resistant.

(2) In more abstract expression, the view is that the essence of existence is the power of acting and the capacity of being acted upon.

The two statements are identical in purport. For the Stoics insisted that nowhere is there action or passion save in the corporeal.

Accordingly they faced without hesitation the question with which in the Sophist Plato endeavours to show that the extreme materialist position is untenable, and after which

1 Diog. Laert. vii. 134. $о к \epsilon \hat{\imath} \delta$ ' is it that Plato means? Perhaps the

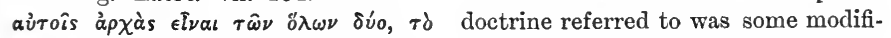

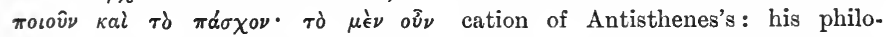

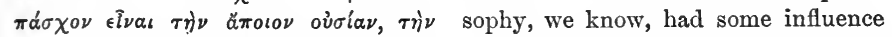

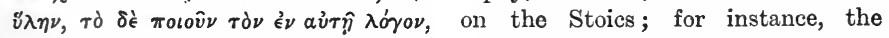

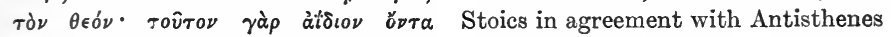

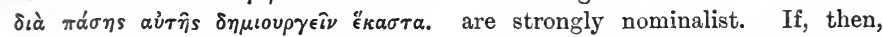
(R.P. 493. Pearson, Fr. of Zeno, 35.) Antisthenes is under criticism in the It is interesting to note that this is the reproduction of a definition which appears in the Sophist $(247 \mathrm{D})$. There it is hinted that the materialists, if the question were pressed, would offer just this definition of matter. Who

Sophist, is it possible that he had advanced to this more refined view? Or was Plato making a present of it to him?

${ }^{2}$ Cf. Aristotle's view. 
he proceeds to put forward the amended definition of the real, as that which acts and is acted upon. ${ }^{1}$ The Stoics will not allow that the soul is not corporeal, that virtues and vices are not corporeal: they are corporeal, just because they are real. ${ }^{2}$ They are states or habits of the soul; and the soul has no existence except as a substance in space, and in real relations of action and passion with the other contents of space. ${ }^{3}$ From the more abstract definition there may be at once derived the important general feature which characterised the Stoic physics: the real is that which acts and is acted on. There is thus always in the real a twofold aspect-the active and the passive. It is the Stoic way of expressing the antithesis which Aristotle expresses by the terms form and matter. Everywhere in what really exists there is to be found this synthesis of the active and the passive-not, however, as though these could ever be absolutely severed from each other.

The Stoics in their own way accept the two Aristotelian positions that form is never really separated from matter, and that form and matter are exactly adjusted to one another, each specific form having its equally specific matter. With the Stoics each variety of action is accompanied by a specific kind of the passive, of the material. If we ask what is this material, which in varied degrees of activity may be represented as extended through space, the briefest answer from the Stoic point of view is that it essentially has the nature of fire. ${ }^{4}$ Perhaps more specially we ought to understand fiery vapour in continual movement, blowing as it were in currents through space, and having at each point in space a certain degree of tension (тóvos). ${ }^{5}$

1 See above, p. 265 , note 1.

2 Plut. Comm. Notit. 45, 2. 490 a.)

3 Nemes, Nat. Hom. 32. (R.P. Pearson, Fr. of Cleanthes, 24.) The 507. Pearson, Fr. of Clcanthes, 36.) theory of tóvos was probably intro4 See, e.g., Diog. Laert. vii. 156. duced by Cleanthes.
(R.P. 494 a. Pearson, Fr. of Zeno, 46.)

5 Stob. Ecl. i. $372 . \quad$ (R.P. 500. 
This degree of tension constitutes, so to speak, the form, the characteristic quality, of the thing $;^{1}$ and, since this degree of tension depends upon and expresses the relation in which the thing stands to all the rest of the physical universe, it follows that the degree of tension at any one point is strictly individual, and different from the degree of tension at any other point. From this there is readily derived a very important special maxim of the Stoics, a maxim which was revived later by Leibniz, and which we may express hypothetically in the rather paradoxical fashion: "If two things were absolutely indistinguishable they would be one"; more logically: "It is impossible to find in the universe two things which are indistinguishable." ${ }^{2}$

Physics, in the more philosophical sense, may be said to be a general theory of the nature, structure, and arrangement of reality. Of physics in the modern sense there is nothing in the Stoic doctrine. In all points of detail their views on what we should call physical science are contemptible. They contain not an iota of scientific thinking. In their general theory the foundation is laid by the answer given to the question, what is the real? For according to the Stoics, as we have seen, the real is definable more abstractly as that which acts and is acted upon, more concretely as the corporeal, that which has the dimensions of space and resistance. It is quite certain that in the Stoic statements we frequently find a distinction introduced into this conception of the real which is open to misinterpretation. Zeno, for example, is recorded as having explained the structure of things by referring all to the two: God, and unqualified matter. ${ }^{3}$ And there are numerous other expressions which might be taken to mean that the

1 Plut. Stoic. Rep. 43, 4. (R.P. and Sceptics, 104. 492 a.)

3 See above, p. 265, note 1.

"See Zeller, Stoics, Epicureans, 
Stoic doctrine contemplated a kind of $\pi \rho \omega \dot{\tau} \eta \quad \tilde{\nu} \lambda \eta$ or primary matter which was acted upon and formed by that which they called God. But on the other hand these expressions must all be read in the light of the general definition: the real throughout is corporeal. If, then, we distinguish material and formal we are merely contrasting varieties of the corporeal; and there is further to be added that, according to the Stoics, there nowhere exists as part of the universe of reality any matter which is wholly unformed. There may, indeed, be practically infinite gradations. The formative element, the activity, the quality, may be in its least marked phase. Or again, in other cases, the activity may be at a maximum. But, throughout, the two are inextricably mingled-to use a word on which the Stoics expended much acute discussion. What they meant by 'mingling' ( $\kappa \rho \hat{a} \sigma \iota \varsigma)$ is to be understood by referring to their general conception regarding the manner in which the whole universe is to be represented. The universe of reality is a whole. It is one and continuous-there is no void in it; its parts are infinitely divisible; it is limited in extent. There is, as Anaxagoras used to say, no separation in it. The kinds, or better, varieties of matter, are fused together in it in so intimate a fashion that to express their meaning most exactly the Stoics steadfastly maintained that not only two but any number of bodies could occupy the same space ( $\left.\kappa \rho \hat{a} \sigma \iota \varsigma \delta \iota^{\prime}{ }^{\prime \prime} \lambda \omega \nu\right){ }^{1}$

The universe is thus a complete whole, one and continuous. All its parts, if we speak of parts, are in the most intimate interrelation with one another; they are all in harmony; the parts conspire together, as it were, to make

1 This interpenetration, permeation, of the material is the conception which saves us from misinterpreting the first expression that the parts of the real are on the one

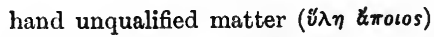
and on the other God: these are really thought of as two aspects of the same thing. 
up the whole. And the basis for this conception of the interdependence of all things in the one world of reality is the physical representation of all as being the corporeal which in its varieties is mingled together in such intimate fusion that, so to speak, in any one part of space all is contained. Obviously there follows from this conception of interdependence, represented through its physical basis, the consequence of importance for the Stoic theory of knowledge that nowhere in the universe of reality are there two things absolutely alike. So far, then, the first general answer. $x$

Now in the second place more concretely. How did the Stoics represent this material reality which occupies the whole universe, and in what way were the changes in it represented? It is here that we find what appears to be the influence of the Heraclitean doctrine. But I believe that in fact the Stoics were mainly influenced by the more detailed conceptions which had found a place in the Aristotelian philosophy. For there, throughout all the biological treatises in particular, explanations had been sought by the help of two ideas: the one the vivifying force of warmth, animal heat; and the other the force of that refined vapour in its nature akin to the corporeal substance that is superior to the elements-the $\pi \nu \epsilon \hat{v} \mu a$, breath or vapour, which Aristotle, as we know, had regarded as the vehicle of soul and reason. The Stoics extend this teaching. Fundamentally, the corporeal is, in the first place, the fiery refined vapour which they with Aristotle distinguish from the elements, and with Aristotle assign locally to the region of the heavens, within which the cosmos is contained. ${ }^{1}$ Then, this fiery vapour from the

${ }_{1}$ Diog. Laert. vii. 137. ả $\nu \omega \tau \alpha \dot{\tau} \omega$ noted that $\alpha i \theta \dot{\eta} \rho, \pi \nu \in \hat{v} \mu \alpha$, though in

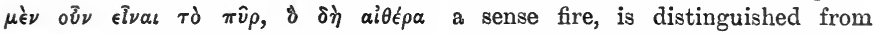

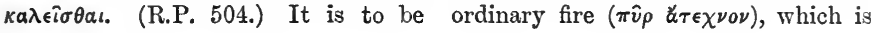


law of its own nature constantly undergoes changes, and is transformed or converted into the various elements. The law of its nature, and therewith the ground of explanation for its changes, the Stoics found in the conception of tension

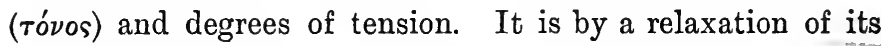
tension that from the original fiery vapour there proceed in due order the various elements, and it is by the necessarily assumed reverse process of increasing concentration of tension that the world's history is reversed in order and the original state restored. ${ }^{1}$

In the transformation which the original fiery vapour undergoes we can trace a certain correspondence between the Stoic view of varying degrees of tension and the Aristotelian conception of a graduated scale of existence; and the Stoics borrow terms of the Aristotelian philosophy to indicate the more important grades of tension. Each definite thing is properly constituted when in it are combined the proper degrees of expansion and contractionthe two aspects of tension. ${ }^{2}$ Each thing existed in so far as it was duly held together. For each thing, then, there might be stated a kind of proportion or ratio which expressed its nature. For this the Stoics adopted the multivocal term $\lambda$ ó $^{\prime}$ s. $^{3}$ The $\lambda$ ó $^{\circ}$, ratios or reasons, the intelligible essences of things, were evidently all contained in the original elementary formation of existence,were determined by it, not as by an external force, but as contained there as parts of the whole. From this point of view the Stoics called them seminal reasons ( $\lambda$ óyoc

a contrary and therefore capable of destroying, as $\pi \hat{v} \rho \tau \epsilon \chi \nu เ \kappa \delta \nu$.

1 For details, see Pearson, Fr. of Cleanthes, 24, and commentary.

${ }^{2}$ Cf. Kant's view that matter can be conceived only as the subject of an attractive and a repulsive force.
Each thing may be represented as an equilibrium of forces at a point. The Greeks, however, never had any conception of a mechanics of the physical universe.

3 This hunt for ambiguous words was a joy to the Stoics. 
$\sigma \pi \epsilon \rho \mu a \tau \iota \kappa o i) .{ }^{1}$ Each grade of existence had its corre-

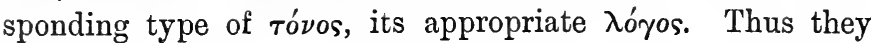
called that lowest degree of tension whereby solid bodies are just held together by the Aristotelian term " $\xi^{\prime} \xi$ เs (state or habit). A higher grade of tension is exhibited in the combination of heterogeneous parts in the unity of organic (vegetable) life, and this is expressed by the Aristotelian term $\phi \dot{v} \sigma \iota s$ (nature). A still higher degree is exhibited in animal life, and this the Stoics called $\psi v \chi \eta^{\prime}$ (soul). And the highest degree, which appears in man only, is called vov̂s (reason). ${ }^{2}$

The Stoics attempted further to work out their picture of the formation of the cosmos by defining the way in which these currents of fiery vapour combine in individual bodies. According to them, it was requisite that such combination should be more than juxtaposition, while at the same time they could not accept as equivalent the Aristotelian notion of mixing, seeing that there the components, by their perfect fusing, were understood to lose their independent qualities. It was necessary for them then to insist that the commingling was perfect, constituted one individual object, while nevertheless the currents

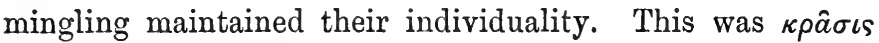
$\delta \iota^{\prime}{ }^{\circ} \lambda o v .^{3}$

${ }^{1}$ Ps. - Plut. Plac. i. 7, 33 . oi

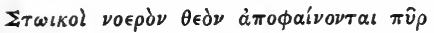

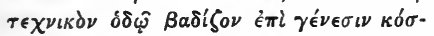

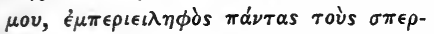

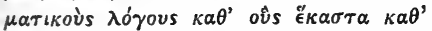

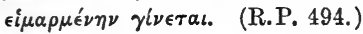

2 Themist. de An., ii. 64, 25 (ed.

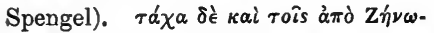

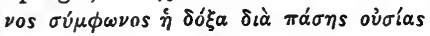

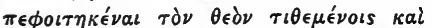

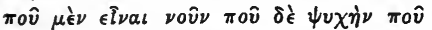

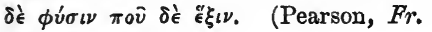
of Zeno, 43.)
${ }^{3}$ See Zeller, Stoics, Epicureans, and Sceptics, 137. The first kind of combination where the portions of the constituents are merely juxtaposed was called $\pi \alpha \rho a ́ \theta \epsilon \sigma i s$ : the second, in which the qualities of the constituents are destroyed and a single new quality resuits, $\sigma u ́ \gamma \chi v \sigma i s$. In the third, $\kappa \rho \alpha \hat{\sigma} \sigma s$, there is complete ( $\delta \iota \delta \hat{\lambda o v) ~ i n t e r p e n e t r a t i o n, ~ b u t ~ t h e ~}$ quality of each constituent is preserved. 
The Stoics, then, ascribe the formation of the universe to the changes of this fiery vapour. The fiery vapour is not, so to speak, exhausted in the elements into which it is so far transformed. There always remains a portion retaining its high degree of tension; and through it the formed universe comes to display just the kind of regular order which we expect in a whole. This supreme highest part is rightly to be regarded as the ground of the explanation of all things. It is the directing, controlling,

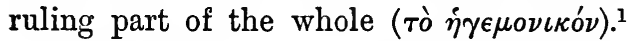

Using freely that conception which had already been formulated by Aristotle, and which has since passed into ordinary thinking, - the conception of the macrocosm and the microcosm,- - the Stoics found no difficulty in assimilating this orderly structure of the universe to the orderly subordination of the parts of human nature $;^{2}$ and indeed they could support their inference from analogy by arguments. Man is but a part of the universe: that which is in him must be, and must be indeed in higher degree, in the universe. ${ }^{3}$ Just as in him Soul and Reason are material, so the material basis of the universe may rightly be called Soul and Reason. The generating fire must be represented, then, as in its own nature Reason, Mind, Providence. The order of things is a rational order. It

1 To this $\dot{\eta} \gamma \in \mu o \nu \iota \kappa$ vo the Stoics tended to assign even a separate local position; and Cleanthes, we know, identified it with the sun. (By the rays of the sun all growth and nurture were maintained, and in it we have the concrete representation of this transfusing force.) The energy of the whole is doubtless inexhaustible, but the cosmical system is not on that account eternal. Generation is in a cycle. After a certain period all returns again into the condition of elemental fire $\left(\epsilon^{\prime} \kappa \pi v ́ \rho \omega \sigma \iota s\right)$, again to undergo transformation into a new system held by the Stoics to be identical, on the whole, with what had preceded. There was some slight difference of opinion as to what happened to human souls. The tendency was to distinguish between the wise men's souls and the fools', but the persistence even of the former was probably only through one cycle, not through all. See R.P. 508.

2 Plut. Comm. Notit. 36, 5. (R.P. 499.)

3 Sext. Emp. Math. ix. 101. 
is one and the same order to which we give the name of necessity, of nature, fate, providence, reason. In the initial fiery vapour there is contained-there is latent, so to speak, or in germ-all the order and relations of the universe in its detail.

God, the supreme mind, is therefore rightly to be called

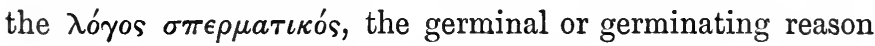
of the universe; and in each thing or type of things that which most fully or best expresses its nature, that is to say, its place in the whole, may also be called its

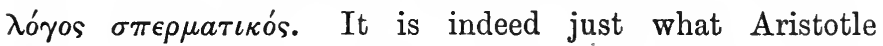
calls the intelligible essence that finds expression in a definition.

The world, then, is to be regarded as at once a physical, corporeal, mechanical whole, and at the same time a system in which all is subordinated to reason. It is a system, therefore, in which everything has that place and function assigned to it which is best for the whole-a system which is to be represented by the notion of final cause. The Stoics identify the mechanical and the teleological, ${ }^{1}$ just as they identify the corporeal and the mental. In the world as a whole it may be said that all comes about by necessity,-fate regulates all: but such necessity, such fate, is at the same time reason, and in reason the end prescribed is the best.

The Stoics, then, will not admit in the universe any element of chance, nor any element of freedom of will. It is true, as we shall see later, that the wise man-and of him the Stoics had a remarkable conception-is at the same time called free; but what the Stoics meant by 'free' in this

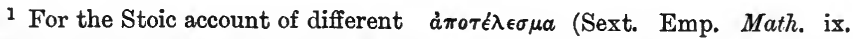
kinds of cause see Zeller, Stoics, Epi- 228). The fundamental type of cause cureans, and Sceptics, $141 \mathrm{ff}$. The is the efficient-

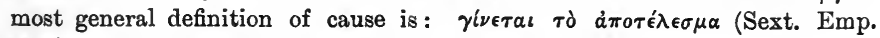

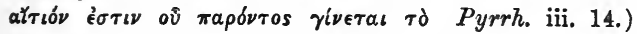


connexion is best explained by the one illustration which they employ-a dog tied under a chariot.

Their emphasis on the mechanical side tends to give great prominence to the Stoic notion of the fate under which all things operate. The difficulties for their moral system involved in that conception they endeavoured to evade by giving equal emphasis to the teleological interpretation. The world is not only a mechanical system but a system of reason. The law that holds is not merely a compelling force but the essence of reason, which is therefore gladly, joyously, accepted by every one who is able to understand it. "Fata volentem ducunt, nolentem trahunt." 1 But the 'volens' and 'nolens' are really the knowing and the unknowing.

Obviously, too, from the point of view of a systematic whole the problem of suffering and evil must have pressed hard upon the Stoics, perhaps all the more because in the moral sphere they were disposed to draw the lines of distinction so sharply that good and evil stood absolutely opposed. Yet from the point of view of the whole no such distinction can be final. There must be some element of good in all that is evil. Evil must have its due place in the whole, and be therefore relatively good. ${ }^{2}$

1 Sen. Ep. 107, 11.

2 From the Stoic arsenal are taken all the weapons of modern controversy in this problem. They offered several explanations of evil :-

(a) Physical pain is explained in accordance with the Aristotelian view of its teleological character : pain indicates what must be avoided.

(b) Moral training requires physical good and evil; their sole purpose is moral discipline.

(c) Variety is needed if we are to have a system at all. 


\section{CHAPTER III}

\section{THEORY OF KNOWLEDGE}

IN accordance with their general principle the Stoics regarded the soul as corporeal. Like the activity spread through the universe, it was spread through the body, and like the world- $\pi \nu \epsilon \hat{v} \mu a$ it exhibited variations of degree of tension.

From this point of view the Stoics could not admit of any absolute distinction between soul and body nor of any absolute distinction between reason and sense-perception. ${ }^{1}$ It is certain, however, that in their expositions the differences tend to become more prominent than the formal identity. The Middle school showed a pronounced drift towards the Platonic distinction between soul and body, and made a distinction between human and animal perceptions tending towards a distinction in kind between the human and animal souls. Some even asked if animals could have souls at all. The Later Stoics tend to go back from this position, which was quite incompatible with the general Stoic doctrine. ${ }^{2}$ The general Stoic view, however, admitted no difference between soul and body. Further, when the Stoics speak as they do of the parts of the soul,

${ }^{1}$ Sext. Emp. Math. ix. 102. (R.P. ${ }^{2}$ Compare Epictetus's and Marcus 510.) Diog. Laert. vii. 159. (R.P. Aurelius's views of the soul. 511.) 
this expression again must be held to signify merely difference of function, not local separation or distinction of nature. At the same time, it must be said that the Stoics differed considerably about the way in which reason and the different types of perception (al $\sigma \theta \eta \sigma \iota s)$ were related. Generally speaking, there were distinguished in the soul:1

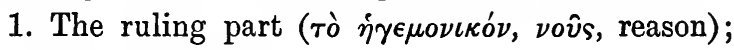

2. The five senses;

3. The faculty of language ( $\tau \grave{o} \phi \omega \nu \eta \tau \iota \kappa o ́ \nu) ; 2$

4. The faculty of generation (

The senses and reason were, I say, represented differently in their relation to one another. According to one view the

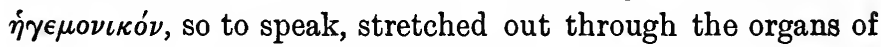
sense, the currents of activity used the organs of sense as channels, and the function of perception (al $\sigma \theta \eta \sigma \iota s)$ was only exercised by reason. ${ }^{3}$ The other view ${ }^{4}$ tended to give a kind of independent function to sense, and to place the contribution of reason in a secondary position. Were it only a relation between reason and sense, it might be possible to reconcile these two views and to give a statement strictly in accordance with the general Stoic principles; but the Stoics introduced such a multiplicity of intermediate stages in their representation of the way in which knowledge comes about, as to make it almost impossible to arrive at a satisfactory result in respect to the psychology involved.

1 Ps. - Plut. Plac. iv. 4, 4. (R.P. responded with the appropriate name 509.) Cf. Nemes. Nat. Hom. 96. or word. All difficulties in this con(Pearson, Fr. of Zeno, 93.)

2 It is remarkable that the Stoics in their view of language should have revived the strange doctrine which we find in some of the Heracliteans. According to them, there was a quite mechanical connexion between sensation and the faculty of speech. They held that when soul was properly affected by any object of sensation it ception the Stoics got over by pointing to the many impediments which prevented sense-apprehension being perfectly appropriate. Thus mistake in a name was said to be due to the fact that the thing was wrongly apprehended.

3 See passages quoted in note 1.

4 Implied in the Stoic theory of knowledge. 
In regard to knowledge, indeed, the Stoics intermixed problems of a logical kind with those more strictly psychological. This distinction was not obvious to them.

It is somewhat difficult to determine finally how the controlling or directing part of the soul was related to the five organs of sense. The Stoics represent the connexion in a thoroughly materialistic way. Streams of rational vapour extend from the $i \gamma \epsilon \mu o \nu \iota \kappa o ́ \nu$ to the organs of sense; and the organs of sense would thus appear to be no more than specialised functions of the controlling intellect. But, as is generally the case with a doctrine which desires to recognise no difference of kind, which proposes to resolve all differences into differences of degree, there is a certain indefiniteness in the Stoic doctrine. Perhaps their view was that, while the senses are properly to be regarded as

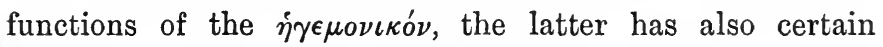
activities of its own. And probably some part of the indefiniteness attaching to the classification of the parts of the soul is to be ascribed to the changes which the Stoic doctrine of knowledge underwent, when it sought to defend itself from criticisms pressed upon it by the Academics and Sceptics.

In general tendency the Stoic theory of knowledge has the appearance of strenuous empiricism. The foundation of all knowledge is sense-perception. And in some ways they are to be found urging the familiar arguments of the Nominalist. ${ }^{1}$ On the other hand, when we push farther into their doctrine, we find them employing notions, calling in processes, which stand widely removed from empiricism as ordinarily understood. Perhaps here again the explanation may be found by reference to their general conception of the cosmos. The substance of things is material, and consequently the process of knowledge is represented as one of mechanical action and

1 Diog. Laert. vii. 61. (Pearson, Fr. of Zeno, 23.) 
reaction. On the other hand, the cosmos is a whole, a system; and, whatever be the substance of its parts, there is possible in relation to them and to their connexions a quite scientific intelligible or rational representation.

Thus the Stoics begin by treating the process of perception (al $\sigma \theta \eta \sigma \iota s)$ as being literally an impression, a stamp. Zeno and Cleanthes both use the word $\tau \dot{v} \pi \omega \sigma \iota \varsigma^{1}$ (obviously taken from the illustration of a block of wax used in the Thecetetus, ${ }^{2}$ probably with reference to Antisthenes). Chrysippus somewhat later maintained that sense-perception must be called an alteration (é $\tau \epsilon \rho o i \omega \sigma \iota \varsigma)$, and an alteration moreover of the rational part of the soul. ${ }^{3}$ Later Stoics insisted that senseperception was not the alteration, but the apprehension of the alteration either in the percipient or in the rational part of the soul. The effect of sense-perception was designated

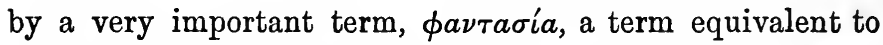
'presentation,' 4 whatever is given to mind, or is there as a content more or less definitely apprehended. On these presentations rested all knowledge; but not all presentations could be called true. ${ }^{5}$ Nor indeed-what I shall afterwards notice ${ }^{6}$ - were all presentations to be ascribed to action upon the organs of sense; presentations could spring up from other causes.7 If, then, not all sense-perceptions are true, what constitutes the ground of distinction between true and false? It was through this particular problem that the Stoics began the general discussion of the criterion of know-

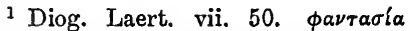
$\delta \epsilon^{\prime} \epsilon \tau \iota \tau \dot{v} \pi \omega \sigma \iota s \epsilon^{2} \nu \psi v \chi \chi \hat{\eta}$. (R.P. $484 \mathrm{a}$. Pearson, Fr. of Zeno, 7.)

2 Plato, Theat. $191 \mathrm{c}$.

3 Sext. Emp. Math. vii. 228-241. Cf. Zeller, Stoics, Epicureans, and Sceptics, 78.

${ }_{4}$ It is used by the Stoics in so comprehensive a way as to be nearly akin to 'idea' in English philosophy (as in
Locke's Essay). The problem of certainty in knowledge is more often approached in Stoic discussions from the side of $\phi a \nu \tau a \sigma i a$ than from that of $\alpha \nmid \sigma \theta \eta \sigma \iota s:$ Cicero always calls it visum.

5 Ps.-Plut. Plac. iv. 8, 9.

6 See below, p. 283.

7 Sext. Emp. Math. vii. 251. (R.P. 484 a.) 
ledge; and they introduced a number of extremely subtle distinctions, with regard to some of which it must be said that it is very difficult to find a quite uniform tendency among the Stoic writers.

First of all, we must remember that in the process of perception there is no doubt a certain stamping or impressing of the organs of sense, and so far the mind might be said to be passive. On the other hand, the mode of existence of the rational faculty is always represented as being more or less active; it stretches out towards the impressions; and these impressions, even when we regard them as made not on the organs of sense but on the rational power, are not received in a merely passive fashion. This indeed is obvious from the consideration that we do not accept as true every sensepresentation that occurs. There is then a kind of double function in sense-presentation. On the one hand it is relatively passive, on the other relatively active. Just as light makes manifest both itself and the objects that are present, so sense-presentation shows itself and also the object that has given occasion to it. ${ }^{1}$

Is there, then, in either of these aspects an element to be detected which will serve to determine when a sensepresentation is deserving of credit, or rather, must inevitably be accepted as true? To this the Stoics seem first to have said that there was in the true sense-presentation a certain

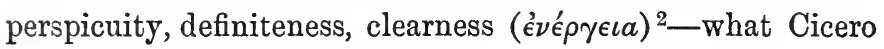
called perspicuitas or evidentia. ${ }^{3}$ This evidence it is that constitutes the ground for our judgment of assent, our affirmation that the sense-presentation represents truth. A presentation which has such qualities that it constrains

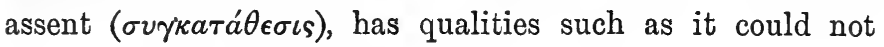

\footnotetext{
1 Ps.-Plut. Plac. iv. 12, 1. (R.P. 484 a. Pearson, Fr. of Zeno, 9.) 484 a.)

${ }^{3}$ Cic. Acad. ii. 17.

2 Sext. Emp. Math. vii. 257. (R.P.
} 
possess if there were not a real thing corresponding to it: Such presentations are true, and they constitute indeed our criterion of truth. The Stoics used in this respect a very remarkable term which has caused much trouble to inter-

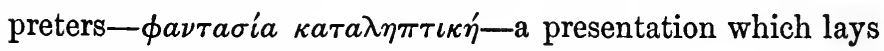
hold upon the mind and extorts from it assent. ${ }^{1}$

The doctrine of this convincing, irresistible, knowledgegiving presentation was subjected to close criticism; and the Stoics found it necessary to make very considerable additions to it. That is to say, they proceeded-and one must allow quite in accordance with their principles-to point out that, even with such presentations, knowledge was not finally attained. These presentations were, so to speak, isolated bits of knowledge. They had to be combined and arranged before they could be said to constitute science. ${ }^{2}$ The Stoics thus contemplated what may be called a genetic account of science, in the midst of which there enters a term which has played too great a part in the general accounts of their

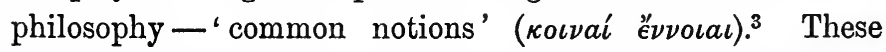
have been taken to mean innate truths; but in fact what the Stoics meant by them was that in the normal development of the human intellect certain truths appeared at a particular time, and could not appear before. The common nature which is in every man, and which indeed constitutes his link of connexion with the universe, of course expresses itself in the natural history of mind in a quite uniform way.

1 Sext. Emp. Math. vii. 247. Cf. Cicero, Acad. ii. 145. For a discussion of the meaning of $\phi \alpha \nu \tau \alpha \sigma i \alpha \kappa \alpha \tau \alpha$. $\lambda \eta \pi \tau \iota \kappa \eta$, see Pearson, Fr. of Zeno, 10. How are we to distinguish this

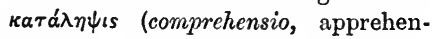
sion) from $\sigma v \gamma \kappa \alpha \tau \alpha \dot{\theta} \theta \epsilon \sigma / s$ (assent) and from kpi $\sigma i s$ (judgment)? They are closely connected probably, and their relation points towards a distinction between content and the thing which gives rise to the content. See below, p. $284 \mathrm{f}$.

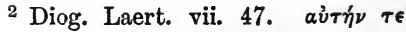

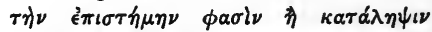

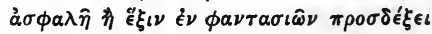

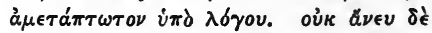

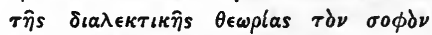

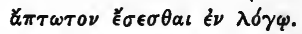

${ }^{3}$ Ps.-Plut. Plac. iv. 11, 1. (R.P. 485.) 


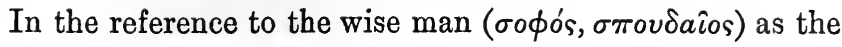
only possessor of wisdom, there is indicated one of the ways by which the Stoics sought to evade the force of the criticisms brought against their doctrine of the convincing presentation. They could hardly maintain that mistakes were impossible, that the inner perspicuity of a presentation was sufficient, even if that were increased by argument-though they maintained that there must be taken into account all the causes of error in regard to receiving a presentation. But they could maintain and did maintain that such error only indicated that the apprehending mind was not perfectly adapted to its surroundings. I Just as on the moral side any vice indicated that the man's moral nature was not in harmony with its surroundings, so in the intellectual world, if a man's reason were quite normal, if he had taken all precautions, if he had attained to wisdom, then for such a person no 'opinions' were possible; he was always right. The wise man, said the Stoics, has no opinions. ${ }^{2}$ And thus also the Stoics sought to overcome the difficulty implied in the conception of assent, which seems to combine two characteristics, freedom and constraint. Divergence between these two is a mark of imperfection. In the wise man they are identical. He never gives his assent except to what has in itself the qualities that constrain assent. He is perfectly free, perfectly necessitated.

Turn now to the passage from Cicero $^{3}$ in which Zeno's

1 Exactly anticipating $H$. Spencer.

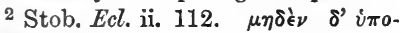

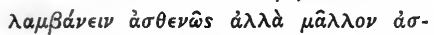

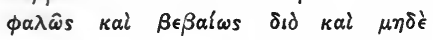

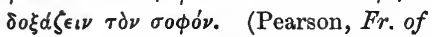
Zeno, 153.) The notion of the 'wise man' is a purely theoretical notion, equivalent to the 'absolute knowledge' of the idealist.
${ }^{3}$ Cic. Acad. ii. 145. At scire negatis quemquam rem ullam nisi sapientem. Et hoc quidem Zeno gestu conficiebat. Nam, cum extensis digitis adversam manum ostenderat, "visum " inquiebat "huiusmodi est." Deinde, cum paullum digitos contraxerat, "adsensus huiusmodi." Tum cum plane compresserat pugnumque fecerat, 
statement concerning knowledge appears. There, as the first stage - that which is symbolised by the hand just put forward with the fingers stretched out-there is what was

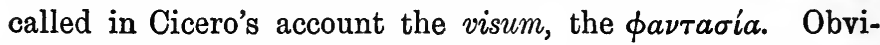
ously the intention is to emphasise the relatively passive character of the whole operation which consists in the

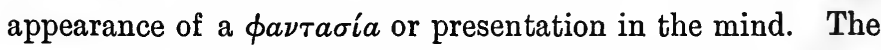

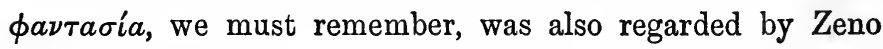
as an impression. Still, it is not to be forgotten that nowhere in the Stoic cosmos is there any exhibition of pure passivity. There must be some reaction on the part of the soul in order that the impression should be received at all. The Stoics might say, so far following Aristotle, that the soul, before impressions were made upon it, was like a tablet on which nothing was written; but they could not forget that the tablet in such a case was anything but purely receptive,- - that it had its own special and variable degree of tension, and must therefore react when stimulated. It is far from clear what function this reaction discharges in the theory of knowledge. The presentation ( $\phi a \nu \tau a \sigma i a)$ is always with the Stoics a content of mind, somethirg at which the inner eye looks and about which our thinking may be exercised. Is it possible that the reaction should be indicated by that second process which Zeno indicated by the figure of slightly bending his fingers, and which Cicero calls adsensus

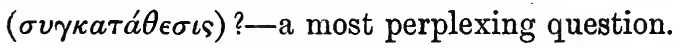

To some extent this view would appear correct. Every

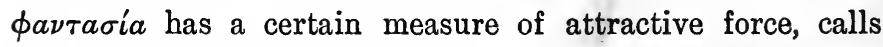
forth assent to a certain amount. The assent might therefore fairly be regarded as, so to speak, the subjective contri-

comprehensionem illam esse dicebat: qua ex similitudine nomen ei rei

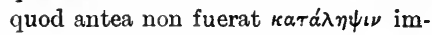
posuit. Cum autem laevam manum adverterat et illum pugnum arte vehementerque compresserat scientiam talem esse dicebat, cuius com. potem nisi sapientem esse neminem. (Pearson, Fr. of Zeno, 33.) 
bution to the whole process of having a presentation. At the same time, it must be allowed that the Stoics use this term $\sigma \nu \gamma \kappa a \tau a \dot{\theta} \theta \epsilon \sigma \iota$ with a great variety of references; and in particular it becomes equivalent in them to the acceptance as true of some judgment propounded or contemplated. Perhaps here it might be possible to establish some kind of genetic connexion. In the same way, in regard to a corresponding modern problem, one may think that there is a most intimate relation-a relation of dependence-between the objectivity which presents itself first at the lower stage of perception, and the highly abstract conception of objective order which appears as implied in our developed judgments.

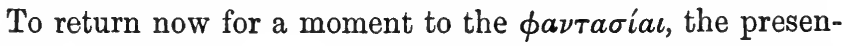
tations. Cicero's passage gives no indication of any variation in the sources from which presentations may come. It is

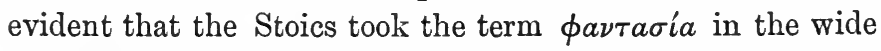
acceptation in which 'presentation' has been employed in modern psychology, and included thereunder all contents of consciousness. Of these no doubt sense-perceptions were the most important, and they perhaps lent themselves the most readily to explanation by the metaphor 'impression.' But there were others. The Stoics allowed of presentations that had no real counterparts, not only for the moment, but from the nature of what was represented. They allowed of presentations of moral qualities and of the divine, both of which, though corporeal, yet did not fall within the direct sphere of sense-perception,-for example, the judgment 'this is good ' or 'is bad.' Such presentations were said by the Stoics to be formed by the understanding. ${ }^{1}$ Evidently in their case, as in the case of sense-presentations, the presentation itself is no guarantee for the existence of the corresponding reality. The senses may deceive us. (This the Epicureans denied.)

1 Ps.-Plut. Plac. iv. 11, 1. (R.P. 485.) 
The Stoics perhaps originally contented themselves with maintaining that, so far at least as sense-presentations were concerned, there must be points of difference sufficient to distinguish a true from a false presentation. Doubtless in support of this they advanced their general proposition that in the universe there are no two things absolutely identical. There are always differences, which it is therefore possible to apprehend.

If this were the first position taken by the Stoics, it becomes intelligible how they should lay the greater stress on what may be called the internal characters of the true presentation. It is by its own light that the true presentation demonstrates its truth. And thus the presentation possessed of such internal clearness and distinctness might have been regarded by them as one that constrained assent. Still, against this there has to be put the doubt as to whether by the expression 'constrained assent' we have correctly signified what is called by 'Cicero here comprehensio ( $\kappa \tau \tau a ́ \lambda \eta \psi \iota \varsigma)$, and indicated by the figure of the clenched fist. It would almost seem as though there were involved that reference from the presentation to the thing of which it is the symbol, whereby we have knowledge of the thing. The state of mind would be that in which we assert without hesitation that there does exist, and must exist, an object corresponding to the presentation in consciousness. The consciousness, the intellectual reference to the outer world, which is distinguished from the presentation, seems to be involved in the idea of comprehensio. The total state of mind is that in which the presentation plays its appropriate part as an instrument of knowledge.

It is quite in accordance with this interpretation that we should find the Stoics later admitting the need for going beyond the internal characters of the presentation and considering what may be called the external relations; for ex- 
perience shows that it is very possible to be deceived even in regard to presentations that seem clear and distinct. Accordingly, all such presentations have to be tested in accordance with such rules of evidence as can be deduced from the general conception of science. Here again, in the case of this comprehensio, the Stoics leave us in the dark as to what is the subjective contribution. It is doubtless some form of assent or judgment-perhaps a judgment that is, so to speak, expressed with a special degree of force. Indeed, their whole manner of conceiving this problem brings them near to the modern representation of the process as consisting in a combination, an adaptation, of outer impression to inner belief.

'Belief' is just the term we want as an equivalent to

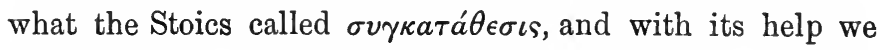
can do justice, I think, to both sides of the Stoic doctrine. For the Stoics desire to do two things: first, to explain objective knowledge from the characteristics of the presentation; and secondly, to allow a share to the reaction of the individual soul on the change produced in it by the presentation. Were the whole weight placed upon the external conditions, the arguments of the Sceptics would be irresistible. But the external characters are not altogether sufficient. On the other hand, the whole weight must not be placed on the internal, for that would place human thinking out of its relation to the system of things. The Stoics do their best to keep both sides together. The external characters are those from which we start. They are, with due correction, those to which we return. The correction which is essential they receive by the inner processes of thinking. What they meant, then, by Belief (as we may call it) is not a purely blind emotional condition, but a state more or less intellectual, capable of finally being made intellectual in the highest degree. 
These inner processes that have been referred to are symbolised, in the passage quoted from Cicero, by the figure of the one hand laid upon and compressing the closed fist. This is called $\dot{\epsilon} \pi \iota \tau \eta^{\prime} \mu \eta$ (science); and here the Stoic teaching is more than usually full of apparent contradictions. There can be no doubt that the Stoics expressed themselves at times in such a manner as to imply a doctrine very much like that of innate ideas. On the other hand, at times they indulge in the crudest empiricism.

The truth is that their position enables them to combine both. The human soul and its rational part has a structure or nature of its own-that is to say, expressive of its place in the universe; and there are a variety of ways in which that implicit nature may become explicit. The preconceptions or common notions, which the Stoics undoubtedly allow to the human mind, might be explained by them in either of the two ways: either as results to which all who develop normally arrive at definite stages, or as expressions of the common nature of all called forth by special occasions. The Stoics did not regard these two ways as in complete opposition. Rather their systematic point of view compelled them to identify them.

There is one part of the Stoic doctrine of knowledge that does not find a place in this treatment of the criterion of truth. The Stoics, as we saw, regarded everything real as corporeal. But they allowed that there were certain things incorporeal and therefore unreal, ${ }^{1}$ and yet not absolutely to be excluded from the realm of existence. In the first place, it followed from the comprehensive picture they entertained of the totality of physical existence that it was one and limited; the world of real existence had therefore to be conceived as having beyond its limits the void, regarded no

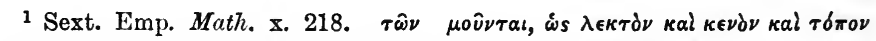

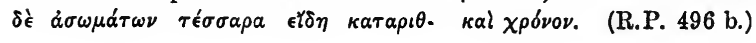




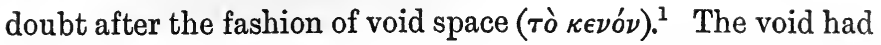
to be admitted as in some way existing, but it lay outside the cosmos in which there was no void, and was therefore incorporeal. Likewise they regarded as incorporeal, and yet as somehow requiring recognition in the scheme of things, place and time, local and temporal position, andmost interesting of all-what they called 'the uttered' ( $\tau \dot{a}$

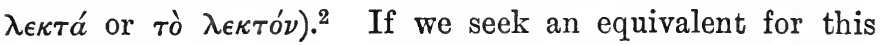
conception in modern language, we shall only find it by the help of the distinctions which one draws in logic and psychology between (1) the verbal act of representing an idea $\left(\sigma \eta \mu a \hat{\imath} \nu o \nu, \phi \omega \nu \eta^{\prime}\right),(2)$ the objective facts to which this representation refers ( $\left.\tau v \gamma \chi a \chi^{\prime} \nu \nu\right)$, and (3) the content of the representation itself ( $\sigma \eta \mu a \iota \nu o ́ \mu \epsilon \nu o \nu, \lambda \epsilon \kappa \tau o ́ \nu)$. Or take, for example, as the Stoics did, a word. We distinguish there (1) the particular sound; (2) the object referred to, John as he exists for himself ; and (3) the signification or meaning, what is said in or by the word. It is this third element

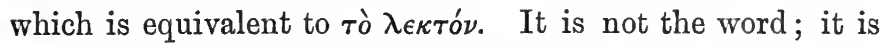
not the thing; it is something between, tied up with the other two factors but not identical with either. ${ }^{3}$ The Stoics (with a few exceptions) had to say that it existed. It is a doctrine which, carelessly stated, can easily lead to the doctrine of representative ideas. A presentation is corporeal; the things apprehended thereby are corporeal; the

${ }^{1}$ Diog. Laert. vii. 140. (R.P. 496.)

${ }^{2}$ Sext. Emp. Math.viii.11. oi àmò $\tau \hat{\eta} s$

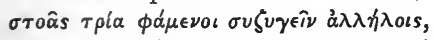

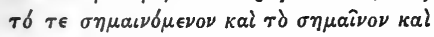

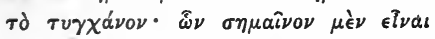

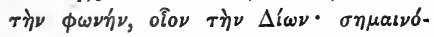

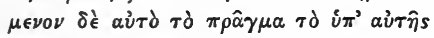

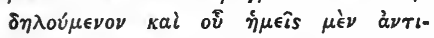

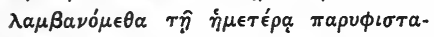

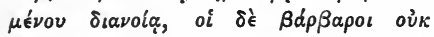

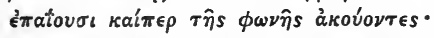

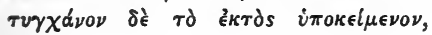

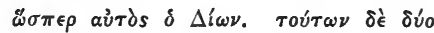

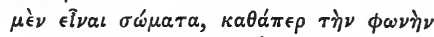

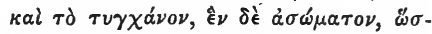

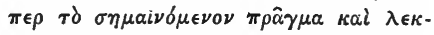

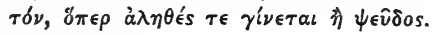
(R.P. 487.)

3 Ammon. De Interpr. 100 a 10 ed.

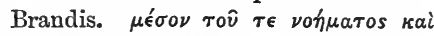

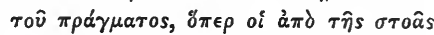

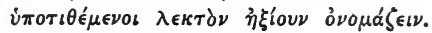
(R.P. 487 a.) 
word is also corporeal; but the meaning of the word (тò $\lambda \epsilon \kappa \tau o ́ \nu)$ is incorporeal. It seems to me that here again we find the Stoics raising a problem of extreme interest which their doctrine did not enable them satisfactorily to solve. It is the same distinction as that between the true and the really existent. Our words, our thoughts, habitually imply reference to an order which nevertheless cannot be simply or without qualification identified with the actual order of fact.

The Stoics seem to have been led to this speculation through their discussion with regard to general terms. They were thorough-going nominalists in one way; but on the other hand they could not fail to see that general terms pre-eminently, many other terms in less degree, indicated what was thought of and yet from its nature could not find a place in the cosmos. They raised the problem but gave no solution. 


\section{CHAPTER IV}

\section{ETHICS}

THe fundamental position of the Stoic Ethics follows very directly from the more comprehensive speculative doctrines. There are, of course, differences in that fundamental position, arising very largely from some differences among the Stoics regarding the relation between intellectual apprehension and volition. Impulse, however, on the whole the Stoics tend, if । not to identify with intelligence, at least to keep in the closest relation therewith. The whole action of man is therefore to be regarded, like his rational life, as the expression on the one hand of his nature, and on the other of his position in the scheme of things. ${ }^{1}$ Everything has a constitution. Man, therefore, by reason of the fact that his constitution is emphatically reason, has a final end prescribed for him, a life in conformity with nature-that is, with reason. Such a character exhibits itself first in its tendency to act in accordance with the fundamental constitution of the agent. The primitive impulse may therefore fairly be called effort after preservation. ${ }^{2}$ This term is all-comprehensive, for it names not only the minimum required for the continuance of animal life but also the full development of what is possible for the rational nature. Modes of action which

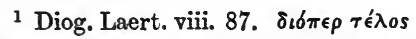

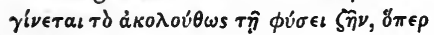

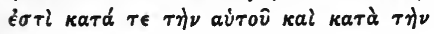

$\tau \hat{\omega} \nu \delta \lambda \omega \nu . \quad$ (R.P. 514 b.)

${ }^{2}$ See R.P. 515 and notes a, b, c. 
thus correspond to what is involved in the nature of the

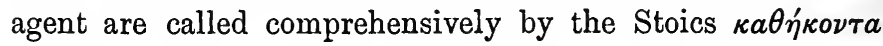
-officia, duties. Among such duties we may, of course, distinguish a gradation from those which lie closest to the individual to those which take in the fortunes and actions of others. All duties have a natural foundation. Sociability and the like have as foundations, first, the natural impulse of friendliness; secondly, the fact that all men form part of one and the same complete system, that they are organic parts of the whole, that the soul of each individual is but a part of the universe, and that therefore for all men there is one state and one law. ${ }^{1}$ This all-embracing state is the end for which our individual nature is constructed, whence it is the natural duty of the individual to prefer the welfare of the whole to his own interest.

So far it has seemed as if nature, working in man, prescribed the first code of moral duties and determined the social structure within which such duties find scope for their realisation. But the nature of man is more than mere impulse $\left(\delta \rho \mu \eta^{\prime}\right)^{2} \quad$ There is in him the power of considering, judging, estimating the relative worth of what is brought before him in a merely mechanical fashion. On this first

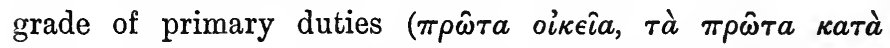
$\phi v ́ \sigma \nu)$ there is superinduced in strict conformity with nature a second code, or re-reading of the primary duties in the light of reflective self-consciousness. More is required of a reasonable being than that he should just act in accordance

1 Cf. M. Aurel. vii. 9. $\pi \alpha ́ \nu \tau \alpha$

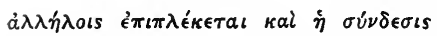

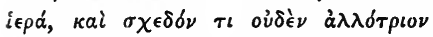

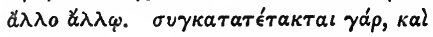

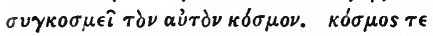

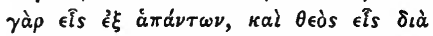

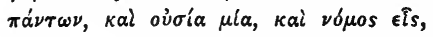

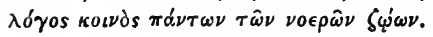

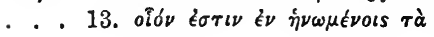

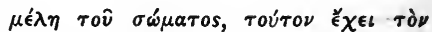

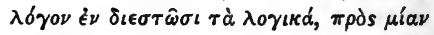

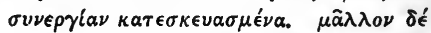

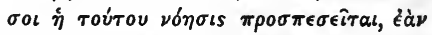

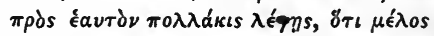

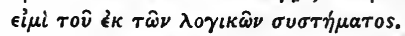

2 In the case of the lower animals what is $\kappa \alpha \tau \check{\alpha} \tau \dot{\eta} \nu \phi v \sigma \omega \nu$ is simply what is $\kappa \alpha \tau d \tau \eta \eta \nu \nu \delta \mu \eta \dot{\eta}$. 
with his nature. A rational being cannot just mechanically act in accordance with his nature. $\mathrm{He}$ is aware of his impulses, and apprehends in them an order and arrangement such as he discerns in the universe at large.

The full and comprehensive ground for the action of a rational being therefore involves a certain harmonious symmetrical arrangement of the natural impulses. (Hence the Stoics always tend to identify the good and the beautiful.) The full and complete ground could be called perfection. From this distinction arises a very important doctrine of the Stoic ethics: Virtue is life in accordance with reason-life, therefore, which has not only natural ends but in which the natural ends have been brought into proportion and harmony by reason. Even the primary duty when performed has no excellence unless illuminated by the light of reason,-unless performed on the rational ground that for a reasonable being such an action is absolutely necessary. The primary duties at this stage become morally right actions which are performed from right impulse, which are recognised as to be done on account of their rightness, $\kappa a \tau о \rho \theta \dot{\omega} \mu а \tau a$. This marks the transition from natural good to moral good. The distinction, once drawn, rapidly became sharper. The Stoics as a whole, especially the more rigorous of them, tended to emphasise the perfection ( $\tau \epsilon \lambda \epsilon \iota$ ó $\tau \eta s$ ) of actions right in themselves and done for the sake of their rightness. Only such constituted the virtuous conduct of the good man ( $\sigma \pi 0 v \delta a i o s, \sigma o \phi o ́ s)$. Some of the Stoics tended to follow the Cynic line of according moral value only to the inner disposition, and of regarding the outer act as in itself indifferent. All other actions were vicious-a strenuousness of distinction which had to be mitigated by the re-admission of some $\kappa a \theta \eta^{\prime} \kappa o \nu \tau a$ as $\mu \epsilon^{\prime} \sigma a \iota \pi \rho a ́ \xi \xi \iota s$. Looking to the end or choice of the good, the absolute distinction between the one perfect good and all else as evil had to be mitigated by 
admitting the wide class of $a \delta \iota a ́ \phi o p a$, indifferent actions, which were subdivided into the relatively preferable $(\pi \rho \circ \gamma \gamma-$

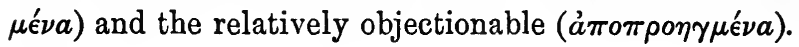

It is part of the Stoic tendency to unity of principle that just as they removed the Aristotelian distinction between reason and the lower functions of the soul, so with much exaggeration they endeavoured to hold fast to the unity of virtue. From the exaggerated statement that all virtues are one, they drew the still more exasperating conclusion that he who has one virtue has all, so that he who is without one is absolutely vicious. But their doctrine of the unity of virtue, more sanely considered, must be interpreted just as we interpret the unity of the soul-that is, as compatible with differences, nay, even as requiring differences in order that the unity may exist. Virtue is not the principle of any one line of action. They gave it the name $\delta \iota a ́ \theta \epsilon \sigma \iota s$ (disposition), a certain settled and permanent state of the soul with regard to action. ${ }^{1}$ Now for a rational being the essential in every such disposition is insight, power of recognising the true relations of things. They thus tended to reproduce, though with important modifications, the old Socratic definition that virtue is knowledge. They evaded the difficulties of Socrates partly by denying the absoluteness of the popular antithesis between knowing and desiring or acting, partly by defining in so concrete a fashion the notion of knowledge that there could be involved in it the characteristic distinct virtues. Thus, for example, in knowledge as required for right action there are implied the four primary virtues-

(1) The relatively more intellectual recognition called

1 The Stoics to some extent reverse $=a \quad \xi_{\xi}(s$ which does not admit of the Aristotelian use of the words $" \xi / s$ variation in intensity. See Stob. Ecl. and $\delta$ เd$\theta \epsilon \sigma \iota s$. With them the latter ii. 7, $5:$ Diog. Laert. vii. 98. 


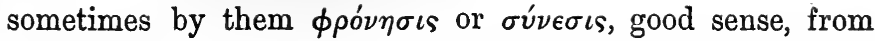
which followed in application good judgment, tactfulness, quickness of perception, dexterity.

(2) Knowledge implies further that power of bearing up on the part of the individual against what seems evil, against his wishes-in short, that which constitutes Courage

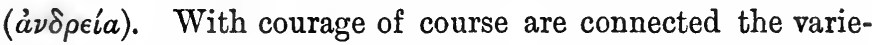
ties of elevation, strength of mind, endurance, perseverance, firmness, all involving and dependent on the quiet confidence in things and in himself, which only the wise man enjoys. (Note how paradoxical any moral doctrine becomes when pressed home.)

(3) The wise man must have as one component of his wisdom that temper which corresponds to his true attitude in regard to that very important component of natural experience, pleasure. The characteristic excellence here is Temperance $(\sigma \omega \phi \rho o \sigma u ́ \nu \eta)$, with which goes invincibility as against the assaults of pleasure, modesty or decorousness, orderliness, moderation.

(4) Wisdom was not, so to speak, an individual fact in the scheme of things recognition of which in its true relations constitutes knowledge. Our fellow-men occupy in it an important determining place, the knowledge of which, involving recognition of our due relations to others, constitutes the characteristic excellence of Justice ( ing fairness, integrity, honesty, \&c. ${ }^{1}$

Thus the Stoics managed to recognise and reproduce the familiar fourfold classification of the virtues presented by Plato. They were inclined to sum up the practical and the theoretical in the ideal concrete form of the Wise Man who has all intellectual excellence and all moral dispositions; whose mode of life, therefore, and action are the

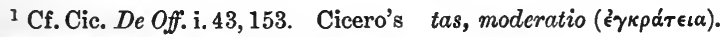
list is justitia, prudentia, magnanimi. 
perfect expression of what ought to be, and who therefore enjoys by right the concomitant of perfect action, perfect happiness.

I said it was almost inevitable that the Stoics should find difficulties in working out their conception of a single principle expressed in an infinite variety of individual forms. The difficulties to some extent resemble the difficulties met with in dealing with the notion of space and time-namely, to do justice to both factors, continuity and discreteness. To the Stoics the difficulty arises from their tendency to make distinctions too absolute for accommodation to their other conception, singleness of principle, which can only admit of differences in degree. ${ }^{1}$

1 The Sceptics turned against the Stoics, particularly against Chrysippus, a favourite form of argument, namely, $\sigma \omega \rho \epsilon i \tau \eta s$, which is really the fallacy termed 'the heap,' or 'the baldhead.' Now Chrysippus, when pressed by arguments of this type, seems to have taken refuge in the arbitrary resolve to go no farther. He in fact just called a halt $(\dot{\eta} \sigma v \chi \dot{\alpha} \zeta \epsilon i \nu)$. See Sext. Emp. Math. vii. 416. 


\title{
INDEX OF AUTHORITIES
}

\author{
(The references are throughout to the footnotes.)
}

\section{Achilles (3rd century A.D.)}

Isagoge in A rati Phenomena, 128 (in Uranologion of Petavius) (R.P. 103), p. 31.

Alexander of Aphrodisias (Al. 200 A.D.)

Comm. in Aristotelis Metaphysica, 84 (ed. Hayduck), p. 89. Ammonius (fl. 500 A.D.)

Comm. in Aristotelis librum de Interpretatione, 100 a 10 (ed. Brandis) (R.P. 487 a), p. 287.

Aristotle (384-322 B.c.)

Analytica Posteriora-

Book i.

$$
\begin{aligned}
& \text { c. } 3, \text { p. } 190 ; \\
& 71 \text { b } 19, \text { p. } 190 ; \\
& 71 \text { b } 33, \text { p. } 186 ; \\
& 75 \text { a } 39, \text { p. } 171 ; \\
& 76 \text { b } 11,37, \text { p. } 171 ; \\
& 77 \text { a } 5, \text { p. } 179 ;
\end{aligned}
$$

Book ii.

$$
\begin{aligned}
& \text { c. } 19, \text { p. } 232 ; \\
& 97 \text { a } 6, \text { p. } 143 ; \\
& 99 \text { b } 35, \text { p. } 208 ; \\
& 99 \text { b } 36, \text { p. } 204 ; \\
& 100 \text { a } 5, \text { b } 4, \text { p. } 185 .
\end{aligned}
$$

Analytica Priora, i. 24 a 22, p. 170 ; ii. 68 b 15, p. 189.

Ars Rhetorica, iii. 1407 b 14, 15, pp. 42, 43.

De Anima-

Book i.

cc. $2 \cdot 5$, p. 199 ; 403 a 1, p. 172 ; 404 a 17, p. 27 ; 404 a 27, p. 65 ; 404 b 7, p. 58 ; 405 a 19, p. 6 ; 407 b 20, p. 27 ; 407 b 23, p. 165 ; 411 a 7, p. 6.

\section{Book ii.}

$$
\begin{aligned}
& \text { cc. } 5,12, \text { p. } 208 \text {; } \\
& \text { cc. } 7.11, \text { p. } 205 ; \\
& 412 \text { a } 7,16,21,28 \\
& \text { p. } 201 ;
\end{aligned}
$$

412 a 13, p. 199;; 412 a 14, p. 164 ; 412 a 22,27, b 6 , b 17 , p. 202 ; 412 a 27, p. 163 ; 413 a 3 , p. 217 ; 413 a 31, b 2, p. 203 ; 413 b 4, p. 204 ; 415 b 3, p. 165 ; 416 b 33, p. 208 ; 417 b 6, 16, p. 209 ; 417 b 23, p. 179 ; 418 a 6, p. 206 ; 418 a 10 , p. 205. 
De Anima (continued)-

Book iii.

cc. 1,2 , p. 208 ;

c. 3, p. 213 ;

cc. $6,7,8$, p. 221 ;

cc. 12,13, p. 205 ;

424 b $22-425$ a 13 , p. 205 ;

425 a 15,20, p. 206 ; 425 b 12-25, p. 207 ;

425 b 4-17, p. 210 ;

425 b 26, p. 209 ;

426 b 12, pp. 207 ,

211 ;

426 b 20, p. 208 ;

427 a 21, p. 58 ;

428 a 5, 18, p. 214 ;

429 a 10,22 , p. 219 ;
429 a 14, 27, p. 218 ;

429 a 18, 29, p. 217 ;

429 a 24, p. 167 ;

429 b 5, p. 244 ;

429 b 16, p. 218 ; 22 , p. 227 ;

429 b 26, p. 225 ;

429 b 30, p. 247 ;

430 a 1 , p. 247 ;

430 a 3, p. 225 ;

430 a 10,14 , p. 220 ;

430 a $17-25$, p. 221 ;

430 a 22, p. 227 ;

430 a 30, p. 57 ;

431 a 16, p. 215 ;

431 a 20, p. 222 ;

432 a 10-14, p. 216 ;

434 b 21, p. 204.

De Animalium Generatione-

ii. 736 b 28 , pp. 167,230 ;

iii. 759 b 10, p. 157.

De Ceclo, i. 269 a 30, p. 230 ; iii. 300 b 8, p. 62 ; 300 b 29, p. 57.

De Generatione et Corruptione, i. c. 5, p. 161 ; 315 b 9, p. 51 ; 322 b 13,

p. $54 ; 324$ b 35 , p. 59 ; 325 a 23 , p. 51.

De Juventute, 469 a 10 , p. 208.

De Memoria, 449 b 26, p. 216 ; 451 b 22, p. 217 ; 453 a 14, p. 216.

De Sensu, c. 7, p. 211.

Ethica Nicomachea-

i. 1098 a 16, p. 244 ; vi. 1143 b 4, p. 184 ; x. c. 7, p. 244 ; 1177 b 34, p. 230.

\section{Metaphysica-}

A c. 6, p. 127 ; c. 9 , p. $132 ; 980$ a 30, p. $204 ; 980$ b 28, p. 185 ; 983 b 6, p. $3 ; 983$ b $20,21,22$, pp. 5,$6 ; 985$ a 18, p. 53 ; 985 a 21 , p. 56 ; 985 b 4, p. 59 ; 985 b 13, p. 61 ; 985 b 23, p. $20 ; 986$ a 17 , p. $23 ; 986$ a 29 , p. $27 ; 986$ b 10, p. 30 ; 990 b, 15, 991 b 6, p. 123 ; 992 b 8, p. 135 .

Г c. 4, p. 174 ; c. 5 , p. $175 ; 1005$ b 2 , p. $174 ; 1005$ b 18, p. 172 ; 1005 b 19, 24, p. $173 ; 1006$ a 5, p. $174 ; 1007$ a 4, 8, p. 175; 1007 b 25, p. 54 ; 1009 b 22, p. 33 ; 1011 b 25, p. 173.

$\Delta 1024$ b 32, p. 80.

Z 1028 b 15, p. 23 ; 1028 b 21, p. 141 ; 1029 a 20, p. 153 ; 1032 a

13, p. $153 ; 1036$ a 9 , pp. $158,167$.

H 1043 b 23, p. 80 ; 1045 a 33, p. 167.

$\Theta$ c. 10, p. 196.

$\Lambda$ cc. 7,9 , p. 225 ; 1069 b 36, p. 153 ; 1072 b 3, pp. 162, 241 ; b 30, p. $140 ; 1074$ b 34, p. 226 ; 1075 a 14, p. $241 ; 1076$ b 1, p. 141.

$\mathrm{M}$ and N, p. 132.

M c. 6, p. $95 ; 1078$ b 9 , p. $93 ; 1078$ b 23, p. 74 .

N 1090 b 19, p. $141 ; 1091$ b 33, p. 142. 
Physica-

i. cc. 2 f., p. 34 ; c. 7 , p. $158 ; 187$ a 12 , p. $14 ; 187$ a 20, p. $8 ; 187$ a 26, p. $50 ; 191$ a 8, p. 158 ;

ii. c. 1 , p. 156 ; cc. $4-6$, p. 157 ; 198 b 29 , p. 57 ; 199 b 1, p. 157 ;

iii. 204 b 22, p. 9 ; 207 a 13 , p. 36 . iv. 213 b 22 , p. 25 .

จ. 224 b 35, p. 155 . vi. 239 b $9,14,30,33$, pp. 39,40 .

Topica, i. 105 a 13, p. 188.

See also Pseudo-Aristotle.

Aristoxenus (c. 320 B.C.)

Elementa Harmonica, ii. 30, p. 128.

Averroës (Ibn Roschd) (1126-1198 A.D.)

De Animce Beatitudine, 354, p. 253.

Cicero (106-43 в.c.)

Academica, ii. 17, p. 279 ; ii. 145, pp. 280, 281.

De Fato, 17, p. 84 .

De Deorum Natura, i. 25, p. 11.

De Officiis, i. 43, 153, p. 293.

Cleanthes (300-220 B.c.)

Fragments (ed. Pearson), 1, p. 262 ; 24, pp. 266, 270 ; 36, p. 266.

Clemens Alexandrinus (c. 200 A.D.)

Stromateis, i. 69 (R.P. 188), p. 60 ; v. 14 (R.P. 35), p. 45 ; v. 714 (R.P. 100), p. 30 .

Protrepticus, 61 (R.P. 285), p. 89.

Diogenes Laertius (2nd century A.D. (?))

ii. 1 (R.P. 15), p. 7 ;

6 (R.P. 153), p. 49 ;

106, 107 (R.P. 290, 291),

p. 84 ;

119 (R.P. 300), p. 87 ;

vii. 2 (R.P. 477 ), p. 259 ;

4, p. 259 ;

41, p. 262 ;

47 , p. 280 ;

50 (R.P. 484 a), p. 278 ;

61, p. 277 ;

98 , p. 292 ;

134 (R.P. 493), p. 265 ;

137 (R.P. 504), p. 269 ;

140 (R.P. 496), p. 287 ;

156 (R.P. 494 a), p. 266 ;

159 (R.P. 511), p. 275 ;

viii. 6 (R.P. 31 a), p. 18 ;

36 (R.P. 88 ), p. 19 ;

87 (R.P. 514 b), p. 289 ;

ix. 31 (R.P. 197), p. 63 ;

50 (R.P. 226), p. 71 ;

51 (R.P. 227), p. 71.

Hippolytus (c. 160-236 A.D.)

Refutatio Omnium Horesium, i. 6 (R.P. 17 a), p. 11 ; i. 7 (R.P. 28), p. 16 ;

i. 13 (R.P. 198), p. 63 ; ix. 10 (R.P. 36 a), p. 46.

Iamblichus (ob. c. 330 A.D.)

Theologumena A rithmeticce, 22 (R.P. 85), p. 27.

Isocrates (436-338 B.c.)

Laudatio Helence, i. 1, p. 80.

Lucretius (95-51 B.c.)

De Rerum Natura, i. 690 ff., p. 47. 
Marcus Aurelius Antoninus (121-180 A.D.)

Eis 'Eavtbv, vii. 9, p. 290 ; 13, p. 290.

Nemesius (c. 300 A.D.)

De Natura Hominis, 32 (R.P. 507), p. 266 ; 96, p. 276.

Philodemus (fl. 80 B.C.)

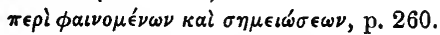

Plato (427-347 B.c.)

Cratylus, 400 c, p. 27 ; 402 A, p. 44.

Gorgias, p. 69.

Leges, x. 889 E, 891 , p. 139 ; x. 896 f., p. 117.

Meno, 80 ff., p. 102.

Parmenides, 128 c, p. 37 ; 126-137, p. 105 ; 132, 133, p. 106 ; 132, p. $139 ; 134$, p. $254 ; 135$, p. 108.

Phcedo, 62 в, p. 27 ; 72, p. $115 ; 72$ ff., p. $102 ; 85$ ff., p. $28 ; 95$ ff., p. 76 ; 96 в, p. 27 ; 97 f., p. 53 ; 105 , p. 116.

Phoedrus, 244 D, p. 20 ; 245 c, p. 117 ; 249 f., p. 102 ; 265 D E, p. 100.

Philebus, 16 f., p. 111 ; 26 D, pp. 102, 112.

Respublica, v. 478 , p. 99 ; vi. 487 f., p. 69 ; 508 f., p. 220 ; 509 f., p. 101 ; vi. sub. fin. and vii., p. 94 ; ix. 583 B, p. 66 ; х. 596, pp. 97,100 ; 597, p. 119.

Sophistes, 246-248, p. 87 ; 247 D, p. 265 ; 248, p. 83.

Symposium, 204, p. 108.

Thecetetus, 151 ff., pp. 46, 79; 152 A, p. $71 ; 180$, p. $42 ; 189$ E, p. 73 ; 191 c, p. 278 ; 191-195, p. 83 ; 201 D, ff., p. 81.

Timceus, 30 в, pp. 117, 131 ; 30 ff., p. 119 ; 31 ff., 35 А, p. 120 ; 38 в, p. $116 ; 48$ A, p. $121 ; 48$ E, p. $120 ; 50$ c, p. $121 ; 51$ D, p. $97 ; 52$ A, p. $124 ; 52$ в, p. $158 ; 55$ c, p. 25 ; 70 ff., p. 122.

Plutarch (fl. 68-125 A.D.)

Adversus Coloten, 23, 1120, p. 86.

De Communibus Notitiis, 36, 5 (R.P. 499), p. 272 ; 45, 2 (R.P. 490 a), p. 266.

De Stoicorum Repugnantiis, 43, 4 (R.P. 492 a), p. 267.

See also Pseudo-Plutarch.

Proclus (410-485 A.D.)

Comm. in primum Euclidis elementorum librum (ed. Friedlein), 35, p. 22 ; 65, p. 21.

Comn. in Platonis Parmenidem, 131 e, p. 145.

Comm. in Platonis Timceum, 105 (R.P. 114), p. 32.

Pseudo-Aristotle.

De Melisso Xenophane Gorgia, 979 a 13, 980 a 19 (R.P. 236, 238), p. 72.

Pseudo-Plutarch.

Placita, i. 3,3, p. 14 ; i. 3,4 , p. 16 ; i. 3,20 , p. 55 ; i. 3,29 , p. 61 ; i. 7,33 (R.P. 494 ), p. 271 ; ii. 6,5 , p. 25 ; iv. 4,4 (R.P. 509 ), p. 276 ; iv. 8 , (R.P. 202), p. 64 ; iv. 8,9 (R.P. 484 a), p. 278 ; iv. 11,1 (R.P. 485 ), pp. 280,283 ; iv. 12,1 (R.P. 484 a), p. 279.

Stromateis, fr. 2, p. 12.

Seneca (5-65 A.D.)

Epistoke ad Lucilium, 107, 11, p. 274. 
Sextus Empiricus (180-210 A.D.)

Adversus Mathematicos-

vii. 17, 19 (R.P. 482 b), p. 261 ; 49 (R.P. 104), p. 31 ; 77 (R.P. 237), p. $72 ; 110$ (R.P. 104), p. 31 ; 135 (R.P. 204), pp. 63, 65; 145 (R.P. 354 ), p. $140 ; 147$ (R.P. 358), p. 144 ; 191, p. 79 ; 228-241, p. 278 ; 247 , p. 280 ; 251 (R.P. 484 a), p. $278 ; 257$, p. 279 ; 389, p. 66 ; 416, p. 294.

viii. 11 (R.P. 487), p. 287 ; 90 (R.P. 161), p. 54 ; 326 (R.P. 104), p. 31.

ix. 18 , p. $70 ; 19$ (R.P. 203), p. 64 ; 51, p. $70 ; 101$, p. $272 ; 102$ (R.P. 510), p. 275 ; 144 (R.P. 102), p. $30 ; 228$, p. 273.

x. 85 (R.P. 296), p. 85 ; 218 (R.P. 496 b), p. 286.

Pyrrhonice Hypotyposes, iii. 14, p. 273.

Simplicius (c. 536 A.D.)

Comm. in Aristotelis libros de Ccelo (ed. Heiberg), 558, 21 (R.P. 147), p. 40.

Comm. in A ristotelis Physica (ed. Diels)-

23, 4 (R.P. 109), p. 31 ; 23, 6 (R.P. 110 a), p. 31 ; 23, 18 (R.P. 108 a), p. $30 ; 24,13$ (R.P. 16), pp. 7, 8, 9 ; 26, 28 (R.P. 28), p. $16 ; 39,1$ (R.P. 121), p. $33 ; 87,6,110,1$ (R.P. 146), p. 40 ; 138, 10 (R.P. 362 ), p. 146 ; 139, 5 (R.P. 132), p. 38 ; 140, 28 (R.P. 133), p. 38 ; 144, 25 (R.P. 117 f), p. 32 ; 151, 30 (R.P. 208), pp. 54, 128 ; 152, 11 (R.P. 210), p. 54 ; 156, 13 (R.P. 155), p. 53 ; 158, 1 (R.P. 166), p. $56 ; 164,23$ (R.P. 160 b), p. $52 ; 189,1$ (R.P. 103), p. $31 ; 562,3$ (R.P. 135), p. 38 ; 732, 30, p. 20 ; 1108, 18 (R.P. 131), p. 38.

Comm. in Aristotelis Categorias (ed. Brandis), 66 b 45, p. 81 .

Stobæus, Johannes (c. 470 A.D.)

Eclogce Physicce, i. 62 (R.P. 359), p. 145 ; i. 372 (R.P. 500), p. 266 ; i. 488 (R.P. 81 ), p. 24 ; ii. 7,5 , p. 292 ; ii. 112 , p. 281.

Themistius (c. 310-390 A.D.)

Periphrasis Aristotelis librorum de Anima (ed. Spengel), ii. 64, 25, p. 271. Theophrastus (Al. 322-288 B.c.)

De Sensibus, 7 (R.P. 177 b), p. 58 ; 27, 29 (R.P. 161 c), p. 53 ; 39 (R.P. 208 a), p. 54 ; 62 (R.P. 199), p. 61 ; 69 (R.P. 204 l), p. 64.

Fragmenta, 2 (R.P. 16), pp. 7, 8, 9.

Xenophon (430-355 B.c.)

Memorabilia, i. 1, 14-16, p. 76.

Zeno (fl. c. 290 B.c.)

Fragments (ed. Pearson), 7, p. $278 ; 9$, p. $279 ; 10$, p. $280 ; 23$, p. 277 ; 33 , p. 282 ; 35 , p. $265 ; 43$, p. $271 ; 46$, p. 266 ; 93 , p. $276 ; 153$, p. 281. 


\section{INDEX OF GREEK WORDS}

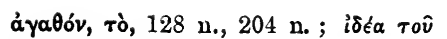

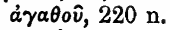

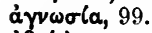

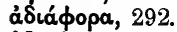

ásıкía, 8.

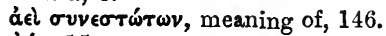

áńp, 15.

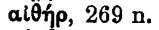

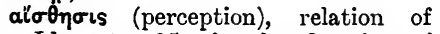
Ideas to, 95 ; in the doctrine of à $\nu \alpha \mu \nu \eta \sigma \iota s, 102$; (sense-perception), antithesis between, and $\nu \delta ́ \eta \sigma \iota s$ modified by Speusippus, 140 ; activity of $\psi v \chi \eta, 164$; characteristic of the 'animal soul,' 165 ; relation to reasou, 275, 276; functions of, Stoic views, 276, $277 \mathrm{f}$.; as Tú $\pi \omega \sigma \iota s$ (Zeno, Cleanthes), 278 and n.; as

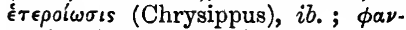
rafia, 278 and n., 279.

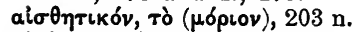

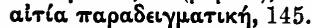

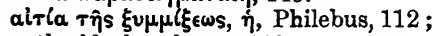
the ideal realm as, 113.

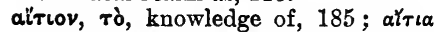
$\tau o \hat{v} \sigma v \mu \pi \epsilon \rho \alpha \sigma \mu \alpha \tau o s, 190$ n. ; каi

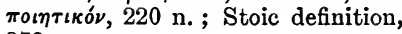
$273 \mathrm{n}$.

ákơ (hearing), animal function, 204.

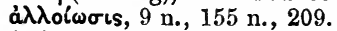

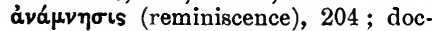
trine of, 102 ; in Phcedrus, Phado, Meno, $i b$. ; development of theory of association, $i b$.; and theory of innate ideas, $i b$.; and doctrine of the soul, 103 ; relation to $\mu \nu \eta \mu \eta$ and фаvтабla, 165, 216 ; early psychology of, 216 and n. ; and association, 217. à $\nu \delta \rho \in l \alpha$, Stoic definition of, a primary virtue, 293.

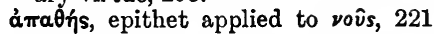
and $\mathrm{n}$.

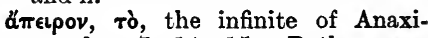
mander, 7, 14, 15; Pythagorean doctrine of, 25 ; use of term by Xenophanes, 31 ; Philebus, nature of, 112.

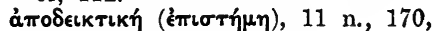

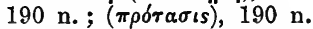

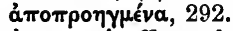

ḋтoppoai, effluxes by means of which, according to Empedocles, bodies act on one another, 58.

ápєtí (excellence), oikeía (characteristic), 244 ; $\dot{\eta} \theta \iota \kappa \dot{\eta}$ (moral), $i b . ; \delta \iota a-$

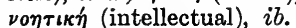

àpXฑ̆, 3 n., 7 and n., 11 n. ; Speusippus' view of, 141; Aristotle on, $i b$.; principle of movement (Aristotle),

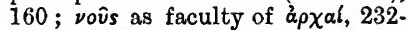
239 ; relation of, to demonstration, 232 ; apprehension of, ib., 233 ; (Stoics), $265 \mathrm{n}$.

á $\tilde{v} \mu \beta \lambda \eta$ rou (non-addible), characteristic of Plato's Ideas, $143 \mathrm{n}$.

áтоно үранцаi, Xenocrates' doctrine of, 146; in Platonic writings, $i b$.

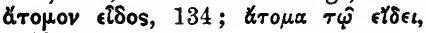
$182 \mathrm{n}$.

aű๊

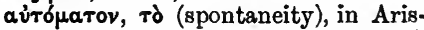
totelian cosmology, 137, 157 and $\mathrm{n}$.

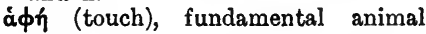
sense, 204.

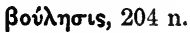


$\gamma \in \dot{v} \in \sigma$ เs, world of generation, and the Pythagorean oupavós, 24; denied by Eleatics, 33, 86 ; Megarian view, $86,88,99$; Platonic Ideas and, 98 ;

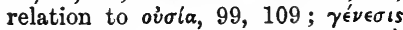

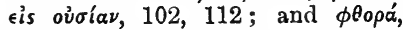
$155 \mathrm{n}$.

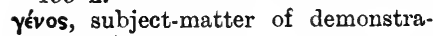
tion, $171,220 \mathrm{n}$.

$\boldsymbol{\gamma} \in \hat{\sigma} \sigma$ เs (taste), 204 ; fundamental animal sense, $i b$.

$\gamma \nu \eta \sigma(\eta)(\gamma \nu \dot{\omega} \mu \eta)$, genuine (one of Democritus's two types of knowledge), 65.

$\gamma \nu \dot{\omega} \mu \eta, \gamma \nu \eta \sigma i \eta$ distinguished from бкотіท, 65.

$\gamma \nu \omega \rho\llcorner\mu \dot{\omega} \tau \in \rho \circ \nu \dot{\eta} \mu \hat{\imath} \nu, \phi \dot{v} \sigma \epsilon\llcorner, 186$.

$\delta \eta \mu$ rovpyós, the divine, Timaeus, 119 ; $\delta \eta \mu \iota 0 v \rho \gamma \in \hat{i}, 265 \mathrm{n}$.

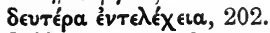

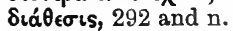

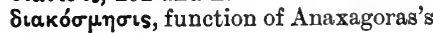
vovิs, 53.

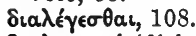

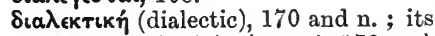
premisses $\dot{\omega} s \epsilon \pi l \tau \dot{\delta} \pi 0 \lambda \dot{v}, 178$; $\tau \dot{\delta}$

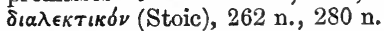

$\delta\llcorner a ́ \lambda \lambda a \xi \xi ı s$, process by which the four elements of Empedocles are separated, 55.

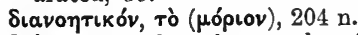

Siávola, mode of apprehension of mathematical aspect of objects (Plato), 101 ; function of the soul (Aristotle), 165; as function of understanding, 214.

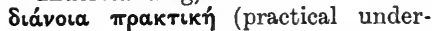

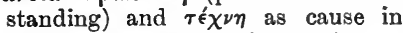
the world of generation, 156.

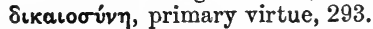

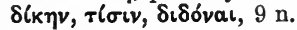

Sivos, rotatory movement of Anaxagoras's mixture, 52.

$\delta \delta \xi \alpha$ (opinion), distinction between Ė $\boldsymbol{\imath} \sigma \tau \mu \eta \eta$ and, 80 ; its object (Plato), 99 ; Xenocrates' theory of, 144 and n.; Platonic antithesis between, and

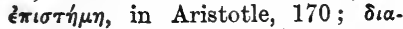
$\lambda \in \kappa \tau \iota \kappa \hat{\eta}, i b$. ; (judgment), function of man, 204; as function of understanding, 213.

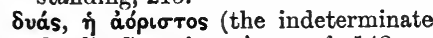
dyad), Speusippus' use of, 142 .

Sívauls (potentiality), 155, 220 n., 233 ; in Stoics, 264.

є̇үкра́тєเа, 293 n.

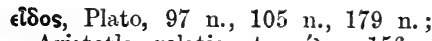

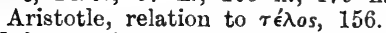

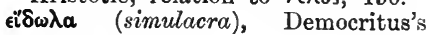
theory of, 64 .

eโvaน, technical term in Aristotle, 242 ; Tdे à $\gamma \alpha \theta \hat{\varphi} \hat{\text { e }} \bar{l} \nu \alpha \iota, 159$.

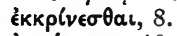

'́к

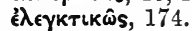

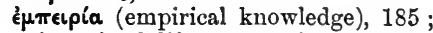
in animal life, 204 ; origin of, 234 ; and $\dot{\epsilon} \pi \iota \tau \tau \dot{\eta} \mu \eta, i b$.

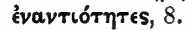

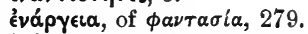

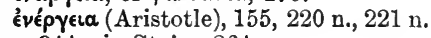
244 ; in Stoics, 264.

Ěv '̇ф' évós, $80,87$.

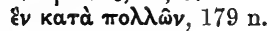

हैvvola, 102.

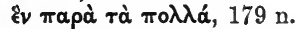

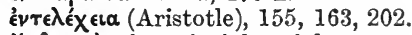

¿ $\xi \hat{\omega} v, \tau \dot{\alpha}$, the principles of demonstration, 171.

$\xi \xi$ เs, lowest degree of tension (Stoic term), 271 and n., 280 n., 292 n.

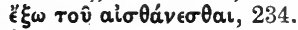

є̇ $\pi \alpha \boldsymbol{\gamma} \omega \boldsymbol{\gamma} \dot{n}$ (induction), 97, 98, 185 f. ; $\delta$

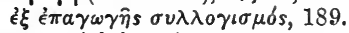

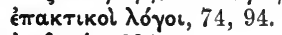

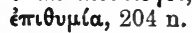

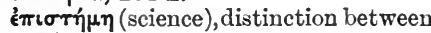
$\delta \delta \xi \alpha$ and, 80 ; Antisthenes on, 83 ; in Plato, Aristotle's equivalent, 170 ; relation to voûs, 233 ; originating in $\epsilon^{\prime} \mu \pi \epsilon \iota \rho^{\prime} \alpha, 234$; relation to the unchangeable, $i b$. ; always true, 235 ; Stoic theory of, 280 n., 286.

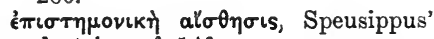
doctrine of, 140

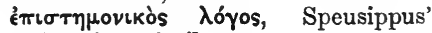
doctrine of, $i b$.

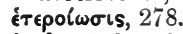

ย́т€ทे, mode of existence of primary qualities, 63.

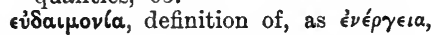
244.

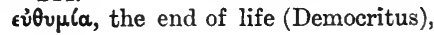
66.

$\zeta \omega \eta \dot{~}, 163$ n., $164 \mathrm{n}$.

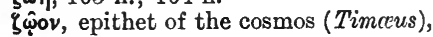
119.

$\dot{\eta} \delta$ ov (pleasure), cause of movement

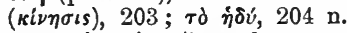

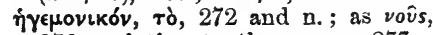
276 ; relation to the senses, 277 . 


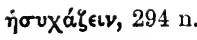

Өárepov, $120 \mathrm{n}$.

$\theta \in \hat{c} 0 v$, tò (the divine), relation to realm of change, 161.

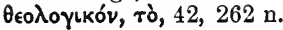

Onpla, 204 n.

Olaros, founded by Pythagoras, 18.

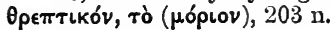

$\theta$ úpa $\theta \in v, 230$.

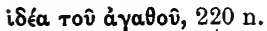

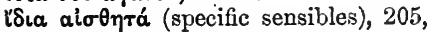
$206 \mathrm{n}$.

ısıaı ảpXal, 171.

каӨарноl, Empedocles' poem, 55.

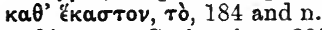

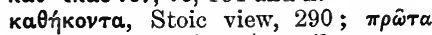

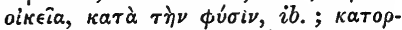
$\theta \dot{\omega} \mu \alpha \tau \alpha, 291 ; \mu \epsilon^{\prime} \sigma \alpha \iota \pi \rho \dot{s} \xi \epsilon \iota s, i b$.

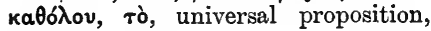
184 n., 185.

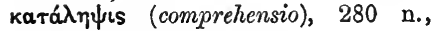
282 n., 284.

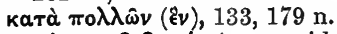

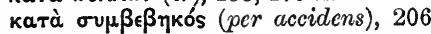
and $\mathrm{n}$.

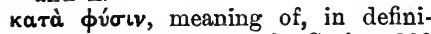
tion of Idea, 145; in Stoics, 290 and $n$.

каторөஸ́ $а \tau \alpha, 291$.

кєvóv, тò, void, Atomist doctrine of, 60 ; mode of existence of, 286 n., 287.

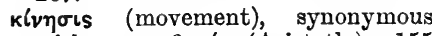
with $\mu \epsilon \tau \alpha \beta o \lambda \hat{\eta}^{\prime}$ (Aristotle), 155 and $\mathrm{n}$.; subdivisions of, $155 \mathrm{n}$.; as activity of $\psi v \chi \chi^{\prime}$, dependent on al $\sigma \theta \eta \iota s, 164$; relation to psychical process, 165 n.; to $\dot{\eta} \delta o \nu \eta, \lambda, \lambda u ́ \pi \eta$, 203 ; to 0 $\rho \xi เ 5,204$ n.; cause of

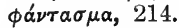

кเvๆтá, $165 \mathrm{n}$.

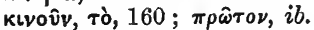

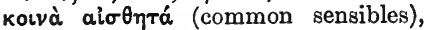
$205,206 \mathrm{n}$.

kotvai àpXaí, 171.

koเval évvolal, meaning of, in Stoic philosophy, 280.

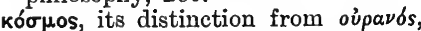
9, 11 and $\mathrm{n}$.; middle region of the Pythagoreans, 24 and n. ; Heraclitus, 45 ; Atomist doctrine of the existence of many $\kappa \sigma \sigma \mu o$, with interspaces, 63 ; Plato, 121 n. ; Stoics, 271 n., $290 \mathrm{n}$.

крâбเs, Stoic theory of matter, 263 ; $\kappa \rho \hat{\alpha} \sigma \iota s \quad \delta \imath \quad \delta ่ \lambda \omega \nu, 268 ; \kappa \rho \hat{\alpha} \sigma \iota s \quad \delta$ ò $\lambda$ ov, 271 and $n$.

кploเs, $280 \mathrm{n}$.

$\lambda_{\epsilon \kappa}$ тóv, тò, existence of, $287 \mathrm{f}$.

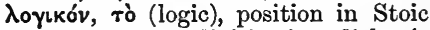
doctrine, 262 ; division into dialectic

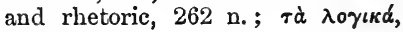
$290 \mathrm{n}$.

$\lambda$ óyos, Aristotle's use of the term in reference to Parmenides, 35 ; reason, as the criterion of truth, 65,280 n. ; (definition), 80, 159,

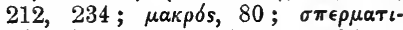
кós, 271 and n.; God as, 265 n., 273.

$\lambda u ́ \pi \eta$, cause of movement ( $\kappa^{\prime} \nu \eta \sigma \iota s$ ), 204.

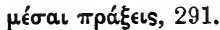

$\mu \in \tau \alpha \beta \circ \lambda \eta ́$ (change), Aristotle's conception of, 155 and $\mathrm{n}$.

$\mu \in \tau a ́ \lambda \eta \psi \iota s$ (participation), of particulars in the Idea, in Parmenides, 105. $\mu \hat{\imath} \gamma \mu a, 13$.

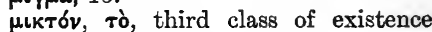
(Philebus), 112.

$\mu l \mu \eta \sigma$ s, in the Republic, 101.

$\mu \imath \xi\llcorner s$, process by which the elements of Empedocles are combined, 55.

$\mu \nu \eta ́ n \eta$ (memory), 165, 204 ; in animals, 204 ; distinguished from à $\nu \alpha ́ \mu \nu \eta \sigma \iota s$ and $\phi a \nu \tau a \sigma^{i} a, 216$.

$v \delta \eta_{\mu} a, 106,287 \mathrm{n}$.

vónoเs (thought), relation of Ideas to, 95.

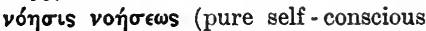
reason), 162.

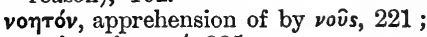
unity of $\nu 0 \eta \tau \dot{\alpha}, 225$.

$v \delta ́ \mu \omega$, mode of existence of secondary qualities, 63.

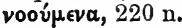

vov̂s, Anaxagoras' source of movement, 49 and n., 52 and n. ; interpretation of, by Plato and Aristotle, 52 ; new element in the conception, $i b$. ; function of, $\delta\llcorner\alpha \kappa \delta \sigma \mu \eta \sigma \iota s, 53$; (Plato) mode of apprehension of the Ideas, 101 ; kinship of $\psi v \chi \dot{y}$ and (Lavos, $\mathrm{x}$.), 117 ; participation of $\psi v \chi^{\prime} \eta$ in (Timoeus), 117, 119; standard of perfection, 119 ; cause of $\kappa \delta \sigma \mu o s$, 121 n. ; relation of, to soul, 131; (Aristotle) divine element in $\psi v \chi \dot{\eta}$, 166 ; relation of, to $\psi v \chi\{, 167,178$; independent of the body, $i b_{0}$; its 
immortality, 168; negative characteristics of, $i b$.; as act of intellectual insight, 190 ; cause of cosmic movement, $200 \mathrm{n}$.; peculiar to man, 204; theory of, 217-239, passim; interpretations of Aristotle's theory, 239; as the divine in man, 245 ; logically separable from soul, 246 ; relation of $\nu$ ovs in man to divine vov̂s, 247 ; use of term, in Stoic philosophy, 271 and $n_{.}$; relation to $\alpha$ t $\sigma \theta \eta \sigma \iota s, 276$; $\tau \dot{\eta} \dot{\eta} \gamma \in \mu o \nu \iota \kappa \delta \nu, i b$.

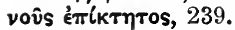

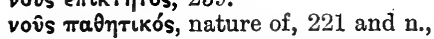
244 n., 249.

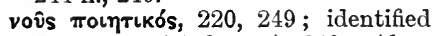
with God (Eudemus), 249; Alexander of Aphrodisias, 251.

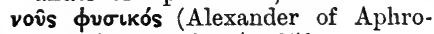

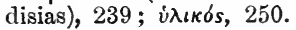

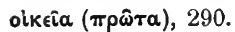

oikeial ảpXaí, 171.

oíkeîos $\lambda$ ó yos, 80.

๖ㅅov, 6 n., 36 .

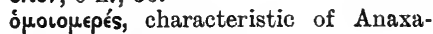
goras's seeds, 50 .

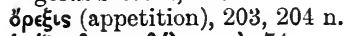

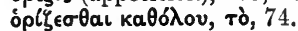

ópıruós (definition), 159.

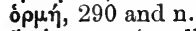

б̋ $\phi p \eta \sigma$ เs (smell), animal function, 204.

oủpavós, its distinction from кó $\sigma \mu o s$, 11 and n.; Pythagorean, 24 n., 25 ; field of $\delta \delta \xi \alpha$, according to Xenocrates, 144 ; partaking of change, 145 ; called Lachesis by Xenocrates, $i b$.

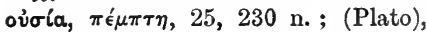

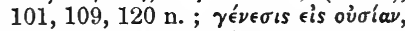
102,112 ; (Aristotle), $\sigma u ́ \nu \theta \in \tau o s, 144$; category, 155 n.; đँoเos, 265 n.; $\mu i \alpha, 290 \mathrm{n}$.

bั४เs (vision), animal function, 204.

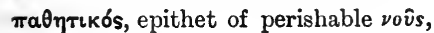
- 221 and $\mathrm{n}$.

$\pi \hat{\alpha} \nu$, т̀े, 42.

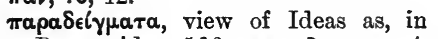

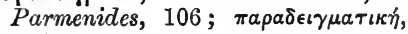
145.

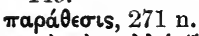

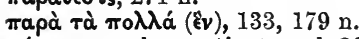

$\pi a ́ \sigma X \in \iota$ $\tau$, the sentient soul, 209 ; $\tau$ d $\pi a ́ \sigma \chi o \nu, 265 \mathrm{n}$.

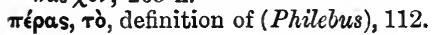

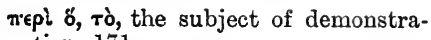
tion, 171.

$\pi \lambda \hat{\eta} \rho \in \mathbf{S}, \tau \dot{o}$, the plenum, Atomist doctrine of, 60 .

$\pi v \in \hat{v} \mu a$ (spirit), Aristotle, 230 ; material basis of reason, ib., 269 ; Stoic explanation of reality, 269 and n., 275.

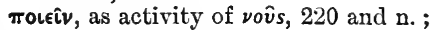

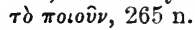

то入ıтடкóv, тò, 42, $262 \mathrm{n}$.

$\pi \rho \hat{k} \xi$ เs, $204 \mathrm{n}$.

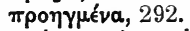

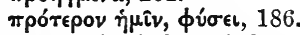

$\pi \rho \hat{\omega} \tau \alpha$, Antisthenes' theory of, 81.

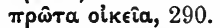

$\pi \rho \omega ́ \tau \eta ~ \epsilon ́ v \tau \in \lambda \epsilon ́ X \in L a, 163$ n., 202.

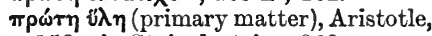
158 ; in Stoic doctrine, 268.

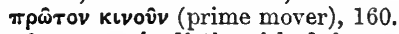

$\pi \hat{v} \rho$ TEX $v\llcorner\kappa o ́ v$ distinguished from $\pi \hat{v} \rho$ ă $\tau \in \chi \nu 0 \nu, 269$ n., $271 \mathrm{n}$.

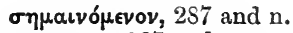

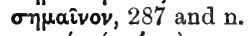

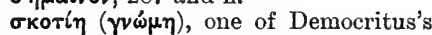
two types of knowledge - the obscure, 65.

бoфós, Stoic doctrine of, 280 n., 281 and $\mathrm{n}$.; conduct of, 291.

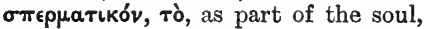
276.

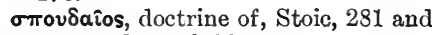
n.; conduct of, 291.

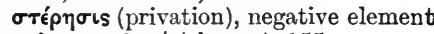
in $\mu \in \tau \alpha \beta \sigma \lambda \dot{n}$ (change), 155.

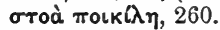

бvүкатá $\theta \in \sigma ı s, ~ 279,280$ n., 282, 283 ; as belief, 285 .

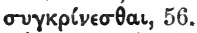

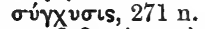

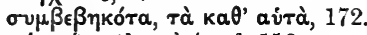

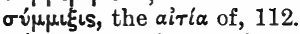

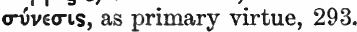

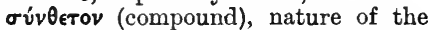
concrete existent, 156 ; form and matter in, $i b$.

$\sigma \omega \rho \in i(\tau \eta)$, Sceptic argument, $294 \mathrm{n}$.

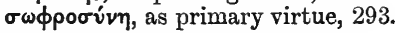

таง่тóv, $120 \mathrm{n}$.

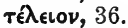

$\tau \in \lambda \in \operatorname{có} \tau \eta \mathbf{s}, 291$.

$\tau \hat{\tau} \boldsymbol{\lambda}$ os (final cause), relation to $\epsilon \hat{\delta} \delta o s$, 156.

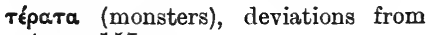
type, 157.

$\tau \in \dot{X} X^{\nu \eta}$, meaning of, in Plato, 146 ; 


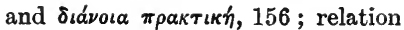
to $v^{\lambda} \lambda \eta, 220 \mathrm{n}$.

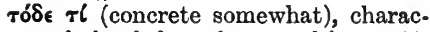
teristic of the existent subject, 154 .

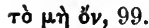

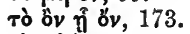

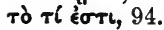

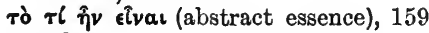
and $n$.

Tóvos, 266 and n. ; degrees of, as law of $\pi \nu \in \hat{v} \mu \alpha, 270$.

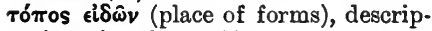
tion of soul as, 218.

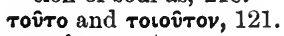

ruүXávov, 287.

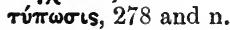

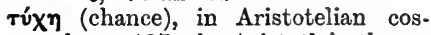
mology, 137; in Aristotle's theory of nature, 157 .

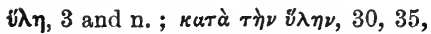
36 ; Aristotle's theory of, 134,220 n.; element in the concrete existent, $156 ; \pi \rho \omega ́ \tau \eta$ ป์ $\lambda \eta, 158$.

v $\lambda \eta$ ămowos (unqualified matter), 265 n., $268 \mathrm{n}$.

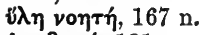

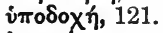

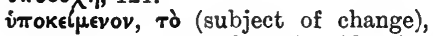
nature of (Aristotle), 153 ; identity of, 212.

i $\pi \delta$ ó $\eta \psi$ เs, as function of the understanding, 213.

фavтaбla, representative function of the soul (Aristotle), 165 ; imagination, 204 ; as intermediate between sense-perception and reason, 213, 214 ; presentation, 278 and n.,

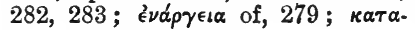
$\lambda \eta \pi \tau \iota \kappa \dot{\eta}, 280$ and $\mathrm{n}$.

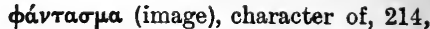
215 ; mechanical determination of, 215 ; relation to theoretical activity, $i b$. ; operation of reason through, $i b$. ; and the functions of desire, $i b$.,

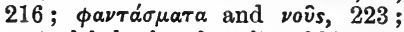
material basis of unity, 224 ; restriction of lowest form of intellect to, 251, 252.

$\phi \theta$ loเs, 155 n., 164 n.

фoopá, $155 \mathrm{n}$.

форá, 155 n., 161.

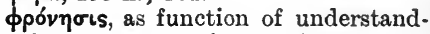
ing, 213 ; as primary virtue, 293.

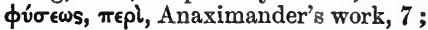
Empedocles' poem, 53.

$\phi v \sigma \iota k o ́ v$, тò, fundamental Stoic doctrine, 261, 262 n. ; фvбเkol, 14 n.; $\phi v \sigma \iota k \dot{~(\phi \iota \lambda o \sigma o \phi i a), ~} 165 \mathrm{n}$.

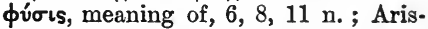
totle's conception of, 156 ; Stoic term, 271 and n., $289 \mathrm{n}$.

$\phi \omega \nu \eta \dot{\eta}, 287$.

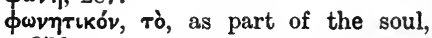
276.

$\mathrm{X} \dot{\omega} \rho, 122$.

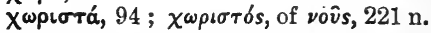

$\psi v \times \eta$, early denotation of the term, 6 n., 7 ; Platonic doctrine, 103 ; and vov̂s, 117 ; Plato on, as principle of self-generated movement, 163 ; Aristotle on, as $\dot{\epsilon} \nu \tau \in \lambda \epsilon \in \boldsymbol{\epsilon} \in[a, i b$. and n.; relation to $\phi v \sigma \iota \kappa,, 165 \mathrm{n}$;

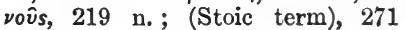
and $n$.

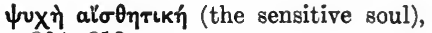
$204,213$.

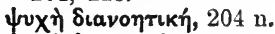

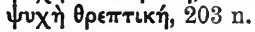




\section{GENERAL INDEX}

Absolute, existence, communion with, Plato's view of, 108; Antisthenes on, ib. ; Plato's conception of, 129 ; relation to truth, 130 ; knowledge, $106,143,186,188,192,281$ n. ; the absolute, 226 ; absolute reason, 227 . 231 ; Neo-Platonic doctrine of absorption into, 253 and $n$.

Abstract, and concrete, in relation to the Ideas, 146; essence ( $\tau \dot{\delta} \tau \hat{\imath} \bar{\eta} \nu$ elval), 159 and n. ; notion, 218.

Academy, the, doctrines of, 139-147 ; criticism of the Stoics, 260 and n., 277.

Accident, fallacies of, Eubulides, 85 ; accidental predicates, 176; ambiguity of Aristotle's use of per accidens, 206 and $\mathrm{n}$.

Achilles. See Index of Authorities.

Action, nature of right, 291 ; class of indifferent, 292.

Activity, of the soul, in sense-perception, 209; in imagination, 215;

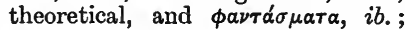
as factor in all reality, 264. 268.

Actuality, and potentiality, 155 ;

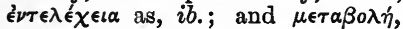
$i b$. ; and matter, 156 ; complete, and God, 159, 161; priority of, 160 ; form as, 201 ; soul as, 202 ; sense-perception as actualisation of potentiality, 209; actual and potential applied to soul and reason, 217-220, 228.

Adsensus, 281 n., 282.

Enesidemus (Sceptic), 260 n.

Ether, function and nature of, 230 ; relation of, to vovs, $i b$.
Agnosticism, of Protagoras and Gorgias, 71, 72.

Agrippa (Sceptic), 260 n.

Air, in Aristotle, 8 n.; in Anaximenes, 15 f., 25 ; in Pythagoreans, 25 ; in Diogenes of Apollonia, 54; in Empedocles, 55 ; in Stoics, 263.

Alcmæon of Croton (Pythagorean), 27.

Alexander of Aphrodisias (Peripatetic), interpretation of $\nu \circ \hat{v} s, 239,250 \mathrm{f}$. See also Index of Authorities.

Alteration, qualitative, 40 ; $\alpha \lambda \lambda o^{\prime} i \omega \sigma \iota s$, 9 n., 209 ; $\varepsilon \tau \epsilon \rho o l \omega \sigma \iota s, 278$ and n.

Ammonius. See Index of Authorities.

Analogy, rejected by Euclides, 84 .

Analysis, 223.

Anaxagoras, his One and Many, 14 n. ; his doctrine, 49-54; and principle of contradiction, 177; ' unmixed' reason, 217; influence on Stoic theory of $\kappa \rho \hat{a} \sigma \iota s, 263$; indivisible nature of the universe, 268.

Anaximander, his cosmological system, $7-15$; Parmenides' debt to, 33 ; anticipation of Empedocles, 57.

Anaximenes, $15 \mathrm{f}$. ; his conception of air as the principle of things compared to the Pythagorean void, 25 ; influence on Stoic doctrine, 263.

Animal life, influence on Anaxagoras, 53 ; on Empedocles, 55 ; distin. guished from vegetable, 203 ; functions, 204.

Anthropomorphism, criticised by Xenophanes, 30.

Antinomianism, relation to, of Socratic and Cynic ethics, 76. 
Antiochus of Ascalon (Academician), $260 \mathrm{n}$.

Antisthenes (Cynic), and the Heraclitean theory of the importance of names, 48, 82 ; doctrine, 79-83, 89 ; criticism of theory of Ideas, 107 ; criticised by Plato, 109 ; influence on the Stoics, $259,265 \mathrm{n}$.; reference to, in Thecetetus, 278.

Antithesis, between $\delta \delta \xi \alpha$ and $\dot{\epsilon} \pi \cdot \sigma \tau \dot{\eta} \mu \eta$, Plato, 170 ; Aristotle, $i b ., 177,178$; between individual and universal, 179 ; Aristotle's solution, in the world of generation, 182; in the intermediate sphere, 183 ; inapplicable to the Divine, $i b$.

Apodictic, Aristotelian, nature of its premisses, 170 and n., 178; contrasted with dialectic, 170, 177, 178.

Appetition (ŏ $\rho \epsilon \xi$ เs), 203, $204 \mathrm{n}$.

Apprehension, development of, 184 ; of individual as embodiment of type, $i b$. ; the immediate object of, $193 \mathrm{f}$. ; intuitive, 195 ; of primary data, $i b ., 196$; of common and specific sensibles, 205-207; of the individual, 206 ; not separate from content, 211; concrete and its abstract notion, 218 ; of the intelligible, by vov̂s, $221 \mathrm{ff}$.; of vov̂s by itself, $225 \mathrm{ff}$; of first principles, $232-239,242.244$.

Arab philosophy, 239, 252-254.

Arcesilaus (Academician), $260 \mathrm{n}$.

Archer-Hind, R. D., on relation of Ideas to the soul, $114 \mathrm{n}$.; introductions to Phcedo and Timceus, $i b$.

Aristippus (Cyrenaic), 78.

Aristotle-

Influence of Plato on, 1, 138, 149,163 ; on the material cause, 3 and n.; on Thales, 5 ; on Anaxim. ander, 8,13 ; on cycle of existence, 20 ; on the Pythagoreans, ib., 21, 23-27; on the Eleatics, 30-35; on Heraclitus, 42, 43, 47; on Anaxagoras, $50-54$; on Empedocles, 56,58 ; on the Atomists, 59,62 , 65 ; on the term Sophist, 68 ; on Antisthenes, 80 ; on error, 82; criticised by Megarians, 84 ; on the theory of Ideas, 92-95, 123, 127, 128,130 n., $132-139,146$; on Speusippus' doctrines, 139 - 143 ; and Xenocrates, 144, 145.

Philosophy, 149.255; difference between Plato and, 150, 238,
239 ; the reality of physical nature, 150, 151 ; fundamental conceptions, $152-169$; conceptions of change and purpose, 153-157; nature of the existent, 153, 154, 156, 172, $175.177,182$; gradation of fixed natural types, 141 n., 154, 156, $157,171,172,191,194,195,220$, 236,270 ; actuality and potentiality, 155,160 ; form and matter, 156, $158,159,264$; relativity of matter,

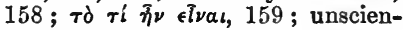
tific view of nature, 157 ; conception of development, 160 ; theory of real causation, $i b . ;$ the prime mover, God, ib., 161, 162 ; eternity of the world of generation, $161,220,235,240,241$; doctrine of the soul, 163-169, 199-231, 282; nature of the immortality of the soul, 165 ; vov̂s, $167,168,190$, 195-198, 200 n., 204, $217 \cdot 231$, $243-251$; negative character of the ultimate real existent, 168; hiatus in Aristotle's metaphysics, $i b ., 169$; theory of knowledge, 170 198 ; principle of contradiction, 54 , 172-177; the concrete individual, 182-186; syllogism and induction, 186-190 ; ultimate data of knowledge, 190-198; immediate object of apprehension, 193, 194 ; induction and the universal, 194, 195; intuition and discursive thought, 195-198; psychology, 199-231; general nature of soul, 199-204; the sensitive soul, 204-213; intermediates between sense-perception and reason, 213-217; the rational soul, $217-227$; truth, 226, 246 ; reason in man and absolute reason, 227-231 ; intelligibility of the universe, 240, 241; difficulties of Aristotelianism, 240-255 ; conception of end, 153-157, 166, 205, 246 ; divine unity and concrete multiplicity, 248, 249; doctrine of reason, later development, 249.254 ; fundamental dualism, 254, 255; modification of his views by Peripatetics, 249-251 ; and Stoics, 257-294 ; continuity of Stoic and Aristotelian doctrine, $263,264-269,270$; eternity and unity of the system of existence, 264 ; doctrine of $\pi \nu \in \hat{v} \mu \alpha$, 230,269 ; macrocosm and microcosm, 272. See also Index of Authorities. 
Aristoxenus. See Index of Authorities.

Art, Sophists and theory of, 70;

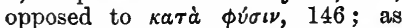
cause in the world of generation, 156 ; relation to chance, 157 ; result of experience, 185, 234 .

Artificial objects, excluded from the Ideas, 146.

Asceticism, tendency of rationalism to, 76 .

Assent, Stoic conception of, 279-285.

Association of ideas, 102; laws of, 217.

Assumption, of essential relation, 189 ; of existence, and definition, 197.

Atomism in Antisthenes' theory of knowledge, 81.

Atomists, their criticism of popular theology anticipated by Anaximander, 12 ; conception of void, 25 ; the indivisible quantum of the, 26 ; theory of perception anticipated by Anaxagoras, 54 ; special doctrines of, $59-66$; distinction between convention and nature, 70 ; effect on the Cyrenaics, 79; their units physical, 109.

Atoms, nature of, 61 and n. ; differences among, 61; question of weight, $i b$. ; movement, 62 ; explanation of movement of, $i b$. ; var. iety of movement of, 63 ; collision of, $i b$.; vortex motion, $i b$.; intelligible atoms, Megarian view, 85, 86 .

Atropos, Xenocrates' name for the intelligible world, 145 .

Attraction, principle of, in Anaxagoras, 53 ; in Empedocles, 56-58.

Augustine, St, and the theory of Ideas, 100.

Averroës (Ibn Roschd), theory of

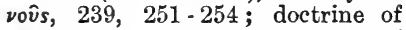
unio, 253. See also Index of Authorities.

Axioms, nature of mathematical, 171 ; common and special, $i b ., 172,190$, 196 ; nature of demonstration from, 172 ; axiom of contradiction, 172 . 177 .

Beautiful, identified with the good (Stoics), 291.

Being, relation of true, to world of generation (Plato), 109 ; as such, 173.

Belief, Stoic conception of, 285.
Biological tendency in early Greek thought, 49.

Body, Platonic explanation of the (Timceus), 122 ; natural bodies possessing life, 200, 201; organised, 201,202 ; relation of soul and, $201,202,203$; as subject of predication, 202 ; gradation of organ. ised bodies, 203.

Bryso, 89.

Burnet, J., his interpretation of Anaximander's doctrine of innumerable worlds, 11; his Early Greek Philosophy cited, 8 (10, 2nd ed.), p. $3 ; 53$ (52, 2nd ed.), p. $13 ; 54$ (59, 2nd ed.), ib.; 57 n., 66 (59 n. 2, 2nd ed.), p. 14 ; 62-73 (61-72, 2nd ed.), p. 9; 67 (64, 2nd ed.), p. $11 ; 79$ f. (\$ 29, 2nd ed.), p. 16; 93 f., p. 18; 135 (149, 2nd ed.), p. $46 ; 325$ (\$157, 2nd ed.), p. 37 ; 260 f. (279 f., 2 nd ed.), p. 57 ; 353 f. (c. 9,2 nd ed.), p. 59 (footnote in each case).

Callias (any individual man), 234.

Callippus, $59 \mathrm{n}$.

Carneades (Academician), 260 n.; criticism of Stoics, 261.

Category, Aristotelian, of ovola, $155 \mathrm{n}$.

Cause, material, 3 ; of change, soul as, 6 ; mind as, 52 ; love and hate as, 56 ; of the mixed class (Philebus), $112 \mathrm{f}$.; of self-originating movement, soul as, 116 f.; errant, 121 ; mechanical (Aristotle), 137; Good not, to Speusippus, 141; in Platonic definition of Idea, 145 ; final, as form, 156 ; types of efficient, in world of generation, $i b$. ; necessity of a first, 160 ; nature of efficient, $i b$. ; of first, 161, 239, 248; know. ledge of, 185 ; efficient and final, 241 ; final and mechanical, indentification by Stoics, 273; Stoic definition of, $i b$. n.

Chance, in Aristotle, theory of nature, 137,157 ; relation to art, 157 .

Change, denied by Eleatics, 32, 40 and n. ; Heraclitus' law of, 44; its meaning, 46 ; interpretation of, by Plato, $i b$. ; Atomist explanation of, 62 ; characteristic of the world of generation, 116, 129 ; soul, the principle of, 116, 117; causes of (Timceus), 125; not explained by the Ideas, 132; Aristotle's criticism of Platonic explanation, $i b ., 135$; in 
Xenocrates, 145; Aristotle's conception of $(\mu \in \tau \alpha \beta 0 \lambda \eta), 151,152,155$, 158 and $\mathrm{n}$. ; as realisation of ends, 155 ; subdivision of, $i b$. n. ; negative element in ( $\left.\sigma \tau \epsilon^{\prime} \rho \eta \sigma \iota s\right), i b$; Kant on, $i b$.; material element in world of, 158,159 ; and the prime mover, 161,226 ; distinction between selfgenerated and accidental movement, 163 ; principle of self-generated movement, $i b$; potentiality and actuality in, 219.

Chaos, original condition of matter, 51.

Chronology of Platonic dialogues, 92-98, $114 \mathrm{f}$.

Chrysippus (Stoic), 259 and n., 260 ; theory of $\alpha$ l $\sigma \theta \eta \sigma \iota s, 278$; and the Sceptic $\sigma \omega \rho \epsilon i \tau \eta s, 294 \mathrm{n}$.

Cicero, reference to Anaximander, 11 f. ; on Stoic terminology, $278 \mathrm{n}$., 279, 281 and n., 282, 284, 293 n. See also Index of Authorities.

Civilisation, origin of, speculation on, 70 .

Cleanthes (Stoic), 259 and n.; identification of $\tau \delta \dot{\eta} \gamma \in \mu o \nu เ \kappa \delta \nu$ with the sun, $272 \mathrm{n}$.; theory of $\alpha$ l $\sigma \theta \eta \sigma \iota s, 278$. See also under List of Authorities.

Cleitomachus (Academician), $260 \mathrm{n}$.

Clement, on Speusippus, 139. See also under List of Authorities.

Clotho, Xenocrates' name for the sensible, 145.

Colour, potential and actual, 220.

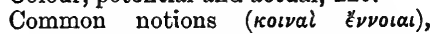
meaning of, in Stoic philosophy, $280,286$.

Complexity, in object or act of apprehension and the problem of error, 82 ; types of, 83 ; Plato on, $i b$.;

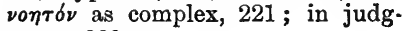
ment, 223.

Compound ( $\sigma \dot{v} \nu \theta \in \tau o \nu)$, nature of concrete existent, 156 ; form and matter in, $i b$. ; compound ov $\sigma i \alpha$ as object of $\delta \delta \xi \alpha, 144 \mathrm{n}$.

Comprehensio, 280 n., 282 n., 284, 285.

Conception, Dugald Stewart on, $214 \mathrm{n}$.

Concrete, thing, nature of the existent subject ( $\tau \delta \delta \delta \epsilon i), 154$; as actuality, 155 ; relation to $\mu \in \tau \alpha \beta o \lambda \eta$, $i b$.; compound nature of ( $\sigma \dot{v} \nu \in \epsilon \tau o \nu)$, 156 ; existence, fixed types of, 171 , $172,194,195$; existents, principle of contradiction and, 173.177 ; ex- istents, perception of, 206 ; individual, 182-186; relation of, to abstract notion, 218 ; and abstract, Aristotle's failure to connect, 227 ; existence, and truth, 246 ; world, and the divine mover, 248 ; individual, not known by the divine intelligence (Averroës), 254 and $n$.

Condensation and rarefaction, 14, 16.

Conduct, problem of, speculation on, 61 ; importance of, to Socrates, 75 , 76 ; in Aristotle, 244.

Consciousness, sense-perception as, 211 ; vov̂s as, 225.

Constancy, as intelligibility, 240.

Constitution, of the body, 64 ; of man, 289.

Contemplation, life of, as the highest good of man, 245 ; contrasted with practical life, $i b$.

Contingency, matter as, 158.

Continuity, nature of Parmenides' One, 32 ; factor in space, 294.

Contradiction, impossibility of, according to Anaxagoras, 54, 177; and to Antisthenes, 80,82 ; principle of, 172-177; double reference of, 173 ; incapable of proof, 174 ; and subjective thinking, 175 ; necessity of, 176 ; Heraclitean, Protagorean, denial of it, $i b ., 177$.

Corporeal, Eleatic One, 34 ; Plato's explanation of the, 122 ; conditions, relation of $\nu$ ov s to, $217 \mathrm{f}$.; nature of reality, 265 ff., 286, 287, 288; virtues, 266 ; $\mathrm{pr}^{-}$entations, 287.

Cosmology, an mythology, 3 ; of Anaximander, $9 \mathrm{ff}$.; Pythagorean, $24 \mathrm{ff}$; ; threefold division of the universe, 24, 25 ; Xenocrates', 144 f. ; Plato's, 119.122 ; Aristotle's, 152, 240; Stoic, 266-274.

Cosmos, Pythagorean conception, 24 ; in Heraclitus, 44 ; in Anaxagoras, 53 ; nature of (Timceus), 119 ; soul of, $i b ., 120,199 \mathrm{f}$. ; Stoic view, 266$274,277,278,282,286-288$.

Courage, Stoic definition, as primary virtue, 293.

Cratylus (Platonic dialogue), reference to Antisthenes, 82 ; basis of doctrine of Ideas in, 99.

Creation, mode of (Timaus), 119, 120 ; Christian doctrine of, 161 .

Criterion, of knowledge, $65,278 \cdot 281$, 286.

Cube, Pythagorean equivalent of the earth, 25. 
Cycle, Anaximander's doctrine of a, $8 \mathrm{n} ., 9,14 \mathrm{f}$.; of existence involved in Pythagorean doctrine, 20 ; Empedocles', effected by love and hate, 56 ; four stages in, 57 ; of generation, in Plato, 115.

Cynic doctrine, relation to, of Socratic ethics, 76 ; theory of knowledge, 79 . 83 ; effect on the Stoics, 258, 259, 291.

Cyrenaics, ethics of, and Democritus, 66 ; ethical views, $78 \mathrm{f}$.

Data, ultimate, of knowledge, 190 . 192 ; indemonstrable, 192, 194; source of, 195 ; mode of apprehension of primary, 196.

Deduction, Aristotle on, 187.

Deductive construction of universe, 131.

Definition, invented by Socrates, 74, 94; Antisthenes on, 80; Speusip. pus on, 143 ; Aristotle on, $i b$., 159, 197.

Degree, and the operation of sense, 217 ; vov̂s not subject to, $i b$.; of tension, 266.

Democritus, his doctrine of innumerable worlds compared with Anaximander's, 11 f.; his philosophy, $60-66$; marks transition from traditional to historical period of philosophy, 67 ; new character of his problems, $i b$.; and definition, 94.

Demonstration, principles of (Aristotle), 171 ; subject-matter, $i b$. ; nature of, 172 ; syllngistic mode of, $i b$. ; axioms in, $i b$.; nature of its subject, 191; weakness of the theory, 192; and intuition, 195, 196 ; and first principles, $232 \mathrm{ff}$.

Design in the cosmos (Plato), 119.

Desire, functions of, and $\phi \alpha \nu \tau \alpha \dot{\sigma} \sigma \alpha \tau \alpha$, $215,216$.

Development, Speusippus' view of, 141 ; Aristotle's conception of, 155, 160 ; difference from modern inter. pretations, $i b . ;$ of the soul, 166 ; of knowledge, 178, 186; order of, 184 ; process of (Aristotle), 235, 236 ; cause of, 236 ; of knowledge in man, 233, 234, 237, 238.

Dialectic, Plato's, Aristotle on, 134 ; (Aristotelian), 170; nature of its premisses, $i b$. and n., 178, 187 ; contrasted with apodictic, 170, 177, 178 ; subdivision of Stoic logic, 262 and $n$.
Dialogues, Platonic, chronology of, 96 ; theory of Ideas in earlier, 97 ; classification in earlier, 98 ; division by dichotomy in later, $i b$.; Lutoslawski's chronology, 115.

Dichotomy, Platonic use of, 98 ; not in earlier Ideal theory, $i b$.

Difference, in Eleaticism, 47 ; importance of, in Anaxagoras, 53; Platonic explanation of, 98, 110, 124 ; specific, 154 ; accepted as ultimate (Aristotle), 239 ; deduction of (Platonic), ib. ; in Stoics, 284.

Diodorus Cronus (Megarian), arguments against potentiality and motion, $84 \mathrm{f}$.

Diogenes Laertius, on the Megarians, 84 ; value of his testimony, $i b$. See also Index of Authorities.

Diogenes of Apollonia, views, 54 ; influence on Stoic doctrine, 263.

Discrete, elements, quantity, 37,85 , 87 ; aspect of space, 294 .

Discrimination, of common and specific sensibles, 207; of heterogeneous sensations, 212 ; of homogeneous sensations, $i b$. ; and unity, $i b ., 243$.

Discursive reason, thought, 101, 197, 122.

Divine, the, unity of (Aristotle), 159 ; nature of, completed actuality, 160 , $161,162,168$; the unmoved mover, 161; element in the soul ( $\nu$ ovs), 166 ; individuality of, 183 ; as form devoid of matter, $i b$.; element of, in the universe, 227,245 ; reason and human, Aristotle's theory, 228. $231,247-249$; and the concrete world, 248; and the active reason

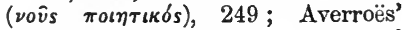
doctrine of unio, 253; nature of its knowledge, 254 and $n$.

Dodecahedron, Pythagorean equivalent of the fifth, unnamed, element, 25.

Doxographi Grceci, Diels', reference to, 12.

Dreams, Democritus' explanation of, 64 ; Aristotle's tractate on, 213.

Dualism, in Plato's theory of Ideas, Aristotle on, 135 ; fundamental, in Aristotle, 254, 255, 257 n. ; Stoics' attempt to avoid, 45, 258, 275, 292.

Dugald Stewart on conception, 214 n.

Duties, Stoic view, 290; natural foundation of, $i b$. ; primary, $i b$., 291; of a rational being, 291; relative, ib., 292. 
Earth, in Aristotle, the cold-dry, $8 \mathrm{n}$; formed from the cube, according to the Pythagoreans, 25; one of Empedocles' four 'roots,' 55.

Elaboration and intuition, 196.

Eleatic school, 25, 29-41; Xenophanes, 29, 30 ; Parmenides, 32-36 ; Zeno, 38, 39; Melissus, 40 ; influence on the Pluralists, 49 ; on Anaxagoras, 51 ; on Empedocles, 55; relation to the Atomists, 59 ; Atomist misinterpretation of, $62 \mathrm{f}$.; Eristics and, 69 ; Euclides and, 84; Megarian agreement with, $86,87,88$; relation to Ideal theory, 109 ; to Aristotle, 168.

Elements, the four, $8 \mathrm{n}$. ; Pythagorean, 25 ; in Empedocles, 55 ; Platonic, 120 and n., 121, 123 ; Aristotle's fifth, $25 \mathrm{n}$., 230 ; development of, from $\pi \nu \in \hat{v} \mu \alpha, 269 \mathrm{f}$.

Empedocles, 13, 14 n., 55 and n.; his philosophy, 55-58.

Empirical doctrine of knowledge, in Aristotle, 184, 185, 232; Stoic tendency to, 259, 277 ; knowledge ('є) $\mu \pi \epsilon \rho^{\prime}(a), 185,204,234$; logic, $260 \mathrm{n}$.

End, of life, Democritus on, 66 ; conception of, Aristotle's, 153-157 ; relation to change ( $\mu \in \tau \alpha \beta o \lambda \hat{\eta}), 155$ 157 ; to form, 156 ; of man, 246.

Energy, continuous, of reason, 246, 247 ; pure, as the Divine first cause, 248.

Enumeration, of species in induction, 189 ; of instances, 190.

Epictetus (Stoic), $261 \mathrm{n}$; view of soul, $275 \mathrm{n}$.

Epicureanism, 260, 261 ; validity of sense-impressions, 283 ; Epicurus' doctrine of innumerable worlds compared with Anaximander's, $11 \mathrm{f}$.

Equilibrium of forces, $270 \mathrm{n}$.

Eristics, as a type of Sophist, 69 .

Error, problem of, 82 ; views of Antisthenes, Plato, and Aristotle, $i b$. ; possibility of, how arising, 83 ; Stoic explanation of, 281.

Essence, of the individual, 181; intelligible, of the subject of demonstration, 192 ; transition to apprehension of, 193 ; incapable of proof, 194 ; intuitive apprehension of, by

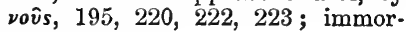
tality of, 221.

Essential, Socrates on the, 94 .

Eternity, of the world of generation

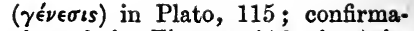
tion of, in Timceus, 116 ; in Aristotle, 161, 235, 240, 264; of type, 235 ; of human genus, 246 ; of truth, $i b$. ; Averroës on, 253.

Ethics, Pythagorean, 27 ; Democritus', 60,66 ; Socratic, $76 \mathrm{f}$.; deficiency of Socratic theory, 77 ; third division of Stoic philosophy, 262, 289-294 ; subdivision of, 262 ; primitive im. pulse of man, 289 ; $\kappa \alpha \theta \dot{\eta} \kappa o \nu \tau \alpha, 290$, 291 ; nature of virtue, 291 ; natural and moral good, $i b$; ; class of indifferent actions, 292 ; classification of virtues, 292-294.

Eubulides (Megarian), author of the fallacies of accident, 85 .

Euclides (Megarian), his teaching and school, $83 \mathrm{f}$.

Eudemus (Peripatetic) on Pythagorean doctrine of pre-existence, 20 ; and phrase 'to preserve phenomena,' $59 \mathrm{n}$.; identification of the active reason with God, 249.

Euthydemus (Platonic dialogue), date of, 105 ; theory of Ideas in, ib.

Evidentia, term used by Cicero for $\epsilon^{\prime} \nu a ́ \rho \gamma \epsilon \iota a$, of presentation, 279 .

Evil, soul, 117 ; as first principle, duality, 143; problem of, Stoic view, 274 .

Evolution, Aristotle and, 236.

Excluded Middle, law of, 173.

Existence, unity of, Xenophanes on, 31 ; Ionic conception, ib. ; Eleatic doctrine, 35 ; Zeno's arguments for, 38 ; conception of, Platonic, 140 ; Speusippus', ib.; Xenocrates', 144 ; Aristotle's threefold division of realm of, 153 ; nature of the existent subject, $i b$; f fixed types of, 141 n., 154, 157, 181, 182, 194, 195 ; compound nature of the existent, 156; and truth, 97, 129, 130, 226,246 ; difficulty of Aristotle's theory of, 167 ; corporeal nature of (Stoics), 265-274, 286, 287, 288 ; of the incorporeal, 286, 287, 288.

Experience, and the order of appre. hension, 184, 185, 204, 234.

Faculty, of sense-perception, 208 ; of vision and its exercise, 209 ; defined by its object, 211 ; of apprehending concrete fact and essence, 218 ; of first principles, 232-239.

Fallacy of accident, Eubulides, 85 .

Fate, Stoic view of, 273. 
Fates, the three, Xenocrates' use of, 145.

Fire, in Aristotle, the hot-dry, $8 \mathrm{n}$.; Heraclitus' reality, 44 ; doctrine of

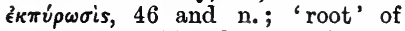
Empedocles, 55; element of body of cosmos (Timaus), 120; as funda. mental element, Stoic view, 263, 266 ; fiery vapour $(\pi \nu \in \hat{v} \mu \alpha), 266$ -

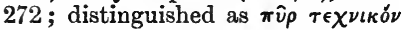
from ordinary fire, $269 \mathrm{n}$.

First cause, mover, 160, 226.

Fixed types, Aristotle's theory of, in nature, 141 n., 154, 157, 171, $194,195,236$; deviation from, 157 ; monsters, ib. ; Aristotle's conception of, in logic and metaphysics, 181 ; and the principle of contradiction, $i b$.; numerical plurality of, 182 ; gradation of, 154-159, 270.

Form, (Aristotle) and matter, 156, 158, 159 ; relation to final cause, 156 ; in the heavenly bodies, 159; as abstract essence expressed in definition, $i b$; in mathematics, 167,223 ; pure, the divine as, 183, 228 ; soul as, 201 , 202 ; soul as place of forms, 218 ; as intelligible essence, 236, 237; and matter, Aristotle's doctrine of, developed by Stoics, 264, 265 and

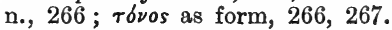

Formal logic, 175, 187.

Free will, Stoic denial of, 273, 274 ; nature of, in the roofss, 281.

Function, good as performance of, 77 ; scale of, in living beings, 164, 165, 200 ; of the soul, $200 \mathrm{ff}$.; of sense, 205 ; of common sense, 207 ; distinction between sensitive and nutritive, 208; combination of unity and plurality in one, 212 ; of understanding, 213, 214, 215; of reason, desire, and $\phi \alpha \nu \tau \alpha ́ \sigma \mu \alpha \tau \alpha$, $215,216$.

General notion, Socrates on, $74 \mathrm{f}$.; maxims, nothing deducible from, $172,187$.

Generalisation, process of, and the Ideas, $106,110 \mathrm{f}$.

Generation, absolute, denied by Eleatics, 33, 49; and by Anaxagoras, 51 ; world of, and the Pythagorean oúpavós, 25 ; denied by Megarians, 86, 99; Platonic Ideas and, 98; mode of being (Plato), 99-102, 109, 116, 119, 120, 129 ; twofold division of, 102 ; materiality of, 120-122,
127 ; soul in, 119,120 ; explanation of, 127, 130, 238 ; relation to the absolute, 131 ; Aristotle's criticism of Plato's view, 133-135; effort towards perfection in, 137; as a system of realised ends, 155 ; two causes in, 156; chance and spontaneity in, 137, 157 ; eternity of, $115,116,161,220,235,240$, 241 ; operation of the divine in, $161,162,242$; eternity of type in, 220, 236 ; relation to vov̂s, 236 , 237 ; fundamental animal function, 203 ; faculty of, 276.

Generic, universals, Ideas as, 89, 133 ; character, of intelligible units, 107 .

Genetic account of science, Stoics', 280 ; theory of judgment, 282.

Geometrical magnitude, made up of indivisible elements, $26,37,146$; Speusippus' principle of, 141, 142.

Geometry, as an abstract science, 22 ; separation of form from matter due to Pythagoras, $i b$. ; relation to arithmetic, $i b$.; relation between the elements and the five solids in Pythagorean cosmology, 25; Democritus and, 60 .

God, Xenophanes on, 30 ; existence of (the gods), Protagoras on, 71; Antisthenes on, 89 ; Aristotle's conception of, the unmoved mover, 160, 161; nature of, 161, 162; unity of, 159, 162 and n.; as pure self-conscious reason, 162 ; identified with the active reason (Eudemus), 249 ; (Alexander of Aphrodisias), 251; and matter, Zeno's view, 267 ; Stoic doctrine, 268 and n.; supreme mind,

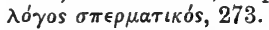

Gomperz, Herkulanische Studien, Heft I., $260 \mathrm{n}$.

Good, discussion of the, by Socrates, 7\%; identified by Euclides with the One, 84; in Plato, $100,111,128$; soul, 117; Speusippus' view of, 141 ; not identified with the One by Speusippus, 142 ; identified with the One by Plato, 143; in Platonic interpretation of the universe, 241 ; opposition of evil and, 274, 291, 292; identified with the Beautiful (Stoic), 291 ; natural and moral, $i b$; perfect, $i b$.

Good sense, primary virtue, 293.

Gorgias, type of sophist, 69 n., 71 ; metaphysical speculation, 72 ; ag. nosticism of, $i b$. 
Gorgias (Platonic dialogue), $69 \mathrm{n}$.

Gradation, of mental processes (Plato), 102; of fixed types in nature (Aristotle), 154-159, 171, 194, 236, 270 ; of organised bodies and psychical activity, 203; of the intelligible, 222,226 ; of the operations of reason, 229.

Happiness, definition of, Socratic and Cynic, 76 ; Aristotle's, 244.

Harmony, Pythagorean researches into, 23 ; scientific results of doctrine of, 24; Pythagorean doctrine of, and Pythagorean ethics, 28; definition of soul as, $i b$.; conception of, according to Heraclitus, 45; scope of the law of harmony, $i b$.; with nature, Stoic conception, 289-291.

Hate, Empedocles' separating force, 56.

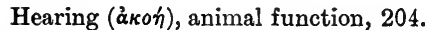

Heavenly bodies, Anaximander's view of, 10 ; in Plato, 123 ; Aristotle's view of, 152, 154 and n. ; matter and form in, 159 ; each sui generis, $i b$.; movements of, how caused, 162 n.; movement of, and psychical change (Plato), 200.

Hedonism, Aristippus' doctrine of, 78, Heraclitus, opinion of Pythagoras, 18 ; doctrines, 42-48; opposition of his school to the Atomists, 70 ; Protagoras and, 71 ; effect on the Cyrenaics, 79 ; Antisthenes' use of Heraclitean view of names, 82 ; influence on Plato, 93 ; denial of law of contradiction, 176 and $\mathrm{n}$.; influence on Stoic logic and physics, 258, 263, 269 ; and Stoic doctrine of language, $276 \mathrm{n}$.

Hesiod, 5.

Heterogeneous sensations, 212 and $n$.

Hippolytus. See under List of Authorities.

Historical period, transition from traditional to, in philosophy, 67; com. position, origin of, 70 .

Homogeneous sensations, 212 and n.

Human species, permanence of (Aristotle), 236, 246 ; process of realisation of type in, 236 ; form and matter in, 237.

Iamblichus. See Index of Authorities. Icosahedron, Pythagorean equivalent of water, 25.

Idea, innate, 102, 114; use of word in
English philosophy, 278 n. ; representation of, in speech, 287; representative, theory of, $i b$.

Idealism, modern, and Plato's theory of Ideas, 114 ; 'absolute knowledge' of, $281 \mathrm{n}$.

Ideas, Platonic theory of, influence of Socrates on, 77, 94; Idea distinguished from Megarian unit, 89; Polyxenus' argument against, $i b$.; early form of the theory, 91-103; origin of theory in early speculation, 91,93 ; development of, 92 96 ; Aristotle's evidence, 92 ff.; connexion of later form with Pythagoreanism, 95 ; importance of distinction of knowledge from perception to theory of, 97 ; inter-connexion among, ib.; properties of, 98 ; correlation of, to reality, 97 , 99 ; apprehended by vov̂s, 101 ; and à $\nu \alpha \nu \eta \sigma \iota s, 102$; and theory of in. nate ideas, $i b$. ; contemporary criticism, 104-108; answered in Par. menides, 105, 106, 108; as natural types, 106, 113 ; as absolute existence, 106-108, 119, 129 ; not isolated from one another (Sophist), 110 ; in the Philebus, 112 ; relation of, to the soul, 114-118; modern interpretations of later theory, $114 \mathrm{f}$; ; objective existence of, 118 ; types of, in Timaus, 123; and numbers, 124, 126, 128, 145; Aristotle on later theory, 127, 128, 132 $135,138,139$; material element in the, 127 ; and the world of generation, 130, 132; and change, failure of Plato's explanation, 132 ; modifications of Platonic school, 139 . 147 ; Speusippus, 142 ; nature of, 143-146; Xenocrates, 145-147.

Identity, exclusive of difference, Antisthenes' view, 80; Megarian view, 86 ; Stoic, of indiscernibles, 267, 269.

Imagination $(\phi \alpha \nu \tau \alpha \sigma i \alpha), 204$; as intermediate between sense-perception and reason, 213, 214; distin. guished from sense-perception and understanding, 214 ; activity of the soul called forth by sensation, 215 ; distinguished from memory and reminiscence, 216 ; connexion with thought, 237, 242, 243.

Immortality, of the soul (Plato), 116 ; of the race, 165 ; of reason, 221.

Impression, 79, 278, 283. 
Impulse $\left(\delta \rho \mu \gamma^{\prime}\right)$, relation to intelligence, 289; nature of, in man, $i b$., 290 and $n$.

Incommensurability, Pythagorean doctrine of, 26,37 .

Incorporeal, conception of the, 34 ; forms, 87 ; Ideas as, 98 ; mode of existence of the, 287,288 .

Indeterminate, void of the Pythagor-

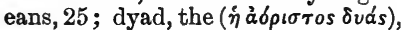
in Plato, 127; Speusippus' use of, 142 ; a fundamental principle of Xenocrates, 145; divisible of Timceus interpreted by Xenocrates as, 147.

Individual, sense-impressions (Cyren. aic), 79 ; elements, in Antisthenes' theory, 81; essence of, identical with infima species, 154 ; antithesis between universal and (Aristotle), 179-181; the concrete, 182-186; apprehension of, 193, 194 ; transition from immediate apprehen. sion to essence, 193; and senseperception, 234 ; as cause of change, 236 ; as realised type, $i b$.; Tóvos, 267 ; everything in the universe, $267,269,271,284$.

Individualism, subjective, of the Cynics, 259.

Indivisible, quanta, 26 ; plenum, 36 ; units, 38 ; bodies, 61 ; acts of apprehension, corresponding to percepta, 81 ; intelligibilia, 86 f.; lines

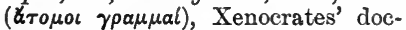
trine of, 146 ; in Platonic writings, $i b$.; the, in Timceus, 120, 147; universals, 234, 243.

Induction, invented by Socrates, 74 ; Platonic interpretation of, 97,98 ; meaning of '̇ $\pi \alpha \gamma \omega \gamma \dot{\eta}$ (Áristotle), 185 ; method of discovery of the universal, $i b$. ; contrast between syllogism and, $188 ; \delta \dot{\xi} \xi$ 'ं $\pi \alpha \gamma \omega \gamma \hat{\eta} s$

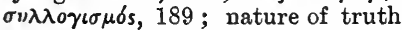
obtained by, $i b$.; and the univer. sal, 194, 195; and ultimate char. acters, $i b . ;$ relativity of function of, 195 ; mode of knowledge of ultimates, 234.

Infima species, 154, 182 and $\mathrm{n}$.

Infinite, Anaximander's doctrine of the, $7,8 \mathrm{n}$., $12 \mathrm{ff}$. ; the first step towards abstraction, 15; Pythagorean, 25 ; the One of Xenophanes, 31 ; in Plato's Philebus, 112.

Infinity of worlds, Anaximander's doctrine of the, 11 ; in Democritus, 63.
Innate ideas, and the doctrine of à $\nu \alpha \nu \eta \sigma \iota s, 102$; modern view of, and Ideal theory of Plato, 114; truths, 280.

Inorganic world, Ideas of, 123.

Intellect ( $\nu \circ \hat{s}$ ), in Anaxagoras, 52 ; in Plato, 101 ; divine element in the soul (Aristotle), 166; relation of, to soul, 167; independent of the body, $i b$. ; its immortality, 168 ; function of, 190, 195; and induction, $i b$.; as source of primary data, $i b$. ; peculiar to man, 204 and $n$.; intermediate between sense-perception and, 213-217, $275 \mathrm{f}$.; operation of, $215,217-231,243$; relation to soul, $217-227,243,246$; universal. ity of, 217 ; knowledge of itself, 225,244 ; in man, and absolute, $227-231,245.248$; as faculty of first principles, 232-239; active and passive, 220, 221, 239, 244, 246, 249-251 ; later interpretations of, 239, 249-251. See also Reason.

Intellectual culture, increased demand for, 67 ; end of, 68 ; the Sophists and, $i b$.

Intellectus acquisitus, 239, 251.

Intcllectus adcptus, 253.

Intellectus agens, 249, 251.

Intellectus materialis, 251, 252.

Intcllectus passibilis, 249.

Intelligence, hierarchy of (Arab doctrine), $253 \mathrm{f}$. ; the divine, 254 and n. ; relation to volition, 289 .

Intelligibilia, Megarian, 86 ; compared with the Ideas, 104, 109 ; Xenocrates' view of, as numbers, 146.

Intelligibility, mark of real existence (Plato), 129; of the universe, 240 ; nature of, in Plato and Aristotle, 240,241 ; constancy as, $i b$.

Intelligible, the, twofold division of, Platonic, 101; apprehension of, by vov̂s, 221-225 ; as a unit, 222-225; not connected with world of generation, $226,228,248$.

Interdependence of the universe, 269.

Intermediates, between sense-perception and reason, $213 \cdot 217$; the simplest, $\phi \alpha \nu \tau \alpha \sigma i \alpha$ (imagination), $213,214$.

Intrusion of opposites, Anaximander's doctrine of, $8 \mathrm{f}$.

Intuition, function of, 195 ; and dis. cursive thought (elaboration), 195. 198; definition and, 197; of voûs, its simplicity, 222, 223. 
Ionian school, 5 ff. ; characteristic of its methods, 17 .

Isocrates, reference to Antisthenes the Cynic, 80. See also Index of Authorities.

Jackson, H., interpretation of later Ideal theory, 113, 114, 115.

Jowett, interpretation of later Ideal theory, 114.

Judgment, logical process of, 196 ; in definition, 197 ; function of man, 204 ; about practical matters ( $\phi \rho \delta \nu$ $\eta \sigma \iota s), 213$; unity of, 222 ; synthesis and analysis in, 223 ; Stoic theory of, 280 n., 283.

Jurisprudence, influence of the Stoics on Roman, 261.

Justice, a square, Pythagorean definition, 28 ; primary virtue, 293.

Justitia, $293 \mathrm{n}$.

Kant, definition of change, 158 ; body as equilibrium of forces, $270 \mathrm{n}$.

Knowledge, theory of, of Alcmæon of Croton, 27; Heraclitean, 47; Democritus' two types of, 65 ; Protagoras on, 69 ; and Gorgias, 72 ; Socrates' theory of, 73 f.; virtue as, 76 ; Cyrenaic theory of, 79; Cynic theory of, 79.83 ; correlated with real existence in Plato, 97 ; distinguished from perception and opinion, ib., 99 ; absolute, 106, 143, 281 n. ; Xenocrates on, 144 ; threefold division of, $i b$.; Aristotle's theory of, 168198 ; metaphysical principles of, 177 . 182 ; ambiguity of the term, 177 ; a modification of Platonic antithesis between types of, 177, 178; development of, 178 ; 'is of the universal,' 179 ; order of, 184 ; empirical doctrine of, Aristotle, $i b ., 185$; of the cause or universal, how gained, 185; distinction between relative and absolute, 186, 188, 192; ultimate data of, 190-192; nature of immediate, 193; and induction, 194, 195; intuition and discursive thought, 195-198, 225; correlation to truth, 226; reason as faculty of first priuciples of, 232-239; origin of, in experience, 234 ; eternity of, 246,247 ; and its object, 249 ; Stoic theory of, $275-288$; mechanical explanation of, 277 ; and presentations, 278, 284; criterion of, 278 , 279 ; virtue as (Socrates), 292.
Lachesis, Xenocrates' name for the world of opinion, 145 .

Ianguage, faculty of, 276 and $n$.

Laws, last work of Plato, 117; elaboration in $x$. of earlier view of soul, $i b$. ; the good and bad soul, $i b ., 132$; summary of Plato's natural theology, 139 ; reference to Aristotle in, ib.

Leibniz, theory of Monads, 150.

Leucippus, originator of Atomist doctrine, 59; follower of Parmenides, $i b$.

Life, in the concrete realm, 199-201; soul as the principle of, 163,200 . 203 ; scale of functions of, 164, 165,200 ; and the body, 163, 201, 202 ; primary functions, $203 \mathrm{f}$.; the contemplative, as realisation of $\nu 0 \hat{s}$, 245 ; contrasted with the practical, $i b$.

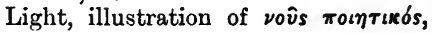
220.

Like to like, doctrine of Empedocles, $57 \mathrm{f}$.

Limited and unlimited, distinction in Pythagoreanism, 23 ; in Plato, 112. Locke, 'substance' of, 153 ; Essay on Human Understanding, $278 \mathrm{n}$.

Logic, Zeno, 38 ; in Socrates, 73 f., 94; Antisthenes, 80; in Euclides, 84 ; in Plato, 97, 98, 100 ; Aristotelian, 154, $170 \mathrm{ff}$; the syllogism, 170, $186 \mathrm{f.}$; principles, special and general, 171, 172; principle of contradiction, 172-177; excluded middle, 173 ; formal, 175,187 ; induction, 185, 188-190; processes of, distinct from intuition, 196; position in Stoic plilosophy, 262; subdivision of, $i b$. ; Stoic confusion between psychology and, 277.

Lotze, on Plato's conception of the Idea, $130 \mathrm{n}$.; on Aristotle's criticism of Plato, $i b$.; view of the universal, $242 \mathrm{n}$.

Love, Empedocles' combining force, 56.

Lucretius, on sense-perception, $47 \mathrm{n}$. ; expounder of Epicurean doctrine, $260 \mathrm{n}$. See also Index of Authorities.

Lutoslawski, W., on the chronology of Plato's dialogues, 115 ; interpretation of later Ideal theory, $i b$.; view of the soul in, $i b$.

Macrocosm, 272.

Magnanimitas, $293 \mathrm{n}$. 
Major term, 189.

Malebranche, interpretation of the Ideal theory, 100, $254 \mathrm{n}$.

Man, original form of, 12 ; the measure, 71 ; divine element in, 166 ; functions of, 204 and n.; vov̂s peculiar to, 204; reason in, and the absolute reason, 227-231, $247 \mathrm{f}$. ; individual, development of, 236, 237; conditions of his knowledge, 237 ; apprehension of the universal, 242,

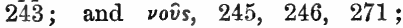
reason and lower faculties in, 249 ff.; part of the universe, 272 ; impulse in, 289, 290, 291; rational constitution of, 289 .

Many, One and, 14 n., 31, 37, 87, 105, $107,111,127,130,133,141-145$, $159,168,212,234$.

Marcus Aurelius (Stoic), 261 n., 275 n. See also Index of Authorities.

Marriage, Protagoras on, 71.

Material, cause, principle, or substratum, 3; Plato's explanation of the, 122; factor in the Ideal realm, 127.

Materialism, criticism of (Sophist), 87 f., 265 ; Stoic, 265-268.

Materiality of world of generation, 120.

Mathematical ratios, relation to the Ideas (Timceus), 124; and sensations, 126 ; as contents of the Ideal world, 128.

Mathematics, Pythagorean interest in, 17 ; symbolic interpretation of, 19 ; influence on philosophy, 21; discovery of incommensurables, $i b$.; of the regular solids, $i b$. ; geometry as an abstract science, 22 ; theorem of the sum of the interior angles of a plane triangle, ib.; Pythagorean conception of numbers, 23 ; Pythagorean doctrine of proportion, $i b$.; Pythagorean theory of the relation between the five solids and the elements, 25 ; line made of indivisible points, 26 ; conception of discrete quantity ascribed to the Pythagoreans on doubtful evidence, 37 ; opposition of Democritus and Protagoras, 66 ; Platonic view of, 101 ; relation to the Ideal theory, $i b$., 127 ; form of $\mu$ i $\mu \eta \sigma \iota s, 101$; twofold character of, $i b$. ; in Timceus, 122 ; form and matter in, 167 and $\mathrm{n}$.; nature of axioms in, 171 ; nature of apprehension in, 218, 223.
Matter, Aristotle's notion of, 35 ; Anaxagoras' characterisation of, 51 ; chaotic state of, $i b$.; move-

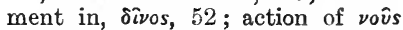
upon, 53 ; element in the concrete existent, 156; common basis of the potential and the actual, $i b$.; as substratum of change, 158 ; as potential existence, $i b$. ; as contingent individuality, $i b$. ; relativity of, $i b$. ; indeterminate final matter, $i b$. ; and numerical multiplicity, $i b ., 159$; and the divine nature, 159,183 ; in the heavenly bodies, 159 ; in mathematics, 167 and n.; as potentially manifold, 182 ; body as, in relation to soul, 183 ; in theory of $\nu$ vos, $219 \mathrm{ff}$; failure of Aristotelian psychology to explain, 226 ; manifestation of the intelligible through, 228, 248; Stoic theory of, influence of Anaxagoras, 263 ; $\kappa \rho \hat{\alpha} \sigma \iota s, i b$. ; influence of Aristotle's doctrine of, 264; developed by Stoics, $i b ., 265,266$; as fire, 266 ; primary, 268 ; unqualified, $i b . n$.

Meaning, Stoic conception of, $287 \mathrm{f}$.

Mechanical movement, 6 ; explanation in Anaxagoras, 53; conception of the universe implied by Aristotle, 136 ; representation of the process of knowledge, 277,278 .

Mechanics, failure of the Greeks to conceive, 270 n.; Stoic, 270, 273, 274 .

Mediæval interpretation of Aristotle's doctrine of vovs, $239,251 \mathrm{ff}$.

Megarian school, 83-89; agreement with Cynics in theory of ultimates, 83 ; Euclides, 83-85 ; Eubulides, and the fallacy of accident, 85 ; view of predication, $86 \mathrm{f}$.; theory, inconsistency of, 87 ; opposition to experience, $i b$.; theory, Plato on, $i b ., 88$; unit, 88,89 ; view of world of generation, compared with Plato's, 99 ; intelligibilia, compared with the Platonic Ideas, 104, 109 ; argument, 'the Third Man,' 89, 107.

Melissus, contrasted by Aristotle with Parmenides, 35 ; non-spatial character of Being, 40 ; on qualitative alteration, $i b$.

Memory $(\mu \nu \eta \mu \eta), 165,204$; in animals, $i b$. ; tractate on, in the Parva Naturalia, 213 ; distinguished from reminiscence and imagination, 216 ; arising from perception, 234. 
Meno (Platonic dialogue), doctrine of à $\nu \alpha \dot{\mu} \eta \eta \sigma$ ss in, 102.

Metaphysics, the Eleatic, 29, 36 ; Plato's later, 104-113 ; final, 119. 128 ; of the Academy, 141-147; Aristotelian, $159-162,172 \cdot 186$; nature of hiatus in Aristotelian, $167 \mathrm{f}$. ; object of Aristotelian, $\tau \dot{\partial} \partial \hat{\nu} \nu$ of $o \nu, 173$; included in Physics, by Stoics, 261.

Method, Zeno's, 38 ; Socratic, 73, 74, 94 ; Sophistic, 73 ; of Euclides, 84 ; of division by dichotomy, 98 ; Platonic idea of, 129.

Microcosm, 272.

Middle term, relation of, to the conclusion, 188 ; in the inductive argument, 189 ; terms, limitation of number of, 196.

Mill, J. S., view of logic, $260 \mathrm{n}$.

Minor term, 189.

Moderatio, $293 \mathrm{n}$.

Monism, of the Eleatics, 31 ; of the Stoics, 258; in physics, 264; in theory of knowledge, 275 ; in ethics, 292, 294.

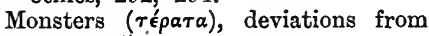
type, 157 .

Morality, Protagoras concerned with, 69, 71; Socrates on, 75 ff. ; Stoic, 289-294.

Motion, Zeno's arguments against, $39 \mathrm{f}$. ; confusion of absolute and relative, 40 ; Melissus on qualitative alteration as distinct from, 41 ; revolving, of Anaxagoras' matter, 52 ; the source of, vovs, $i b$.; of the atoms, 61 ; explanation of, 62 ; vortex, 63; Diodorus' arguments against, 85 ; self-originating, soul the principle of, 125, 142; Aristotle's theory, 135; the first cause of, 136, 160, 248; teleological direction of, 136; and change in general, 155 and $n$. ; subdivisions of, $155 \mathrm{n}$.; to cause, function of the soul, dependent on sense-apprehension, $164 \mathrm{f}$. ; cosmic, and the soul, 200 ; relation of pleasure, pain, and appetition to, 203, 204; difficulties of Aristotelian theory of, $254 \mathrm{f}$. ; processes of soul, $258 \mathrm{n}$.

Multiplicity, Zeno's arguments against, 38 ; and unity, 222 ; of intelligible essences of the world of generation, 248. See also Plurality.

Mythology, influence on philosophy, 2,3 ; popular, Democritus' explan- ation of, 64 ; Sophistic speculation on, 70 and $n$.

Names, importance of, in Heraclitus, 48 ; in Antisthenes, $i b ., 82$.

Natural types, Ideas as, 106, 113 ; theology, Plato's, in the Laws, 139.

Nature, ordinary knowledge of, among the Greeks, 3 ; distinction between convention and, Sophists on, 70 ; Atomists on, $i b$. ; Plato on, 150 ; chance and spontaneity in, 137, 157 ; in Platonic school, 145 f.; Aristotle's conception of, 139, 154, 156 ; gradation of fixed types in, 141 n., $154,156,157,171,172,181$. $194,236,270$; deviation from, 157 ; cause in the world of generation, 156; in Strato, 257 n.; in Stoics, 263-274; conformity with, $289,290,291$.

Nebular theory, analogy of Anaximander's speculations with, 12.

Necessity, in Democritus, 62 ; in Timceus, 120 f.; in propositions, $170,191$.

Negation, Plato's explanation of, in Ideal realm, 98 .

Negatives excluded from the Ideas, 146.

Nemesius. See Index of Authorities.

Neo-Platonism, doctrines of, 183 ; as a development of Aristotelian theo$\log y, i b$. ; interpretation of Aristotelian doctrine of $\nu$ ôvs, 239, 252 ; doctrine of absorption in the absolute, 253.

Nomenclature, unscientific (Aristotelian), 213.

Nominalism, Antisthenes', 81, 259, $265 \mathrm{n}$. ; in the Stoic philosophy, 259,265 n., $277,288$.

Notion, general, in Socrates, 74,87 ; class-notion, 86 ; Idea as generic, 86,133 ; Idea as, in the mind, 106 ; common (Stoic), 280, 286.

Numbers, Pythagorean theory of, 21 ; the essence of things, $i b$. ; conceived arithmetically by Pythagoras, 23 ; space dimeusions of, $i b$; doctrine of proportion of, ib.; barrenness of the Pythagorean theory, 24 ; separated by void, 25 ; indivisibility of, in space, 26 ; type of Idea, in Timceus, 124 ; Speusippus' view of, 141, 142 ; Ideas as, $i b$.; Xenocrates' view, 145 ; Ideas distinguished from, by Plato, 
as $\dot{\alpha} \sigma \dot{u} \mu \beta \lambda \eta \tau o \iota, 143$ and n. ; Xenocrates' view of intelligibilia as, 146.

Nutrition, simplest function of life, $164,200,202$; necessity of, 203 ; senses necessary for, 204 ; distinction between sensitive and nutritive functions, 208.

Object of apprehension, the immediate, $193 \mathrm{f}$.

Objective philosophy replaced by subjective, 67.

Objectivity, 283, 285.

Octahedron, Pythagorean equivalent of air, 25.

Odd and even, distinction important in Pythagoreanism, 23.

Officia (Stoic view), 290 ; primary, ib.;

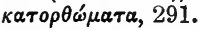

One, Pythagorean theory of, 23 ; Xenophanes on, 31 ; Ionic conception, ib. ; Eleatic doctrine, 35 ; Zeno's arguments, 38 ; identified by Euclides with the Good, 84 ; the, and the Many, 14 n., 105, 107, 111, 130, 234 ; Speusippus on, 141-143; Aristotle's criticism of, $i b$. ; Xenocrates on, 145, 147 ; Aristotle's doctrine of the, 159,168 ; the Eleatic, 168 ; negative character of the, $i b$.

Opinion $(\delta \delta \xi \alpha)$, and truth, 32 ; and knowledge, 80, 83 ; Platonic antithesis, 99-103; antithesis between science and (Aristotle), 170, 177, 178 ; transition from, to science, 178 ; as function of understanding, 213 ; and Stoic $\sigma \circ \phi 6 s, 281$ and $n$.

Opposites, Anaximander's doctrine of the, 8; Pythagorean, 23 f.; in Parmenides, 33.

Opposition, implication of harmony in, according to Heraclitus, 45 ; nature of logical, 176 ; fundamental to thought and elaboration, 196.

Order in the universe, in Heraclitus, 45 ; result of $\nu$ ovs, $53 \mathrm{f}$.; in Stoics, 288, 289, 290, 291.

Organ, central, 214.

Organic world represented by Ideas (Timceus), 123 ; life, relation to soul (Aristotle), 164 ; connexion, $i b$.

Organism, view of the universe as an, $247,290$.

Orphic doctrine, connexion with Pythagoreanism, 19.

Pain $(\lambda \cup ́ \pi \eta)$, cause of movement, 66, 203.
Panætius (Stoic, middle school), 261 n.

Parmenides, 32 ; his poem, $i b$. ; his teaching, 32-36 ; Plato's reference to, 37 ; Leucippus, follower of, 59 ; contradiction of his doctrine by the Atomists, 60 ; his one predication, 87.

Parmenides (Platonic dialogue), criticism of Ideal theory in, 105-108; its nature, 107; $\mu \in \tau \alpha ́ \lambda \eta \psi \iota s, 105$; ideas as notions or $\pi \alpha \rho \alpha \delta \epsilon^{\prime} \gamma \mu \alpha \tau \alpha$, 106 ; ' the Third Man' argument in, $i b ., 139$; answers to contemporary criticisms, 107, 108; relation of true being to the world of generation, 109 ; negative treatment, ib., 110 ; Ideas and the inorganic, 123; theory of Ideas in, 139.

Particular, relation of, to the Ideas, $89,98,100,104,105,107,111,130$. 134 ; Aristotle's criticism of Plato's treatment, 134, 135; antithesis between universal and, Platonic,

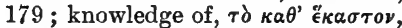
184 and n. ; apprehension of, by sense-perception, 185, 193 ; induction from, 185 ; character of our knowledge of, 186.

Parva Naturalia, tractates of Aristotle, 213.

Pearson, Fragments of Cleanthes, 262 n., 266 n., 270 n. ; Fragments of Zeno, 265 n., 266 n., 271 n., 276 n., 277 n., 278 n., 279 n., 280 n., 281 n., $282 \mathrm{n}$.

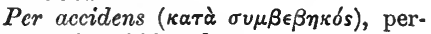
ception, 206 and $\mathrm{n}$.

Percepta, 82, 109.

Perception. See Sense-perception.

Perfect action, 291, 294; happiness, 294.

Peripatetics, doctrine of reason, 249, 250, 251; Strato of Lampsacus, 250 ; Alexander of Aphrodisias, $i b$. ; modification of Aristotelianism, 257 ; relation to the Stoics, 257 and n., $259,260$.

Permanence of type, 236.

Perspicuitas, term used by Cicero for the é $\nu$ d $\rho \gamma \epsilon \iota \alpha$ of presentations, 279.

Phoedo (Platonic dialogue), chronology of, 96 ; doctrine of à $\nu \alpha$ ' $\mu \nu \eta \sigma \iota s$ in, 102 ; relation of Idea to particulars, and between Ideas, 105 ; soul and body, 115 ; eternity of the cycle of generation, 116 ; relation of the soul to the Ideas and the Idea of Life, 
$i b$. ; the soul as the first principle of change, $i b$.

Phædrus (Epicurean), $260 \mathrm{n}$.

Phcedrus (Platonic dialogue), chronology of, 96 ; account of generalisation in, 100 ; doctrine of d $\nu \alpha{ }^{\prime} \mu \nu \eta \sigma \iota s$ in, 102 ; the soul the principle of self-originating change, 116 ; soul has vision of the Ideas, 117 ; elaboration of position of, in Laws, $i b$.

Phenomenal, to 'preserve' the, 51, 59 and $n$.

Pherecydes, 5.

Philebus (Platonic dialogue), connexion between One and Many, 111; classification of kinds of existence, 112 ; place of Ideas in classification, ib. ; lower limit of sensation, 126.

Philo of Larissa (New Academy), $260 \mathrm{n}$.

Philodemus (Epicurean), treatise on logic, $260 \mathrm{n}$. See also Index of Authorities.

Philolaus (Pythagorean), on the soul, 26 and $\mathrm{n}$.; threefold division of reality, 144 .

Philosophy, distinguished from wisdom by Socrates aud Plato, 108 ; dependent on the existence of Ideas, $i b$.

Physical, the Ionian school, in its ideas, 17 ; Eleatic doctrine not, 34.

Physics, Stoic, 263-274 ; metaphysics and, $261 \mathrm{f}$.

Place, existence of (Stoic view), 287.

Placita philosophorum. See PseudoPlutarch in Index of Authorities.

Plato, influence of earlier thinkers on, 1, 72, 97; influence on Aristotle, $1,138,149,158,163,238$; reference to Alcmeon of Croton, 27 ; to Parmenides, 37 ; to Zeno, ib.; on Heraclitus, $42,44,46,47$; on Anaxagoras' vov̂s, 52, 53; definition of Sophist, 68 ; criticism of Sophists, 69 and n. ; on Protagoras, 71 ; Socrates, 76, 77; reference to the Cyrenaics, 79; opposition to Antisthenes' nominalism, 79-82 ; on the problem of error, 82 ; on complex apprehensions, 83 ; on the Megarians, 87,88 ; theory of Ideas (q.v.), early, 91-103 ; later, 104-113, 119-128 ; development in, 92 ; Aristotle on the, ib., 93, 98, 127, 132135,179 ; dualism, 97-101, 130, 258,275 ; $\delta \delta \xi \alpha$ and $\dot{\epsilon} \pi \sigma \tau \tau^{\prime} \mu \eta, 97-$ $101,170,177,178$; on induction and definition, 97, 98; method of dichotomy, 98 ; conception of scale

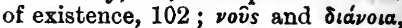
101 ; à á $\mu \nu \eta \sigma_{\iota s}, 102$; doctrine of the soul, 103, 114-120, 135, 147, $163,164,199,200$; the One and the Many, 107, 111 ff., 130; absolute and relative knowledge, existence, 106-108, 119, 129, $254 \mathrm{n}$.; school of, 138-147; difference between Aristotle and, 149-151, $163,164,238,239$; correlation of reality and knowledge, $97,129,130$, 226,246 ; intelligibility as constancy, 240, 241; influence on Stoicism, 258, 259, 275. See also Ideas, theory of ; and Index of Authorities.

Pleasure, 66, 79, 100, 203, 293.

Plurality, attacked by Zeno, 37 ; numerical, as accident of real subjects, 180 ; nature of, 182 ; of fixed types, $i b$.; absent from the divine, 183; and unity, in the same mental function, 212.

Plutarch. See Index of Authorities.

Politics, effect on Greek culture, 68 ; subdivision of Stoic ethics, 262.

Politicus (Platonic dialogue), 98.

Polytheism, criticised by Xenophanes, 30.

Polyxenus, 'the Third Man,' 89, 107.

Posidonius (Stoic, middle school), $261 \mathrm{n}$.

Potential existence, Aristotelian doctrine, attacked by Diodorus, 84 .

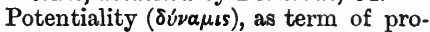
cess, 155 ; matter and, 156, 158, 201; God and, 161; of life, in body, 201 ; first and subsequent realisation of, 202 ; realisation of, through sense-perception, 209; in reference to vov̂s, 217-220, 228, 247.

Predication, difficulties involved by the Eleatic principle, 47; Antisthenes' view, 80 ; Megarian view, 86 f. ; Parmenides on, 87 ; in Plato, 105 , 110 ; final subject of, $153 \mathrm{f}$., 175, 182, 191, 192, 194, 197, 202.

Preller. See Ritter.

Premisses, in apodictic and dialectic, $170,178,190$; in the syllogism (ordinary), 188; in the inductive syllogism, 189.

Pre-Platonic philosophy, its influence on Plato, 1; speculations on the material cause, $3,6 \mathrm{ff}$.

Presentation ( $\phi \alpha \nu \tau \alpha \sigma(\alpha), 278$ and $n$. ff., 287 ; truth of, 278,279 ; per- 


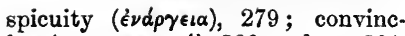

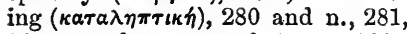
284 ; modern use of term, 283 ; corporeality of, 287.

Primary qualities, distinguished by Democritus from secondary, 54,63 ; the only really existent ( $\dot{\epsilon} \tau \in \hat{\eta})$ qualities, $i b$. ; duties, 290.

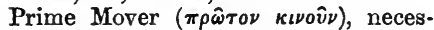
sity for, 160; completed actuality, $i b$. ; and the world of change, 161 ; God, ib., 226, 248.

Principle, in Pre-Platonic philosophy, $3,6,7,15,21$; in Plato, 112,116 ; principles, two, of Plato, Aristotle on, 128 ; in Speusippus, $141 \mathrm{ff}$. ; in Xenocrates, 145, 147 ; of motion, 160,163 ; logical, Aristotelian divi-

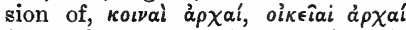
(general and special), 171, 172; 'ं $\xi$ $\omega \nu, i b$.; of contradiction, 172-177; necessity of first, 190 f., 196 ; vital principle, 200 ; first, and reason, 232-239 ; relation to demonstration, 232 ; apprehension of, $i b ., 233$; and scientific knowledge, 235.

Privation ( $\left.\sigma \tau \tau^{\prime} \rho \eta \sigma / s\right)$, negative element in change $\left(\mu \in \tau \alpha \beta 0 \lambda \eta^{\prime}\right), 155$.

Proclus, 21, 22. See also Index of Authorities.

Prodicus, speculations of, $70 \mathrm{n}$.

Proof, nature of, 174 ; and the principle of contradiction, $i b ., 175$; induction and, 188 f.; no infinite regress of, 190, 193, 196.

Protagoras, relativism of, relation to Atomism, 65, 66 ; philosophical type of Sophist, 69 ; his views, 70,71 ; effect on the Cyrenaics, 79 ; and contradiction, 177.

Protagoras (Platonic dialogue), 71.

Providence, theory of, 254 and $\mathrm{n}$.

Prudentia, 293 n.

Pseudo-Aristotle. See Index of Authorities.

Pseudo-Plutarch. See Index of Authorities.

Psychology, line of development, 3 ; Pythagorean, 26.28; in Empedocles, 58 ; Democritus on, 64 ; theory of simulacra, ib.; Platonic, 114-118; Aristotelian, 163.169, 199.231; difficulties of Aristotelian, 167. $169,224,226,248$; difference between Platonic and Aristotelian, 199, 200; general nature of the soul, 199-204; the sensitive soul, 204-213 ; intermediates between sense - perception and reason, 213217 ; the rational soul, $217-227$; reason in man and the absolute reason, 226-231 ; early, and memory, 216 and n. ; Stoic, 266, 271, 272, $275,276,282,283,286,287$; Stoic confusion between logic and, 277 ; modern, 283; distinction between elements in word, 286.

Pyrrho (Sceptic), $260 \mathrm{n}$.

Pythagoras, founder of school, 18; geometrical discoveries, 22 ; view of the relation between arithmetic and geometry, $i b$.

Pythagorean school, 17-28; its independence, 17 ; lateness of the authorities for, $i b$. ; loss of early writings of, $i b$. ; mathematical studies, $i b$.; views on transmigration, $i b$., 19 f.; influence of Orphic doctrines, 19 ; theory of numbers, 21; statement of Aristotle, 20, 21; number, the essence of things, 21; abstract geometry, 22; arithmetical conception of numbers, 23 ; idea of oppositeness in things, $i b$. ; conception of the One, $i b$. ; cosmology of, 24 ; threefold division of the universe, $i b$. ; conception of the infinite, a $\pi \epsilon \iota \rho o \nu, 25$; correspondence of the elements and solids, $i b$.; theory of void, $i b$.; conception of the universe as figured space, 26 ; the indivisible point, $i b$. ; and the doctrine of the soul, 26-28; Aristotle on this, 26,27 ; definition of virtues, $i b$.; Parmenides' debt to, 33 ; doctrine of incommensurability, 37 ; and the later Ideal theory, 95 .

Qualitative alteration, 40 and n.; change, Anaxagoras on, 53 ; distinctions, Anaxagoras' theory of, 54.

Qualities, Democritus' distinction between primary and secondary, $63 \mathrm{f}$.

Quality, abstract notion of, 8 .

Quantity, pure, in the Ideal realm, 127.

Rarefaction and condensation, 14, 16.

Ratio, arithmetic, in Pythagoreanism, 21; of the elements (Timceus), 120 ; geometric, of space, 122 ; of sensation, 126 ; of the Ideas, 95, 128.

Reaction of the mind, $282,285$.

Realisation of ends, nature as process of, 155 ; of potentiality, first and subsequent, 202 ; soul as first, $i b$. 
Reality, concrete, abstraction from, 15 ; Xenophanes' view of, 31 ; Eleatic conception of, 34 ; how far non-corporeal, 35,40 ; Atomist conception of, according to Aristotle, 64 ; corporeal, 87 ; intelligible, 89 ; in early Ideal theory, 97 ; correlated with knowledge in Greek speculation, $i b$; relation to world of change, $99,101,102,150$; unity of, 143; apprehension of, by the soul, 166 ; nature of, a combination of matter and form, 167, 201 ; propositions concerning sum-total of, 173 ; connexion of thinking with, 175; apprehension of, the principle of contradiction and, 176 ; Platonic amended definition, 265, 266,267 ; corporeality of, Stoic view, 265-269, 286-288.

Reason ( $\nu$ vos), in Anaxagoras, 52 ; in Plato, 101; divine element in the soul (Aristotle), 166 ; relation of, to soul, 167 ; independent of the body, $i b$.; its immortality, 168 ; function of, 190, 195; and induction, $i b$.; as source of primary data, $i b$.; peculiar to man, 204 and n. ; intermediates between sense-perception and, 213-217; operation through $\phi a \nu \tau \alpha ́ \sigma \mu a \tau a, 215-217$; the rational soul, 217.227 ; in man and absolute reason, 227-231; as faculty of first principles, 232-239 ; later interpretations of, 239 ; relation to lower faculties, 243, 249; nature of its apprehension, 243 ; knowledge of itself, 225,244 ; active and passive, $220,239,244,246,249-251$; relation of, in man, to divine, $245 \mathrm{ff}$; r relation to the intelligible, 248, 249; Peripatetic and Stoic doctrine, 249, 250,251; Alexander of Aphrodisias, 250, 251; Averroës, 251 ff. ; difficulties of Aristotelian theory, 254, 255 ; material nature of (Stoic); 272 ; as material basis of the universe, $i b$; ; as highest degree of tension ( $(\nu 0 \hat{s}), 271$; and sense-perception, 275 f.; life according to, 291 ; unity of, 292.

Reasoning, existence of Ideas, basis of, 108; from particulars to particulars, 185 ; not affected by nature of premisses, 187 ; and reason, 195 ; function of man, 204.

Relative and absolute, 106 ; knowledge (Aristotle), 186, 188.
Relativism, of Protagoras, relation of Atomist doctrine to, 65 ; Cyrenaic doctrine of, 79 .

Relativity, of matter, 158 ; of function of induction, 195; of evil, 274 and $\mathrm{n}$.; of moral quality of actions, $291,292$.

Religious, revival, and Orphic doctrines, 19 ; tendency in Heraclitus, 41 ;

Reminiscence (à $\alpha \dot{\mu} \mu \nu \eta \sigma \iota s)$ Plato's theory of, 102 f. ; in Aristotle, 204, 213 ; distinguished from memory and imagination, 216 ; early psycho$\operatorname{logy}$ of, $i b$. and $n$. ; and association, 217.

Republic of Plato, 96 ; early theory of Ideas in, $i b ., 99$; attempt in, to connect the two realms of objects, 101 ; theory of $\mu i \mu \eta \sigma i s$ in, $i b$.; twofold division of the intelligible in, $i b$.; twofold division of world of generation in, 102; conception of gradation in, opposed to à $\nu$ á $\mu$ $\nu \eta \sigma i s, i b$.; treatment of Ideas in, compared with that in Sophist, 110 ; concrete conceptions in, and later Ideal theory, 128.

Republic of Zeno, 259.

Rhetoric, taught by the Sophists, 68 ; early Sophists and, 69 ; subdivision of Stoic logic, 262 and $n$.

Ritter and Preller, Historia Philosophice Grocece (8th ed.), cited :

$\S 10$, pp. 3,$6 ; \quad \S 100,101,102$,

13, p. 6 ;

15, p. 7 ;

16, pp.7,8,9,14;

17 , p. 11 ;

19-21, p. 9 ;

21, p. 11 ;

22, p. 12 ;

$24,26,28$, p. 16 ;

30 , p. 42 ;

31, p. 18 ;

32 , p. 43 ;

33 , p. 44 ;

35, p. 45 ;

36 , p. 46 ;

66 , pp. 23,27 ;

75, p. 25 ;

76, p. 23 ;

80 , p. 25 ;

81 , p. 24 ;

85, p. 27 ;

86 , p. 27 ;

89 , p. 27 ;

90, p. 27 ; p. 30 ;

103,104 , p. 31 ;

108 , p. 30 ;

109,110 , p. 31 ;

114, 117 f., p. 32 ;

121,128 , p. 33 ;

$131,132,133$, 135, p. 38 ;

136, 137, 138, p. 39 ;

$139,146,147$, p. 40 ;

151, p. 50 ;

153 , p. 49 ;

155, pp. 52,53 ;

160 , p. 52 ;

161 , pp. 53,54 ;

164 f., p. 55 ;

166 , p. 56 ;

173, p. 57 ;

176,177, p. 58 ;

188 , p. 60 ; 
$\S 192$ f., p. 59 ;

195 , p. 62 ;

197,198 , p. 63 ;

199 , p. 61 ;

202, 203, p. 64 ;

204, pp. 63, 64, 65 ;

208,210, p. 54 ;

226, 227, p. 71;

236, 237, p. 72 ;

249 , p. 74 ;

272, p. 79 ;

285, p. 89 ;

286, p. 80 ;

287 , p. 81

$290,291,295$, p. 84 ;

296, p. 85 ;

299,300 , p. 86 ;

352 , p. 143 ;

353, p. 141 ;

354,355, p. 140 ;

358, p. 144 ;

Roman world and later Stoicism, 261 ; system of jurisprudence, $i b$. ; Stoicism, practical character of, 263.

Scale of existence, 102 ; of functions of living beings, 164, 165, 200.

Sceptic philosophy, Atomism as, 65 ; criticism of the Stoics, 260 and n., 261, 277, 294 n.; Carneades, 260 n., 261 ; problem of knowledge, 262 ; use of the $\sigma \omega \rho \in i \tau \eta s, 294 \mathrm{n}$.

Scholastics, on the eternity of the world of generation, 161 ; on the 'animal soul,' 165.

Schwegler, History of Philosophy, Aristotle's conception of God, 161, 162.

Science ( $\dot{\pi} \pi \sigma \tau \eta \dot{\eta} \mu)$, and opinion, Platonic antithesis, 94, 100 ff.; in Aristotle, 170, 177, 178; apodictic, 170 ; nature of its premisses, $i b$.; transition to, from opinion, 178 ; point of view of, 191 ; absence of real, from Stoic physics, 267; Stoic theory of, $280,286$.

Scott, W., Fragmenta Herculanensia, $260 \mathrm{n}$.

Secondary qualities, distinguished by Democritus from primary, 54, 63; existing by convention $(\nu \delta \mu \varphi), 63$; correlation with combinations of atoms, ib.; in Timceus, 122.

Seeds, Anaxagoras', 49.

Self-preservation, primitive impulse of man, 289.
Self-realisation, 245 ; in the contemplative life, $i b$.

Seneca (late Stoic school), 261 n., 274. See also Index of Authorities.

Sense-perception, Heraclitus on, 44, 47 ; Lucretius on, 47 n.; Anaxagoras on, 54 ; Empedocles' doctrine of, 58 ; Democritus on, 64 ; Protagoras on, 71; Cyrenaic view, 79; ultimates of Antisthenes apprehended by, 81 ; and image, 83 ; Megarian rejection of, 84 ; in Plato, $93,95,99-102$; subjectivity of (Timceus), 121 f., 125 ; lower limit of (Philebus), 126; in school of Plato, 140, 142, 144; contrasted with reasoning, 186, 188 ; mode of apprehension of particulars, 185, 193,195 ; in the scale of organic functions, $164 \mathrm{ff}$., 200, 202 ; characteristic of animal life, 203 ; gradation in, 204 ; the five senses, 205 ; specific sensibles ( $(\delta \iota \alpha$ ai $\sigma \eta \eta \tau \alpha ́), 205$ -

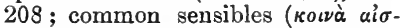
$\theta \eta \tau \alpha ́)$, ib.; per accidens, 206 ; as discriminative faculty, 208; distinction between sensitive and nutritive faculties, $i b$.; nature of, 209 ; change involved in, realisation of potentiality, $i b$. ; relation of, to its object, $i b ., 210$; consciousness of, $i b$. f. ; intermediates between reason and, 213-217; distinguished from imagination, 213, 214; truth of, 214 ; relation of $\phi a ́ \nu \tau \alpha \sigma \mu \alpha$ to, $i b$., 215 ; comparison with reason ( $\nu$ ovss), 217,218 ; identical with sensible form, 219 ; simplicity of, 223 ; unifying function of, and vovss, $i b$., 224 ; faculty of all living creatures, 233 ; memory arising from, $i b ., 234$; concrete imagery of, 237 ; universal of, 242 and n., 243; and reason (Stoics), 275, 276 and n., 279 ; functions of, 276 and n., $277 \mathrm{ff}$; as an impression, 278 ; as an alteration, $i b$. ; presentation ( $\phi \alpha \nu \tau \alpha \sigma i \alpha), i b . \mathrm{ff}$; objectivity, 283.

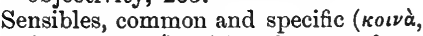

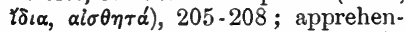
sion of, 206 ; discrimination of, 207 209, 212; common, lacuna in Aristotle's account of, 213.

Separability of the Ideas, 94 ; of vovs, 217.

Separation of things from the infinite, Anaximander's doctrine of the, $8 \mathrm{f}$.; of the numbers, Pythagorean theory, 
25 ; of things by vov̂s, Anaxagoras, 53 ; of things by hate, Empedocles, 56.

Sextus Empiricus (Sceptic), quotation from Democritus, 65 ; authority for Speusippus, 139, 140; for Stoics, 260 n. See also Index of Authorities.

Siebeck, on Aristotle's criticism of Plato, 138.

Simon (Sceptic), $260 \mathrm{n}$.

Simples, 82.

Simplicity of sense-perception and intuition, 223.

Simplicius. See Index of Authorities.

Simulacra $\left(\epsilon^{\prime} \delta \omega \lambda \alpha\right), \quad$ Democritus's theory of, 64 .

Sleep, Aristotle's tractate on, 213.

Socrates, as a Sophist, 68, 72 ; and the Eristics, 69 ; relation to Platonic doctrine, 72 ; external features of method, 73 ; special processes, 74 ; practical end, 75 ; ethics, $76 \mathrm{f}$.; influence on Cyrenaics, 78; on $\mathrm{An}$ tisthenes, 79 ; on Euclides, 83 ; Aristotle on his relation to the Ideal theory, 94 ; his view of the essential, $i b$. ; and of universals and definitions, $i b$. ; in Parmenides, 105 , 106 ; in Philebus, 112.

Sophist (Platonic dialogue), reference to Megarians, 87 ; compared with the Parmenides, 110 ; treatment of non-being, $i b . ;$ element of relations among the Ideas, $i b$. ; compared with the Republic, ib.; identity and difference, relation of, to the Ideas, 124 ; theory of Ideas in, 139.

Sophists, place in Greek philosophy, 67 ; connexion with education, $i b$., 68 ; teachers of rhetoric, 68 ; meaning of the name, $i b$.; not a philosophical sect, $i b$.; Plato and Aristotle on, ib., 69 and n.; influence on Greek character, 69 ; types of, $i b$. and $\mathbf{n}$.; speculations of, on practical problems, education, art, 70 ; distinction between convention and nature, $i b$. See also Protagoras and Gorgias.

Soul, mythical view of the, 2 ; early denotation of the term, 7 ; Pytha. gorean conception of, 26 ; Aristotle on conception of, $i b ., 27$; separability from body, according to Pythagoreans, $2 \tau$; Alcmaon of Croton on, ib. ; Parmenides on, 33 ; Heraclitus's conception of, 45 ; Empedocles on, 58 ; functions of, in Plato, 103 ; á á $\mu \nu \eta \sigma \iota s$ and, $i b$. ; immortality of (Phaedo), ib. ; Platonic doctrine of, 114.118; relation to Ideas, 103,114 , $115,117,118$; relation to Idea of life, 116 ; principle of change, 117, 125 ; composite nature, 120, 122 ; relation to $\nu$ vis, $117,119,131$; indestructibility of, 131 ; as intermediate, ib.; good and bad (Laws), 117, 132 ; Aristotle on, 135 ; Speusippus on, Xenocrates' definition of, 142, 147; Aristotle on, 163-169, 199.

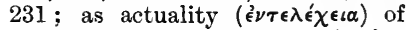
body, 163 f.; functions of the, 164 f.; dependence on the body, 165 and n.; individuality of, 165 ; nature of its immortality, $i b$.; divine element in, vovis (intellect), 166 ; apprehension by, of the real, $i b$.; relation to intellect, 167 ; general nature of, 199-204; Platonic view of, 199, 200; scale of functions of, 200, 202, 203, 204; the sensitive, 204-213 ; unity of, 207 ; function of, $i b ., 208,211$; nature of operation, 208, 209; cousciousness of perception, $210 \mathrm{f}$.; intermediates between sense and reason, 213-217; the rational, $21 \tau-22 \tau$; as $\tau \delta \pi$ os $\epsilon i \delta \hat{\omega} \nu$, 218 ; vov̂s in the human, 219 and n., 243, 246 ; unity of, 219 ; potentiality and actuality in, $i b ., 220$; immortality of, as percipient of truth, 221; vovis as function of, 223,227 ; dependence of, on material conditions, 229 ; severance of

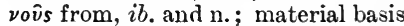
of, 230,231 ; later interpretations of Aristotle's conception, 249 ff. ; corporeal nature of (Stoics), 266, 272,275 ; parts of the, 276 ; relation between $\tau \delta \dot{\eta} \gamma \epsilon \mu о \nu เ \kappa o ́ \nu$ and the senses, 277 ; reaction of the, 282 , 285 ; individual structure of the, 286.

Space, in Pythagorean theory, $25 \mathrm{f}$. ; divisibility of, in Zeno and the Megarians, 39 f., 85 ; in Timceus, 122,125 ; factors of, 294.

Species, enumeration of, in the inductive syllogism, 189 ; continuation of, 203.

Specific difference, ultimate, in classification, $154,180 \mathrm{f}$.

Speculation, early Greek, and the theory of Ideas, 91 ; Greek, identifies truth and reality, 97 . 
Spencer, H., Stoic anticipation of, $281 \mathrm{n}$.

Speusippus, doctrines of, 139-143.

Spinoza, procedure of, compared with Plato's, 131.

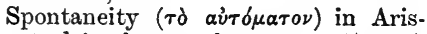
totle's theory of nature, 137, 157 and $n$.

St Augustine, interpretation of the Ideal theory, 100.

Stimulation, of the sense organ, 214; cause of $\phi \alpha^{\prime} \nu \tau \alpha \sigma \mu \alpha, i b ., 215$.

Stobrus, 260 n. See also Index of Authorities.

Stoic philosophy, periods, 259 ; the later Stoics, 258, 259, 261 and n., 263, 275; the Middle Stoics, 259, 261 and n., 275; the early Stoics, 258,259 and n., 261-294; influ. ence of Aristotle, 249 f., 258, 263, 269, 270; of Heraclitus, 45 f., 258; of Antisthenes and the Cynics, 83, 258 f., 265 n.; monism, 258; empiricism, 259, 277; criticised by the Epicureans, Sceptics, and Academics, 260; authorities for, $i b$. n.; influence on Rome, 261 ; division of philosophy into logic, physics, ethics, 261 f.; in. fluence of pre-Platonic speculation, 263 ; physics, 263-274 ; development of Aristotle's doctrine of form and matter, 264; antithesis be. tween active and passive, 264, 265 and n., 266 ; definition of real existence, 265, 266 ; corporeal nature of reality, 265, 266, 286 ; matter as fire, 266 ; form as $\tau \delta$ vos, ib., 267 ; individuality of $\tau \delta$ vos, 267 and n. ; $\pi \rho \omega \dot{\tau} \tau \eta \tilde{v} \lambda \eta$. 268; $\kappa \rho \hat{\alpha} \sigma \iota s$, $i b ., 271$ and $n_{\text {. ; interdependence of }}$ the universe, $269 ; \pi \nu \in \hat{v} \mu \alpha, i b$. and n., 270,271 ; $\tau 6$ ovos, 270 ; degrees of tension, $i b ., 272,275$; $\lambda \delta$ jol, $i b$.,

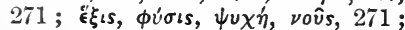

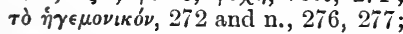
macrocosm and microcosm, 272 ; rationality of the universe, $i b ., 274$; God as germinal reason, 273 ; mechanical view of the universe, $i b$., 274 ; denial of free will, $i b$; ; problem of evil, $i b$.; theory of knowledge, $275-288$; relation of vov̂s to

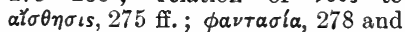
n. ff. ; criterion of knowledge, 278

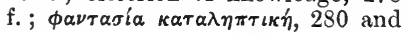

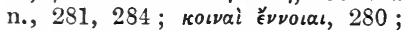
doctrine of the oopós, 281 and n. ; $\sigma v \gamma \kappa \alpha \tau \alpha^{\prime} \theta \epsilon \sigma \iota s, 279,280$ n., 282 , 283,285 ; 'belief,' 285 ; reaction of the soul, 282, 285; existence of the incorporeal, 286,288 ; distinction between the true and the real existent, 288; ethics, 289-294; identification of good and beautiful, 291 ; nature of virtue, $i b$. ; unity of virtue, 292 ; primary virtues, $i b$., 293 ; difficulties of Stoic monism, 294 and $n$.

Strato of Itampsacus, 250; leader of Peripatetic school, 257 n. ; characteristics of his teaching, $i b$.

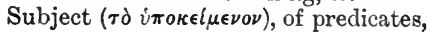
153 ; of $\mu \in \tau \alpha \beta o \lambda \eta, 155$; as $\sigma \dot{v} \nu \theta \in \tau o \nu$ (compound), 156; the concrete individual as, 154, $182 \mathrm{f}$. ; living body as, 202 ; of vision, 203 ; identity of, 212 ; Aristotle's view of the individual, 231.

Subjective philosophy, appearance of, 67 ; historical causes of, $i b$. ; and objective, $i b ., 72$.

Substance, reference to Spinoza's, 131 ; to Locke's, 153.

Sun, in Anaximander's cosmology, 10; vov̂s compared to, by Plato, $220 \mathrm{n}$.; identified by Cleanthes with $\tau o$ o $\dot{\eta} \gamma \epsilon \mu o \nu$ เк $\delta \nu, 272 \mathrm{n}$.

Survival of the fit, Empedocles on the, 57.

Syllogism, use of, in apodictic knowledge and dialectic, $170,172,178$; nature of, 186, 187; and induction, $i b ., 188$ f. ; the inductive ( $\delta \dot{\epsilon} \xi$

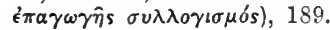

Symposium (Platonic dialogue), chronology of, 96 ; early theory of Ideas in, $i b$.

Synthesis, 223.

Tannery, P., Science hellene, $10 \mathrm{n}$.

Taste $(\gamma \in \hat{v} \sigma \iota s)$, animal sense, 204.

Teleological view, of the body, Plato, 122 ; of sense-perception (Aristotle), 204, 205, 210; Stoic identification of, with mechanical, 273,274 .

Temperance, primary Stoic virtue, 293.

Tension ( $\tau \delta$ vos), Stoic theory of, 266 , 267 ; individuality of, 267 ; degrees of, as law of $\pi \nu \in \hat{v} \mu \alpha, 2 \tau 0,271$; as ratios, 271.

Tetrahedron, Pythagorean equivalent of fire, 25 .

Thales, his speculations, 5-7.

Thecetetus (Platonic dialogue), refer- 
ence to the Cyrenaics, 79; references to Antisthenes, 81, 83 .

Themistius. See Index of Authorities.

Theology, popular, Xenophanes' criticism of, 30 ; Democritus', 64, 12 ; Aristotle's, 161 f., 183, 248; diff. culties of Aristotelian, 255 ; Stoic, 262, 267, 268 and n., 273.

Theophrastus, his account of Anaximander, 7,8 n. ; criticism of Democritus, 64 ; importance as historian of philosophy, 140. See also Index of Authorities.

Theory of Knowledge, Atomists', 65 ; in Sophists, $71 \mathrm{f}$. ; Socrates', $73 \mathrm{ff}$.; Cyrenaic, 79 ; Antisthenes', ib. ff. ; Euclides', 83 ff. ; Plato's, 94 f., 98 ff., 106 ff., 110 f.; Aristotle's, 170. 198 ; metaphysical principles of, 177-182; difficulties of Aristotle's, $177,178,179$; Aristotle's solution of the problem, $182 \mathrm{f}$. ; difficulties of this solution, $183 \mathrm{ff}$; ultimate data, 190-192, 195; difficulties of the theory, $195 \mathrm{f}$.; part of Stoic logic, 262; Stoic, 275-288; tendency to empiricism and nominalism, 277 ; treatment of $\alpha$ lo $\sigma \eta \sigma c s, i b$. f.; $\phi \alpha \nu$ $\tau \alpha \sigma l \alpha, 278$ and n. ff. ; criterion of knowledge, 278-286.

Thing and quality, conception of, 8 .

'Third Man, the,' argument first enunciated by Polyxenus, 89, 107 ; in Parmenides, 106, 139 ; in Aristotle, 107 ; in Republic and Timceus, $119 \mathrm{n}$.

Thomas Aquinas, $251 \mathrm{n}$.

Thought, aud the principle of contradiction, 172-177, 187; discursive, and intuition, 195-198.

Timceus (Platonic dialogue), expository nature of, 114; eternity of the world of generation ( $\gamma \in \dot{\epsilon} \nu \in \sigma / s), 116 ; \psi v \chi \chi^{\prime}$ and vov̂s, 117 f.; metaphysic of, $119-128 ; \delta \eta \mu$ covprós and cosmos, 119 ; nature and function of the soul, $i b ., 120,124,125$; generation of the universe, 120,121; the errant cause, 121 ; $\chi \omega ́$ p $\alpha, 122,127$; Ideas in, 123,124 ; cause of change other than soul, 122, 125; nature of sensation, $i b ., 126$; defects of senseperception, 126; and Speusippus, 140 n., 142 ; and Xenocrates, 147; a philosophical romance, 150.

Time, conception of an absolute limit of, 15 ; and the world of generation,
116 ; existence of, Stoic view, 286 n., 287.

Touch ( $\dot{\alpha} \phi \hat{\eta})$, fundamental animal sense, 204.

Traditional period, transition from, to historical, in philosophy, 67 .

Tranquillity, the end of life, Democritus, 66 .

Transcendentalism, of Plato's ideas (Timceus), 124.

Transformation, rejected by Anaxagoras, 51.

Transmigration of souls, view of Pythagoras, 17, $26 \mathrm{f}$; connexion with Orphic doctrine, 19; involved the idea of a continuous cycle of existence, 20 ; in $\kappa a \theta \alpha \rho \mu o i ́$ of Empedocles, 55,58 .

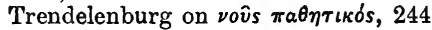
n.

Truth, and opinion, Parmenides, 32 ; Atomist criterion of, 65 ; identified with real existence in Greek speculation, 97; in Plato, 129 f.; Lotze on Plato's view of, $130 \mathrm{n}$; principle of contradiction and, $173-177$; necessary, 178 ; necessary, not obtained by induction, 189; of primary data, indemonstrable, 190-192; apprehension of, and vov̂s, 221, 222, 225 ; eternity of, 221, 226, 246 ; Averroëв on, 253; criterion of (Stoic), $279 \mathrm{ff}$. Types, fixed, $141 \mathrm{n} ., 154,157,171$, 181 f., 194, 195, 220, 236, 270.

Ultimate, $\pi \rho \hat{\omega} \tau o \nu$, Antisthenes' theory of the nature of, 81 ; subjects, nature of, in realm of change, 154 ; specific difference, $180 \mathrm{f}$. ; data of knowledge, 190-192; knowledge of, 234 ; difference, Aristotle's view of, 239.

Understanding, and perception, 47 ;

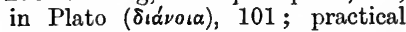

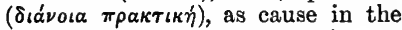
world of generation (Aristotle), 156; in the scale of mental life, 164, 165, $200,202,204$; imagination discriminated from, 214 ; function of, 222 ; distinguished from voûs, 224 ; presentations of the (Stoic), 283.

Unification, in intellectual processes, 223 ; function of vov̂s, 224.

Unio, Averroës's doctrine of, 253 and n.

Units, indivisible, in Zeno's arguments, 38,85 ; abstract, unrelated, of Megarians, 86.89; generic character of intelligible, 107 ; reality as 
multiplicity of, Plato on, 109 ; intelligible, as objects of vovs, 222.

Unity, of existence, first statement of, ascribed by Aristotle to Xenophanes, $30 \mathrm{f}$. ; insistence of the Eleatics on, 35 ; Zeno's arguments for, 38 ; of nature, Diogenes of Apollonia on, 54 ; Speusippus' view, 141, 143; fundamental principle of Xenocrates, 147 ; indivisible, of Timceus, interpreted by Xenocrates as, $i b$. ; of the divine, 159,162 ; numerical, 180 ; as a common sensible, 206 ; of the sensitive soul, 207 ; and discrimination, 208; and plurality in the same function, 212 ; of the soul, 219 ; of the intelligible, 222, 243 ; reduction of multiplicity to, by vov̂s, 223,224 ; of judgments, 222 ; and the central sense, $i b$. ; nature of, conveyed by vovss, 224,225 ; of the subject, 231; of the cosmos, Stoic view, 263, 268 and n., 269; of the system of existence (Aristotle), 264; and form, 265 and n. ; Stoic tendency to, 292; of virtue, $i b$.

Universal, Socrates and Plato on, 94 ; relation to the particular, 98, 131 . 134 ; antithesis between individual and, Aristotle on, 179 ; reconciliation of individual and, $182 \mathrm{ff}$.; propositions, 185, 234 ; in order of our knowledge of, 186; and induction, 194, 195, 234 ; apprehension of, by man, 242 ; of sense, $i b$. and $n$.

Universality of $\nu$ vis (reason), 217.

Universe, in Anaximander, 7; divided by Pythagoreans into three regions, 24 ; conceived by Pythagoreans as reducible to figures in space, 25 ; element of the divine in (Âristotle), 227 ; a system, 240 f.; individuality of things in (Stoic), 267, 269, 284; interdependence of parts, 269 ; rationality of, 272 ; mechanical conception of, $273,274$.

'Unmixed,' nature of vov̂s, 217, 221.

Vegetable life, distinguished from animal, 203.

Virtue, Pythagorean definitions, 27 ; Socratic theory of, 76 ; teachability and unity of, $i b$.; lower and higher, in Plato, 100; of man, moral and intellectual, 244 ; Stoic definition of, 291,292 ; unity of, $i b$.; fourfold classification of (Platonic, Stoic), 293.

Vision, Empedocles' theory of, 58 and n.; Aristotle on, 203, 204, 209, 211,220 and $\mathrm{n}$.

Visum (term in Cicero), 278 n., 281 n., 282.

Void, Pythagorean, relative, 25 f.; as separating numbers from one another, 25; as drawn in by the oủpavós, $i b$.; resembling Anaximenes' Air, as the principle of things, $i b$.; absolute, conception of Eleatics and Atomists, ib.; Atomist doctrine of, 60 ; use of Eleatic doctrine of, 63; Anaxagoras' denial of, 50 ; Empedocles' denial of, 57 ; existence of, 286 and n., 287.

Volition, relation of, to intelligence, 289.

Vortex motion, in Anaxagoras, 52 f.; of the atons, Democritus on, 63 .

Water, as primitive substance, 6; in Aristotle, the cold-moist, 8 n.; formed from the icosahedron, according to the Pythagoreans, 25; one of Empedocles' 'roots,' 55 ; in Plato's cosmology, 120.

Weight of atoms, $61 \mathrm{f}$.

Wise man, Stoic doctrine of, 281 and n., 291, 293.

Word, 287 ; meaning of, incorporeal, 288.

World of generation. See Generation.

Xenocrates, definition of soul, 142, 147; classification of the world of real existence, and of knowledge, $144 \mathrm{f}$. ; fundamental principles of, 145 ; view of Ideas as numbers, $i b ., 146$; definition of 'Idea' in Platonic school, 145 and $n$.; doctrine of

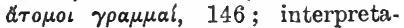
tion of the Timceus, 147.

Xenophanes, founder of the Eleatic school, 29; a rhapsodist, ib. ; criticism of polytheism, 30 ; doctrine ascribed to him by Aristotle, $i b$.; the unity of existence, 31 ; vague distinction between appearance and reality, 32 .

Xenophon. See Index of Authorities.

Zeller, E., his interpretation of Anaximander's doctrine of innumerable worlds, 11 f. ; interpretation 
of Parmenides, 33, 34; Zeno's arguments, summarised by, $38 \mathrm{ff}$;

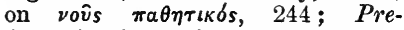
Socratic Philosophy, cited, i. 589 f., p. 34 ; i. 614 f., p. 38 ; Plato and the Older Academy, 538, p. 140; Stoics, Epicureans, and Sceptics, 67 ff., p. 262 ; 104, p. $267 ; 137$, p. 271 ; 141 f., p. 273 ; 78, p. 278 (footnote in each case).

Zeno of Elea, his puzzles, 23 ; Plato on, 37 ; the first logician, 38 ; his method, ib. ; Zeller's summary of his arguments, $38-40$; argumêts against multiplicity, 38 ; argnments against movement, 39 ; his method of indirect refutation used by Euclides, 84 ; his arguments used by Diodorus, 85 ; dialectics of, and the Platonic Ideas, ' 105.

Zeno, founder of Stoic school, 258, 259 ; on God and matter, 267 ; on perception, 278 ; theory of know. ledge, 281-285.

\section{ERRATA.}

P. 27, note 3. . Read Phcedo for Phedr.

P. 45 , note 2. Read R.P. 40 for R.P. 35 .

P. 243. Delete note 2 . 




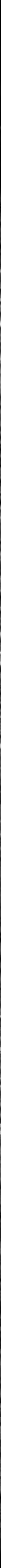


